\title{
Distinguishing Turbidite Tails from Background Sedimentation on the Hikurangi Margin and the Implications for Turbidite Paleoseismology
}

by

Stephanie Elizabeth Tickle

A thesis

Submitted to Victoria University of Wellington

In partial fulfilment of the requirements for the degree of Master of Science in Geology 


\section{Abstract}

The Hikurangi margin is one of the largest sources of seismic and tsunami hazards in New Zealand, but there is still much that remains unknown about previous ruptures on the subduction interface. Turbidite paleoseismology has the potential to increase the spatial density and temporal extent of paleoearthquake records. However, it is heavily reliant on temporal correlation of turbidites, and thus, requires them to be precisely dated. Typically, ages are obtained using radiocarbon dating of pelagic foraminifera from background sediments deposited between turbidites. This dating method requires background sedimentation to be accurately distinguished from the finegrained tails of turbidites. Along the southern and central Hikurangi Margin, background sedimentation and turbidite tails have proven difficult to distinguish from one another. Here, a quantitative approach is developed to distinguish turbidite tails and background sediments using machine learning.

This study utilizes a natural experiment generated by the $M_{w} 7.8$ Kaikōura earthquake, which caused the deposition of co-seismic turbidites at locations both proximal and distal to active canyon systems. The 2016 turbidite could be recognised due to its stratigraphic position at core tops. Turbidites and background sediments were independently identified using ${ }^{210} \mathrm{~Pb}$ activity profiles to identify gradual accumulation. Additionally, foraminiferal assemblages were used to identify transported material. The physical and geochemical properties of the sediments were then analysed using non-destructive (computed tomography density, magnetic susceptibility, micro X-ray fluorescence derived geochemistry) and destructive (grain size, carbonate content, organic content) techniques, to develop a quantitative definition of turbidite tails and background sediments. The destructive datasets were then compared to the nondestructive data that acts as a proxy for these analyses because the latter are rapidly generated at high resolutions down core and are now routinely acquired in most turbidite paleoseismology studies. It was determined that there was a statistically significant correlation between the destructive data and the non-destructive proxies, such that the non-destructive data could be used as a viable alternative to the time consuming destructive analyses. 
The machine learning technique, Linear Discriminant Analysis (LDA), successfully distinguishes background sediment and turbidite tails in areas where they are visually indistinguishable. The LDA model shows that in cores distal from active canyon systems, background sediment and turbidite tails are more distinct than in cores proximal to active canyon systems. Difference between canyon-proximal and distal sites may be due to the impact of weak bottom currents that are inferred to be acting on the background sedimentation processes along this margin. This study shows that quantitative identification of background sediments and turbidite tails is possible, and could allow for more robust identification and dating of turbidites globally, which is of paramount importance for the effective application of turbidite paleoseismology. 


\section{Acknowledgements}

Firstly, I would like to thank my supervisor Jamie Howarth, for the help and guidance throughout my studies. Thank you for the support in making this thesis a great piece of science, in what has turned out to be a particularly tumultuous year. Thank you to Katie Maier, my NIWA co-supervisor, for the input and helpful feedback into this study. A big thank you to Bruce Hayward and Ashwaq Sabaa for providing the foraminiferal data that has been integral in the production of this thesis. Thank you to Jenni Hopkins, for her knowledge on tephra. Thank you to Alan Orpin, Helen Bostock and Grace Frontin-Rollet for the support with my lab work out at NIWA. Thank you to NIWA and the crew of the TAN1705 and TAN1613 voyages for providing the cores and access to labs to complete this work. Also, thank you to MBIE, as this project is part of an MBIE Endeavour Funded project entitled "Diagnosing Peril Posed by the Hikurangi Subduction Zone, New Zealand's Largest Plate Boundary Fault".

Of course, thank you to the office crew, Laura, Philippa, Jake, and Maia, for the coffee runs, cards, opinions on figures, and just generally being great office mates. To my friends and family, to Mum, Dad, Sean, Nana and Gran-nan - thank you for your neverending support and for letting me rant about mud when required. Finally, thank you to David, for being there for me every step of the way. I would not be half as sane as I am now without you. 


\section{Table of Contents}

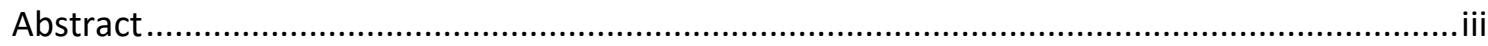

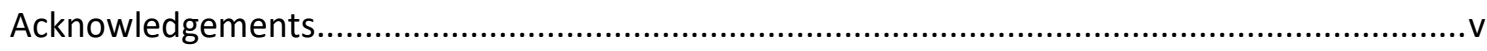

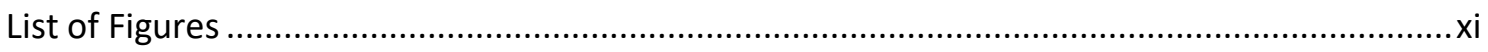

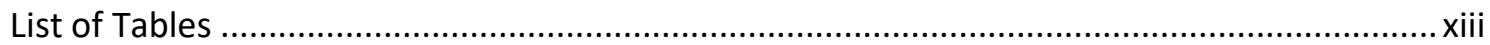

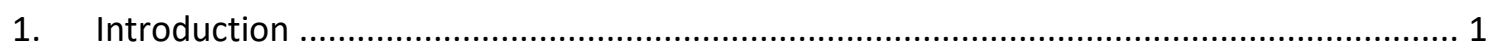

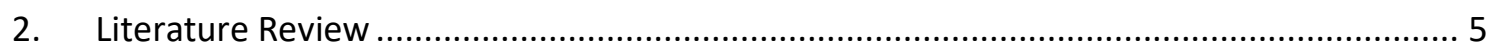

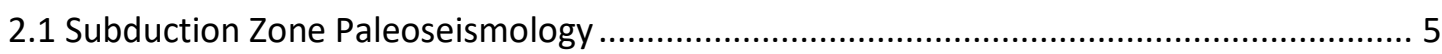

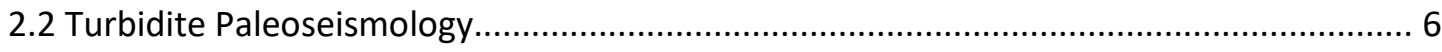

2.3 Applications of Turbidite Paleoseismology ........................................................ 7

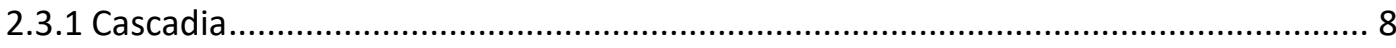

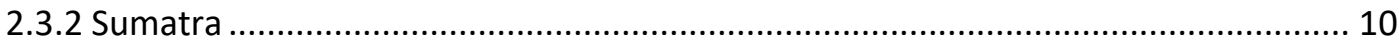

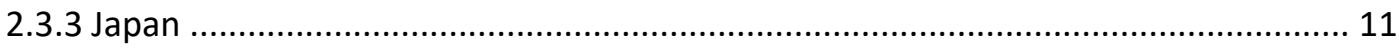

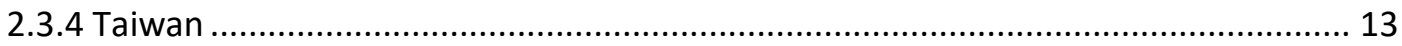

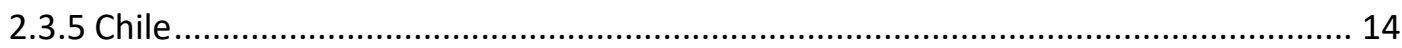

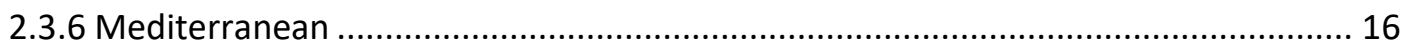

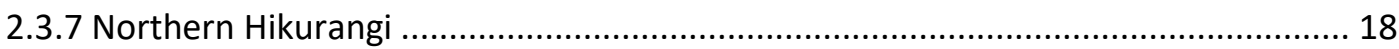

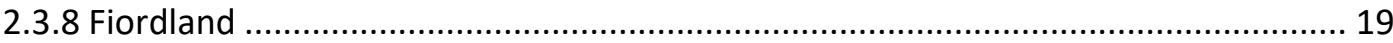

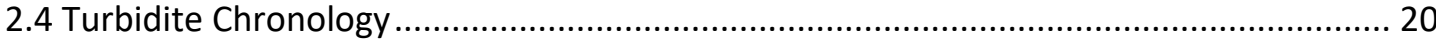

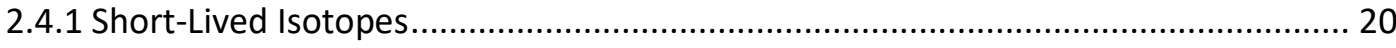

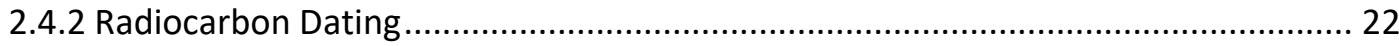

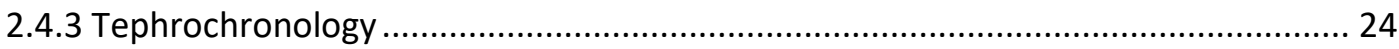

2.5 Identification of Background Sedimentation........................................................ 25

2.5.1 Methods Used for the Identification of Background Sedimentation...................... 26

2.5.2 Identification of Background Sedimentation in Literature .................................. 32

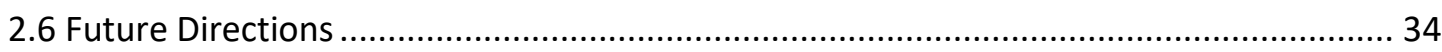

2.6.1 Research Aims and Objectives of This Study............................................. 35

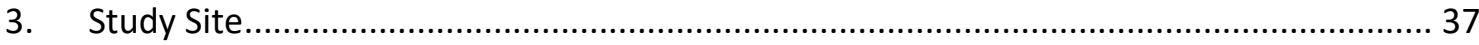

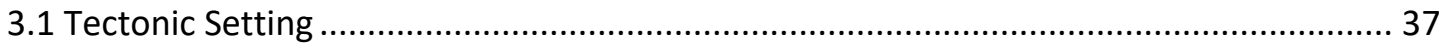

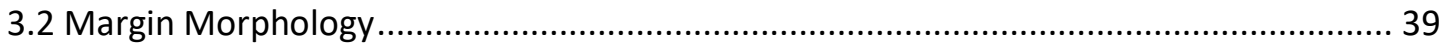

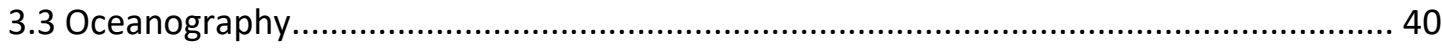

3.42016 Kaikōura Earthquake and Turbidity Current................................................... 41

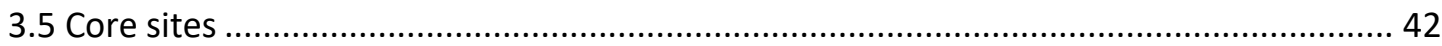

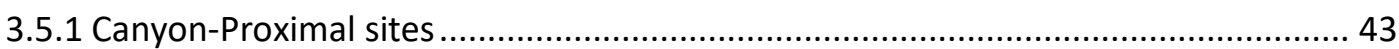




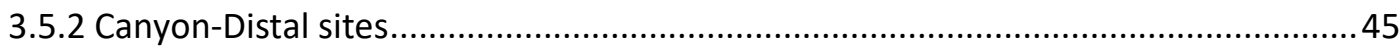

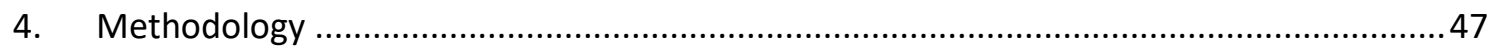

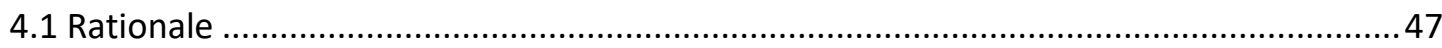

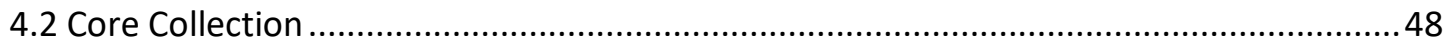

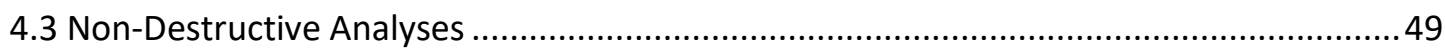

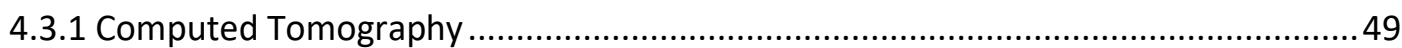

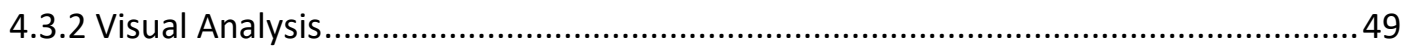

4.3.3 Magnetic Susceptibility............................................................................ 51

4.3.4 Micro X-Ray Fluorescence Spectrometry .............................................. 51

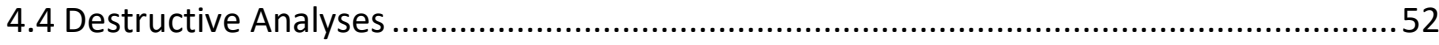

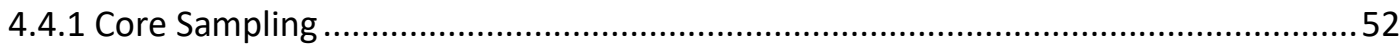

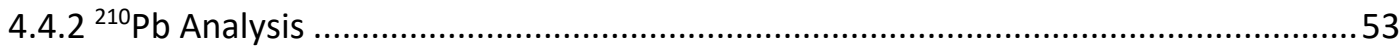

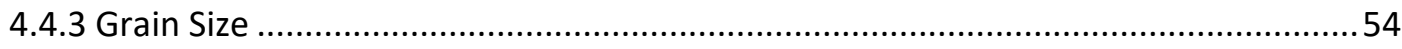

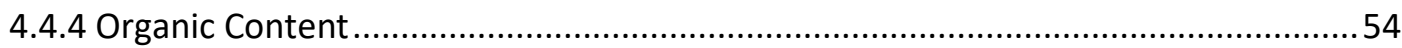

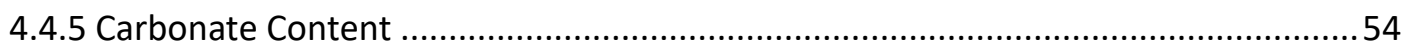

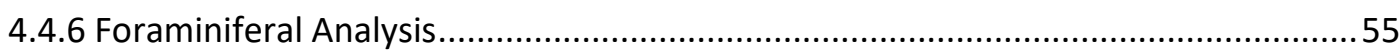

4.5 Validating the Use of Non-Destructive Proxies ................................................... 58

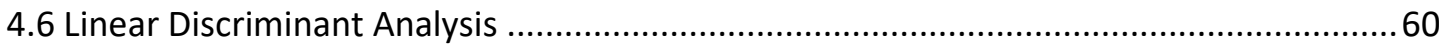

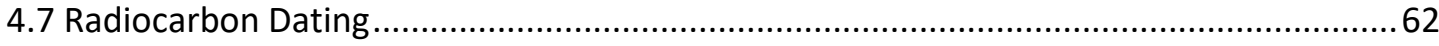

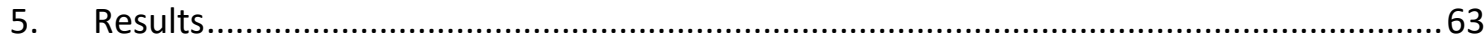

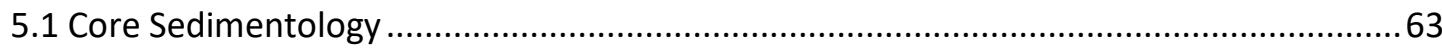

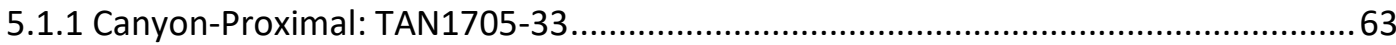

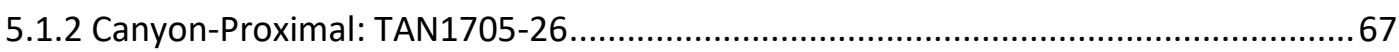

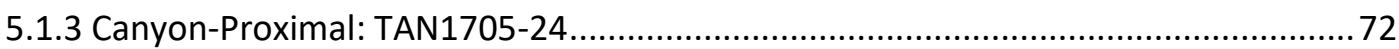

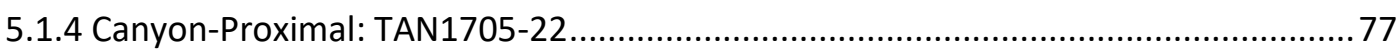

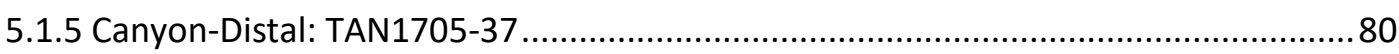

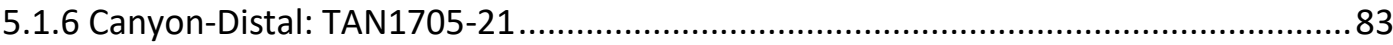

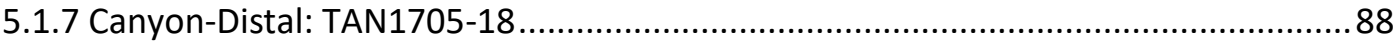

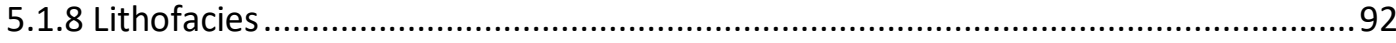

5.2 Quantification of turbidite and pre-turbidite sediments ........................................ 95

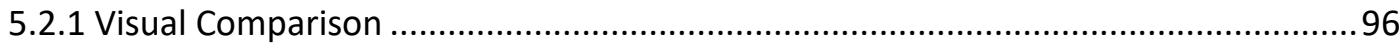

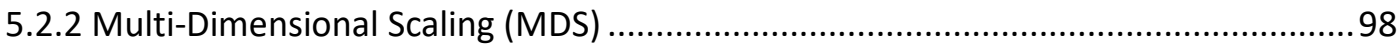

5.3 Use of non-destructive data to distinguish turbidite tails and background sediments.. 100

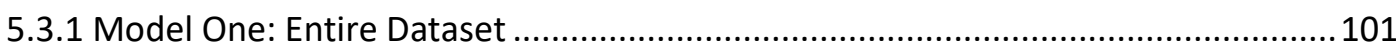

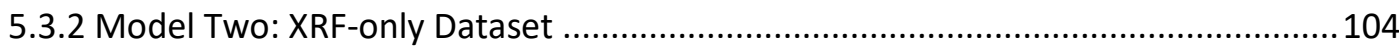


5.4 Application of the approach for radiocarbon dating background sediment. 107

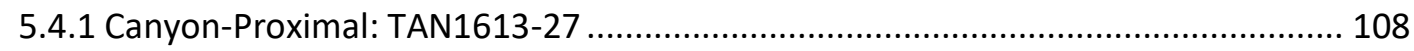

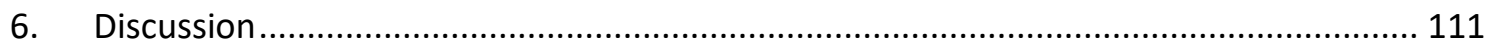

6.1 Comparison of turbidite tail and background sediments.......................................... 111

6.1.1 Distinguishing turbidite tails and background sediments using machine learning. 114

6.1.2 Can background and turbidite tail sediments be predicted using machine learning?

6.1.3 Differences between models and limitations

6.2 Defining the sediments and depositional processes present along the southern Hikurangi margin

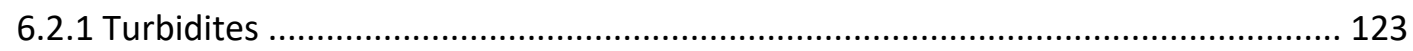

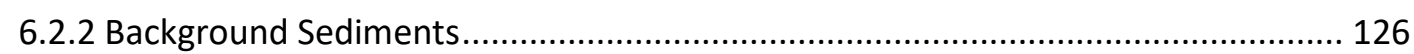

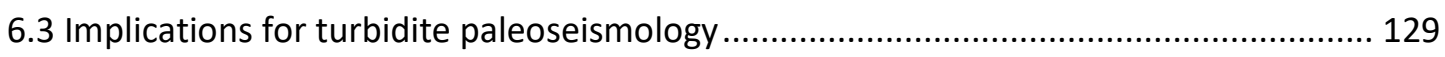

6.3.1 Implications for the Hikurangi margin .............................................................. 129

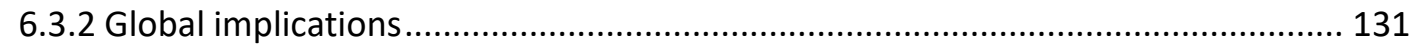

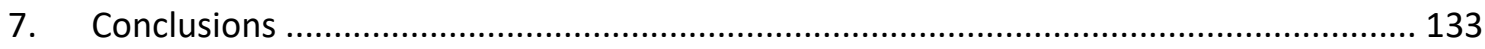

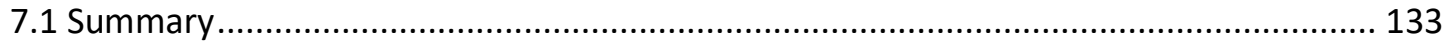

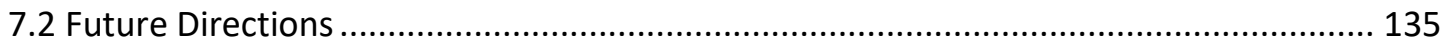

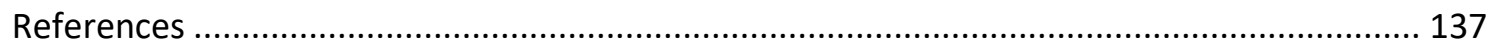

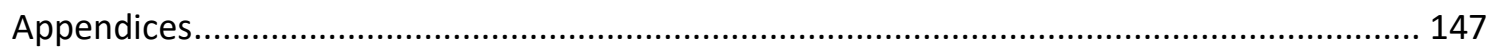

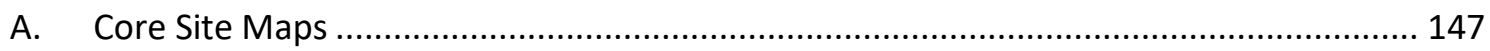

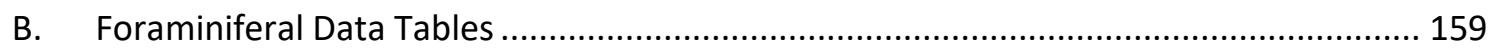

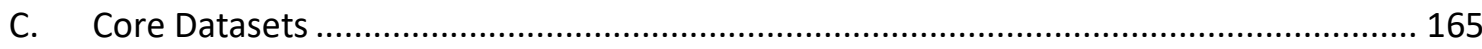

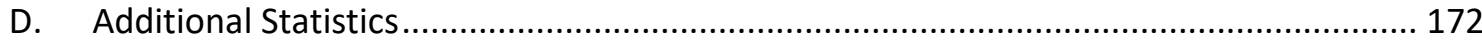

E. Non-Destructive Datasets for Additional Cores ............................................................ 174

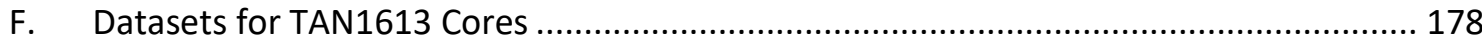




\section{List of Figures}

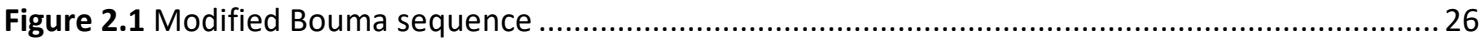

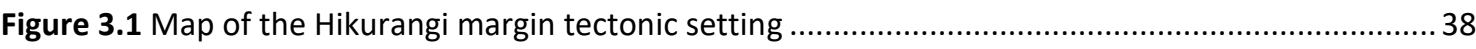

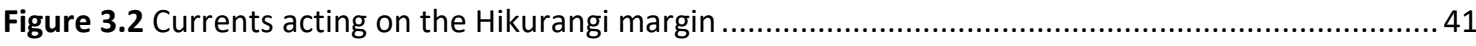

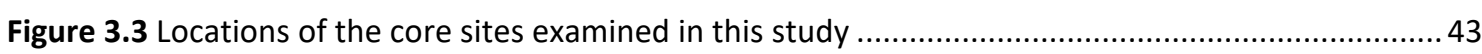

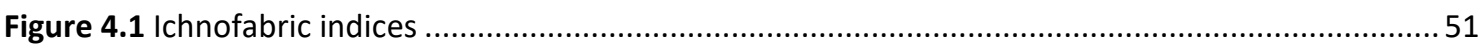

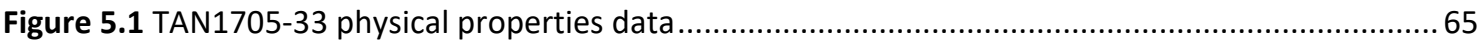

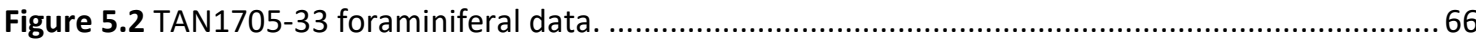

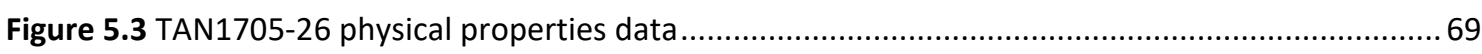

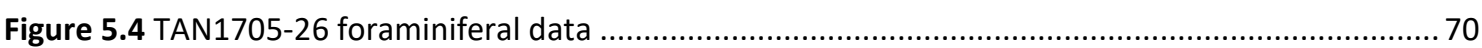

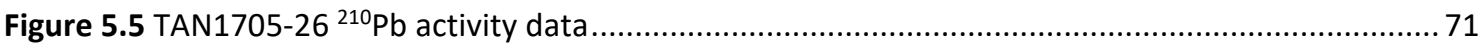

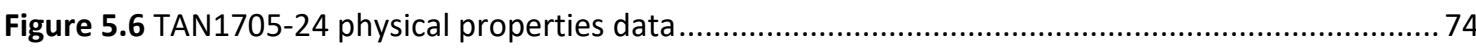

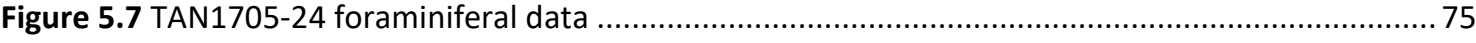

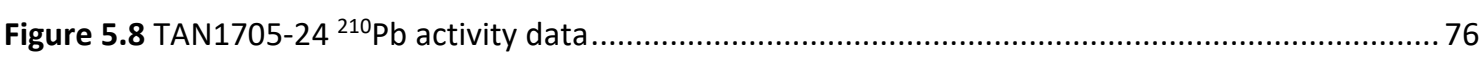

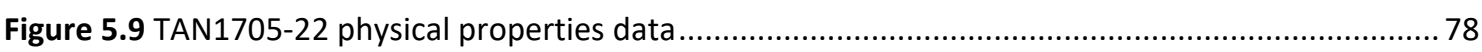

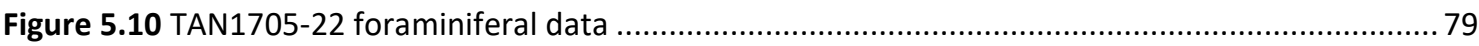

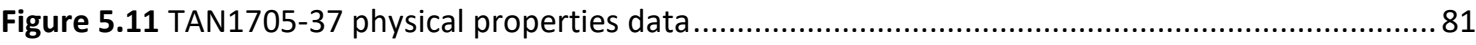

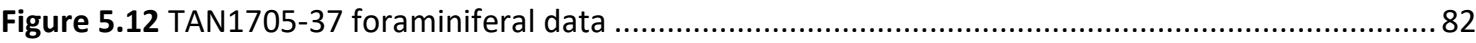

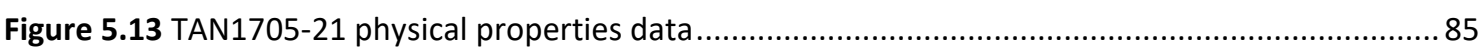

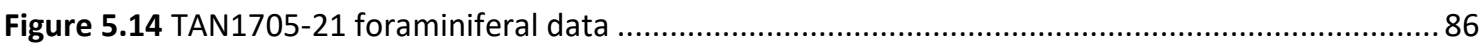

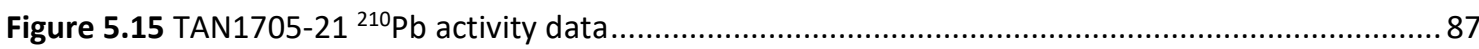

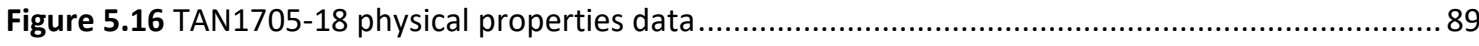

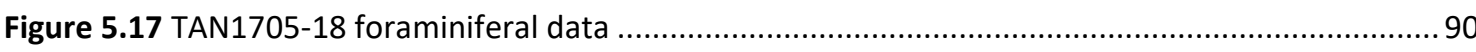

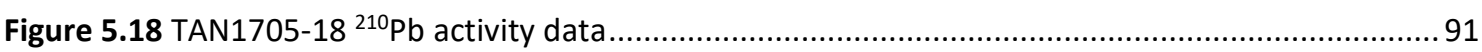

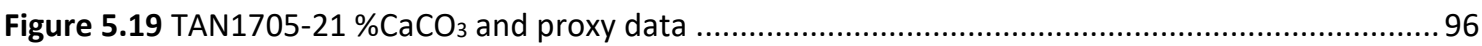

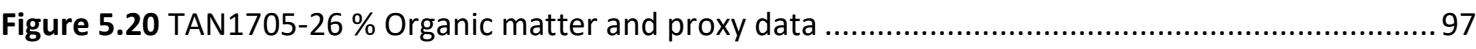

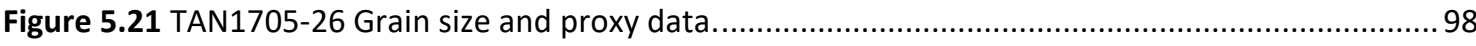

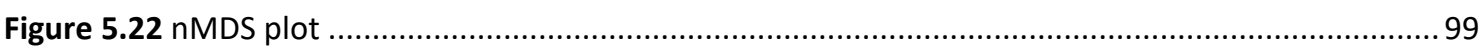

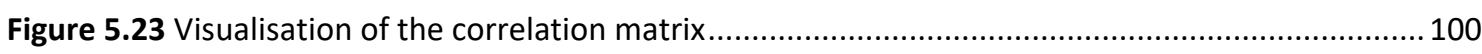

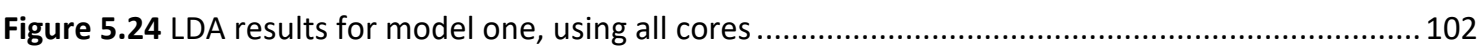

Figure 5.25 LDA results for model one, using canyon-proximal cores............................................ 103

Figure 5.26 LDA results for model one, using canyon-distal cores .................................................. 104

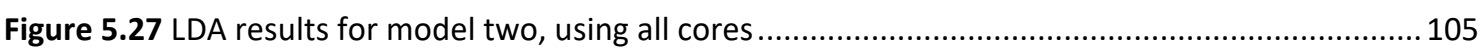

Figure 5.28 LDA results for model two, using canyon-proximal cores............................................... 106

Figure 5.29 LDA results for model two, using canyon-distal cores ................................................... 107

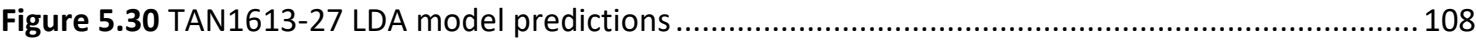

Figure 5.31 TAN1613-27 relative abundance of benthic genera plot................................................. 109

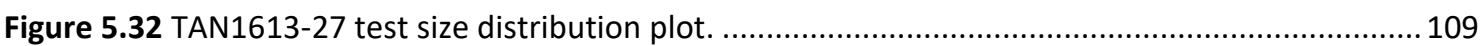


Figure 5.33 Calibrated radiocarbon age results for TAN1613-27.

Figure 6.1 Distribution of decision rule scores for each of the location-specific models

Figure 6.2 Posterior probabilities of a sample being a turbidite tail calculated using the canyon-proximal models, plotted for TAN1705-33

Figure 6.3 Posterior probabilities of a sample being a turbidite tail calculated using the canyon-proximal models, plotted for TAN1705-22

Figure 6.4 Posterior probabilities of a sample being a turbidite tail calculated using the canyon-proximal models, plotted for TAN1613-27 120

Figure 6.5 Posterior probabilities of a sample being a turbidite tail calculated using the canyon-distal

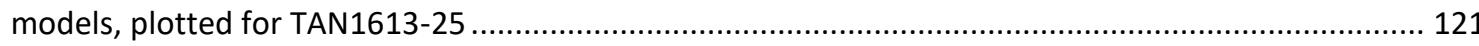

Figure 6.6 Model for the deposition of fine-grained sediments in deep water environments .............. 127

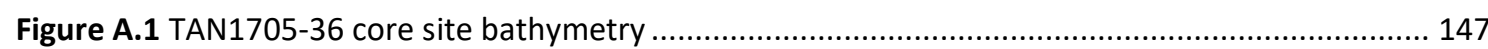

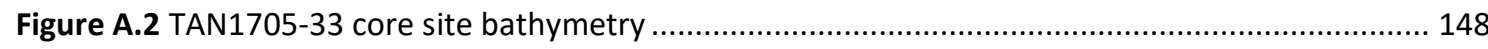

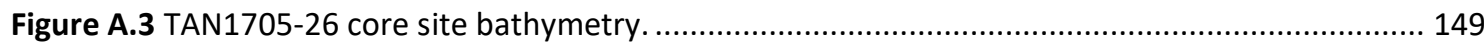

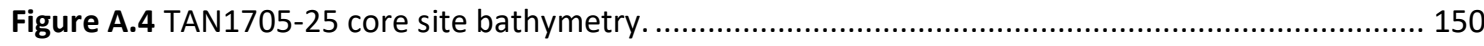

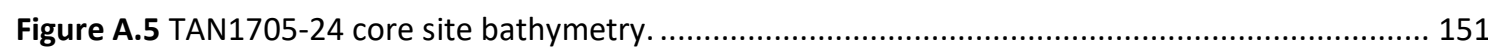

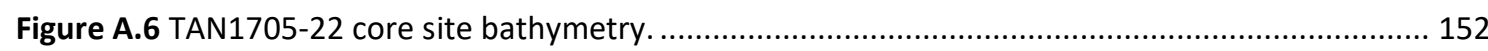

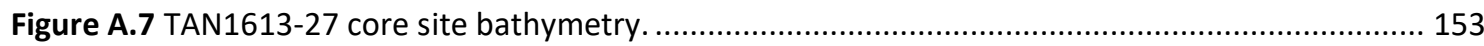

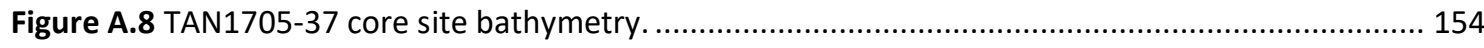

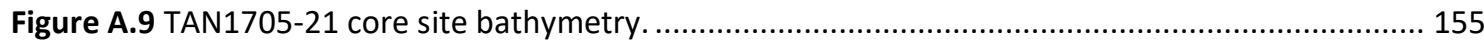

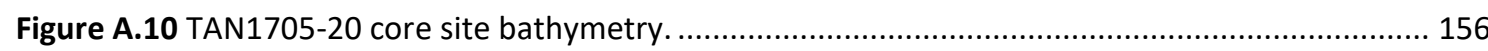

Figure A.11 TAN1705-18 and TAN1613-25 core site bathymetry.............................................. 157

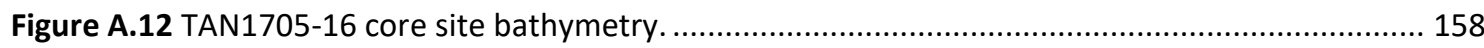

Figure C.1 TAN1705-33 destructive and non-destructive datasets ............................................. 165

Figure C.2 TAN1705-26 destructive and non-destructive datasets ............................................. 166

Figure C.3 TAN1705-24 destructive and non-destructive datasets ................................................ 167

Figure C.4 TAN1705-22 destructive and non-destructive datasets .............................................. 168

Figure C.5 TAN1705-37 destructive and non-destructive datasets ............................................... 169

Figure C.6 TAN1705-21 destructive and non-destructive datasets ............................................. 170

Figure C.7 TAN1705-18 destructive and non-destructive datasets ................................................ 171

Figure E.1 TAN1705-36 non-destructive dataset ..................................................................... 174

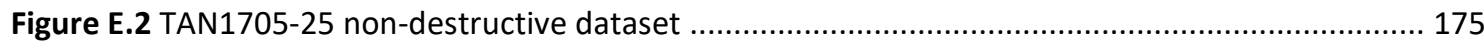

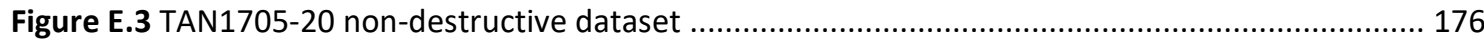

Figure E.4 TAN1705-16 non-destructive dataset .................................................................. 177

Figure F.1 TAN1613-27 destructive and non-destructive datasets ................................................ 179

Figure F.2 TAN1613-25 non-destructive dataset..................................................................... 180 


\section{List of Tables}

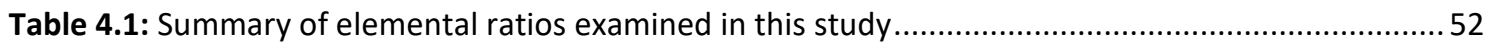

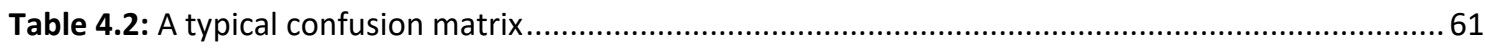

Table 4.3 The confusion matrix presented using the terminology of this study ................................61

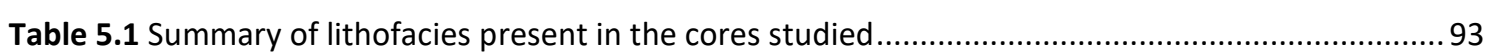

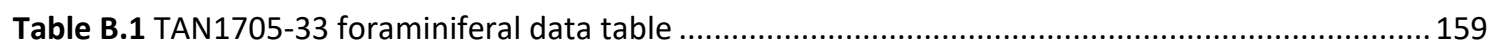

Table B.2 TAN1705-26 foraminiferal data table ..................................................................... 160

Table B.3 TAN1705-24 foraminiferal data table ................................................................... 161

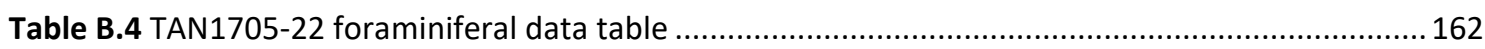

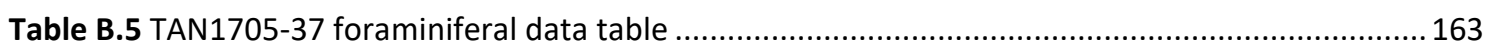

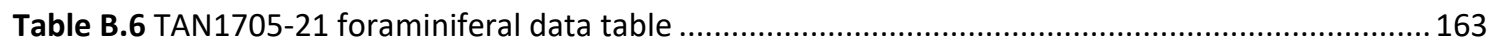

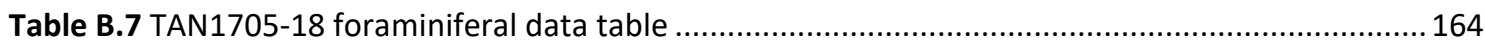

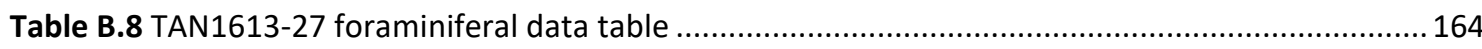

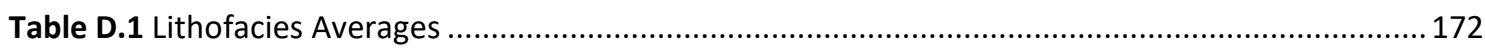

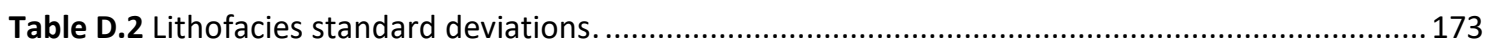

Table D.3 P-values calculated for the correlation of destructive data and the relevant non-destructive proxies using Pearson's correlation test. 



\section{Introduction}

The Hikurangi subduction margin off the east coast of New Zealand poses a significant source of seismic and tsunami hazard for New Zealand. However, as New Zealand has a short historical record of seismicity (<170 years), there is much that remains unknown about the seismic and tsunami potential of the Hikurangi margin (Wallace, Cochran, Power, \& Clark, 2014). Therefore, to understand the seismic hazard posed by the subduction interface, it is important to develop long and spatially extensive paleoseismic records to allow for the location, frequency and approximate magnitude of past events to be established (Clark et al., 2019).

Earthquakes have been shown to be one of the main triggers of turbidity currents (Goldfinger et al., 2013; Goldfinger et al., 2012; Heezen \& Ewing, 1952; Mountjoy et al., 2018), and turbidite paleoseismology exploits this relationship, using the distinct graded deposits of turbidites as evidence of past earthquakes. Turbidite paleoseismology has proven to be one of the most successful approaches for generating long paleoseismic records of subduction earthquakes (Barnes, Bostock, Neil, Strachan, \& Gosling, 2013; Goldfinger et al., 2012; Patton et al., 2015; Pouderoux, Proust, \& Lamarche, 2014). While earthquakes are not the only trigger for turbidity currents, they are the most likely process to cause widespread slope failure. Therefore, if turbidites can be identified as having been deposited at the same time, a significant distance apart, the argument can be made that these turbidites were triggered by the same event (Talling, 2014). To establish synchronous triggering of turbidity currents, the age of the turbidite must be known. The most common method to obtain a turbidite age is by radiocarbon dating the surrounding in situ sediment to produce an age-depth model of the sediments. In this context, in situ is used to describe the material that has accumulated at a given core site under background sedimentary processes, and thus does not contain reworked material that may be older than the age of the deposit as a whole. Therefore, in situ sediment is background sedimentation, the sediment that accumulates gradually on the sea floor by vertical settling processes in the open ocean (Stow \& Smillie, 2020). Thus, to apply turbidite 


\section{1: Introduction}

paleoseismology to a given setting, there must be a robust understanding of background sedimentation in that setting (Goldfinger, 2011).

Along the southern Hikurangi margin, background sediment is visually indistinguishable from the "tails" of turbidites. Turbidite tails are defined as the finegrained uppermost components of a turbidite deposit, linked to the deposition of the finest sediment remaining in suspension from a dying turbidity current (Stow \& Smillie, 2020; Talling, Masson, Sumner, \& Malgesini, 2012). Therefore, to use turbidites to build up a paleoseismic record, a method must be devised to reliably distinguish background sediment from turbidite tails. In other settings, a combination of physical properties data, such as density and magnetic susceptibility, and geochemical proxies have been used to attempt to distinguish turbidite tails from background sedimentation (Goldfinger et al., 2013; Gracia et al., 2010; Polonia et al., 2013; Ratzov et al., 2015). However, these studies rely on subjective interpretation of the data, and differences between turbidite tails and background sediments can be subtle and difficult to discern. Using the physical and geochemical data in Cascadia, Goldfinger et al. (2013) found mud turbidites in sediments that had previously been identified as background sediments. This study highlighted the need for a more data-based approach in the identification of background sediments to facilitate their distinction from turbidite tails (detailed in section 2.5).

On the $14^{\text {th }}$ of November, 2016 , the $M_{w} 7.8$ Kaikōura earthquake shook New Zealand, triggering turbidity currents along the southern Hikurangi margin (Howarth et al., in review; Mountjoy et al., 2018). This event has provided an unprecedented opportunity to examine recently-deposited turbidites along the southern Hikurangi margin. Because these turbidites lie at the surface of sediment cores, turbidite tails can be easily identified. Likewise, recently-deposited background sediments can also be robustly identified using ${ }^{210} \mathrm{~Pb}$ activity profiles to establish that sediment has been deposited gradually (Dezileau et al., 2016), and through the use of foraminiferal assemblages to determine if the sediment has been transported from shallower depths, and therefore indicate if the sediment has accumulated in situ (Hayward, Sabaa, \& Triggs, 2019). Thus, the Kaikōura turbidite provides a natural experiment to quantitatively examine the properties of turbidite tails, so that they can be compared 
with the properties of background sediments, to determine what differences there are between these two sediment groups.

The research presented in this thesis aims to use the natural experiment the Kaikoura earthquake has provided, to determine if there is a quantitative difference between turbidite tails and background sediments from physical properties and geochemical datasets along the southern Hikurangi margin. Then, if there is a quantifiable difference between these sediments, this study will aim to assess if these differences can be used to objectively identify background sediment and turbidite tails using machine learning. The machine learning approach will then be assessed to determine if this approach can be applied to the southern Hikurangi margin for the purposes of radiocarbon dating to model the ages of turbidites, and thus aid in building up a paleoseismic record for the southern Hikurangi margin.

This thesis is organised into seven chapters. Chapter 2 presents a review of the literature surrounding turbidite paleoseismology globally, details how other studies have distinguished turbidite tails and background sediments, and identifies the knowledge gaps that this thesis aims to address. Chapter 3 describes the tectonic and morphological setting of the southern Hikurangi margin, and details the sites from which cores were obtained for study. Chapter 4 outlines the overarching methodology and details the specific methods used to produce and analyse the data. Chapter 5 presents the results. Chapter 6 discusses the implications of the findings, to determine if the physical and geochemical properties of turbidite tails and background sediments can be used to quantitatively distinguish these sediments, as well as discussing the depositional processes acting along the southern Hikurangi margin and the implications this research has for turbidite paleoseismology studies. Chapter 7 summarises the main findings and details the conclusions drawn from this research. 
1: Introduction 


\section{Literature Review}

\subsection{Subduction Zone Paleoseismology}

Subduction zones are the source of some of the largest earthquakes and tsunamis in recent history (Cisternas et al., 2005; Koshimura \& Shuto, 2015; Patton et al., 2015). New Zealand straddles the plate boundary between the Pacific and Australian plates. To the east of the North Island, the Pacific plate subducts beneath the Australian plate in the Hikurangi subduction zone. While only moderate $\left(\mathrm{M}_{\mathrm{W}}<7.2\right)$ subduction interface earthquakes have been observed historically, there is evidence that this margin has the potential to produce $M_{w} 9.0$ earthquakes (Wallace et al., 2014). Thus, the Hikurangi margin represents one of the largest sources of seismic and tsunami hazard to New Zealand. Understanding both past earthquakes along this margin and similar subduction interface earthquakes globally is of paramount importance.

Notably, the impacts of the 2011 Tohoku-Oki earthquake and tsunami (Fujii, Satake, Sakai, Shinohara, \& Kanazawa, 2011; Lay, Ammon, Kanamori, Xue, \& Kim, 2011) have highlighted the hazards posed by subduction interface earthquakes and the need to understand how these fault systems behave over geological timescales (Garrett et al., 2016). Since the historical record of earthquakes is often too short to capture the recurrence of large earthquakes, the geological record allows for earthquake observations to be extended over the relevant timescales, and can be used to improve our understanding of seismic hazard (Clark et al., 2015; Moernaut et al., 2018; Mueller, Briggs, Wesson, \& Petersen, 2015).

Evidence of prehistoric subduction interface earthquakes can come from a variety of sources, including direct evidence of coastal deformation (e.g. Briggs et al., 2014; Sieh et al., 2008), or indirect evidence such as tsunami deposits (e.g. Clark et al., 2015; Sawai, Namegaya, Okamura, Satake, \& Shishikura, 2012) or turbidite deposits (e.g. Goldfinger, Nelson, \& Johnson, 2003; Pouderoux et al., 2014). Coastal deformation gives the most robust indication of past earthquakes along a subduction margin. However, evidence of coastal deformation can often be limited, as it is dependent on a variety of factors, such as the magnitude of the earthquake, location relative to the rupture patch of the subduction interface, sea level, and the geomorphology of the 


\section{2: Literature Review}

coastline. Subsequently, there can be large spatial and temporal gaps in coastal deformation records due to erosion, geomorphological characteristics that inhibit the preservation of uplift, human modification of the landscape, and overprinting of events with different distributions of slip causing uplift during one event and subsidence during another (Clark et al., 2019). Therefore, while coastal deformation provides the most indisputable evidence of past subduction interface earthquakes, it does not necessarily provide the most complete record of these earthquakes. Thus, indirect lines of evidence obtained from earthquake-triggered turbidites archived in more continuous sedimentary records, such as marine and lake sediment cores, can be useful for filling these gaps.

\subsection{Turbidite Paleoseismology}

Turbidite paleoseismology utilizes the distinctive characteristics of turbidite deposits (detailed in section 2.5) as a record of ground shaking during earthquakes. While the generation of turbidity currents is not strictly limited to earthquake processes, synchronous triggering of turbidity currents along a wide spatial extent is inferred to be solely produced by earthquakes (Goldfinger, 2011). Therefore, turbidite paleoseismology heavily relies on the identification of synchronously-triggered turbidites.

In its simplest form, synchronicity can be identified by comparing the number of turbidites in individual tributaries to the number present beneath the confluence. If the turbidites in the tributaries were triggered by separate events, this would result in the presence of two turbidites beneath the confluence. Conversely, if these turbidites were triggered by the same event, only one turbidite would be present beneath the confluence (Adams, 1990). However, there are many limitations with this approach. Turbidite deposition in individual tributaries may vary along a margin due to differences in morphology and variability in the thickness of the flow itself. Additionally, this can impact the number of turbidites recorded within the same channel at different locations (Talling, 2014).

Turbidites can also be correlated by identifying physical properties that are unique to a particular event, known as turbidite fingerprinting. The parameters used are generally grain size proxies, and these are represented as wiggle traces. These traces can be 
compared between cores to identify any unique attributes a particular event bed possesses. Unique turbidite fingerprints found across a wide area can be used as evidence of synchronicity, particularly when combined with independent age control (Goldfinger, 2011). However, not every turbidite has a unique signature in the physical properties data, and this 'fingerprint' is not always present in every synchronouslytriggered turbidite (Clark et al., 2019).

However, the most robust evidence for synchronous deposition comes from accurate dating of each turbidite. There are a variety of methods that can be used for this purpose, including short-lived isotopes, tephrochronology, and radiocarbon dating. Short-lived isotopes such as ${ }^{234} \mathrm{Th}$ and ${ }^{210} \mathrm{~Pb}$ record the age of particles settling on the seafloor and can be used to distinguish gradual and instantaneous deposition. However, these isotopes do not persist through time, and so can only be used on recently deposited sediment (Dezileau et al., 2016; Mountjoy et al., 2018). Tephrochronology uses the ages of volcanic material present in sediment cores to constrain the age of material within these cores, using either primary tephra horizons as an absolute age, or reworked tephra can be used as a relative marker to identify turbidites that post-date an eruption (Goldfinger et al., 2003; Shane, 2000).

Radiocarbon dating uses the decay of ${ }^{14} \mathrm{C}$ within the carbonate present in foraminifera to obtain the age of a sample (Thomson \& Weaver, 1994). This method can extend further back in time than short-lived isotopes, however, the turbidite itself cannot be directly dated, as it may contain reworked foraminifera with a wide variety of ages. Thus, it is crucial that the difference between reworked and in situ sediment is understood when obtaining the age of a turbidite (Goldfinger, 2011). Radiocarbon dating is the most commonly-used method to obtain ages for turbidites (Barnes et al., 2013; Goldfinger et al., 2012; Patton et al., 2015).

\subsection{Applications of Turbidite Paleoseismology}

Turbidite paleoseismology has been applied to a variety of locations globally, with research particularly focused on obtaining earthquake histories at convergent plate margins (Goldfinger, 2011). Certain locations are more favourable for the use of this technique than others. The ideal location for the application of turbidite 


\section{2: Literature Review}

paleoseismology is an area in which the recurrence time between large-magnitude earthquakes is long, there are high sedimentation rates, high biogenic productivity, and isolated slope basins or discrete channels (Bernhardt, Melnick, Hebbeln, Lückge, \& Strecker, 2015). It is key that there is enough time for sediment to build up between events, that the sediment contains sufficient dateable material, and that enough sediment builds up so that a large-magnitude event destabilizes the slope. Additionally, it is important that the margin morphology allows for sediment to either be trapped in isolated slope basins, or be directed by discrete channels, allowing the flow path of the turbidity current to be easily understood. This makes plate boundaries ideal, however, other factors that limit background sedimentation or affect the flow path of turbidity currents can complicate the use of turbidite paleoseismology (Goldfinger, 2011). This review will interrogate locations where turbidite paleoseismology has been applied, to examine where the approach has been successful, and where it has not, to understand what is required to successfully produce a paleoseismic record from turbidite evidence.

\subsubsection{Cascadia}

Off the coast of the NW United States, the Juan de Fuca and Gorda plates subduct beneath the North American plate at a rate of $36-50 \mathrm{~mm} / \mathrm{yr}$ to form the Cascadia subduction zone (Patton et al., 2013). This subduction margin has been widely recognised as a favourable location for the purposes of turbidite paleoseismology. The dip of the subducting plate is shallow, and there are high sedimentation rates and a filled trench, which drives the development of fan systems and discrete channel systems that lead away from the margin. Sediment largely supplied to the margin by rivers, (e.g., Colombia River), and accumulates on the top of the continental slope until submarine failure occurs and the sediment that has accumulated between failures travels down the channels in a turbidity current. This pattern of accumulation and failure has existed through the last $6000-7000$ years. Prior to 7000 years ago, lower sea level meant that sediment was instead continually supplied to the deep sea (Adams, 1990). Cascadia is also located in an area of high biological productivity, so the background sedimentation between turbidite deposits contains an adequate amount of material for dating, and the high sedimentation rates allow enough sediment to 
build up between turbidite-triggering events to easily distinguish separate events (Goldfinger, 2011).

Multiple studies have examined turbidite deposits along the Cascadia margin. Adams (1990) first examined the possibility of utilizing turbidites to expand the paleoseismic record of the Cascadia subduction zone, identifying 13 turbidites in the Cascadia channel that could be linked to turbidites found in individual tributaries, thus satisfying the conditions of the confluence test. The eruption of Mount Mazama at $7627 \pm 150$ cal. yr. B.P. (Goldfinger, 2011) was used as a tie point for the turbidites on the Cascadia margin. The eruption was not large enough to deposit directly on the margin, but much fell into the catchment of the Columbia River, subsequently being washed out to sea and deposited on the shelf. Following this event, turbidity currents resulting from the destabilization of the slope contained the reworked Mazama tephra. While this does not provide direct age control for these turbidites, the study identified 13 turbidites since the eruption of Mount Mazama, postulating a recurrence interval of $590 \pm 170$ years based on the age of the tephra, the total number of turbidites above the tephra, and radiocarbon data from plant fibres within the eighth turbidite in the sequence. Large earthquakes along the Cascadia margin were determined to occur approximately every $590 \pm 170$ years from this data.

Other studies have built on this research - Goldfinger et al. (2003) extended the record further back in time to identify 18 earthquakes in the last 9850 years, using radiocarbon ages derived from planktic foraminifera deposited in background sediments underlying the turbidites to correlate events temporally. Goldfinger et al. (2013) further refined the record, examining mud turbidites ubiquitous through the southern section of the Cascadia margin. These mud turbidites were previously identified as background sediment, and account for the difference in the thickness of background sediments observed between the Juan de Fuca and Rogue Apron in previous studies. The mud turbidites were correlated over $100-300 \mathrm{~km}$ of the southern margin, and indicate that this section of the margin ruptures more frequently (approximately every 240 years during the Holocene) than margin-wide ruptures. Atwater, Carson, Griggs, Johnson, and Salmi (2014) revisited the confluence test of Adams (1990), highlighting that sediment routing may be more complex along the 


\section{2: Literature Review}

Cascadia margin than was initially thought, and sediment may travel by way of spillover paths to give misleading results.

\subsubsection{Sumatra}

The Sumatra-Andaman subduction zone in the northeast Indian Ocean is formed by the subduction of the Indo-Australian plate beneath the Burma microplate at a rate of $50-70 \mathrm{~mm} / \mathrm{yr}$. On December $26^{\text {th }}, 2004$, a section of the megathrust ruptured in a $\mathrm{Mw}$ 9.2 earthquake which resulted in a tsunami that killed over 220,000 people (Patton et al., 2015). In contrast to Cascadia, the Sumatran margin has less physiographical factors in its favour for the application of turbidite paleoseismology. The Sumatra trench is not filled, and lies beneath the carbonate compensation depth (CCD) at $\sim 4200 \mathrm{~m}$, meaning that no calcium carbonate is present at these depths, and thus radiocarbon dating cannot be used to obtain ages for these sediments. Channel systems in the trench are short or not detectable, and the flow path of turbidity currents through these channels is restricted further by bending moment normal faults that offset and deform the channels. Sedimentation rates have also been low in this region since at least the Pleistocene (Patton et al., 2013). However, slope basins can provide a viable option for turbidite paleoseismology, as these lie above the $C C D$, and can be isolated from terrigenous sediment input, as well as input from other sources. However, slope basins can be more proximal to source than is ideal, meaning that some may not be wide enough to accommodate the transition from a slump-debris flow to a turbidity current (Goldfinger, 2011).

Sumner et al. (2013) examined the viability of applying turbidite paleoseismology along the Sumatran margin by attempting to link turbidite deposits to historical earthquakes using ${ }^{210} \mathrm{~Pb}$ chronology and radiocarbon dating. They found no evidence of turbidites generated by either the 2004 (Mw 9.1) or 2005 (Mw 8.7) earthquakes, casting doubt on the viability of turbidite paleoseismology along the Sumatran margin. Out of six slope basin cores examined in this study, five did not show any turbidites deposited in the last 100-150 years, and the age of the youngest turbidite in the sixth core did not correspond with any known earthquake. Cores taken from the trench contained turbidites that could have been triggered by the 2004 or 2005 earthquakes, however, the authors argue that trench evidence alone is insufficient to make an argument for 
earthquake triggering. This study concluded that the Sumatran margin may not be an appropriate setting for the application of turbidite paleoseismology, as large earthquakes along this margin do not always generate turbidity currents.

However, Goldfinger et al. (2014) questioned the site selection and sampling strategy of Sumner et al. (2013), arguing that the results of the study were insufficient to rule out the use of turbidite paleoseismology along the margin. Patton et al. (2015) also studied turbidites along this margin, obtaining age control for the sediments via radiocarbon and short-lived isotope dating, finding 21 examples of turbidites inferred to have been linked to the 2004 earthquake. Additionally, this study identified at least 43 turbidites triggered in the region that ruptured in 2004 over the last $\sim 6.6$ thousand years, with an average recurrence interval of 160 years. The issue of the CCD impacting on the ability to obtain age control for turbidite deposits was accommodated through the sampling of slope basins above the CCD, and using the lithostratigraphic "fingerprint" of these turbidites to correlate them below the CCD. This study reiterated the point of Goldfinger et al. (2014) that though the Sumatran margin may not be the ideal setting for turbidite paleoseismology, it can still be applied if core sites are more carefully selected.

\subsubsection{Japan}

The east coast of Japan is marked by the subduction of the Pacific plate beneath the Okhotsk plate to the north, forming the Japan Trench off the Sanriku coast and the Kuril trench off the Kuril Islands (Ikehara et al., 2016; Noda, Tuzino, Kanai, Furukawa, \& Uchida, 2008). Most notably, the Japan trench was the site of the Mw 9.0 Tohoku-Oki earthquake and tsunami in March of 2011, which affected over 600,000 people and flooded $561 \mathrm{~km}^{2}$ of land (Koshimura \& Shuto, 2015).

The Pacific plate subducts beneath the Okhotsk plate to the northwest at a rate of 80$86 \mathrm{~mm} / \mathrm{yr}$ in the Japan Trench. The depth of the trench at its axis is between 6800$7500 \mathrm{~m}$, thus lying below the CCD ( 4000-4500 $\mathrm{m}$ in the NW Pacific). Few canyon systems exist that link the shelf to the floor of the trench, and these are only present in the northern part of the trench. The waters of north western Japan are characterized by high primary productivity, resulting in the deposition of diatomaceous silts, clays, 


\section{2: Literature Review}

and ooze on the lower slope and trench floor, while the upper slope sediments are dominated by calcareous and diatomaceous clay with clastic and pumiceous grains (Ikehara et al., 2016).

Ikehara et al. (2016) examined turbidites triggered by previous ruptures of the Japan Trench. Three such turbidites were identified in cores taken from the floor of the Japan Trench, the youngest of which was determined to be linked to the 2011 Tohoku-oki earthquake. Though samples were taken from below the CCD, radiocarbon dating of bulk organic carbon was used instead of carbonates, allowing this issue to be circumvented. However, these ages were about 2000-3000 years older than the age of a tephra layer within the same cores, leading the authors to conclude that these radiocarbon ages were affected by contamination by older organic carbon. The older two turbidites were correlated to tsunami deposits found on the Sendai and Ishinomaki plains, which also corresponded with historical records of tsunami. The second turbidite was determined to be related to either the "Keicho" tsunami (AD 1611) or the "Kyotoku" tsunami (AD 1454), while the third was linked with the "Jogan" tsunami (AD 869). These results highlight the recurrence of large earthquakes near the epicentre of the 2011 earthquake through the last 1500 years.

Usami, Ikehara, Kanamatsu, and McHugh (2018) also examined turbidites from the Japan Trench, targeting their sampling at the mid-slope terrace at 4000-6000 m depth, an area with no direct connections to regular sediment transport paths, so the origin for any turbidites present in the mid-slope terrace must be the adjacent landward slope. From the two cores taken in this area, 12 turbidites were identified in the upper $4 \mathrm{~m}$ of sediment. Since these cores lie below the CCD, the timing of the events was constrained using a mixture of tephrochronology, short-lived isotopes $\left({ }^{210} \mathrm{~Pb}\right.$ and $\left.{ }^{137} \mathrm{Cs}\right)$, and paleomagnetic secular variation (PSV). PSV is a geomagnetic field change that occurs on timescales ranging from years to millennia (Kanamatsu, Usami, McHugh, \& Ikehara, 2017). Ages are obtained by observing the record of remnant magnetization split into the component inclination and declination curves, and comparing that to a reference curve with known ages - in this case, from Lake Biwa, Japan. From this, the ages of the 12 turbidites were estimated, giving a recurrence interval of $\sim 700$ years for large magnitude $\left(\mathrm{Mw}_{\mathrm{w}} \sim 9\right)$ earthquakes in the Japan Trench through the last 4000 years. Evidence also suggests that the recurrence interval has shortened slightly in more 
recent times, linked to decreases in the release of accumulated slip in earthquakes in the northern and southern areas off the Sanriku coast.

The Kuril trench lies to the north of the Japan Trench, where the Pacific Plate subducts beneath the Okhotsk plate at a rate of $\sim 80 \mathrm{~mm} / \mathrm{yr}$, and large earthquakes $\left(\mathrm{Mw}_{\mathrm{w}}>8\right)$ are frequently produced in this region. The forearc slope in this area ranges from the upper slope at depths between $130-1000 \mathrm{~m}$, the middle slope (1000-3000 m), and the lower slope (3000-3500 m), placing it above the CCD for the NW Pacific. The upper slope is incised by a series of gullies, and some of these cut the middle slope, leading to the development of a submarine fan on the lower slope where turbidites can accumulate (Noda et al., 2008).

Noda et al. (2008) studied turbidites located on the aforementioned submarine fan on the lower slope, between 3100-3300 m water depths. Turbidites were identified that could be correlated to historical earthquakes in 1952, 1961, and 1973, using ${ }^{210} \mathrm{~Pb}_{\mathrm{ex}}$ and ${ }^{137} \mathrm{Cs}$ chronology, and the full record was extended through the last $7 \mathrm{kyr}$ using radiocarbon dating and tephrochronology to constrain age models. Through this time period, the interval between turbidites ranged between 113 and 439 years. However, it was estimated that only half of the earthquakes that produced sufficient ground shaking around the source area were present in this record, potentially due to changes in the flow path of turbidity currents through time or the frequent removal of unstable sediments on the slope. Additionally, no single core from this study contained the full record of turbidites, suggesting that the recurrence interval may be less than 113 years.

\subsubsection{Taiwan}

Taiwan is located in the transfer zone between two opposing subductions - in the east, the Philippine sea plate subducts northwards beneath the Eurasian plate, and to the south, the Eurasian plate subducts eastwards beneath the Philippine sea plate. The Philippine sea plate converges north-westward at a rate of $81 \mathrm{~mm} / \mathrm{yr}$. Sedimentation rates in this region are high, directed into three major submarine canyons. Additional channels cut into the continental slope and link to these canyons, and it is inferred that 


\section{2: Literature Review}

the dominant processes within these channels are marine erosional processes such as turbidity currents (Lehu et al., 2015).

Dezileau et al. (2016) examined recent turbidites off the coast of eastern Taiwan using ${ }^{210} \mathrm{~Pb},{ }^{137} \mathrm{Cs}$, and ${ }^{241} \mathrm{Am}$ chronologies, identifying three turbidites within the last 100 years that correlate to three historical large $\left(M_{w} \geq 6.8\right)$ earthquakes, the 2003 Taitung earthquake ( $\left.M_{w} 6.8\right)$, the 1951 Chengkong earthquake ( $\left.M_{w} 7.1\right)$, and the 1935 Lutao earthquake ( $M_{w}$ 7.0). Lehu et al. (2016) expanded on this work, examining the turbidite record of Taiwan over the last 2700 years. This study targeted areas away from continental sediment input such as isolated terraces and perched basins to avoid any turbidites not triggered by seismic activity. Timing of turbidite deposition was determined using the sedimentation rates derived from radiocarbon dating and ${ }^{210} \mathrm{~Pb}$ and ${ }^{137} \mathrm{Cs}$ chronologies. The results of this study determined that the paleoseismic record from turbidites is incomplete. This is likely due to the high rates of seismicity leaving little time for sediment to accumulate between earthquakes, so slope failure does not occur with every single event. Additionally, the high level of seismicity means that synchronicity of slope failure across a wide area cannot be used as justification for earthquake triggering as the recurrence interval of large (i.e. $M_{w}>7$ ) earthquakes is smaller than the uncertainty on radiocarbon ages. Variations in sediment supply through time results in a change to the earthquake magnitude threshold for turbidite triggering. For reasonable conclusions to be drawn about changes in earthquake frequency, it is assumed that sediment supply remains constant through time. The results from Taiwan show that the frequency of turbidites increased by approximately four times after 1900, likely related to the intensification of typhoons and the monsoon that contributes to increasing erosion onland. This highlights the limitations of turbidite paleoseismology in areas where large earthquakes are frequent.

\subsubsection{Chile}

Off the coast of Chile, the Nazca plate subducts beneath the South American plate at a rate of $\sim 70 \mathrm{~mm} / \mathrm{yr}$. This margin has been the site of a number of large earthquakes in recorded history, including the $M_{w} 9.5$ megathrust earthquake in 1960. The subduction zone can be divided into three segments - the Valdivia segment to the south (site of the 1960 earthquake), the Concepción segment in Central Chile (site of 
the $M w$ 8.8 Maule earthquake in 2010), and the Valparaíso or Metropolitan segment in the north. Offshore Chile, the submarine accretionary forearc is characterized by an irregular marine slope. This contains many features that can serve as sediment conduits or traps, such as small intraslope plateaus, basins, ridges, and submarine canyons that traverse the slope to the trench. Terrigenous sediment supply to the margin is largely controlled by climate, and more specifically, precipitation. The highamplitude north-south precipitation gradient plays a significant role, with high precipitation in southern Chile driving high sedimentation rates in the south, while the semi-arid region in northern Chile results in lower sedimentation rates. Additionally, the Peru-Chile Current (or Humboldt Current) extends along the coast of Peru and Chile, driving strong coastal upwelling and thus resulting in high biological productivity (Bernhardt et al., 2015).

The applicability of turbidite paleoseismology to the Chilean margin was assessed by Bernhardt et al. (2015), who examined sediments across $950 \mathrm{~km}$ of the margin, encompassing the range of sediment supply regimes and different segments of the subduction zone detailed above. This study found variations in turbidite generation between the northern and southern regions, linked to the difference in sedimentation rates across this area. In the north, background sediments had a pronounced colour difference from turbidite deposits, as well a difference in magnetic susceptibility measurements. Virtually no Holocene turbidites were recorded in this area due to the low sediment input from the semi-arid mainland. In the south, there was no pronounced colour difference between background sediments and turbidite muds, and these were differentiated by examining X-ray images of the cores. Here, turbidites were recorded that could correlate with earthquakes, but the high terrigenous sedimentation rates created difficulty in obtaining radiocarbon ages, as high sedimentation impacted the accumulation of foraminifera for radiocarbon dating. The findings from Chile highlight the key role sedimentation rates play in the applicability of turbidite paleoseismology in a given setting, and how this is limited by each extreme of sedimentation. The authors suggest that there is the potential for turbidite paleoseismology to be applied in the transition zone between these two 


\section{2: Literature Review}

sedimentation regimes, which captures the northern section of the 2010 Maule earthquake rupture zone.

\subsubsection{Mediterranean Sea}

Various locations in the Mediterranean Sea have been examined for turbidite paleoseismology studies. This region is characterized by a number of slow-convergence margins, including the Iberian margin to the east of Portugal, the Algerian margin, offshore Algeria, and the Calabrian arc subduction system in the Ionian Sea off the coast of Italy. These areas pose significant seismic hazard to the Mediterranean, and records of large earthquakes date back to ancient Roman times (Cattaneo et al., 2012; Gracia et al., 2010; Polonia et al., 2013).

Off the coast of Portugal, the Eurasian and African plates converge at a rate of 4.5-5.6 $\mathrm{mm} / \mathrm{yr}$, accommodated by a wide deformation zone, forming the lberian margin. Notably, this region was the site of the $M_{W} 8.0$ Horseshoe earthquake in 1969, and the 1755 Lisbon earthquake $\left(\mathrm{M}_{\mathrm{w}} \sim 8.5\right)$. This area has an abrupt, irregular physiography, with large ridges and seamounts, narrow canyons, and abyssal plains infilled by alternating background and turbidite sediments (Gracia et al., 2010).

Gracia et al. (2010) studied turbidite deposits in deep-sea basins off the coast of Portugal, identifying 6 seismically-triggered turbidites during the Holocene that were correlated across the study area using radiocarbon dating. The youngest widespread turbidites could be linked to historical earthquakes using ${ }^{210} \mathrm{~Pb}$ and ${ }^{137} \mathrm{Cs}$ chronology, including the 1969 Horseshoe earthquake and the 1755 Lisbon earthquake.

Additionally, two of the older turbidites could also be correlated to tsunami evidence of the same age. The ages of these 6 widespread turbidites indicated that great earthquakes occur along this margin approximately every 1800 years, and overall, this study demonstrated the applicability of turbidite paleoseismology to a slowconvergence margin.

East of the Iberian margin, off the coast of Algeria, the African plate converges towards the Eurasian plate at a rate of 3-6 mm/yr, in the diffuse boundary that is the Algerian margin. Moderate to large earthquakes have been recorded in this region, such as the $2003 M_{w} 6.8$ Boumerdès earthquake (Ratzov et al., 2015). The continental slope off Algeria is steep, and heavily incised by small canyons and escarpments. The deep basin 
20-30 km away from the continental slope provides the most ideal location for examining turbidite deposits, as its distal nature means that likely only the largest earthquakes are recorded (Babonneau et al., 2017).

Cattaneo et al. (2012) examined the 2003 Boumerdès earthquake that triggered large turbidity currents off the central Algerian coast, evidenced by a complex pattern of submarine cable breaks over approximately $150 \mathrm{~km}$ from west to east. This study provided an analysis of the response of the seafloor to a known earthquake, showing that turbidites were triggered synchronously across a wide area in response to this event. The authors also identified a distal area in the Algiers canyon which contained thin turbidites interbedded with hemipelagic sediment, and preliminary findings based on radiocarbon ages indicated a mean recurrence interval of 800 years. Ratzov et al. (2015) expanded on this work, examining the record of prehistoric turbidites in the Kramis region, west of the epicentre of the Boumerdès earthquake. This study dated 13 paleoearthquakes through the last 8 kyrs using radiocarbon dating. These paleoearthquakes form three clusters of events with recurrence intervals between $300-600$ years within the clusters, and two quiet periods between these clusters lasting approximately 1600 years. Babonneau et al. (2017) revisited the central Algerian area, using radiocarbon dating to identify 36 synchronous events through the last $9 \mathrm{kyr}$, with the most recent turbidites reasonably correlating with historical events. The turbidite evidence shows that recurrence intervals range between 50 and 900 years, with quiescence periods that exceed 450 years, suggesting an irregular earthquake cycle in this region. The authors also compared their findings with that of Ratzov et al. (2015), stating that while the number of events and recurrence intervals do not necessarily match between the different sections of the margin, the irregular earthquake cycle is observed in both regions, and the discrepancy could be explained by the difference in the locations of the faults, which are further inland in the Kramis area.

The Calabrian arc subduction complex in the Ionian Sea is located off the coast of Italy where the African plate subducts beneath the Eurasian plate at a rate of 2-5 mm/yr. Numerous large earthquakes have been recorded in this region through history, including a $M_{w} 7.24$ earthquake and tsunami in 1908, and extending back to a $M_{w} \sim 6.6$ 


\section{2: Literature Review}

earthquake in A.D. 361. The Ionian Sea was deemed a promising area of study for turbidite paleoseismology as it is characterized by a long interval of deposition not influenced by river inputs, as well as having high sedimentation rates driven by erosion of the mountains behind the sedimentary basin (Polonia et al., 2013).

Polonia et al. (2013) studied the sediments in the Ionian Sea, showing that turbidites make up over $80 \%$ of sedimentation in this region, and identifying three turbidite deposits emplaced in the last millennia that correlated with historical earthquakes, dated using ${ }^{210} \mathrm{~Pb},{ }^{137} \mathrm{Cs}$, and radiocarbon dating at 1908, 1693, and 1169 A.D. However, because only three events in the last 1000 years were identified in the turbidite record, this suggests that not every earthquake along this margin triggers a turbidity current - it is likely that only large or offshore earthquakes result in the remobilization of sediments.

\subsubsection{Northern Hikurangi}

Off the east coast of the North Island of New Zealand, The Pacific plate subducts beneath the Australian plate at a rate of $50 \mathrm{~mm} / \mathrm{yr}$ in the northern Hikurangi margin. This area has historically been impacted by large earthquakes, including the March $1947 M_{w}$ 7.1 Poverty Bay subduction interface earthquake (Clark et al., 2019). The northern Hikurangi margin is characterized by a continental slope that is scarred by three morphological re-entrants, which represent independent Quaternary sedimentary systems, made up of gullies and canyons on the upper slope, mid-slope basins, and trench basins. Sedimentation rates in this region are high, providing sufficient material to trigger turbidity currents (Pouderoux et al., 2014; Pouderoux, Proust, Lamarche, Orpin, \& Neil, 2012).

Pouderoux et al. (2014) documented a 16,000-year history of turbidites using sediment cores from three distinct morphological re-entrants. From this turbidite record, 41 synchronous turbidites were determined to originate from earthquake-triggered slope failures, using a combination of radiocarbon dating and tephrochronology to produce age models. The 41 synchronous turbidites were linked to the rupture of three active faults in the region, including the subduction interface, using well-established empirical relationships, combining peak ground accelerations, earthquake magnitudes, and earthquake locations. From this record, twenty subduction interface earthquakes 
were identified, with an average recurrence interval of $\sim 800$ years. Ten margin events identified in the turbidite record could be correlated with terrestrial paleoearthquake evidence, including the uplift of marine terraces and paleotsunami evidence. This record showed patterns in the recurrence of large earthquakes along the Hikurangi margin, suggesting that there are alternating periods of more frequent, smaller magnitude events and periods of relative calm with larger magnitude events.

\subsubsection{Fiordland}

Offshore Fiordland, New Zealand is located at the boundary of the Australian and Pacific plates. The Alpine Fault is a dextral strike-slip plate boundary zone which extends over $800 \mathrm{~km}$ through the South Island, and the southern $230 \mathrm{~km}$ of it extends offshore Fiordland. Along the Alpine Fault, the average dextral slip rate ranges from 14 $\mathrm{mm} / \mathrm{yr}$ in the north to $31 \mathrm{~mm} / \mathrm{yr}$ offshore Fiordland. Beneath Fiordland, the Australian plate subducts beneath the Pacific plate in the Fiordland subduction zone, which is associated with a west-verging thrust system that intersects the seafloor west of the Alpine fault. While no Alpine fault earthquakes have been observed since European settlement of New Zealand, evidence suggests the most recent rupture occurred around A.D. 1717, estimated at magnitude $M_{w} 7.9$ (Howarth et al., 2018). Shallow thrust interplate earthquakes or intraslab events located close to the Alpine fault have been recorded in recent times, such as the $2009 \mathrm{Mw}_{\mathrm{w}} 7.8$ Dusky Sound earthquake (Clark, Johnson, Turnbull, \& Litchfield, 2011). These earthquakes are related to the complex structure of the Fiordland subduction zone, rather than being actual Alpine fault ruptures. Offshore Fiordland is characterized by relict, well preserved glacial moraines, submarine outwash fans, and channel systems that have been displaced by the Alpine fault. The region is also marked by low sedimentation rates, due to highly resistant basement rocks limiting the amount of suspended sediment carried to the margin from river catchments (Barnes et al., 2013).

Turbidites offshore Fiordland were studied by Barnes et al. (2013), to document 2300 year record of earthquakes from both the Alpine fault and Fiordland subduction zone. The study analysed turbidites in three sedimentary basins along the margin, finding stacked sequences of sand-silt turbidites with no intervening background sedimentation. The turbidites themselves were radiocarbon dated, and while the 


\section{2: Literature Review}

dated material represented the age of the source sediment, rather than the event itself, the cyclic nature of sediment being evacuated during earthquakes and replenished between events during storms give in-sequence radiocarbon dates through the turbidite stacks. This allowed for the age modelling program OxCal (Ramsey, 2008) to be used, modelling the probability distributions for the ages of each turbidite, with ${ }^{210} \mathrm{~Pb}_{\text {ex }}$ profiles being used to constrain the ages of younger events. The turbidite record appears to have recorded two recent interplate earthquakes, the 1993 Mw 6.8 Fiordland earthquake and the $2003 \mathrm{Mw}_{\mathrm{w}} 7.2$ Fiordland earthquake, as well as the A.D. 1717 Alpine fault earthquake, showing that this record contains evidence for both interplate and Alpine fault earthquakes. The study found that the average recurrence interval for turbidites decreased southward through the basins studied, ranging from $\sim 190$ years to $\sim 150$ years, indicating turbidites occur at higher frequency in the south of the margin. This increase in recurrence intervals is likely due to an increase in the signature of the Fiordland subduction zone, and potentially an increase in segmentation of the Alpine fault offshore.

\subsection{Turbidite Chronology}

As demonstrated by the review of turbidite paleoseismology studies above, the approach relies heavily on obtaining accurate ages for the deposition of turbidites. Turbidites can be dated using a variety of methods to accurately determine when a turbidite was deposited, including the use of short-lived radioisotopes, radiocarbon dating, and tephrochronology (Goldfinger, 2011). This review will examine how the aforementioned dating methods are used to obtain the ages of turbidites, and what understanding is required around the deposition of the turbidites and the surrounding background sedimentation to utilize these dating methods effectively.

\subsubsection{Short-Lived Isotopes}

Obtaining the age of a turbidite deposit from short-lived radioisotopes utilizes the decay profile of these isotopes within sediments to identify reworked sediments, which disrupt this profile (Philp \& Jardé, 2007). There are two radioisotopes that are commonly used for this purpose: Thorium-234 and Lead-210.

${ }^{234} \mathrm{Th}$ is produced constantly by the decay of ${ }^{238} \mathrm{U}$ in seawater, which attaches to sediment as it settles out of the water column. The ${ }^{234} \mathrm{Th}$ produced from the decay of 20 
${ }^{238} \mathrm{U}$ within the sediments is removed to produce a profile of only the ${ }^{234} \mathrm{Th}$ that settled out along with the sediment, known as excess ${ }^{234} \mathrm{Th}$. The half-life of ${ }^{234} \mathrm{Th}$ is 24 days, so it becomes undetectable in sediment after 120 days (Nour, Burnett, \& Horwitz, 2002). Because of this short half-life, the excess ${ }^{234}$ Th profile in undisturbed sediment would show a rapid decrease within the top few centimetres of a core. However, a recently emplaced turbidite would disrupt this profile, showing a spike in excess ${ }^{234}$ Th in the sediment underlying the turbidite, representing the sea floor prior to the deposition of the turbidite (Mountjoy et al., 2018). This method is limited by the short half-life of ${ }^{234} \mathrm{Th}$, in that samples must be analysed within $\sim 4$ months of an earthquake, however, it provides confirmation of the source of the turbidite simply and unambiguously, allowing for the triggering of a turbidity current to be considered in the study of a very recent earthquake.

${ }^{210} \mathrm{~Pb}$ is used in a similar way - it is produced by the decay of ${ }^{222} \mathrm{Rn}$ in the atmosphere or water column which is then incorporated into sediments (excess ${ }^{210} \mathrm{~Pb}$ ), as well as through in situ decay of ${ }^{226} \mathrm{Ra}$. Excess ${ }^{210} \mathrm{~Pb}$ is calculated by subtracting the activity related to the parent isotope $\left({ }^{226} \mathrm{Ra}\right)$ from the total ${ }^{210} \mathrm{~Pb}$ activity in the sediment. It has a half-life of 22.3 years, and so can be used to study sediments deposited up to $100-$ 150 years ago. In undisturbed background sediment, the excess ${ }^{210} \mathrm{~Pb}$ profile exponentially decreases with depth. However, if sediment that was deposited rapidly (as in a turbidite) is present, the profile is interrupted. From excess ${ }^{210} \mathrm{~Pb}$ profiles, sedimentation rates can be calculated using the constant flux-constant sedimentation (CFCS) model (Drab, Ferrari, Schmidt, \& Martinez, 2012). Though the CFCS model does not account for turbidite deposition, the excess ${ }^{210} \mathrm{~Pb}$ profile can be corrected to remove the turbidites, leaving only the background sedimentation and the exponential decay curve. Then, the CFCS model can be applied to calculate the event ages.

The ${ }^{210} \mathrm{~Pb}$ ex age model can be constrained through the examination of artificial nuclides related to human activity, such as ${ }^{137} \mathrm{Cs}$ and ${ }^{241} \mathrm{Am}$. These radionuclides were introduced to the atmosphere with the testing of nuclear weapons through the mid20th century, and their activities produce a peak in sediment records corresponding to 1963, when atmospheric values were at their highest, along with smaller increases in 1971 and 1974 (Philp \& Jardé, 2007). These peaks can be used to calibrate ages and 


\section{2: Literature Review}

sedimentation rates obtained from ${ }^{210} \mathrm{~Pb}_{\text {ex }}$ activity (Dezileau et al., 2016). The accumulation of ${ }^{210} \mathrm{~Pb}_{\mathrm{ex}}$ can also be impacted by physical or biological mixing of the sediment, which flattens the ${ }^{210} \mathrm{~Pb}$ ex profile. However, the peaks in ${ }^{137} \mathrm{Cs}$ or ${ }^{241} \mathrm{Am}$ can be used as a test for mixing, as if the peak is well-resolved, it is likely that any mixing has been negligible (Appleby, 1998).

Short-lived radioisotopes provide the simplest and most accurate method of identifying and dating turbidite deposits. Additionally, an exponential decay profile of ${ }^{210} \mathrm{~Pb}_{\text {ex }}$ can be used to provide unequivocal evidence that sediments have accumulated gradually. However, short-lived radioisotopes are limited in that they can only be used on turbidites deposited up to 150 years ago, and can only be used where there is constant background sedimentation. Because the recurrence interval of subduction interface earthquakes is often much longer, these methods are incapable of building up the larger record of earthquakes along a particular margin. Despite these limitations, short-lived isotopes can provide evidence of turbidites that can be linked to historical earthquakes, giving valuable insight into the triggering mechanisms of these turbidity currents.

A multitude of studies have examined ${ }^{210} \mathrm{~Pb}$ records where there have been earthquakes through the last 100-150 years, including other studies in Taiwan (Dezileau et al., 2016; Lehu et al., 2016), and Japan (Ikehara et al., 2016; Noda et al., 2008; Usami et al., 2018), as well as Sumatra (Patton et al., 2015; Sumner et al., 2013), the Mediterranean (Gracia et al., 2010), and Fiordland (Barnes et al., 2013).

\subsubsection{Radiocarbon Dating}

Radiocarbon dating has also been used to obtain the ages of turbidite deposits. This method utilizes the decay of Carbon-14 in the carbonate shells of planktic foraminifera that accumulate gradually as a part of background sedimentation processes. ${ }^{14} \mathrm{C}$ is incorporated into organisms along with other isotopes of carbon in equilibrium with the carbon present in the environment that organism lived in. The uptake of carbon ceases with the death of an organism, at which point ${ }^{14} \mathrm{C}$ begins to decay, while the other stable isotopes of carbon do not. The amount of ${ }^{14} \mathrm{C}$ left in a sample relative to the amount of other carbon isotopes is used to calculate the time that has elapsed since the death of that organism. ${ }^{14} \mathrm{C}$ has a half-life of 5730 years, and therefore can be 
used to obtain the age of a sample up to 50,000 years ago. However, since the ratio of carbon isotopes in the atmosphere and oceans has not remained constant through time, the age calculated from radiocarbon dating must be calibrated to account for this (Broecker, 2014). Additionally, marine samples are affected by the marine reservoir effect, so these samples appear older than they truly are. The movement of carbon through the oceans is not uniform, and so the marine reservoir correction varies both spatially and temporally and a function of local and regionally hydrography, along with climatological variables (Austin \& Hibbert, 2012).

For dating turbidites, foraminifera are taken from the background sediment directly below the turbidite, and have the appropriate regional marine reservoir correction applied to them. Since the turbidite is not directly dated itself, Bayes' theorem is used to analyse multiple criteria for the age of an event and build up an age model using the radiocarbon ages and any other age data that is available (Blaauw \& Christen, 2011; Ramsey, 2008). It is important that samples for radiocarbon dating are not taken from the turbidite itself, as it is usually made up of reworked sediments and thus likely contains older foraminifera. Older foraminifera pose an issue for radiocarbon dating, as the ${ }^{14} \mathrm{C}$ within the sample will have already begun to decay, and thus is not in equilibrium with the ocean reservoir at the time that the reworked sediments were deposited, giving an inaccurate age for the deposit. Hence, the distinction between the fine-grained tails of turbidites and the background sedimentation is a key aspect of radiocarbon dating to obtain the age of a turbidite (Goldfinger, 2011). The marine reservoir correction is also an important part of radiocarbon dating. It is subject to a significant amount of uncertainty due to its regional variability $(\Delta R)$, and often averages are used that encompass a wider area than is appropriate. As the accuracy of radiocarbon dating increases, so too does the need for accurate reservoir corrections (Clark et al., 2019). This is of particular importance to turbidite paleoseismology, as the rationale behind it requires the identification of synchronous triggering across a wide area, which may include varying reservoir ages.

Most turbidite paleoseismology studies have used radiocarbon dating in some capacity, including in Cascadia (Goldfinger et al., 2013; Goldfinger et al., 2003), Chile (Bernhardt et al., 2015), Japan (Noda et al., 2008), the Mediterranean (Cattaneo et al., 


\section{2: Literature Review}

2012; Gracia et al., 2010; Polonia et al., 2013) and New Zealand (Barnes et al., 2013; Pouderoux et al., 2014).

\subsubsection{Tephrochronology}

Tephrochronology can also be used to constrain the ages of turbidites, using volcanic ash beds present in marine sediments as an age horizon that can be correlated to specific volcanic eruptions. The timing of these eruptions is determined by radiometric dating techniques and the "geochemical fingerprint" of a tephra can be analysed to match it to a particular eruption, without having to radiometrically date every occurrence of said tephra (Shane, 2000). Tephra deposits can be grouped into four lithofacies types; primary deposits, volcaniclastic-rich turbidites, blebs or pods of volcaniclastic-rich material, and complex deposits, a combination of the previous three lithofacies (Hopkins et al., 2020). Primary deposits are ideal, as they represent the direct accumulation of tephra via airfall on the ocean surface, which settles over hours to days onto the sea floor. Therefore, these deposits are equal to the age of the eruption. The other lithofacies are tephra deposits that have been reworked, through either a turbidity current or bioturbation. These can be made up of material from a single eruption or multiple eruptions. The former can provide a maximum age for the deposit, while the latter can be more complex, but a maximum age can be assigned using the age of the youngest event, if the events can be identified from the geochemical signature (Hopkins et al., 2020).

In turbidite paleoseismology, tephrochronology is used in conjunction with other dating methods as tephra is not deposited continuously. However, it has been used in multiple settings as a tie-point for correlation between cores along the same margin, as well as for additional age constraint in age models (Noda et al., 2008; Pouderoux et al., 2014). Reworked tephra can also be used to aid in turbidite correlation, as the first appearance of turbidites containing this volcanic material can be used as a diagnostic property to link turbidites triggered simultaneously, as well as providing a maximum age for the deposition of the turbidite (Goldfinger et al., 2013). Tephrochronology is the only dating method that does not strictly require the presence of background sedimentation. However, volcanic activity is not present in every setting, and where it is present it is not deposited continuously, so it cannot be the sole source of age 
control for turbidite paleoseismology, though it does provide independent ages which can be used to test the accuracy of other dating methods.

Many other studies have used the presence of tephra deposits as supplementary age control, generally combined with the use of radiocarbon dating and added to agedepth models, in addition to their use as stratigraphic tie points between cores along the same margin. This has been applied in Sumatra (Patton et al., 2013), Japan (Noda et al., 2008), Italy (Polonia et al., 2013), and New Zealand (Pouderoux et al., 2014). Of the dating methods discussed, tephrochronology provides the most robust age control through the longest timescales, but it is restricted in its application to turbidite paleoseismology by the frequency of eruptions and the proximity of volcanism to a given study area. Short-lived isotopes and radiocarbon dating are both more widely applicable, but are both affected by the nuances of background sedimentation, and for radiocarbon dating in particular, the accurate identification of background sedimentation is vital.

\subsection{Identification of Background Sedimentation}

The identification of background sedimentation plays an important role in turbidite paleoseismology. The typical turbidite sequence described by Bouma (1962) is capped by massive, fine-grained mud, with little distinction between turbiditic mud and the mud that accumulates gradually in normal background sedimentation. Stow and Piper (1984) described an extended version of this model (Figure 2.1), which divided the mud section of Bouma's model into laminated mud, graded mud, and ungraded mud, as well as adding a section for pelagite or hemipelagite.

Pelagite is defined as the sediment that accumulates in the open ocean, largely made up of skeletal plankton remains, with a very small component of fine silt and clay. Hemipelagite is the sediment that accumulates on continental margins, made up of a mixture of indigenous biogenic material and silt and clay sized terrigenous detritus, deposited primarily by the slow settling of material unaffected by any substantial turbidity current or bottom current activity (Stow \& Piper, 1984; Stow \& Tabrez, 1998). 


\section{2: Literature Review}

Since the most widely used method for dating turbidites is radiocarbon dating of pelagic foraminifera, turbidite paleoseismology requires a robust understanding of what background sedimentation is in the area of study (Goldfinger, 2011).

There are a variety of different methods that can be used to distinguish background sedimentation from the fine-grained tails of turbidites, ranging from simple visual analysis to analysis of foraminiferal assemblages.

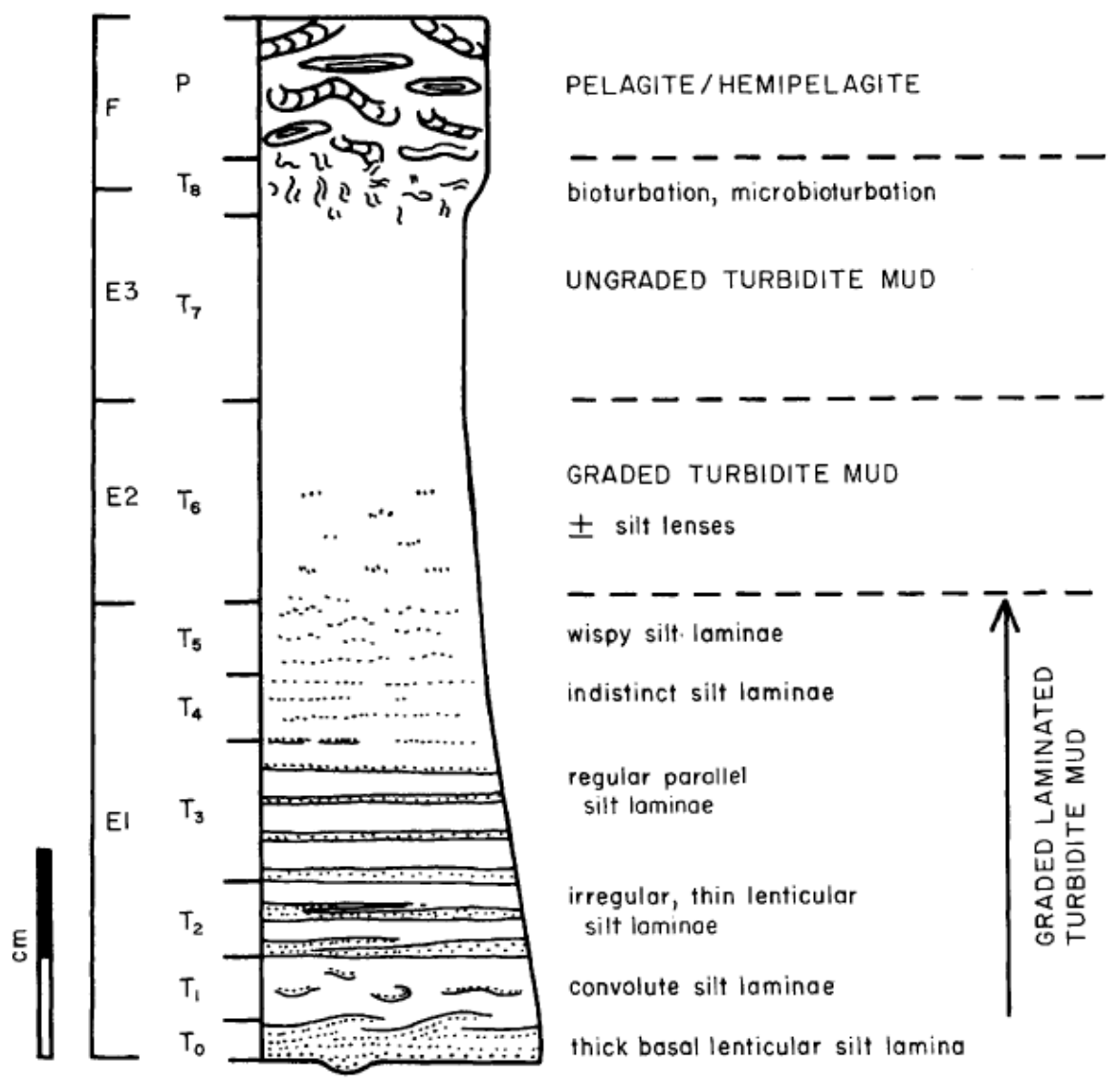

Figure 2.1 Modified Bouma sequence from Stow \& Piper (1984), showing the facies model for a mud turbidite.

\subsubsection{Methods Used for the Identification of Background Sedimentation}

\section{Visual Analysis}

Visual analysis and description of a sediment core is often the first analysis performed and provides an overview of the characteristics of a core. High-resolution digital colour images of sediment cores are routinely obtained using either a digital camera taking multiple shots in succession or by using a linescan camera (Zolitschka, Mingram, Van Der Gaast, Jansen, \& Naumann, 2002). Visually distinguishing turbidite tails from 
background sediment can be more or less difficult depending on the location and the characteristics of background sedimentation of a specific location. In some locations, such as Cascadia, there is a distinctive change in colour between turbidite tails and background sediment due to a change in biogenic $\mathrm{CaCO}_{3}$ content - however, this distinction is not ubiquitous across the margin, and becomes more subtle at more proximal and southerly sites (Goldfinger et al., 2013). In other regions, such as southern Chile, background sediment is indistinguishable from turbidite tails visually, so other methods must be used to identify background sediment (Bernhardt et al., 2015).

\section{Bulk Density}

The bulk density of sediments can show where significant changes in lithology occur, such as in the difference between the sandy base of a turbidite and the underlying background sedimentation. Density has also been used to inform correlation of turbidites over a wide area (Goldfinger, 2011). Typically, the turbidite is characterised by density values declining upward through the turbidite tail, while background sediments have a constant low density (Goldfinger et al., 2013; Pouderoux et al., 2014). However, these differences can be subtle, thus bulk density cannot be used as the sole line of evidence for the distinction between background sediment and turbidite tails. Density can be obtained from gamma ray attenuation, or computed tomography (CT) scans. Gamma ray attenuation was included in one of the first corelogging systems that logged the core on an automated track, the GRAPE system, developed by Evans (1965). CT scans have only been used since 1980 in the oil industry, though their popularity has grown through the years (Rothwell \& Rack, 2006). The boundaries between different lithological facies can often be difficult to visually distinguish, so computed tomography (CT) scans of cores are often used to obtain a clearer image to work with. CT scans work by using X-rays that are emitted by a source, attenuated by whatever sample is placed in the scanner, and picked up by standard Xray detectors. The $\mathrm{X}$-ray source and detectors are rotated through a plane, changing their geometry a number of times. This produces a map of X-ray attenuation in a slice through the sample in the plane that the source and detectors were rotated through. This provides a series of cross-sectional images of the core, which can also be 


\section{2: Literature Review}

recombined to create a cross-section of the full length of the core (Orsi, Edwards, \& Anderson, 1994). These images are presented as a greyscale image, where lighter and darker shades indicate higher and lower X-ray attenuation, respectively, showing features in the sediment which are barely visible to the naked eye. The X-ray attenuation is influenced by both the bulk density and the chemical composition of the sample, highlighting subtle variations in the sediment not visible to the naked eye, such as bioturbation, core deformation, or movement to a new stratigraphic interval (Goldfinger, 2011). Due to the influence bulk density has on X-ray attenuation, a series of density values through the sample can also be obtained using this method (Boespflug, Long, \& Occhietti, 1995). CT scans have the benefit of producing a 3D dataset, providing not only a detailed image, but high-resolution density data $(0.5 \mathrm{~mm}$ resolution) as well (Reilly, Stoner, \& Wiest, 2017; Rothwell \& Rack, 2006). While there is generally good agreement between the densities obtained from gamma ray attenuation and computed tomography, the latter has the benefit of providing imagery at the same time as obtaining density, as well as providing higher resolution data 0.5 mm vs. $2 \mathrm{~mm}$ ) (Boespflug et al., 1995; Zolitschka et al., 2002).

\section{P-Wave Velocities}

P-wave velocities can be used to study the acoustic and elastic properties of marine sediments (Breitzke, 2000). To analyse the P-wave velocities from sediment cores, two compressive wave transducers are attached to either side of the core, and will transmit pulses. The time taken for this pulse to travel through the sediment and core liner, along with the thicknesses of the sediment and the liner are used to calculate the Pwave velocity (Zolitschka et al., 2002). When P-wave velocity is plotted against bulk density, environments such as siliceous, calcareous, and terrigenous sediments group together, providing a method of inferring the lithology of these sediments. P-wave velocity also gives an indication of variations in grain size, and in particular is useful for identifying interbeds of sand and silt (Rothwell \& Rack, 2006). P-wave velocities tend to show similar fluctuations down core to bulk density profiles, in that velocities tend to be more varied through turbidites, while background sediments hold at a more constant velocity. However, there is some overlap in the ranges of velocities seen in both sediment types, thus P-wave velocities alone cannot be used to distinguish turbidite tail from background sediment (Pouderoux, Lamarche, \& Proust, 2012). 


\section{Magnetic Susceptibility}

Magnetic susceptibility is the ease at which sediments can be magnetised, which is influenced by the presence of iron-bearing minerals. It is routinely measured using a point sensor for split cores, or a loop sensor for whole cores, at $5 \mathrm{~mm}$ resolution (Zolitschka et al., 2002). Magnetic susceptibility is primarily controlled by the concentration of magnetite, associated with terrigenous sediment input (Fukuma, 1998). As such, changes in magnetic susceptibility often occur with deposition of transported sediments in turbidites, and can be used to aid in the identification of individual events across a wider area (Goldfinger, 2011). Magnetic susceptibility measurements typically follow similar patterns to both bulk density and P-wave velocity, with all three methods providing a grain size proxy, particularly when taken together. However, the difference in grain size between background sediment and turbidite tails as detected by these methods can be subtle, so they often cannot definitively separate the two (Goldfinger, 2011; Pouderoux, Lamarche, et al., 2012).

\section{Micro X-Ray Fluorescence Spectrometry}

X-ray fluorescence (XRF) spectrometry measures the abundance of elements within a sediment sample, by channelling X-radiation at the sample, which causes electrons to be ejected from the inner atomic shells. These gaps are then filled by electrons from the outer shells falling inwards. There is an energy difference between the inner and outer shells, so as the outer electrons move inwards, the surplus energy is emitted as a pulse of X-radiation. Specific elements have characteristic energy and wavelength spectra that their atoms emit, which is used to obtain the abundance of that element (Rothwell \& Rack, 2006). Typically, micro-XRF core scanners, such as CORTEX (Jansen, Van der Gaast, Koster, \& Vaars, 1998) or ITRAX (Croudace, Rindby, \& Rothwell, 2006) are used to obtain a continuous profile of elemental concentrations through a core quickly and non-destructively, at resolutions of $1 \mathrm{~mm}$ (CORTEX) to $0.2 \mathrm{~mm}$ (ITRAX). The geochemical composition of sediments is dependent on a variety of factors, and geochemical proxies can give some insight into the provenance of the sediments. These proxies can be used to identify terrigenous sediment input, shallow-water carbonates, organic-rich layers, and have many applications in sedimentological and 


\section{2: Literature Review}

paleoenvironmental studies (Croudace \& Rothwell, 2015). In the study of turbidites, the examination of proxies that indicate shallow sources in deep marine cores can be valuable in distinguishing turbidite deposits from background sedimentation. For example, Drab et al. (2012) used Ca/Ti as a proxy, as it captures ocean productivity (Ca) and terrigenous input ( $\mathrm{Ti}$ ). Thus, the $\mathrm{Ca} / \mathrm{Ti}$ ratio was at its maximum in the background sediment. This study also examined the individual elemental composition of the sediments, finding increased values of zirconium within the turbidites, with localised variations in bromine and titanium within sand and silt sublayers in major turbidites. Minor turbidites did not show a significant signature in the XRF data, and were identified using grain size measurements.

\section{Grain Size}

While grain size can be inferred from bulk density and P-wave velocities, direct observations of grain size can be a powerful tool in the determination of the sedimentary processes in action (Joseph, Rea, \& van der Pluijm, 1998). There are a variety of methods used to measure grain size, including the traditional sieve-pipette method, electroresistance particle counting, photometrical techniques, X-ray attenuation, and laser diffractometry, though these methods give slightly different results due to differences in the principles these methods are based upon. Commonly, grain size is measured using a laser diffraction grain size analyser, which works on the principle that particles of a given size will diffract light through a given angle. The grain size distribution is obtained by putting the sample in suspension and passing a narrow beam of light through it, allowing the diffracted light to be picked up by an array of detectors. This method is commonly chosen due to its speed and reproducibility, in addition to the fact that it requires only small amounts of sediment and produces detailed grain size distribution data that is in a digital format so is easily manipulated (Beuselinck, Govers, Poesen, Degraer, \& Froyen, 1998). The grain size distribution in a given sample is a product of its source and the sedimentary processes acting upon it (McLaren, 1981). Turbidites are characterized by their normal grading, while background sediments are typically fine-grained and ungraded (Stow \& Piper, 1984). Often, grain size analyses are done in addition to the proxies discussed above (bulk density, P-wave velocity, magnetic susceptibility) as a way of validating those proxies 
(Goldfinger et al., 2013). However, as with those proxies, grain size alone often provides insufficient evidence to distinguish background sediment and turbidite tails.

\section{Foraminiferal Assemblages}

Study of the foraminifera present in marine sediments can provide valuable information about their source environments, in addition to their use in obtaining radiocarbon ages of sediments. Hayward et al. (2019) devised a method that uses foraminifera to distinguish displaced and gradually accumulating sediments. This method is made up of three major elements, examining the test size distribution, planktic percentage, and relative abundance of bathymetric groups of benthic genera.

The test size distribution uses the size of foraminiferal tests (shells) to distinguish areas where the sediment has been sorted by a turbidity current from the unsorted rain of foraminiferal tests associated with background sedimentation. A sample is split into three size groups (>250 $\mu \mathrm{m}, 125-250 \mu \mathrm{m}, 63-125 \mu \mathrm{m}$ ), and the number of tests within each of these groups is counted to obtain the test size distribution. In a turbidite, this will be expressed with a lower percentage of smaller tests towards the base, which will increase through the turbidite into the tail, where the relative percentage of smaller tests can exceed that seen in the test size distribution observed in background sediments (Hayward et al., 2019).

The planktic foraminiferal percentage is a measure of the relative abundance of planktic foraminifera. This increases with increasing water depth, so can be used as an indication of sediment transport from shallower depths. The planktic percentage is calculated by counting and identifying all foraminifera in a sample to the species level, taking the percentage of these that are planktic. The planktic percentage can be related to an estimated water depth using a regression function. For samples around New Zealand, this function is detailed in Hayward and Triggs (2016). Typically, the sandy parts of turbidites have low planktic percentages, indicating a shallow origin (Hayward et al., 2019).

The benthic foraminiferal composition examines the relative abundance of six different bathymetric groups, which correspond to different ranges of water depths. Much like the planktic percentage, the benthic foraminiferal composition is calculated by 


\section{2: Literature Review}

identifying and counting the foraminifera in a sample to give a percentage of the sample that belong to each of the six bathymetric groups. Turbidite deposits will typically show a greater proportion of shallower bathymetric groups than background sediments (Hayward et al., 2019).

Foraminifera provide a reliable method of determining the source of sediments, which is of particular interest in the study of turbidites. Usami, Ikehara, Jenkins, and Ashi (2017) examined the benthic foraminiferal assemblages from within the turbidite triggered by the 2011 Tohoku-oki earthquake and tsunami in Japan. This data was used to estimate the source depth of the turbidite at two sites. The turbidite was shown to have originated from the steepest part of the slope, destabilized during earthquake shaking. At one site, the surface layer of the turbidite contained outer slope to inner bay species, interpreted to be the result of tsunami-related agitation in shallow water, which was resuspended and deposited in the bathyal zone following the deposition of the slope-derived turbidite. Additionally, the study showed good preservation of fragile, thin-walled species, which suggests that the sediment was transported with minimal internal friction. This study of a modern turbidite provides useful context for the application of foraminiferal assemblages to turbidite paleoseismology. Foraminiferal assemblages as a whole can be a powerful tool in determining if sediment has accumulated in situ, and thus, can be diagnostic in identifying turbidite tails and background sediments.

\subsubsection{Identification of Background Sedimentation in Literature}

The sediment that accumulates in the background of a margin can vary significantly both worldwide and even locally, such as is seen in Chile (Bernhardt et al., 2015). Thus, ease of distinguishing background sedimentation from turbidite tails can be equally variable depending on the location. While there are many methodologies that can be applied, there is no one method or combination of methods that has been applied universally, although there are some similarities in the approaches used globally (Drab et al., 2012; Goldfinger, 2011).

Physical properties data such as bulk density, magnetic susceptibility, and P-wave velocity are some of the most widely used methods in turbidite paleoseismology. In Cascadia, though there are many areas in which background sediment can be 
identified visually, through a distinct change in colour, the physical properties data, largely gamma density and magnetic susceptibility are also used as grain size proxies to support this interpretation. P-wave velocity was also used, however the data contained noise due to artefacts from air in the core liner, making it less useful. The density and magnetic susceptibility measurements were compared to direct grain size measurements in some areas to validate the use of the proxies. This analysis of the physical properties data matched with the changes in colour observed for identifying the background sediment-turbidite tail boundary. One of the primary issues with the identification of this boundary is bioturbation, making a boundary measured using a one-dimensional data series problematic. However, $\mathrm{CT}$ imagery provided the best method for narrowing down this boundary, though it is still not a perfect solution (Goldfinger et al., 2012). The understanding of hemipelagic sediments in Cascadia has expanded through the many years turbidites have been studied along this margin. Goldfinger et al. (2013) found evidence of mud turbidites in the southern part of the margin, identifying these by subdued changes in the physical properties data (density, magnetic susceptibility) and through the use of CT imagery where they were difficult to discern with the naked eye.

Geochemistry derived from XRF measurements can also be a powerful tool in identifying the boundary between background sediment and turbidite tails, though it has been less widely used in the literature. In Cascadia, XRF was not used, as it was not widely available before many samples were taken from older cores studied, so taking new continuous measurements from these cores was impossible (Goldfinger et al., 2012). Micro XRF-derived geochemistry was applied off the coast of Portugal. Gracia et al. (2010) used $\mathrm{K} / \mathrm{Ti}$, a detrital proxy, and $\mathrm{Ca} / \mathrm{Ti}$, a biogenic carbonate proxy, as a part of their method of distinguishing turbidite tails from background sediment, which also included the examination of bulk density and magnetic susceptibility. Contrastingly, in northern Algeria, sedimentation is derived from largely calcareous watersheds, making the contrast between background sediments and turbidite tails relatively low, limiting the use of geochemical composition, bulk density, or magnetic susceptibility for purposes of distinction between the two. To combat this Ratzov et al. (2015) examined sediment sorting, using the contrast of well sorted turbidites and unsorted background 


\section{2: Literature Review}

sediments to circumvent the low compositional contrast. Where bioturbation impacted sorting, blurring the distinction between background sediments and turbidite tails, the interval was considered as an uncertainty included in the age model. Foraminiferal assemblages give valuable information about the depth at which sediments originated, which is particularly useful in the identification of reworked sediments. Polonia et al. (2013) applied this method off the coast of Italy in the Ionian Sea, along with magnetic susceptibility, XRF, and grain size. Pelagic sediments were recognised by their biogenic composition, the dominance of a particular benthic foraminifera (Articulina tubulosa), peaks in $\mathrm{Ca}$ and $\mathrm{Sr}$, uniform and bioturbated units, composition of less than $20 \%$ lithic fragments, and their purplish-grey colour. Conversely, turbidite beds contained a mixture of lithic clasts and displaced benthic foraminifera from a variety of depths, and contained $\mathrm{Zr}, \mathrm{Mn}, \mathrm{Fe}$, and Ba peaks at varying points in the turbidite sequence. While foraminiferal assemblages provide a powerful diagnostic tool for determining if sediment has been transported, it is impractical to apply as a systematic approach due to the volume of sampling required. Therefore, it cannot reasonably be applied in isolation, but can be useful in confirming the conclusions of other methods.

The methods used to distinguish between background sedimentation and turbidite tails ranges in complexity in studies undertaken globally, with most studies using at least density and magnetic susceptibility (Goldfinger et al., 2013), and others expanding into geochemical proxies (Drab et al., 2012) and foraminiferal data (Polonia et al., 2013). However, as Goldfinger et al. (2013) showed, changes in physical properties data can be subtle, and thus, the more evidence that can be used to aid in the distinction of turbidite tails and background sediments, the more robust these distinctions will be.

\subsection{Future Directions for Turbidite Paleoseismology}

Turbidite paleoseismology provides a viable extension of traditional paleoseismology, however, due to its nature as a shaking proxy there are more uncertainties that must be addressed for reliable paleoearthquake records to be produced. The studies discussed above show that it is possible for turbidite paleoseismology to be applied to a variety of settings, provided that conditions are favourable for the preservation of 
turbidites and the ages of said turbidites can be reliably determined. The accurate identification of background sedimentation is of the utmost importance for obtaining said ages, and yet, many studies still rely on subjective identification techniques. As more research has been undertaken, it has become generally accepted that a multiproxy approach provides the most robust differentiation between turbidite tails and background sedimentation, but interpretation of a large dataset can be subjective and time-consuming. What is necessary moving forward is a more objective approach to identifying background sediments that can distinguish turbidite tails and background sedimentation rapidly.

\subsubsection{Research Aims and Objectives of This Study}

As outlined above, future turbidite paleoseismology work requires an objective approach to distinguishing between turbidite tails and background sediments, to streamline the process of identifying intervals of background sediment that are appropriate to radiocarbon date. This study aims to examine turbidite tails and background sediments along the southern Hikurangi margin, to determine if these sediments can be distinguished from one another in a quantitative manner. This research tests the hypothesis that there is a subtle, but quantifiable difference between the physical and geochemical properties of turbidite tails and background sediments along the southern Hikurangi margin that can be exploited to objectively identify these lithofacies in sediment cores.

To test this hypothesis, there are four main research objectives to complete:

1. Identify turbidite tails and background sediment independently using the stratigraphic position of the 2016 Kaikōura turbidite, ${ }^{210} \mathrm{~Pb}$ activity profiles and foraminiferal assemblages.

2. Compare destructive and non-destructive datasets to determine if nondestructive data provides reasonable proxies for the destructive datasets.

3. Determine if there is a quantifiable difference between turbidite tails and background sediments using their physical and geochemical properties. 


\section{2: Literature Review}

4. Use the differences between the physical and geochemical properties of turbidite tails and background sediments to develop a model that can predict if a sample is a turbidite tail or is background sediment 


\section{Study Site}

\subsection{Tectonic Setting}

The Hikurangi subduction margin lies off the east coast of New Zealand, where the Pacific plate has been subducting beneath the Australian plate since $20-25 \mathrm{Ma}$, at rates ranging from $27 \mathrm{~mm} / \mathrm{yr}$ in the south to $57 \mathrm{~mm} / \mathrm{yr}$ in the north (Clark et al., 2019; Nicol et al., 2007). The subduction interface is expressed at the surface by the Hikurangi Trough (Wallace et al., 2009). Along the margin, oblique convergence is partitioned, where most of the margin normal component occurs on the subduction thrust, with a smaller amount accommodated by upper plate reverse structures, while the margin parallel component is accommodated by a combination of forearc rotation and upper plate strike-slip faulting (Nicol \& Beavan, 2003; Wallace et al., 2012). At the southern end of the margin, plate motion transitions into oblique continental transpression through the Marlborough fault system, where the motion is accommodated by upper plate faulting (Clark et al., 2019). The subduction interface is interseismically coupled to depths of $30-40 \mathrm{~km}$ along the southern section of the margin, abruptly transitioning into an aseismic-creep dominated interface around $40^{\circ} \mathrm{S}$, as shown in figure 3.1 (Wallace et al., 2014).

Subduction interface earthquakes have also been recorded along the Hikurangi margin. The largest and most well-documented of these are the $25^{\text {th }}$ March 1947 Poverty Bay earthquake ( $\mathrm{Mw}_{\mathrm{w}}$ 7-7.1) and the $17^{\text {th }}$ May 1947 Tolaga Bay earthquake (Mw 6.9-7.1), both in the northern section of the margin (Figure 3.1). These earthquakes have the characteristics of tsunami earthquakes with the intensity of shaking low relative to the magnitude of the earthquake (Kanamori, 1972). The epicentres of both earthquakes were shallow $(<10 \mathrm{~km})$, located on the subduction interface near the trench, related to the subduction of a seamount. Both events triggered tsunami, with the March event affecting $120 \mathrm{~km}$ of coastline and runup heights of up to 10-11 m, while the May event was smaller, with runup heights of up to $6 \mathrm{~m}$ (Wallace et al., 2014). Following the 1947 earthquakes, other large subduction interface earthquakes include the 1961 Mw 6.4-6.5 earthquake offshore Cape Palliser (southern Hikurangi margin) and the $1993 \mathrm{Mw}_{\mathrm{w}}$ 5.6-6.0 Tikokino earthquake (central Hikurangi margin), in 


\section{3: Study Site}

addition to a number of smaller earthquakes near Gisborne, central Hawkes Bay, and Cape Palliser that ruptured the subduction interface, or are likely to have (Clark et al., 2019).

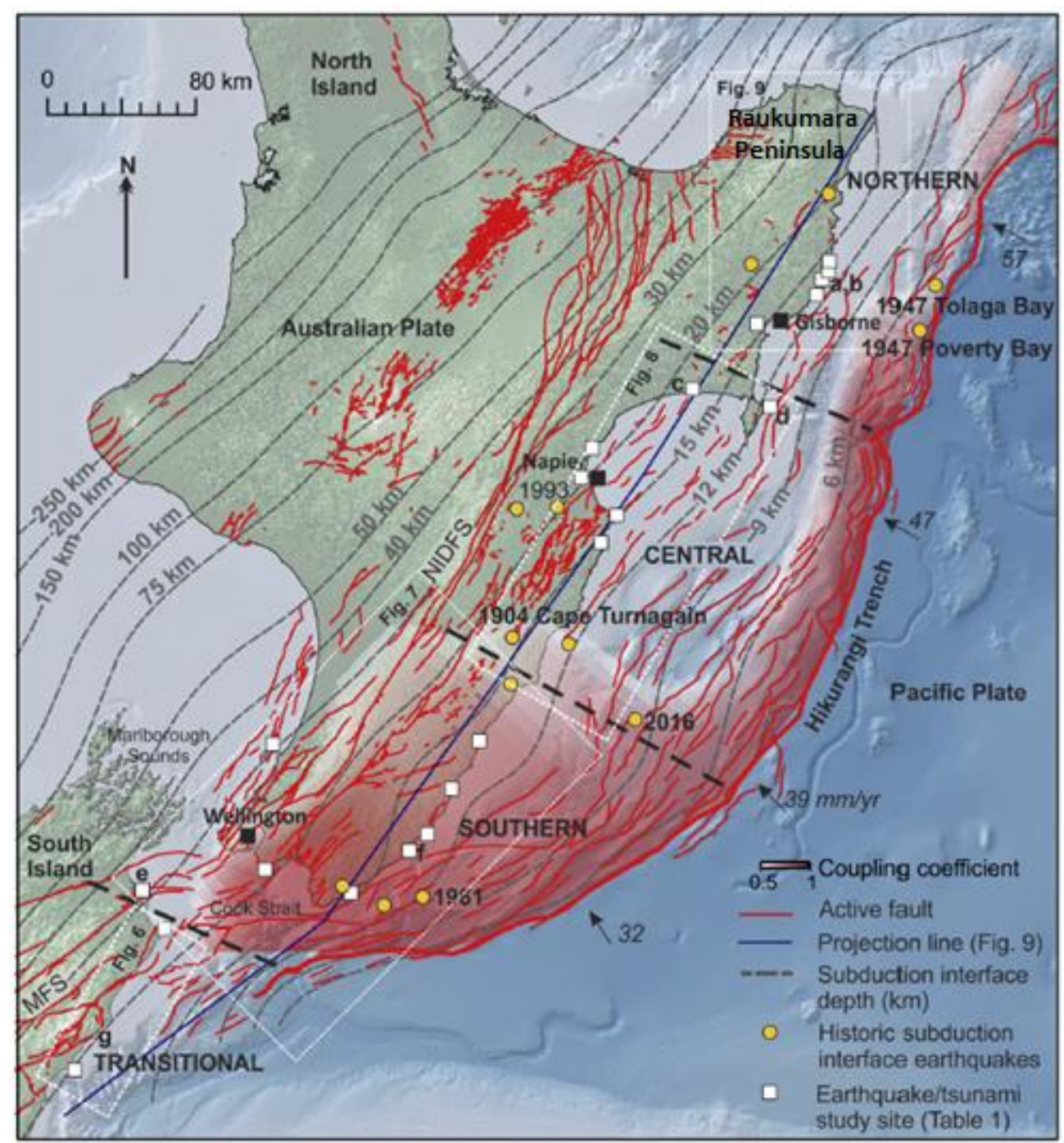

Figure 3.1 Map of the Hikurangi margin tectonic setting, adapted from Clark et al. (2019). Shows upper plate faulting as red lines, and shows interseismic coupling shaded in red.

In addition to subduction interface earthquakes, a number of upper plate earthquakes have been shown to have impacted the subduction interface as well, including the $1855 \mathrm{Mw}$ 8.2 Wairarapa earthquake, 1931 Mw 7.6 Hawke's Bay earthquake, and the 2016 Mw 7.8 Kaikōura earthquake. The Kaikōura earthquake triggered a slow slip event in the central and northern sections of the Hikurangi margin, 250-600 km away from the epicentre of the earthquake, spanning $>15,000 \mathrm{~km}^{2}$ (Hamling et al., 2017). Slow slip events have been shown to occur on all parts of the margin, with deep, long duration events occurring near the downdip limit of interseismic coupling in the southern 
section of the margin, and more frequent, shorter events occurring through the central and northern sections of the margin (Clark et al., 2019).

Geological records of prehistoric earthquakes along the Hikurangi subduction margin have also been investigated. These paleoseismic records have been derived from evidence of coseismic coastal deformation (Berryman, Clark, Cochran, Beu, \& Irwin, 2018; Berryman et al., 2011; McSaveney et al., 2006; Ota et al., 1996) and paleotsunami deposits (Clark et al., 2015; Clark et al., 2016), and have identified 10 possible subduction earthquakes through the past 7000 years (Clark et al., 2019). Additionally, turbidite paleoseismology work has been investigated in the northern section of the margin, as detailed in chapter 2.3.7 (Pouderoux et al., 2014).

\subsection{Margin Morphology}

The morphology of the Hikurangi margin is highly variable along the strike of the subduction interface, due to variations in the thickness of sediment filling the trench, the efficiency of frontal accretion, the topography of the Pacific plate, and obliquity and rate of convergence (Barnes et al., 2010). North of the Raukumara Peninsula is relatively sediment starved, and the northern section of the margin is characterised by the subduction of seamounts and tectonic erosion, while the central and southern sections of the margin are dominated by frontal accretion (Wallace et al., 2009). The continental shelf is variable in width offshore the eastern North Island, and narrows through the southern Hikurangi margin to nothing at Kaikōura canyon in the south. At the shelf edge, the continental slope projects down at a few degrees to $\sim 3000 \mathrm{~m}$ water depth into the Hikurangi trough (Mountjoy, Barnes, \& Pettinga, 2009). Incised within the trough is the Hikurangi Channel, an active turbidity current channel, which meanders through the Hikurangi trough for around three-quarters of its length, then turns east out of the trough to deeply incise the Hikurangi Plateau, and deposits sediment into a distal fan-drift at the edge of the Southwest Pacific Basin (Lewis, Collot, \& Lallem, 1998). Sediment supply to the Hikurangi margin is dominated by large river systems in the north-eastern North Island, which have very high suspended sediment loads, in addition to rivers throughout the length of the Hikurangi margin. Thus, the northern section of the margin receives a much larger amount of sediment 


\section{3: Study Site}

than other regions along the east coast (Hicks, Gomez, \& Trustrum, 2004; Mountjoy et al., 2009). Deposition along the Hikurangi margin through the Quaternary takes the form of background sedimentation, turbidites, debrites, and tephra layers (Lewis, 1980; Pouderoux, Proust, et al., 2012). The Hikurangi channel is fed by sedimentary distributary systems, characterised by multiple feeder canyons that incise the continental shelf (Howarth et al., in review) such as the Kaikōura canyon, (Lewis \& Barnes, 1999) and Cook Strait canyon (Mountjoy et al., 2009).

\subsection{Oceanography}

The east coast of New Zealand is impacted by several fast, narrow boundary currents that form part of the western boundary current system of the South Pacific (Figure 3.2). From the north, the East Auckland current (EAUC) feeds into the East Cape Current (ECC), which travels southwards along the east coast until it splits off north of the Chatham Rise (Fernandez, Bowen, \& Sutton, 2018). The flow of the ECC is assumed to persist to $2000 \mathrm{~m}$ water depth (Chiswell, 2005). The ECC carries warm, high salinity subtropical water, with speeds varying from up to $25 \mathrm{~cm} / \mathrm{s}$ at $100 \mathrm{~m}$ water depth and $10 \mathrm{~cm} / \mathrm{s}$ at $1000 \mathrm{~m}$ water depth, and volume transport between 10-25 Sv (Carter, Manighetti, Elliot, Trustrum, \& Gomez, 2002). Embedded in the ECC is the Wairarapa Eddy (WE), an eddy situated over the Hikurangi trough, between the Chatham Rise and the south-east coast of the North Island, and is estimated to exceed $2000 \mathrm{~m}$ water depth (Chiswell, 2005). From the south, the Southland current (SC) feeds into the north-flowing Wairarapa Coastal Current (WCC), which is also likely impacted by the D'Urville Current (DUC) flowing through the Cook Strait. The WCC carries cool, lowsalinity water northwards, with measured surface current speeds of $40-50 \mathrm{~cm} / \mathrm{s}$ and volume transport of $1.6 \mathrm{~Sv}$ off the southern North Island, and decreases as the WCC reaches Hawke Bay (Carter et al., 2002). The WCC is slowly entrained into the ECC as it moves to the north (Chiswell, 2002). There appear to be no direct measurements of bottom flow of the WCC through the site of this study. 


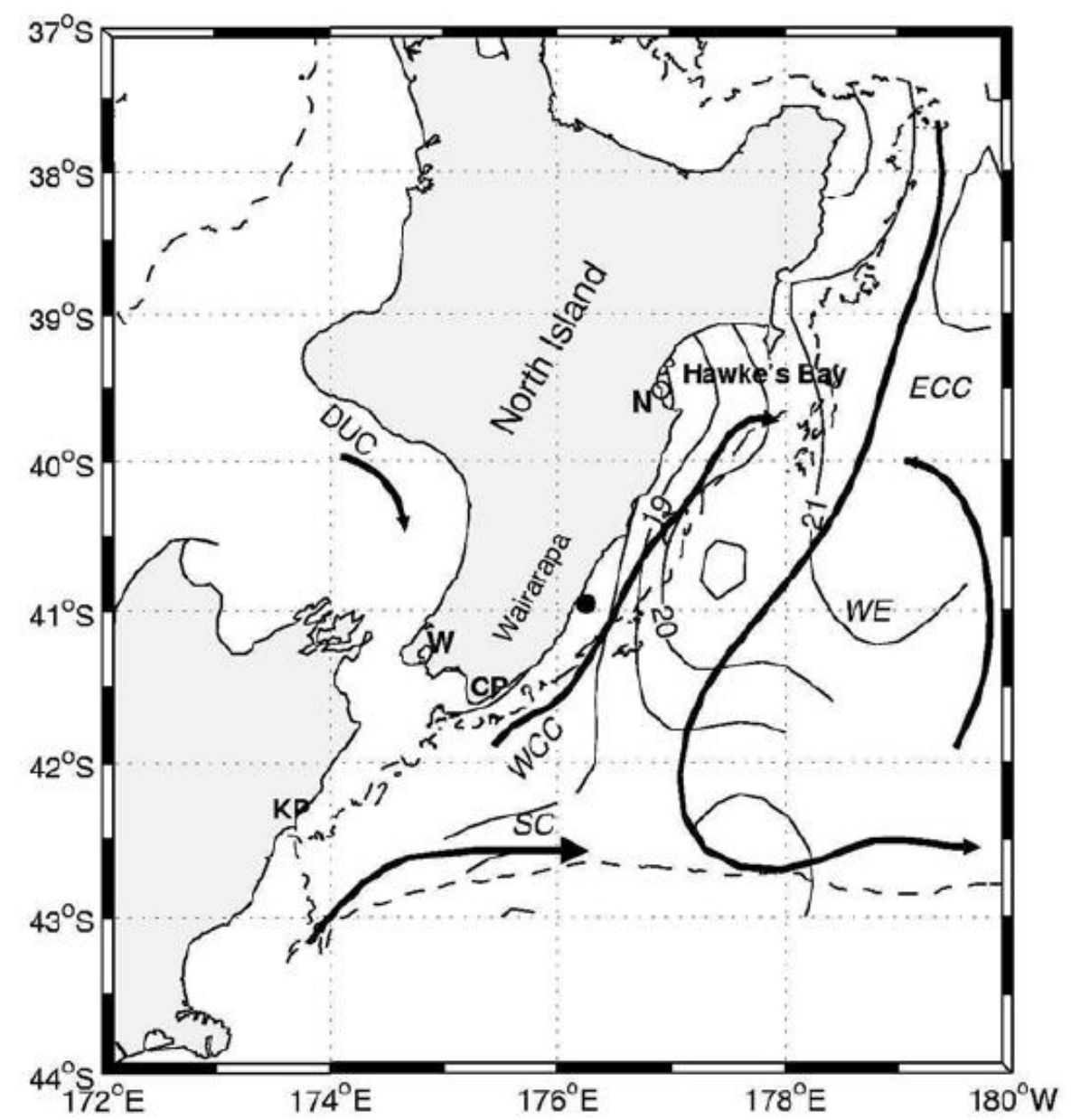

Figure 3.2 Currents acting on the Hikurangi margin, including the East Cape Current (ECC), the Wairarapa Coastal Current (WCC), the D'Urville Current (DUC), the Southland Current (SC) and the Wairarapa Eddy (WE). The dashed line shows the $1000 \mathrm{~m}$ isobath. From Chiswell (2002)

\subsection{Kaikōura Earthquake and Turbidity Current}

On the $14^{\text {th }}$ of November, 2016, a Mw 7.8 earthquake struck Kaikōura, New Zealand, the most complex crustal earthquake ever recorded (Holden et al., 2017). The rupture propagated northward over $170 \mathrm{~km}$ along mapped and unmapped faults, before continuing offshore. The earthquake ruptured 21 faults, generating horizontal fault displacements over $10 \mathrm{~m}$, triggering a regional tsunami, widespread landsliding, and large-scale slow-slip events along the central and northern Hikurangi margin (Hamling et al., 2017; Holden et al., 2017).

Strong ground shaking during the Kaikōura earthquake caused widespread sediment failure along the southern Hikurangi margin, triggering turbidity currents in 11 consecutive canyons. Turbidite deposits were sampled in cores across the southern 


\section{3: Study Site}

Hikurangi margin, and were established to be related to the Kaikōura earthquake using excess ${ }^{234} \mathrm{Th}$ activities, observing high ${ }^{234} \mathrm{Th}$ ex activity within turbidites up to $40 \mathrm{~cm}$ thick, and in oxic layers underlying the turbidite. As ${ }^{234}$ Th should show rapid decay within a few centimetres of the sediment-water interface under background sedimentation processes (see chapter 2.4.1), this data indicates that these turbidites were indeed the result of turbidity currents triggered by the Kaikōura earthquake (Howarth et al., in review; Mountjoy et al., 2018).

The spatial distribution of turbidity current triggering aligns with the modelled peak ground velocities (PGV) for this earthquake, where turbidity currents were triggered in distributary systems where PGV $17-24 \mathrm{~cm} / \mathrm{s}$. The turbidity currents travelled from these canyons into the Hikurangi Channel, amalgamating into a flow that travelled over $680 \mathrm{~km}$ along the channel. (Howarth et al., in review; Mountjoy et al., 2018).

The 2016 earthquake had an enormous impact on the seafloor. In Kaikōura Canyon, bathymetric differences observed prior to and following the earthquake showed $\sim 14.2$ $\mathrm{x} 10^{6} \mathrm{~m}^{3}$ of sediment was removed from the canyon rim, destabilized by the earthquake. Additionally, comparison of the head of Kaikōura canyon between 2006 and three months following the earthquake show that previously observed biomass communities of benthic invertebrates were completely absent, and it was estimated that $39 \times 10^{6} \mathrm{~kg}$ of biomass was removed by the earthquake (Mountjoy et al., 2018).

\subsection{Core sites}

Thirteen cores taken from twelve core sites along the southern Hikurangi margin were examined in this study (Figure 3.3). Cores are split into "canyon-proximal" (7 core sites) and "canyon-distal" (5 core sites) categories, to recognise the spatial variations in background sedimentation with distance from active canyons. The canyon-proximal cores are located at, within, or at the distal end of active canyon systems that incise into the continental slope. The Hikurangi Channel is grouped with the active canyons as it is a major active sediment conduit (Lewis, 1994). Conversely, canyon-distal cores are located in slope basins on the lower slope or out on the Hikurangi trough. One canyon-distal core (TAN1705-37) is a slight outlier to this definition, however, as it lies within a relict canyon system, it has been grouped with the canyon-distal cores. 
There are many different ways these cores could be grouped, including based on canyon morphology, and on core location on the continental slope. However, for the purposes of this study, the simpler definition of canyon-proximal and canyon-distal was favoured, so that the data from these cores could be used to create a relatively generic model of the physical and geochemical characteristics of turbidite tails and background sediments that could be applied across the Hikurangi margin. A more generic approach to categorizing core sites allows for wider application of the model, whilst still accounting for potential variations in depositional processes related to differences in location. Magnified maps of each core location are shown in Appendix A.

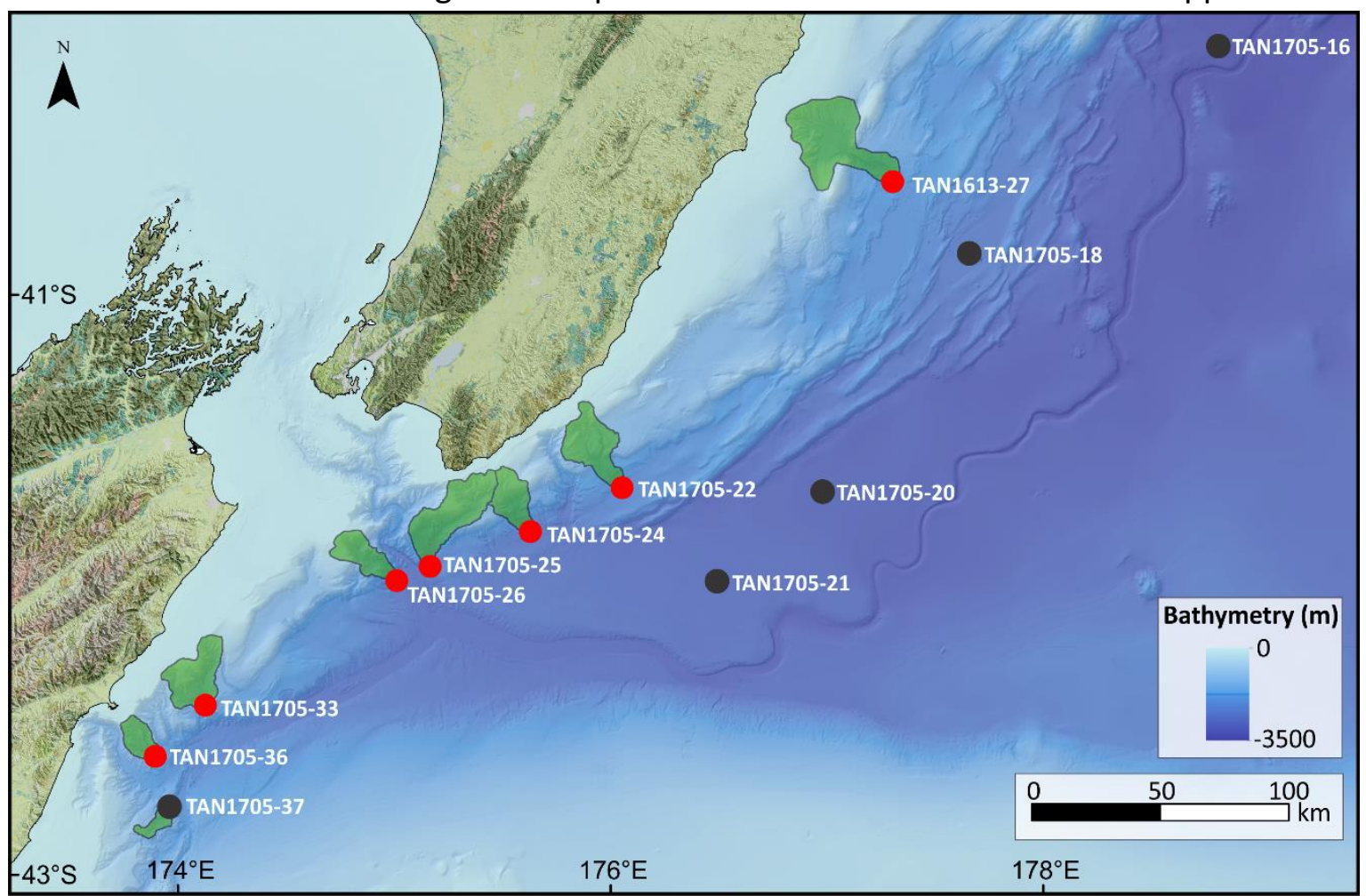

Figure 3.3 Locations of the core sites examined in this study. Green indicates the canyon catchment areas. Red dots denote the locations of canyon-proximal cores, while black dots show the locations of canyon-distal cores.

\subsubsection{Canyon-Proximal sites}

TAN1705-36

TAN1705-36 is located at a water depth of $1647 \mathrm{~m}$, within an active canyon, at the southern end of the Kowhai Sea-valleys, off the coast of the north-eastern South Island (Figure 3.3). The distributary has a catchment area of $160 \mathrm{~km}^{2}$. The core site is positioned $4 \mathrm{~m}$ above the maximum channel depth within a $2 \mathrm{~km}$-wide channel with an irregular channel floor that traverses normal to the slope. This site lies $\sim 2 \mathrm{~km}$ below 


\section{3: Study Site}

the junction of three major tributaries. This core contains the Kaikōura turbidite at its surface, which is $4 \mathrm{~cm}$ thick. The core is located on average $10 \mathrm{~km}$ from turbidity current source areas, defined as canyon wall slopes that have gradients $>5.5^{\circ}$ where slope failure likely occurred (Howarth et al., in review; Micallef \& Mountjoy, 2011).

\section{TAN1705-33}

TAN1705-33 is located at $1541 \mathrm{~m}$ water depth. It is located off the north-eastern South Island, within an active canyon, at the northern end of the Kowhai Sea-valleys (Figure 3.3). The catchment area upstream of the core site is $353 \mathrm{~km}^{2}$. The core is located within a 700-800 $\mathrm{m}$ wide channel, $9 \mathrm{~m}$ above the channel's maximum depth, and $\sim 2$ $\mathrm{km}$ below the junction of two major tributaries. This core contains the Kaikōura turbidite at its surface, which is $4.5 \mathrm{~cm}$ thick. The core is located on average $14 \mathrm{~km}$ from turbidity current source areas.

\section{TAN1705-26}

TAN1705-26 is located at $2423 \mathrm{~m}$ water depth, $1.5 \mathrm{~km}$ from the outlet of Campbell canyon, an active canyon that incises the continental slope, off the north-eastern South Island (Figure 3.3). This distributary has a catchment area of $190 \mathrm{~km}^{2}$. The core is located to the north of the channel centre, at a $2 \mathrm{~km}$ wide cross-section of the channel, $6 \mathrm{~m}$ above the maximum channel depth, and has no confluences upstream of the core site. This core contains the Kaikōura turbidite, which is $18 \mathrm{~cm}$ thick. The core site has an average distance to turbidity current source areas of $15 \mathrm{~km}$.

\section{TAN1705-25}

TAN1705-25 is located at a water depth of $2304 \mathrm{~m}$, within the active Opouawe Canyon (Figure 3.3). The canyon has a catchment area of $480 \mathrm{~km}^{2}$. This core site is positioned $32 \mathrm{~m}$ above the maximum channel depth to avoid gravelly substrates with strong acoustic backscatter, in a cross-section of the channel approximately $2 \mathrm{~km}$ wide, and lies downstream of two confluences. This core contains the Kaikōura turbidite, which is $10.5 \mathrm{~cm}$ thick. The core site is on average $25 \mathrm{~km}$ from turbidity current source areas.

\section{TAN1705-24}

TAN1705-24 is located at $2459 \mathrm{~m}$ water depth within an active canyon that incises into the mid-slope off the coast of the southern Wairarapa (Figure 3.3). The distributary has 
a catchment area of $210 \mathrm{~km}^{2}$. The core is located in the centre of the channel floor, in a cross-section approximately $1 \mathrm{~km}$ wide, $2 \mathrm{~m}$ above the maximum depth, and has no confluences upstream of the core site. This core contains the Kaikōura turbidite at its surface, which is $6 \mathrm{~cm}$ thick. The core is located on average $12.5 \mathrm{~km}$ from turbidity current source areas.

\section{TAN1705-22}

TAN1705-22 is located at $2108 \mathrm{~m}$ water depth, $2.5 \mathrm{~km}$ from the active Honeycomb Canyon, offshore the south-eastern North Island (Figure 3.3). At this site, there is a regional break in the continental slope, where turbidity currents enter the Glenhu Trough, and continue on to flow to the southwest. Upstream of the core site is this break in the continental slope, while downstream lies a series of scour holes in the floor of the trough. This core does not contain the Kaikōura turbidite, as it lies further north, where PGVs did not exceed the triggering threshold (Howarth et al., in review).

\section{TAN1613-27}

TAN1613-27 is located at 1950 m water depth, in Madden Channel, within the active Madden Canyon, offshore Hawke's Bay (Figure 3.3). The core site is within a $\sim 2 \mathrm{~km}$ cross-section of the channel, bordered to the north by a $\sim 4^{\circ}$ slope and to the south by a $\sim 1.7^{\circ}$ slope (McKeown, 2018), and has no confluences upstream of the core site. This core does not contain the Kaikōura turbidite, as with TAN1705-22, it lies too far north from the earthquake epicentre, and PGVs in this area did not exceed the triggering threshold (Howarth et al., in review).

\subsubsection{Canyon-Distal sites}

\section{TAN1705-37}

TAN1705-37 (PUK1) is located at a water depth of $1776 \mathrm{~m}$, in the lower reaches of the Hurunui canyon, off the north-eastern South Island (Figure 3.3). This core sits in a 1.3 $\mathrm{km}$ wide cross-section of the channel, $6 \mathrm{~m}$ above the maximum depth, and $\sim 3-4 \mathrm{~km}$ above the confluence with Pegasus canyon. Hurunui and Pegasus canyons are thought to be sediment pathways that were active during periods of glacially lowered sea levels, and thus are largely inactive today (Lewis \& Barnes, 1999). Therefore, this core 


\section{3: Study Site}

site was included as a canyon-distal core site because while it is located at the lower reaches of a canyon, it is still distal from active canyons, $(26 \mathrm{~km}$ away from the Hikurangi Channel) and thus depositional processes at this location will be more comparable to other canyon-distal core sites, rather than the canyon-proximal core sites. This core does not contain the Kaikōura turbidite, as PGVs in the upper reaches of the Hurunui canyon did not exceed the triggering threshold (Howarth et al., in review)

\section{TAN1705-21}

TAN1705-21 is located at $2733 \mathrm{~m}$ water depth, on the Hikurangi trough, $28 \mathrm{~km}$ from the Hikurangi Channel, surrounded on all sides by relatively flat seafloor, with a maximum elevation change of $<20$ m (Figure 3.3). This core contains the Kaikōura turbidite, which is $9 \mathrm{~cm}$ thick at this core site.

\section{TAN1705-20}

TAN1705-20 is located at $2874 \mathrm{~m}$ water depth, on the Hikurangi trough, $49 \mathrm{~km}$ from the Hikurangi Channel, surrounded on all sides by relatively flat seafloor, with a maximum elevation change of $<20 \mathrm{~m}$ (Figure 3.3). This core contains the Kaikōura turbidite, which is $16 \mathrm{~cm}$ thick at this core site.

\section{TAN1705-18 and TAN1613-25}

TAN1613-25 and TAN1705-18 are both located at 2409 m water depth at the centre of the Akitio trough, $45 \mathrm{~km}$ from the nearest active canyon, Madden Canyon. The catchment area for these cores is $191 \mathrm{~km}^{2}$. In the area surrounding this core location, there is a maximum elevation change of $\sim 16 \mathrm{~m}$, with a maximum dip angle of $\sim 0.4^{\circ}$ (McKeown, 2018). These cores do not contain the Kaikōura turbidite, as with TAN161327, it lies too far north from the earthquake epicentre, and PGVs in this area did not exceed the triggering threshold (Howarth et al., in review)

\section{TAN1705-16}

TAN1705-16 is located at $3234 \mathrm{~m}$ water depth, on the Hikurangi trough, $9 \mathrm{~km}$ from the Hikurangi Channel, surrounded by relatively flat seafloor, with a maximum elevation change of $<20 \mathrm{~m}$ (Figure 3.3). This core contains the Kaikōura turbidite, which is $6.5 \mathrm{~cm}$ thick at this core site. 


\section{Methodology}

\subsection{Rationale}

The southern Hikurangi margin is one of the largest sources of seismic hazard in New Zealand, and yet, there are still many things that are unknown about past margin ruptures (Clark et al., 2019; Wallace et al., 2014). Turbidite paleoseismology can be used to aid in addressing these knowledge gaps. However, turbidite paleoseismology is largely dependent on reliably dating turbidites, which requires the accurate identification of background sediments. Previous work has indicated that a multi-proxy approach provides the most reliable means of distinguishing between turbidite tails and background sediments, however, qualitative analysis of these proxies is subject to inherent human biases. Thus, a quantitative approach is required. In the case of the southern Hikurangi margin, there has been no methodology developed to clearly distinguish turbidite tails from background sediment.

The Kaikōura turbidite was sampled three days following the earthquake (voyage TAN1613), as well as 8 months later (voyage TAN1705). This turbidite provides a unique opportunity to study the characteristics of turbidites triggered along the southern Hikurangi margin and quantify how they differ from the sediment that accumulates in the background along this margin.

The recent turbidites triggered by the Kaikōura earthquake provide a natural experiment to examine the difference between background sediments and turbidite tails along the southern Hikurangi margin. As the studied cores were taken 8 months following the Kaikōura earthquake, the tail of the Kaikōura turbidite sits at the sediment-water interface, allowing for the tail to be easily identified. Background sediments that have been recently deposited can be identified in cores that do and do not contain the Kaikōura turbidite using ${ }^{210} \mathrm{~Pb}$ decay profiles. Therefore, turbidite tails and background sediments can be confidently identified and distinguished from one another, without relying on sedimentological proxies.

Because the background sediments and turbidite tails can be robustly identified independently, a quantitative approach to distinguishing these facies can be examined. 


\section{4: Methodology}

The background sediments and turbidite tails were analysed using a suite of nondestructive and destructive methodologies, for two main reasons. The first was to provide a suite of data that would characterise the physical and geochemical properties possessed by turbidite tails and background sediments. The second was to compare the results of the destructive and non-destructive analyses, to test the use of the non-destructive proxies, and justify their use as an alternative to the direct destructive measurements. If the non-destructive proxies can replace the destructive data, it is preferable to utilise this, as the non-destructive methodologies are less time consuming, provide higher resolution datasets, and leave sediment cores intact. Additionally, the non-destructive datasets are routinely generated on most sediment cores collected, and as such, a method developed based on these datasets would be widely applicable. This suite of data allows for background sediments and turbidite tails to be defined quantitatively, and thus, a machine learning approach can be applied to identify these sediments.

The identification of background sediments is very important in obtaining good age control of turbidites. Not only must material be obtained from background sediments for radiocarbon dating, the thickness of background sediment intervals are used to inform age models (Ramsey, 2008). To determine if the quantitative approach devised here could identify background sediments that would produce reliable radiocarbon ages, the method was applied to TAN1613-27, which contains primary Taupō tephra in amongst turbidites. Background sediment was identified both above and below the tephra using this method, and radiocarbon dates from these intervals were obtained to be compared with the age of the tephra, to determine if these sediments can be accurately radiocarbon dated once background sediment had been identified.

\subsection{Core Collection}

The cores examined in this study were collected using an Ocean Instruments MC-800 Multi-Corer during the TAN1705 voyage aboard the R/V Tangaroa. Cores were taken in areas deemed to be optimally situated to record turbidite deposition triggered by the Kaikōura earthquake, and these sites were identified using high-resolution digital elevation models obtained using multibeam echosounder data and TOPAS PS 18 subbottom profiler data. The corer was equipped with an ultra-short baseline (USBL) 
acoustic beacon with positional accuracies on the seafloor of $<10 \mathrm{~m}$. because of this spatial precision, the majority of cores were acquired from proximal locations slightly offset from the canyon thalweg but generally less than 10 vertical metres from it or in the centre of slope basins. This method of coring samples the uppermost sediments, yielding cores up to $70 \mathrm{~cm}$ long. The sediment-water interface is preserved via this method, allowing for examination of the most recently deposited sediments.

The multi-corer produced 6 cores at each site. The two most well-preserved cores (cores 1 and 2) obtained with the Multi-Corer were archived for onshore analysis, pushing a $65 \mathrm{~mm}$ internal diameter tube through the sediment to obtain a sub-core.

\subsection{Non-Destructive Analyses}

\subsubsection{Computed Tomography}

X-ray Computed Tomography (CT) scans of each of the unsplit cores were taken using a GE BrightSpeed medical CT scanner, set to $120 \mathrm{kV}, 250 \mathrm{~mA}$, pitch of $0.625 \mathrm{~mm}$ and a $100 \mathrm{~cm}^{2}$ window. The CT scan data is given as a series of horizontal cross-sectional images through the core, and these were combined using the open-source program ImageJ to create a vertical cross-section (sagittal slice) of each core.

The CT scan data is generated by the attenuation of X-rays, and reflect both sediment density and atomic number. This data is represented as relative grayscale values, known as Hounsfield units (HU). HU values have a linear relationship with density, and thus can be converted to density via the formula (Reilly et al., 2017):

$$
\text { Density } \mathrm{g} / \mathrm{cm}^{3}=8.0 e^{-4} \times H U+1
$$

The HU data was also extracted using ImageJ, then converted to density using the above formula.

\subsubsection{Visual Analysis}

The visual sedimentological characteristics of each core examined in this study were logged and visually described. These descriptions included: the colour in both 


\section{4: Methodology}

descriptive terms and in Munsell colour notation; the texture of the sediment, in terms of grain size and sorting; any laminations, grading, or other sedimentary structures; and the nature of the contacts between identified units (Pickering, Stow, Watson, \& Hiscott, 1986).

Each of the cores were split into two halves - the working half, to be sampled for destructive analyses, and the archive half, to be preserved for future analyses. The split core was imaged by a GEOTEK Linescan camera on a multi-sensor core logger (MSCL). Core images were obtained using a camera with three 2048 pixel charged-coupled detector (CCD) arrays, which measure light in the red, green and blue bands (RGB). A gain correction was applied to the image to account for lens effects, uneven lighting and pixel-to-pixel variations, calibrated by imaging black and white reference tiles before image analysis. The split core was imaged at an across- and down-core resolution of $50 \mu \mathrm{m}$. The surfaces of the split cores were illuminated during imaging using two high-frequency lamps on either side of the image acquisition line, which minimised any shadow effects caused by irregularities on the surface of the split core. The RGB data was collected from the middle third of the core, to avoid any deformation present at the edges of the core as a result of the coring process. Bioturbation was described using the CT scans of each core, which allows for bioturbation to be seen more clearly than in direct imaging of a split core. The percentage of bioturbation was visually estimated from the CT imagery, and classified using the Deep-Sea ichnofabric indices as detailed by Mcllroy (2004), with each index corresponding to a bioturbation percentage range (Figure 4.1). 


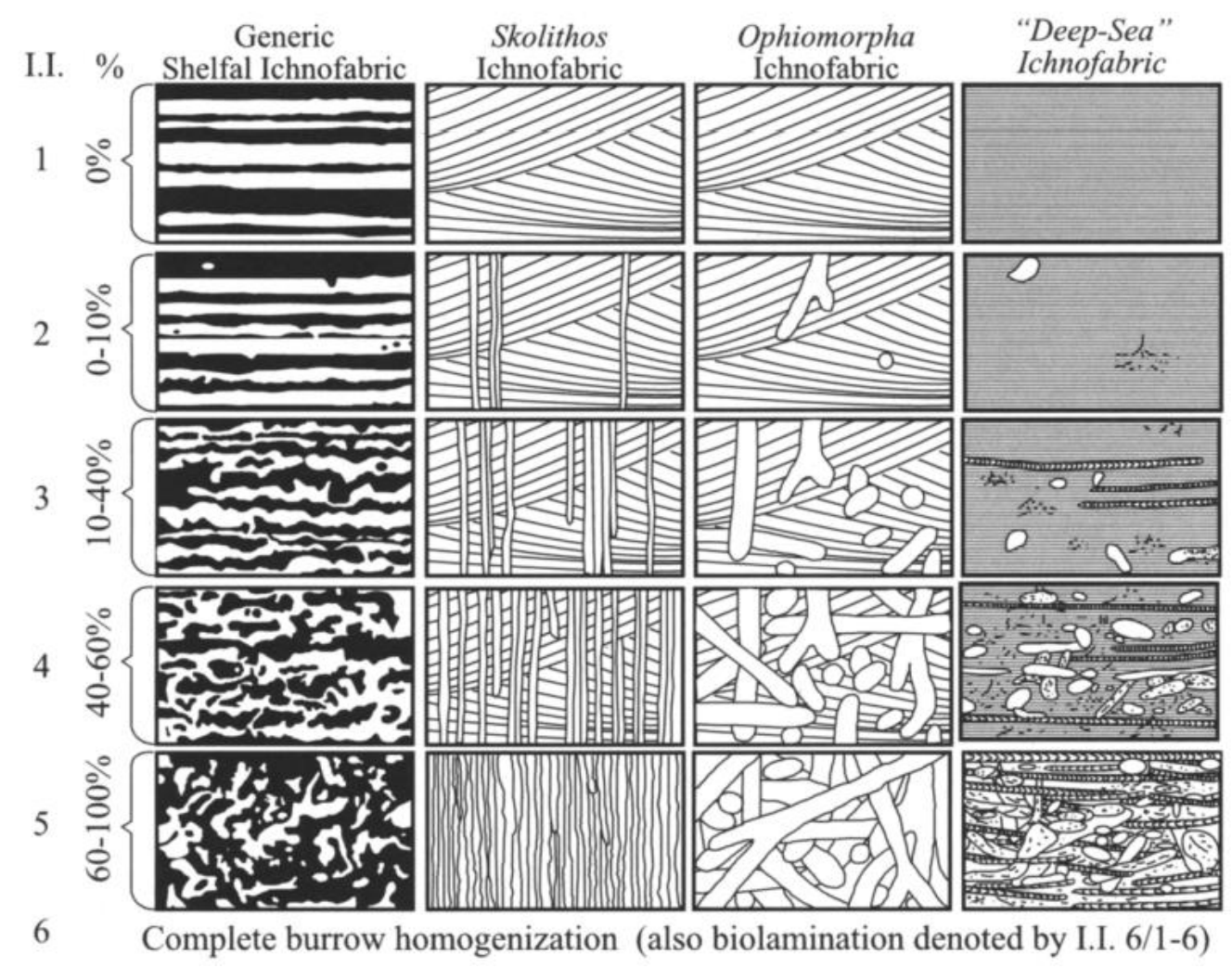

Figure 4.1 Ichnofabric indices, based on the percentage of bioturbation observed in cross-section view, from Mcllroy (2004)

\subsubsection{Magnetic Susceptibility}

Magnetic susceptibility measurements were made using a Bartington MS2E point source sensor at $5 \mathrm{~mm}$ increments down the surface of split cores, with measurements taken as the average signal over 10 seconds. A point sensor was used as loop sensor data did not have sufficient down core resolution to show the stratigraphic bedding of the cores. As the field of the point source sensor decreases to $50 \% 1 \mathrm{~mm}$ away from the surface of the sensor, the surface of the core was scraped back to remove any microtopographic irregularities. The point sensor is also highly sensitive to temperature variations, and thus was zeroed every five measurements.

\subsubsection{Micro X-Ray Fluorescence Spectrometry}

U-channels were taken from the working half of each core and sent to the ITU-EMCOL Core Analysis Laboratory, Turkey. These U-channels were analysed by Prof. Dr. Namık Çağatay and PhD. student Nurettin Yakupoğlu, using a COX Analytical Systems ITRAX XRF core scanner. A Mo X-ray tube was used, with tube voltage set to $30 \mathrm{kV}$, tube current at $50 \mathrm{~mA}$, and exposure time at $20 \mathrm{~s}$, measuring at a resolution of $1 \mathrm{~mm}$. This 


\section{4: Methodology}

method gives a continuous profile of elemental concentrations through the core, though this data is semi-quantitative, expressed as counts per second (cps). For some elements, changes in water content or organic content can impact the raw cps values in a manner that is unrelated to the geochemistry of the sediments. Thus, instead of examining the output for single elements, the data was processed into different elemental ratios to negate closed-sum effects (Croudace \& Rothwell, 2015). The proxies examined in this study are detailed in Table 4.1. Proxies were chosen as those with well-known process interpretations that have been used extensively in the literature.

Table 4.1: Summary of elemental ratios examined in this study

\begin{tabular}{|l|l|}
\hline Elemental Ratio & Use \\
\hline $\mathrm{Ca} / \mathrm{Sr}$ & $\begin{array}{l}\text { Distinguishes between biogenic and detrital carbonates, as } \\
\text { biogenic } \mathrm{CaCO}_{3} \text { has greater Sr than inorganic } \mathrm{CaCO}_{3} \text { (dolomite). A } \\
\text { greater proportion of detrital carbonates could suggest a } \\
\text { transported source (Croudace \& Rothwell, 2015). }\end{array}$ \\
\hline $\mathrm{Ca} / \mathrm{Ti}$ & $\begin{array}{l}\text { Shows biogenic input (Ca) vs. terrigenous input (Ti). An increase in } \\
\text { terrigenous input could suggest a transported source. Ca/Ti can } \\
\text { also be used as a proxy for carbonate content (Cattaneo et al., } \\
2012 ; \text { Croudace \& Rothwell, 2015; Drab et al., 2012; Gracia et al., } \\
\text { 2010). }\end{array}$ \\
\hline $\mathrm{Zr} / \mathrm{Rb}$ & $\begin{array}{l}\text { Provides a grain size proxy, as Zr is generally present in coarser } \\
\text { grains, while Rb is predominantly present in clays (Croudace \& } \\
\text { Rothwell, 2015). }\end{array}$ \\
\hline $\mathrm{inc} / \mathrm{coh}$ & $\begin{array}{l}\text { The incoherent/coherent scattering ratio, which is a proxy for } \\
\text { organic content (Croudace \& Rothwell, 2015). }\end{array}$ \\
\hline $\mathrm{Mn} / \mathrm{Fe}$ & $\begin{array}{l}\text { Used to assess redox conditions. Mn is mobile under sub-oxic } \\
\text { conditions, so Mn/Fe peaks during suboxic diagenesis, when Mn is } \\
\text { mobilised (Croudace \& Rothwell, 2015). }\end{array}$ \\
\hline
\end{tabular}

\subsection{Destructive Analyses}

\subsubsection{Core Sampling}

The working halves of each core were sampled at 1 or $2 \mathrm{~cm}$ intervals from the top of the core to at least $10 \mathrm{~cm}$ below the Kaikōura turbidite where it was present. The nondestructive analyses detailed above were also used to inform intervals for sampling. These samples were divided in two, one sample for foraminiferal analysis, and one for organic content and carbonate content. A pea-sized portion $\left(\sim 0.5 \mathrm{~cm}^{3}\right)$ of the sample was also reserved for grain size analysis. These samples were weighed to obtain the wet weight of each sample. 
The archive half of each core was also sampled for ${ }^{210} \mathrm{~Pb}$ analysis, as there was not enough material present in the working half to undertake all of the analyses required. For these samples, 1 or $2 \mathrm{~cm}$ sample intervals were used, and samples were staggered to one every $\sim 5 \mathrm{~cm}$ in some cases at greater core depths to ensure the full ${ }^{210} \mathrm{~Pb}$ decay profile was captured. These samples were weighed, then placed in a - 80 freezer overnight, then freeze-dried over at least 24 hours using a FreeZone 6 Benchtop Freeze Dry System. Once dry, they were reweighed, crushed into a fine powder using a mortar and pestle, and packaged in plastic bags.

\subsection{2 ${ }^{210} \mathrm{~Pb}$ Analysis}

The freeze-dried samples from four of the studied cores were sent to the Institute of Environmental Science and Research (ESR) in Christchurch, New Zealand. Radionuclide measurements were made on these samples using alpha spectrometry. A well-known amount of internal tracer ( $\left.{ }^{209} \mathrm{Po}\right)$ was added to the sample, the acidified, digested, and filtered. The filtrate contains most of the Po (80-100\% recovery), which was then plated onto a silver disk. The plated sample was then analysed using alpha spectrometry for ${ }^{209} \mathrm{Po}$ and ${ }^{210} \mathrm{Po}$. The ${ }^{210} \mathrm{Po}$ activity measurements are considered to be equal to ${ }^{210} \mathrm{~Pb}$ activity, as it is assumed that ${ }^{210} \mathrm{~Pb}$ is in radioactive equilibrium with ${ }^{210}$ Po (Ebaid \& Khater, 2006).

Activities were reported in $\mathrm{Bq} / \mathrm{kg}$, with uncertainties based on the combined standard uncertainty (uc), multiplied by a coverage factor $(k)=2$, providing a $95 \%$ confidence level. The down-core profile of ${ }^{210} \mathrm{~Pb}$ activity was then plotted to visually assess the nature of this profile. Because the ${ }^{210} \mathrm{~Pb}$ data is being used to identify gradual vs. instantaneous deposition, the activity profile is sufficient to determine this, as gradual background sedimentation presents as an exponential decrease of ${ }^{210} \mathrm{~Pb}$ activity with depth, whereas instantaneously deposited sediments disrupt this profile (Dezileau et al., 2016).

Excess ${ }^{210} \mathrm{~Pb}$ was not calculated, as at the time of writing sufficient samples that could be used to robustly identify if ${ }^{210} \mathrm{~Pb}$ activity levels had reached supported ${ }^{210} \mathrm{~Pb}$ had not been received. Therefore, sedimentation rates based on excess ${ }^{210} \mathrm{~Pb}$ data have not been calculated in this study. 


\section{4: Methodology}

\subsubsection{Grain Size}

Each grain size sample was left to dry completely, and then had a washing solution (1g $\mathrm{Na}_{2} \mathrm{CO}_{3}$ and $4 \mathrm{~g} \mathrm{NaHCO}_{3}$ in $20 \mathrm{~L}$ of distilled water) added to them to prevent grains clumping. The samples were then analysed in a Beckman Coulter multi-wavelength Particle Sizing Analyzer.

Obscuration was examined prior to each measurement. If obscuration was above $24 \%$, the measurement of the sample was recorded, then the sample was diluted, and obscuration was examined again. This process was repeated until obscuration was below $24 \%$. With each dilution, the sample was measured, and the mean grain size was compared to ensure obscuration was not significantly impacting the results. Samples were measured between 1 and 3 times to obtain an obscuration reading below the threshold. The data was then processed using GRADISTAT (Blott \& Pye, 2001), to present the data in terms of mean grain size, sorting, skewness, kurtosis, and cumulative percentile values (e.g. $\left.D_{50}, D_{90}\right)$.

\subsubsection{Organic Content}

The combined samples for both organic content and carbonate content were placed in an oven at $110^{\circ} \mathrm{C}$ for two hours to drive off all moisture. The samples were then weighed and crushed with a mortar and pestle. Approximately $2 \mathrm{~g}$ of dried sediment was measured out and placed in a $400^{\circ} \mathrm{C}$ furnace for 2 hours. The sample was reweighed following this, and the change in weight after ignition was used to calculate the percentage of organic content in each sample using the formula below (Heiri, Lotter, \& Lemcke, 2001).

$$
\% \text { Organic Matter }=\frac{\text { Weight of oven dry sample }- \text { Weight of sample after ignition }}{\text { Weight of oven dry samples }} \times 100
$$

\subsubsection{Carbonate Content}

The percentage of carbonate present in each sediment sample taken was evaluated using a vacuum-gasometric technique, where the carbonate present in a sample is 
converted to carbon dioxide, and the amount of $\mathrm{CO}_{2}$ produced is used to calculate the amount of carbonate in the sample, to a precision of $\pm 2 \%$ (Jones \& Kaiteris, 1983).

The samples were dried in the oven and crushed as described for the organic content analyses. Approximately $0.3 \mathrm{~g}$ of sample was weighed out and placed in the bottom of a test tube with a side arm. Approximately $3 \mathrm{~mL}$ of $70 \%$ orthophosphoric acid was placed in the side arm of the test tube, and the test tube was sealed. The temperature of the room was recorded, and the test tube was placed on the vacuum line. The pressure in the test tube was measured, and a vacuum created within it, and then acid was added to the sediment and left to react for 90 minutes. The test tube was then added back to the vacuum line and the pressure in the test tube was re-measured. The number of moles of gas produced is calculated using the Ideal Gas Law:

$$
n=\frac{\Delta P V}{R T}
$$

Where:

$n$ is the number of moles of gas produced

$\Delta P$ is the change in pressure (end pressure - start pressure)

$V$ is the volume of the test tube

$R$ is the Ideal gas constant

$T$ is the temperature in Kelvin

The number of moles of gas is then multiplied by 100.8 to obtain the weight of the carbonate within the sample, which was then converted into the percentage of the total sample that is carbonate using the original dry weight of the sample.

\subsubsection{Foraminiferal Analysis}

Foraminiferal samples were dried in an oven at $60^{\circ} \mathrm{C}$ overnight. These samples were weighed, then had a washing solution $\left(1 \mathrm{~g} \mathrm{Na}_{2} \mathrm{CO}_{3}\right.$ and $4 \mathrm{~g} \mathrm{NaHCO}_{3}$ in $20 \mathrm{~L}$ of distilled water) added to them to separate the grains, and were washed through a $63 \mu \mathrm{m}$ sieve with deionized water. The $>63 \mu \mathrm{m}$ portion was left to dry on filter paper, weighed, and then packaged in a glass vial. The $<63 \mu \mathrm{m}$ portion was left to settle out in the deionized 


\section{4: Methodology}

water. The overlying water was periodically poured out, with care taken not to disturb the settled sediment, until only a small amount of water remained and the sample could air dry. The dried sample was then packaged in a plastic bag and archived.

The $>63 \mu \mathrm{m}$ sub-samples were then analysed by Bruce Hayward and Ashwaq Sabaa (Geomarine Research) according to the methods set out in Hayward et al. (2019). This comprises three main methods: test size distribution, planktic percentage, and relative abundance of bathymetric groups of benthic genera. Additionally, the Planktic Foraminiferal Fragmentation Index (Le \& Shackleton, 1992), and the abundance of foraminiferal tests were also examined.

\section{Test Size Distribution}

The test size distribution is a measure of the abundance of foraminiferal tests that fall within three different size ranges: $>250,125-250$, and 63-125 $\mu \mathrm{m}$. The relative abundance of these groups can be used to identify if the tests have been sorted, through comparison to the test size distributions expected from planktic rain through the water column. The test size distribution can give an indication that the tests have been size-sorted by some external mechanism. Each sample was sieved into these three parts, and the number of tests in each of these fractions was counted, and the relative abundance (\%) of each fraction calculated. These were compared to the test size distributions of modern sea-floor samples from Hayward et al. (2019).

\section{Planktic Percentage}

The planktic percentage is a measure of the relative abundance of planktic foraminifera, which is known to increase with distance from land (Hayward et al., 2019). The $>125 \mu \mathrm{m}$ fraction of the sample was split, and the number of both benthic and planktic specimens within this split were counted, and the percentage of planktic were calculated.

\section{Planktic Foraminiferal Fragmentation Index}

The fragmentation index uses the percentage of planktic foraminifera that have fragmented into chamber-sized pieces as a proxy for dissolution, and for breakage during transport (Le \& Shackleton, 1992). The sample was split and the number of whole planktic tests were counted, along with the number of chamber-sized 
fragments. The number of fragments was divided by 8 , as it is assumed that each test will break into an average of 8 fragments, to obtain the number of fragmented planktic foraminifera. The fragmentation index was calculated as:

Fragmentation index $=\frac{\text { No. of fragmented planktics } / 8}{\text { No. of whole planktics }+ \text { No. of fragmented planktics } / 8} \times 100$

\section{Revised Fragmentation Index}

The fragmentation index calculated above assumes that each test will break into an average of 8 fragments. However, since only fragments $>63 \mu \mathrm{m}$ are counted, a test $<125 \mu \mathrm{m}$ would not produce any fragments within the size fraction studied. Most planktic foraminifera have 2-6 chambers per whorl, and there are few specimens in which the last chamber is greater than half the original test dimensions in size. Thus, a more appropriate fragmentation index was calculated assuming that there would be approximately two fragments per test, rather than eight, given by the below formula.

Fragmentation index $=\frac{2(\text { No.of fragmented planktics })}{\text { No. of whole planktics }+2(\text { No. of fragmented planktics })} \times 100$

\section{Revised Planktic Percentage}

In the deep sea, dissolution preferentially attacks planktic over benthic foraminifera, as the latter are buried in sediment and thus better protected. Therefore, the planktic percentage can decrease due to dissolution. There is often a rough anticorrelation between planktic percentage and the fragmentation index, which can indicate that dissolution is the cause of higher FI and lower planktic percentages. Using the revised fragmentation index, the original planktic percentage prior to dissolution can be estimated using the following formula: 


$$
\text { Planktic } \%=\frac{p 2 \times(100 / 100-F I)}{(p 2 \times 100 / 100-F I)+(100-p 2)} \times 100
$$

Where $\mathrm{Fl}$ is the revised fragmentation index and $\mathrm{p} 2$ is the planktic\% calculated from the sample. However, this is only an estimate, as it does not account for complicating factors such as mechanical fragmentation increasing the FI.

\section{Relative Abundance of Benthic Genus Groups}

The relative abundance of benthic genus groups uses the number of benthic foraminifera belonging to one of six bathymetric groups in a sample to give an indication of the depth at which the foraminifera and sediment within that sample were derived. These groups are: shelf-restricted, or shallower than $200 \mathrm{~m}(<200 \mathrm{~m})$; shelf- and upper-bathyal restricted, with lower depth limits between 200 and $500 \mathrm{~m}$ $(<500 \mathrm{~m})$; shelf to mid bathyal-restricted, with lower depth limits between 500 and $1000 \mathrm{~m}(<1000 \mathrm{~m})$, bathyal or deeper, with an upper depth limit between 200 and 400 m (>200 m), mid bathyal or deeper, with upper depth limit at $400 \mathrm{~m}$ or deeper $(>400$ $\mathrm{m})$, and eurybathic ( 0-4000 m).

A split of the $>125 \mu \mathrm{m}$ fraction of each sample was examined and benthic foraminifera were identified as belonging to one of the above six groups, and the percentage of foraminifera in each group was calculated.

\section{Abundance of Foraminiferal Tests}

The abundance of foraminiferal tests compares the number of tests to the proportion of mud and sand in the sample, as an indication of productivity in a sample. The number of benthic and planktic foraminifera were both counted to report the number of each, as well as the total number. These numbers were then compared to the weights of the sample before and after sieving to report the abundance in tests per gram of sediment (whole sample weight), and per gram of sand ( $>63 \mu \mathrm{m}$ fraction weight).

\subsection{Validating the Use of Non-Destructive Proxies}

The non-destructive methodologies described above provide data that has much higher resolution, and said data is obtained rapidly in comparison to destructive 58 
techniques. However, destructive methods provide absolute data points for the properties studied. To fully utilize the benefits of the non-destructive techniques, they were examined in tandem with the destructive methods to assess the effectiveness of the proxies. The destructive and non-destructive datasets were examined in two ways. Initially, visual assessment of the trends in each dataset were examined, and then, to further validate correlation, a statistical approach (multi-dimensional scaling) was applied.

Grain size, carbonate content, and organic matter were all compared to their corresponding non-destructive proxies, density, magnetic susceptibility, and the microXRF derived geochemical proxies ( $\mathrm{Zr} / \mathrm{Rb}, \mathrm{Ca} / \mathrm{Ti}, \mathrm{Ca} / \mathrm{Sr}$, and inc/coh) that have been used in other studies, to validate their use along the southern Hikurangi margin. In the first instance, each variable was plotted alongside the corresponding proxies, and variations were visually assessed.

To further test the correlation between the destructive data and the non-destructive proxies, multidimensional scaling (MDS) was used. This method visualises the similarity between samples by plotting points in 2D space (Cox \& Cox, 2008). The nondestructive data was averaged so that it was the same resolution as the destructive data. The MDS was used to examine two key questions:

1. Are the physical and geochemical properties (both destructive and nondestructive) of a given lithofacies significantly different to those of another lithofacies?

2. Are direct measurements equivalent to proxies of those measurements?

The R package "vegan" (Oksanen et al., 2013) was used to create an ordination plot of all samples based on the Bray-Curtis dissimilarity metric. To answer the first question, the differences between lithofacies groups were determined using the "adonis" function, which is analogous to MANOVA (multivariate analysis of variance) and generates a $p$-value to determine if the differences between lithofacies groups are statistically significant.

To address the second question, the MDS was also used to visualise the correlation matrix, plotting the variables themselves, where variables that are more similar plot 


\section{4: Methodology}

closer together. Pearson's correlation test was used to assess the correlation between the destructive datasets and their relevant proxies, obtaining the $p$-value to determine if the correlations between the destructive dataset and each proxy is statistically significant ( $p$-value $<0.05)$.

\subsection{Linear Discriminant Analysis}

To develop a method to independently identify turbidite tails and background sedimentation along the southern Hikurangi margin, the machine learning technique, linear discriminant analysis (LDA) was used. This method is a classification technique that takes multivariate observations that are known to come from predefined classes with similar characteristics, and uses these observations to create a classification rule (Izenman, 2008). This method works best with more data points to inform the classification rule. Destructive techniques take a significant amount of time and effort to produce few data points, and are limited by the amount of material available. Nondestructive techniques take very little time to obtain many data points, while leaving the sediment intact. Thus, the destructive data was replaced in favour of the higherresolution non-destructive proxies, which is deemed reasonable based on the test outlined in the above section. To obtain the number of data points needed for LDA using destructive techniques would require a large amount of time and resources, in addition to depleting the limited amount of sediment from a core.

Sediment intervals from the studied cores were classed as either turbidite tail (1) or background sediment $(0)$ based on the foraminiferal analyses and the ${ }^{210} \mathrm{~Pb}$ chronology and stratigraphic position (in the case of the Kaikōura turbidite). Only turbidite tail lithofacies (e.g. $\mathrm{T}_{\mathrm{E}-1}$ and $\mathrm{T}_{\mathrm{E}-2}$ as per Talling et al. (2012)) were used, as these are the most difficult to distinguish from background sediment qualitatively. The nondestructive data was averaged to the smallest common depth intervals, to create a set of data points for each core. Using $R$, the data was pre-processed to normalise it by scaling and centring the data, and this data was randomly split in two, with $75 \%$ being used as the "training set", and the other $25 \%$ used as the "test set". The training set was used to develop the model, using the Ida() function in the R library "MASS", which takes the training set and calculates the coefficients of linear discriminants for each of 
the non-destructive predictor variables. These are used to form the decision rule, which calculates the linear discriminant of each sample, in the form:

$$
L D 1=\left(\text { Coefficient }_{\text {predictor }_{1}} \times \text { Value }_{\text {predictor }_{1}}\right)+\ldots+\left(\text { Coefficient }_{\text {predictor }_{n}} \times \text { Value }_{\text {predictor }_{n}}\right)
$$

The decision rule is used to produce a model that can then be used to predict the posterior probability that a sample belongs to a particular class, given as a value between 0 and 1 , and the sample is assigned to that class if this value is above the decision threshold (0.5). The test set is used to assess the accuracy of the model, comparing the output of the model to the known class (Kassambara, 2018). Because the training/test set split is random, the LDA function was run 10 times, with the split saved using set.seed() each time, to obtain the best-performing split of the data.

The results are output in two ways: as a confusion matrix, and as a Receiver Operating Characteristic $(\mathrm{ROC})$ curve. A confusion matrix is a two-dimensional matrix that is used to summarise the performance of a classifier. It displays the number of correctly and incorrectly classified instances, broken down into true positives, true negatives, false positives, and false negatives, as detailed in Table 4.2 below (Ting, 2017).

Table 4.2: A typical confusion matrix, adapted from Ting (2017)

\begin{tabular}{|c|c|c|c|}
\hline \multicolumn{2}{|c|}{} & \multicolumn{2}{c|}{ Assigned Class } \\
\cline { 3 - 4 } \multicolumn{2}{|c|}{} & Positive & Negative \\
\hline $\begin{array}{c}\text { Actual } \\
\text { Class }\end{array}$ & Positive & True Positives & False Negatives \\
\cline { 2 - 4 } & Negative & False Positives & True Negatives \\
\hline
\end{tabular}

In this study, the confusion matrix can be described as in Table 4.3, below.

Table 4.3 The confusion matrix presented using the terminology of this study (adapted from Ting (2017))

\begin{tabular}{|c|c|c|c|}
\hline \multicolumn{2}{|c|}{} & \multicolumn{2}{|c|}{ Assigned Class } \\
\cline { 3 - 4 } \multicolumn{2}{|c|}{} & Turbidite Tail & Background \\
\hline \multirow{3}{*}{$\begin{array}{c}\text { Actual } \\
\text { Class }\end{array}$} & $\begin{array}{c}\text { Turbidite } \\
\text { Tail }\end{array}$ & $\begin{array}{c}\text { No. correctly classified as } \\
\text { turbidite tail }\end{array}$ & $\begin{array}{c}\text { No. incorrectly classified as } \\
\text { background }\end{array}$ \\
\cline { 2 - 4 } & Background & $\begin{array}{c}\text { No. incorrectly classified as } \\
\text { turbidite tail }\end{array}$ & $\begin{array}{c}\text { No. correctly classified as } \\
\text { background }\end{array}$ \\
\hline
\end{tabular}




\section{4: Methodology}

The Receiver Operating Characteristic (ROC) curve examines the relationship between the sensitivity and specificity of a binary classifier. The sensitivity is the true positive rate, or the proportion of positives correctly classified, and so equates to the percentage of turbidite tail samples correctly identified as such. The specificity is the true negative rate, or proportion of negatives correctly classified, and thus equates to the percentage of background samples correctly identified as such. The ROC curve is plotted as the true positive rate against the false positive rate ( 1 - true negative rate) as calculated for every possible decision threshold, creating a curve. The area under the ROC curve, known as the AUC, is a statistic used to summarize the ROC curve, and gives a value between 0 and 1 , where $A \cup C=1$ is achieved if every positively-classified instance has a higher score than every negatively classified instance (Flach, 2010).

The best-performing model was determined to be the model with the highest AUC value. This may not be the most accurate model in terms of the proportion of correctly classified instances, but it is the model that has the greatest separation of classes overall.

\subsection{Radiocarbon Dating}

The LDA model was applied to data from a core (TAN1613-27) containing primary Taupō tephra, as identified by Hopkins et al. (2020). The non-destructive data from these cores was applied to the model, treated as a test set. The posterior probability that a sample was turbidite tail was given for each sample depth and plotted downcore. This plot was examined, and sample depths were selected to be as close to the tephra as possible while remaining within the sediment deemed most likely to be background sedimentation. Foraminiferal samples from these intervals were sieved to obtain the $>250 \mu \mathrm{m}$ fraction and planktic foraminifera within this size range were picked to obtain $\sim 10 \mathrm{mg}$ of foraminifera. The samples were sent to Rafter Radiocarbon Laboratory at the National Isotope Centre, GNS Science, Lower Hutt. Carbon dioxide was generated from the foraminifer by carbonate $\mathrm{CO}_{2}$ evolution. The carbon dioxide was converted to graphite by reduction with hydrogen over iron catalyst, and measured on a compact accelerator mass spectrometer (AMS). The reservoir correction applied to these samples was a $\Delta R$ of $126 \pm 69$ years, obtained using the Marine20 calibration curve (Heaton et al., 2020). 


\section{Results}

\subsection{Core Sedimentology}

\subsubsection{Canyon-Proximal: TAN1705-33}

TAN1705-33 is a $28.5 \mathrm{~cm}$ core with the Kaikōura turbidite in the top $4.5 \mathrm{~cm}$, located at $1541 \mathrm{~m}$ water depth (Figure 5.1). The base of this turbidite has a sharp, slightly wavy contact, overlain with dark grey (5Y 4/1) very fine to fine sand lamination at the base, grading upward into olive grey (5Y $4 / 3)$ very fine sandy silt with faint colour laminations. The turbidite contains no bioturbation, classed as deep-sea ichnofabric index 1 , which equates to $0 \%$ visible bioturbation. Beneath the turbidite is an olive grey ( $5 Y 5 / 2$ ) very fine sandy mud, with dark grey colour mottling and bioturbation, classed as deep-sea ichnofabric index 4 , which equates to $40-60 \%$ visible biotrubation, and organic-rich mud blebs.

Within the turbidite, density is relatively constant $\left(\sim 1.5 \mathrm{~g} / \mathrm{cm}^{3}\right)$ with a peak $\left(\sim 2 \mathrm{~g} / \mathrm{cm}^{3}\right)$ at the base, while magnetic susceptibility shows a broader peak $\left(\sim 2-16 \times 10^{-5} \mathrm{SI}\right)$ through the turbidite. The grain size data shows a few small peaks in the D50, with a slight increase then decrease upwards through the $4.5 \mathrm{~cm}$ of turbidite, while sorting is variable ( 24-44 $\mu \mathrm{m})$. The grain size data does not record the peak observed in the density data, potentially due to lower sampling resolution. The percentage of carbonate increases down through the turbidite, from $\sim 5-7 \%$, while the percentage of organic matter decreases, from $\sim 5-2 \%$.

Beneath the turbidite, density, magnetic susceptibility, and percentage of organic matter are all relatively constant $\left(\sim 1.7 \mathrm{~g} / \mathrm{cm}^{3}, \sim 15 \times 10^{-5} \mathrm{SI}\right.$, and $\left.\sim 2 \%\right)$. The grain size data shows an increasing trend in the D50 down core, while sorting sits around $20 \mu \mathrm{m}$, with a peak of $\sim 30 \mu \mathrm{m}$ at roughly $10 \mathrm{~cm}$ depth. The percentage of carbonate dips slightly beneath the turbidite to $~ 6 \%$, and stays around $\sim 7.5-8 \%$ through the remainder of the samples. The Mn/Fe ratio is constant throughout the entire core.

\section{Foraminiferal Analysis}

The foraminiferal data shows shallow-restricted benthic foraminifera throughout the entire core, with the $<1000 \mathrm{~m}$ group having significant abundance in every sample, 


\section{5: Results}

along with the $>200 \mathrm{~m}$ and $>400 \mathrm{~m}$ groups, while there are smaller numbers from the $<200 \mathrm{~m}$ and $<500 \mathrm{~m}$ groups in most samples (Figure 5.2). The fragmentation index is moderately high for the depth of this core (14-21\%), while the original planktic percentage is $71-91 \%$ beneath the turbidite, and $62-83 \%$ within the turbidite, where in situ accumulation at this depth is $90-95 \%$. When adjusted for $\mathrm{FI}$, planktic\% becomes 95-98\% beneath the turbidite. The test size distribution shows a higher relative abundance of small tests and lower amounts of medium-sized tests throughout the core. A full data table for the foraminiferal data for this core (and each subsequent core) can be found in Appendix B. 


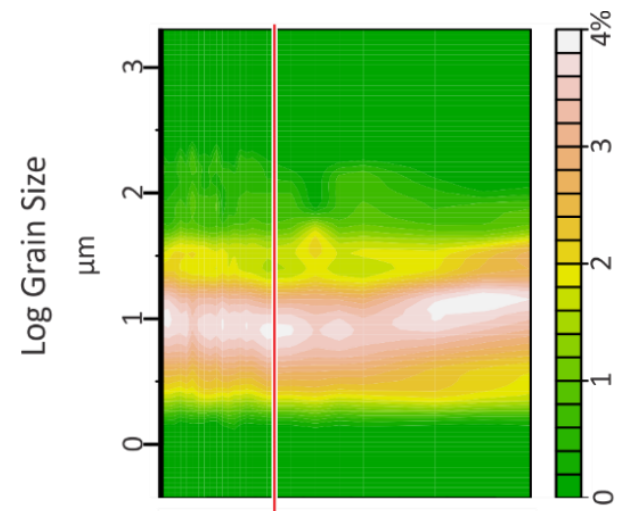

ơ

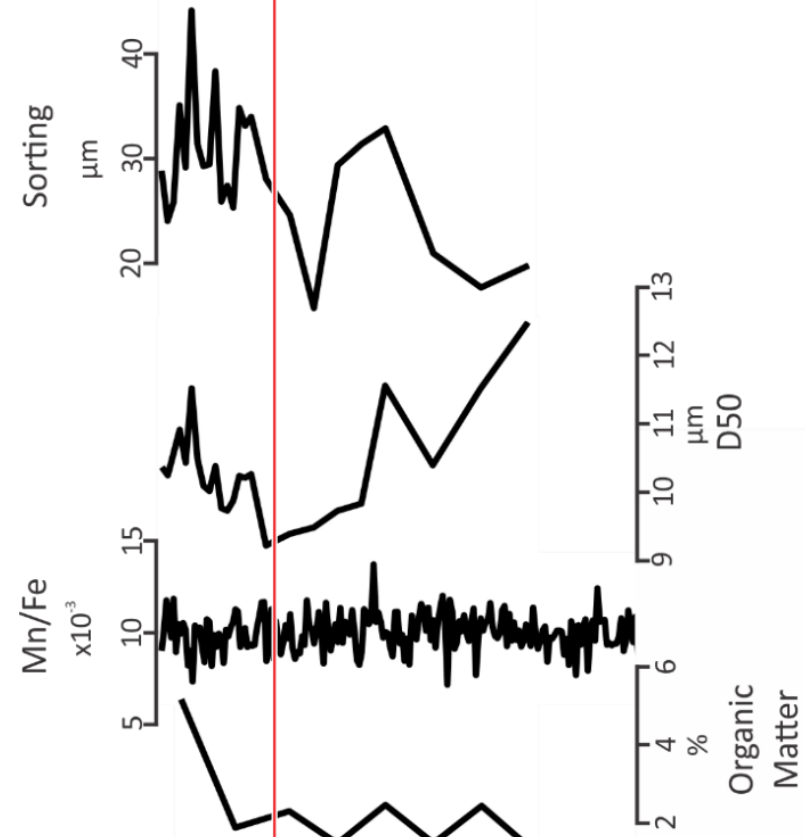

离

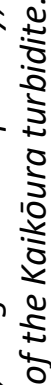

से ปั

ป

จे

文范

है

응
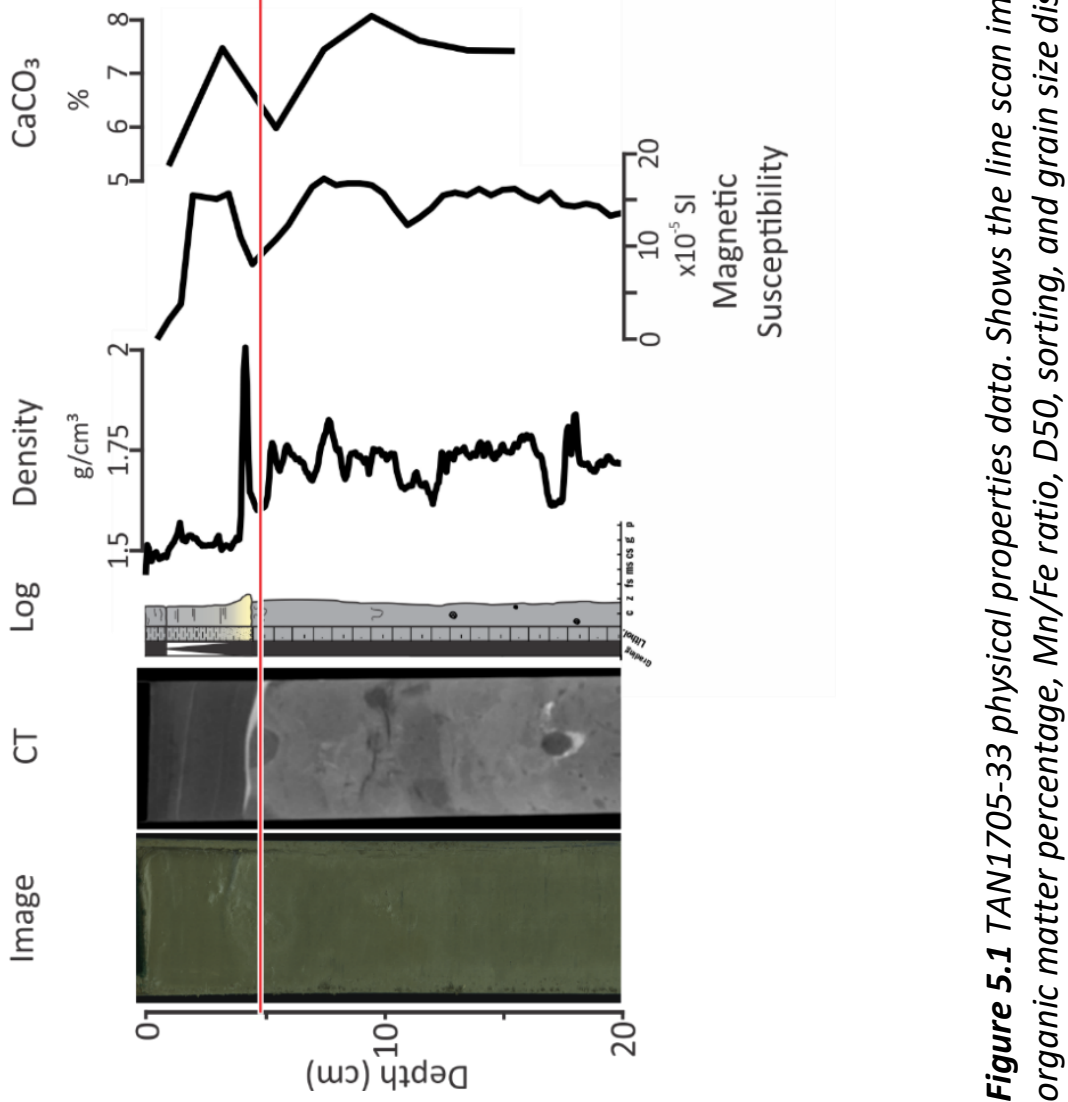


\section{5: Results}

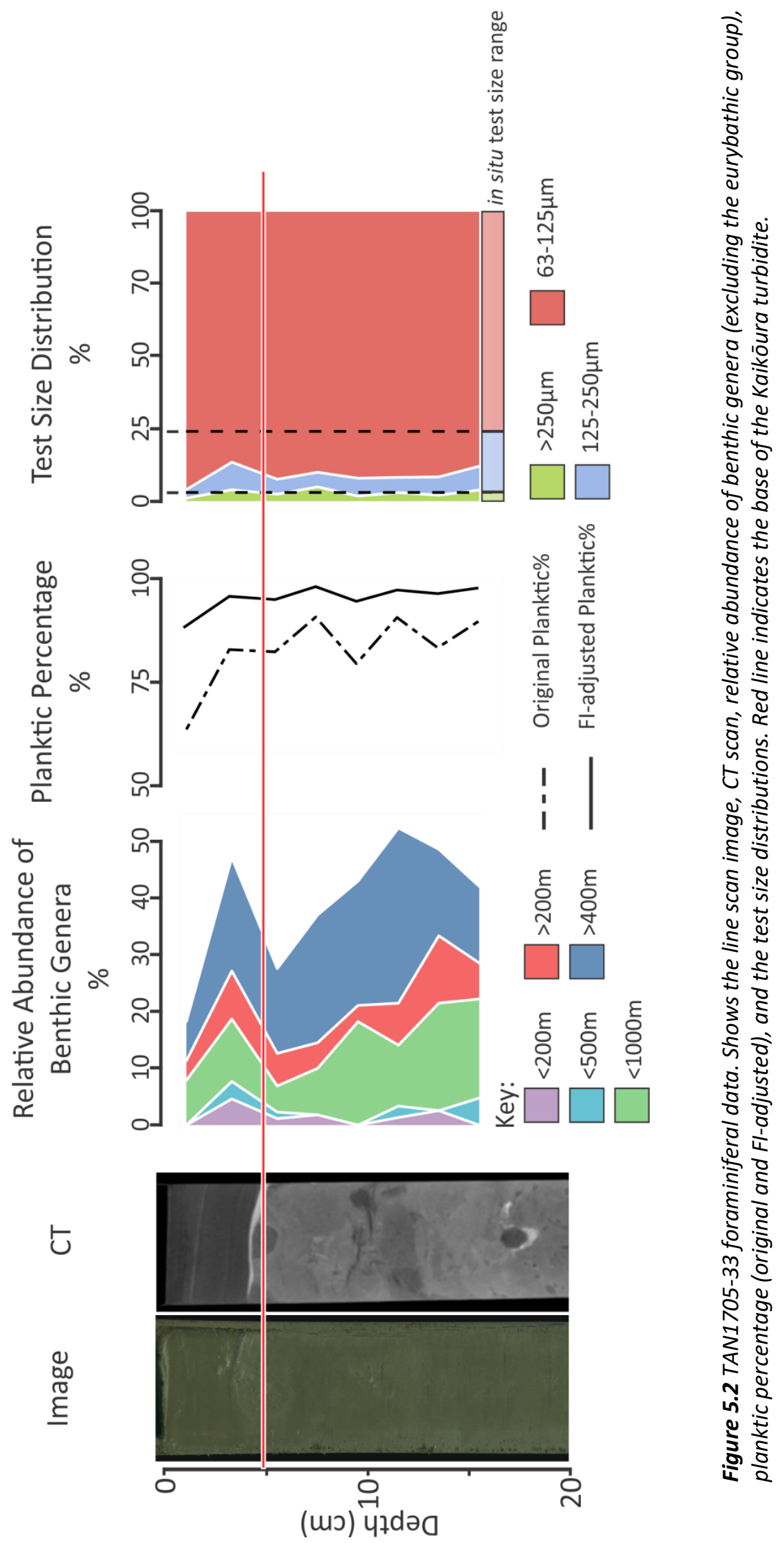




\subsubsection{Canyon-Proximal: TAN1705-26}

TAN1705-26 is a $50.5 \mathrm{~cm}$ core with the Kaikōura turbidite in the top $18 \mathrm{~cm}$, located at $2423 \mathrm{~m}$ water depth (Figure 5.3). The base of this turbidite has a sharp and undulating contact. The turbidite is made up of three normally graded bands, with $\mathrm{mm}$-scale laminations of dark grey (5Y 2.5/2) very fine sandy silt, which grade up into planar laminated and normally graded olive-grey $(5 Y 4 / 2)$ mud. The turbidite contains no bioturbation (index 1). Beneath the turbidite is an olive-grey (5Y 4/2) mud that has light colour mottling and bioturbation, classed as ichnofabric index 3 , which equates to $10-40 \%$ visible bioturbation.

Within the turbidite, density and magnetic susceptibility both show a general upwards decreasing trend through each of the normally graded bands $\left(\sim 1.4-2 \mathrm{~g} / \mathrm{cm}^{3}\right.$ and $\sim 11$ $37 \times 10^{-5} \mathrm{SI}$ ), correlating with similar peaks in the $\mathrm{D} 50$, sorting, and grain size distributions. The percentage of carbonate within the turbidite is relatively low ( 4$6 \%)$, with a large increase in the lowermost sample, taken near the undulating boundary. Percentage of organic matter varies between $\sim 0.6-3 \%$.

Beneath the turbidite, density and magnetic susceptibility are relatively constant ( 1.4 $\mathrm{g} / \mathrm{cm}^{3}$ and $\sim 15 \times 10^{-5} \mathrm{SI}$ ). The grain size distribution and D50 also show little variation until a slight step at $\sim 25 \mathrm{~cm}$ depth, and sorting is on average lower than within the turbidite. Percentage of carbonate is slightly higher on average than the turbidite $(\sim 5-$ $7 \%)$. The percentage of organic matter varies with a similar range to within the turbidite ( $\sim .6-3 \%)$, but is on average higher directly beneath the turbidite. The $\mathrm{Mn} / \mathrm{Fe}$ ratio stays relatively constant between the turbidite and the underlying sediment, but shows very slightly lower values beneath the turbidite.

\section{Foraminiferal Analysis}

The foraminiferal data shows that there is a significant proportion of benthic foraminifera from shallow-restricted groups within the turbidite, largely the $<500 \mathrm{~m}$ and $<1000 \mathrm{~m}$ groups, and much lower proportions of the $>200 \mathrm{~m}$ and $>400 \mathrm{~m}$ groups when compared to the pre-turbidite sediment directly beneath (Figure 5.4). The preturbidite sediment contains very few shallow-restricted tests, making up only 1-6\% of tests through all the samples studied. The fragmentation index is high throughout the 


\section{5: Results}

core, but is highest within the normally graded bands and lowest in the pre-turbidite sediment and in the uppermost samples from this core. Original planktic\% ranges between $32-54 \%$, well outside the expected range for the depth of this core (>95\%), though when adjusted for $\mathrm{Fl}$, ranges between $76-86 \%$ beneath the turbidite. Within the turbidite the $\mathrm{Fl}$-adjusted planktic percentage is not considered as fragmentation is likely related to mechanical processes rather than dissolution. The test size distribution through the turbidite has a larger number of small tests than in situ faunas, while much more of the pre-turbidite sediments have values closer to in situ.

\section{${ }^{210} \mathrm{~Pb}$ Analysis}

The ${ }^{210} \mathrm{~Pb}$ activity profile (Figure 5.5 ) has highly variable values within the turbidite, with peaks roughly corresponding to the finer grained "tails" of each of the normallygraded bands, though this pattern may be affected by the sampling resolution $(1 \mathrm{~cm})$. Beneath the turbidite, ${ }^{210} \mathrm{~Pb}$ activity is at $107 \mathrm{~Bq} / \mathrm{kg}$, and decreases relatively consistently down core. ${ }^{210} \mathrm{~Pb}$ activity appears to be beginning to plateau towards the bottom of the core, reaching $45.8 \mathrm{~Bq} / \mathrm{kg}$ in the lowest sample, though there are not enough data points to determine if ${ }^{210} \mathrm{~Pb}$ activity have reached supported ${ }^{210} \mathrm{~Pb}$ levels, however, supported ${ }^{210} \mathrm{~Pb}$ has an estimated maximum value of $\sim 45 \mathrm{~Bq} / \mathrm{kg}$. 


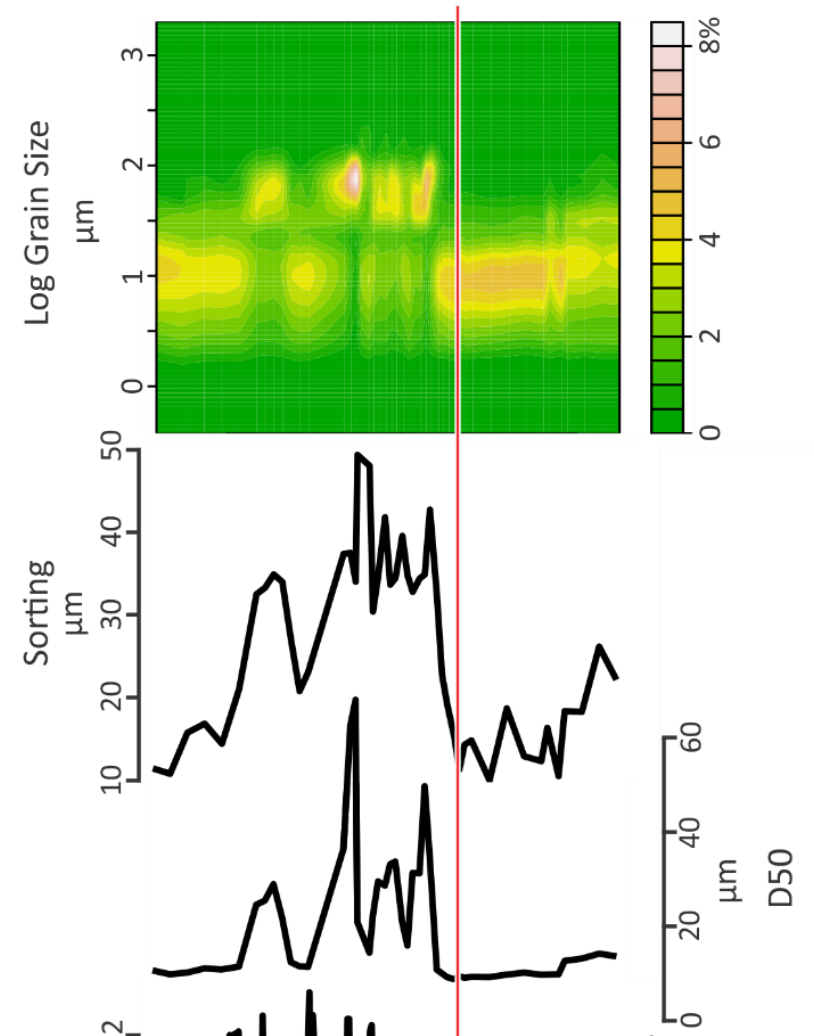

宛

式

잉

ปิ

䓠

¿

डิ क्ष

ते

के

요

춘

(1)

है

ڤั

ริ थ

岕 :

نิ

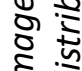

ธิ \&

un

$\stackrel{5}{\equiv}$

ई

ง

ปे

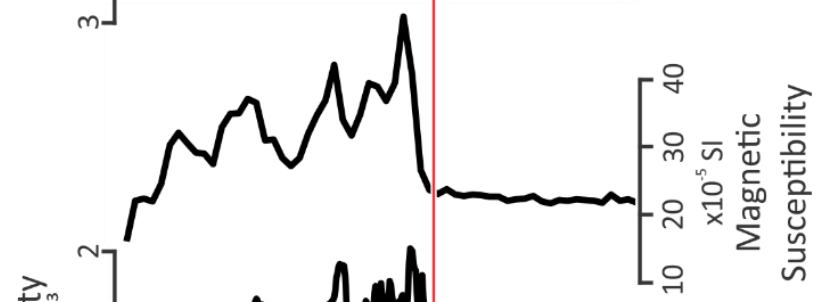

응 웅

ฯ 0

ะั

ㅇํㅇ

는

ठิ

तs

हे ริ

$\stackrel{0}{\sim}$

นิ้

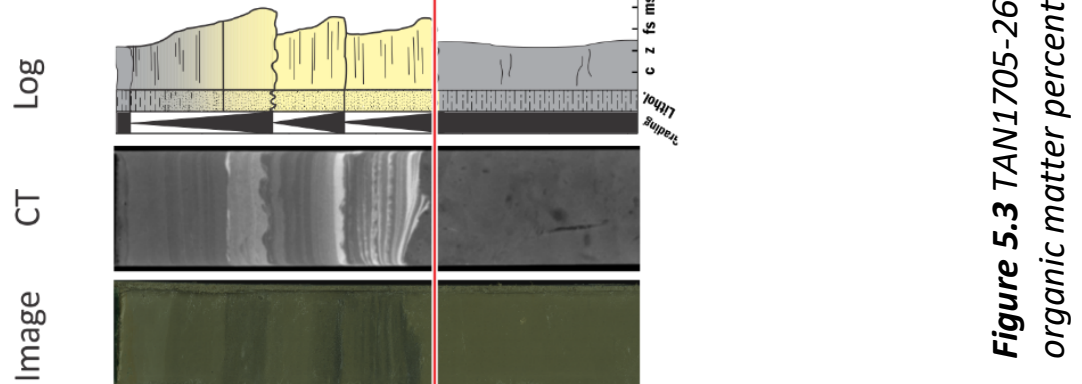

(uכ) पzdə0 


\section{5: Results}

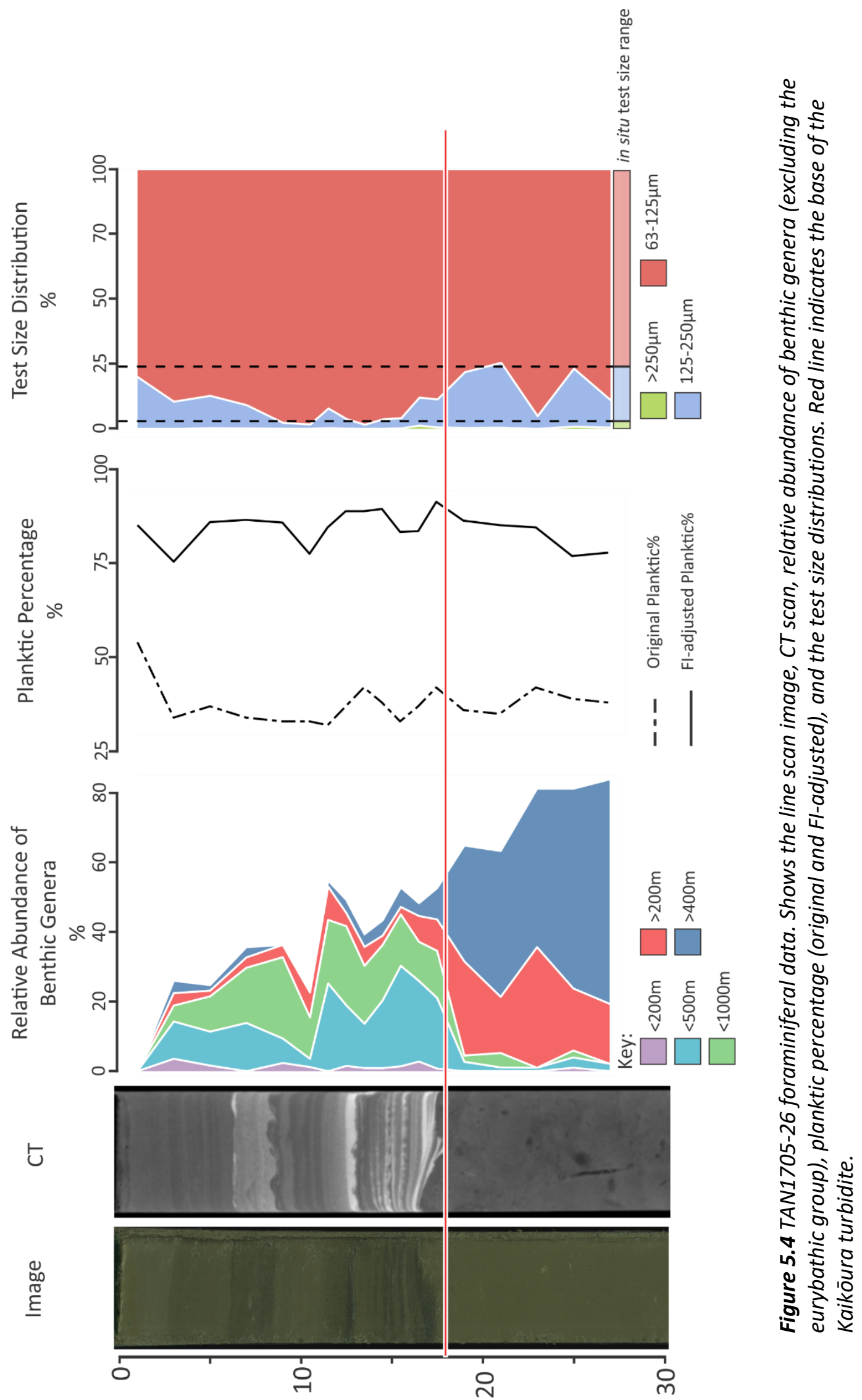

(uכ) प7də0 


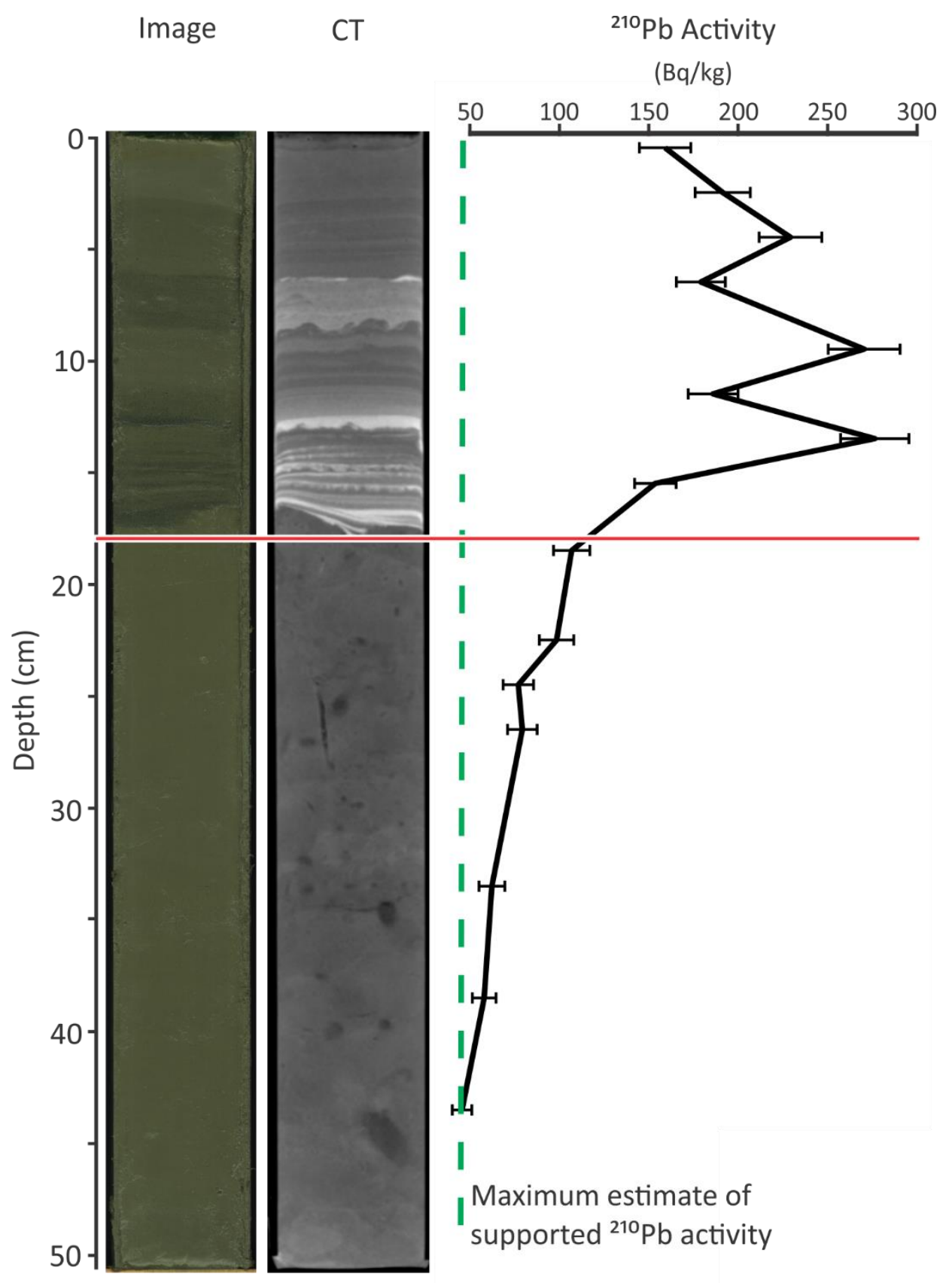

Figure 5.5 TAN1705-26 ${ }^{210} \mathrm{~Pb}$ activity data. Shows the line scan image, CT scan, and ${ }^{210} \mathrm{~Pb}$ activity profile. Green dashed line indicates the maximum estimate of supported ${ }^{210} \mathrm{~Pb}$ activity. Red line indicates the base of the Kaikoura turbidite. 


\section{5: Results}

\subsubsection{Canyon-Proximal: TAN1705-24}

TAN1705-24 is a $73.5 \mathrm{~cm}$ core with the Kaikōura turbidite in the top $6 \mathrm{~cm}$, located at $2459 \mathrm{~m}$ water depth (Figure 5.6). The base of this turbidite has a sharp, undulating contact. The turbidite is made up of three normally-graded bands, with mm-scale laminations of olive grey ( $5 Y$ 4/3) fine sand that grades upwards into very fine sandy mud, with faint colour mottling near the top. The turbidite contains no bioturbation (index 1). Beneath the turbidite is an olive (5Y 4/4), fine sandy mud, with faint rustycoloured mottling (5Y 4/2), bioturbation (index 3 ), and faint, cm-scale wavy and discontinuous, faintly visible in the CT image.

Within the turbidite, density is slightly increased $\left(\sim 1.4-1.5 \mathrm{~g} / \mathrm{cm}^{3}\right)$, and magnetic susceptibility shows a broad peak $\left(\sim 18-22 \times 10^{-5} \mathrm{SI}\right)$. The grain size data shows a spike in the D50 at around $2 \mathrm{~cm}$, in line with the lamination at this depth, then a gradual increase through the rest of the turbidite. Sorting is highly variable through the turbidite $(\sim 12-22 \mu \mathrm{m})$. The percentage of carbonate is $\sim 5 \%$ through the turbidite, while the percentage of organic matter is slightly more variable between $\sim 2-4 \%$.

Beneath the turbidite, density is relatively constant $\left(\sim 1.4 \mathrm{~g} / \mathrm{cm}^{3}\right)$ while magnetic susceptibility shows slight variability down core $\left(\sim 16.7-19 \times 10^{-5} \mathrm{SI}\right)$. The grain size data shows higher D50 values beneath the turbidite than within it while sorting sits around $17.8 \mu \mathrm{m}$ with a peak to $21.5 \mu \mathrm{m}$ in the lowermost sample. The percentage of carbonate is $\sim 6 \%$. The percentage of organic matter varies between $\sim 3-5 \%$, on average higher than within the turbidite. The Mn/Fe ratio has a slight peak beneath the turbidite, corresponding with the rusty-coloured mottling.

\section{Foraminiferal Analysis}

The foraminiferal data shows the turbidite contains more shallow-restricted benthic foraminifera (from the $<200 \mathrm{~m}$ and $<1000 \mathrm{~m}$ groups) within the turbidite, while beneath the turbidite benthic assemblage is dominated by the $>200 \mathrm{~m}$ and $>400 \mathrm{~m}$ groups, with two samples containing one specimen each from the $<500 \mathrm{~m}$ group (Figure 5.7). The fragmentation index has no clear distinction between turbidite and pre-turbidite sediments. The original planktic percentage is significantly higher within the turbidite (70-83\%) than beneath it (39-49\%), where it is expected to be $>95 \%$ for in situ accumulation. When adjusted for $\mathrm{FI}$, the pre-turbidite sediments are $76-84 \%$. The 
test size distribution through the turbidite shows an increase abundance of mediumsized tests at the top of the core, and the relative abundance of the small tests increases down into the base of the turbidite at the expense of the other size fractions. Beneath the turbidite, the test size distributions are relatively constant, with similar abundances of large tests to in situ accumulation, while there is a slight overabundance of small tests.

\section{${ }^{210} \mathrm{~Pb}$ Analysis}

The ${ }^{210} \mathrm{~Pb}$ activity profile (Figure 5.8 ) increases slightly with depth through the turbidite, from 197 to $309 \mathrm{~Bq} / \mathrm{kg}$. Activity plateaus slightly at $730 \mathrm{~Bq} / \mathrm{kg}$ directly beneath the turbidite, then decreases with depth from $\sim 10 \mathrm{~cm}$, reaching $94 \mathrm{~Bq} / \mathrm{kg}$ at $\sim 30 \mathrm{~cm}$ depth. It is unclear if supported ${ }^{210} \mathrm{~Pb}$ has been reached at this depth, but is estimated to be at maximum $\sim 95 \mathrm{~Bq} / \mathrm{kg}$. 


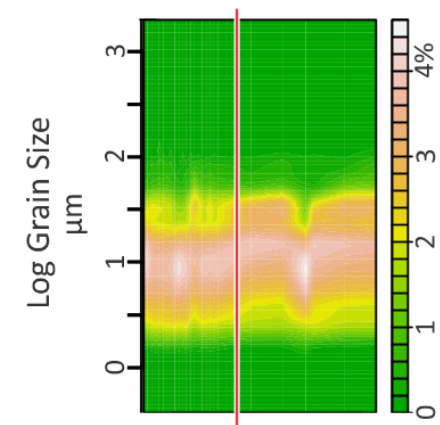

突

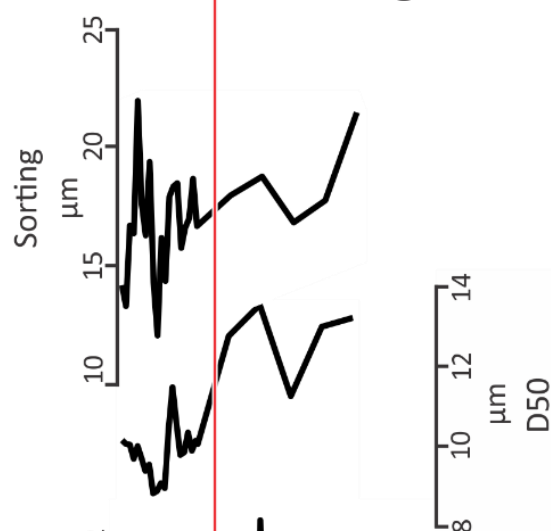

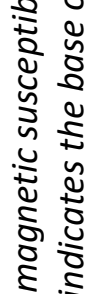

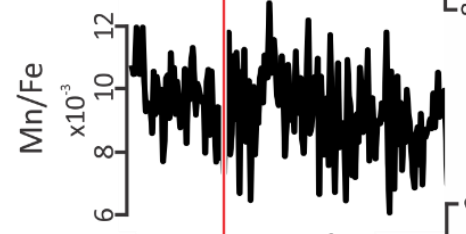

तิ้

के व

ㅇํ जิ

ㅎำ

है

\&. ज

ธ્屯ิ

๑

ปั่

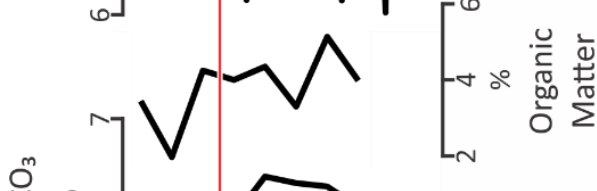

है के

ธิ के

जे

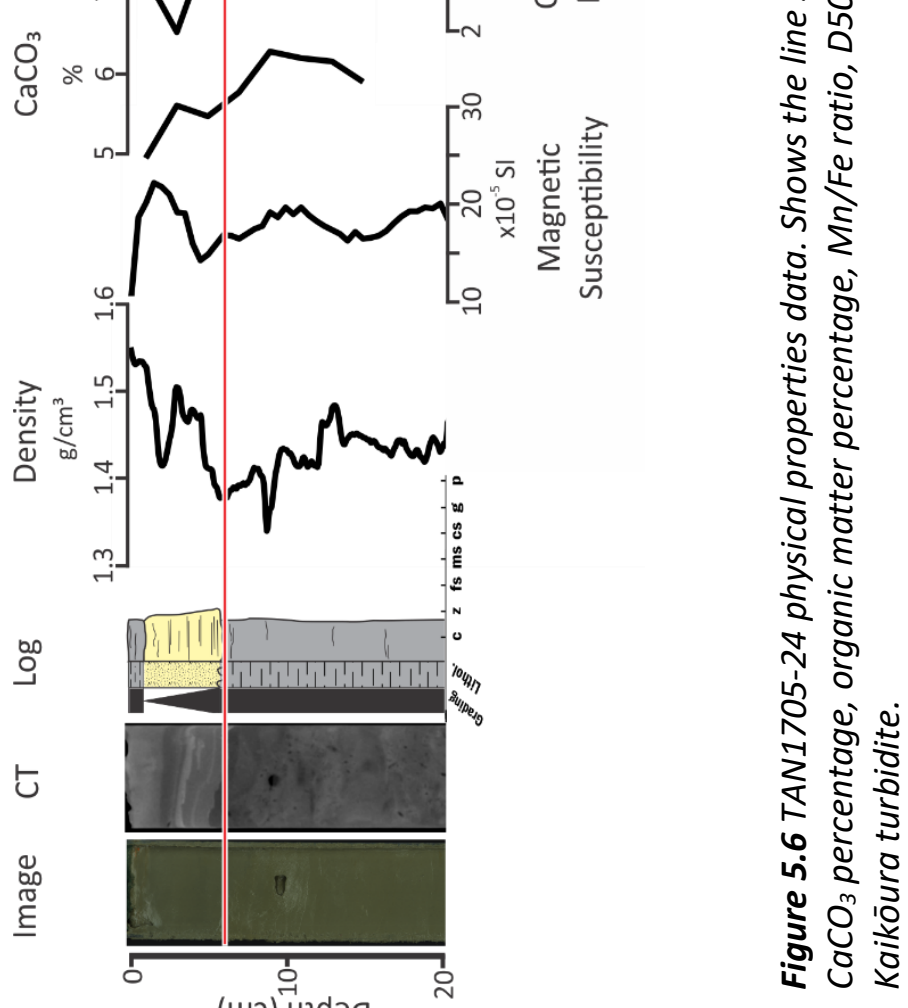

(uว) पㄱ dә0 


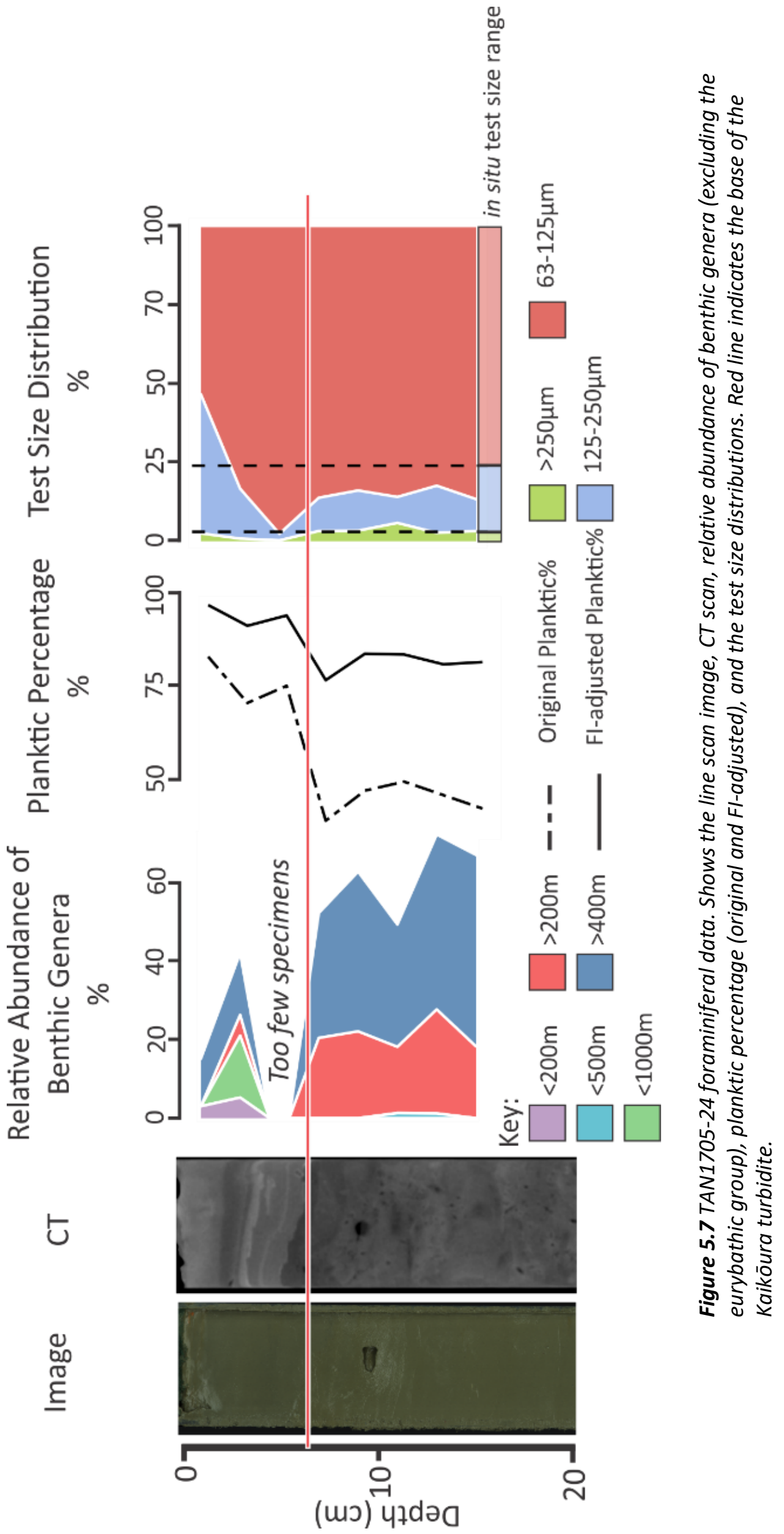




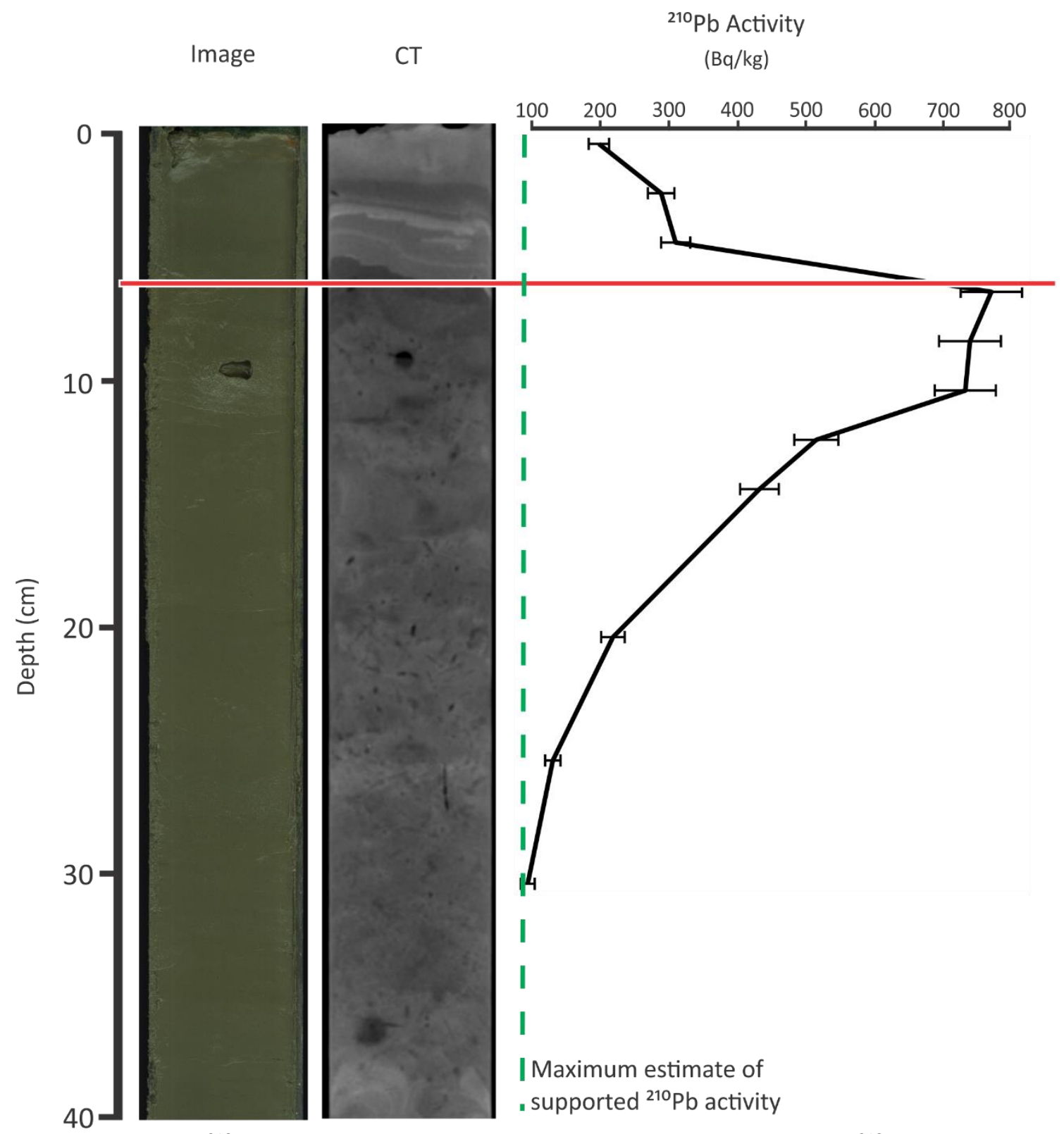

Figure 5.8 TAN1705-24 ${ }^{210} \mathrm{~Pb}$ activity data. Shows the line scan image, CT scan, and ${ }^{210} \mathrm{~Pb}$ activity profile. Green dashed line indicates the maximum estimate of supported ${ }^{210} \mathrm{~Pb}$ activity. Red line indicates the base of the Kaikoura turbidite. 


\subsubsection{Canyon-Proximal: TAN1705-22}

TAN1705-22 is a $45 \mathrm{~cm}$ core that does not contain the Kaikōura turbidite, located at $2108 \mathrm{~m}$ water depth (Figure 5.9). The sediment in this core can be broken into three distinct sections. The uppermost section $(0-7 \mathrm{~cm})$ is an olive grey $(5 Y 4 / 2)$ very fine sandy silt, with faint rusty-coloured mottling in the top $2 \mathrm{~cm}$. This section has a gradational lower contact and bioturbation traces (index 4), that grades up into a very fine sandy silt. The middle section $(7-24 \mathrm{~cm})$ has a sharp planar lower contact overlain by a very dark grey (5Y 2.5/1) medium-coarse sand that grades up into a grey (5Y 4/1) fine sandy mud, with colour mottling, large blebs of dark grey coarse sand, and bioturbation (index 4). The lowermost section is an olive grey (5Y 4/2) very fine sandy mud, with darker colour mottling and bioturbation (index 4).

The density, D50 and percentage of carbonate all show similar trends, being relatively consistent ( $\sim 1.6 \mathrm{~g} / \mathrm{cm}^{3}, \sim 11 \mu \mathrm{m}$, and $\left.\sim 6 \%\right)$ with a sharp increase at $\sim 22 \mathrm{~cm}$, corresponding with the layer of dark coarse sand. Sorting shows increased values in the uppermost section (top $\sim 5 \mathrm{~cm}$ ) as well as another peak at $\sim 22 \mathrm{~cm}$. Magnetic susceptibility sits around $\sim 20 \times 10^{-5} \mathrm{SI}$ and shows a sharp decrease at $\sim 22 \mathrm{~cm}$ to $\sim 10 \times 10^{-5}$ $\mathrm{SI}$, while percentage of organic matter shows a smaller and broader decrease through this section. The Mn/Fe ratio shows a small peak at the top of the core.

\section{Foraminiferal Analysis}

The foraminiferal data shows benthic foraminifera from all bathymetric groups in every sample (Figure 5.10). The fragmentation index is relatively high, and the original planktic percentage varies between $25-82 \%$, where in situ accumulation would be 95\% for this depth. The Fl-adjusted planktic percentage varies between 77-96\%, closer to expected in situ values. The test size distribution shows a higher relative abundance of small tests in the majority of samples, while the abundance of mediumsized tests is decreased when compared to in situ values. 


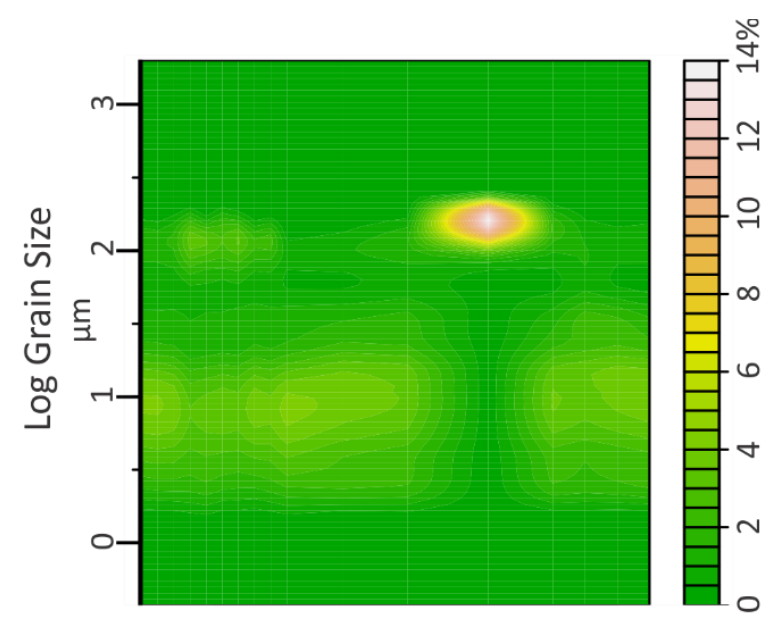

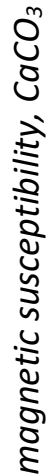

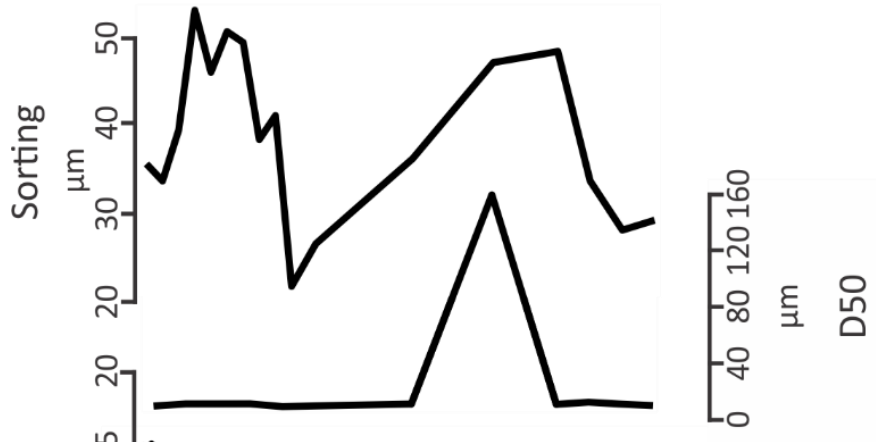

$\frac{2}{\frac{2}{2}}$

익

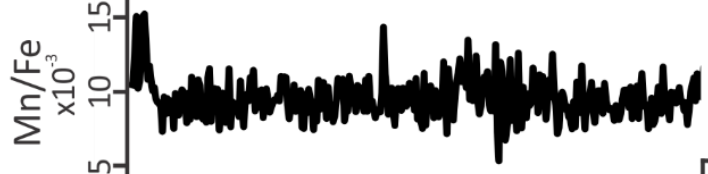
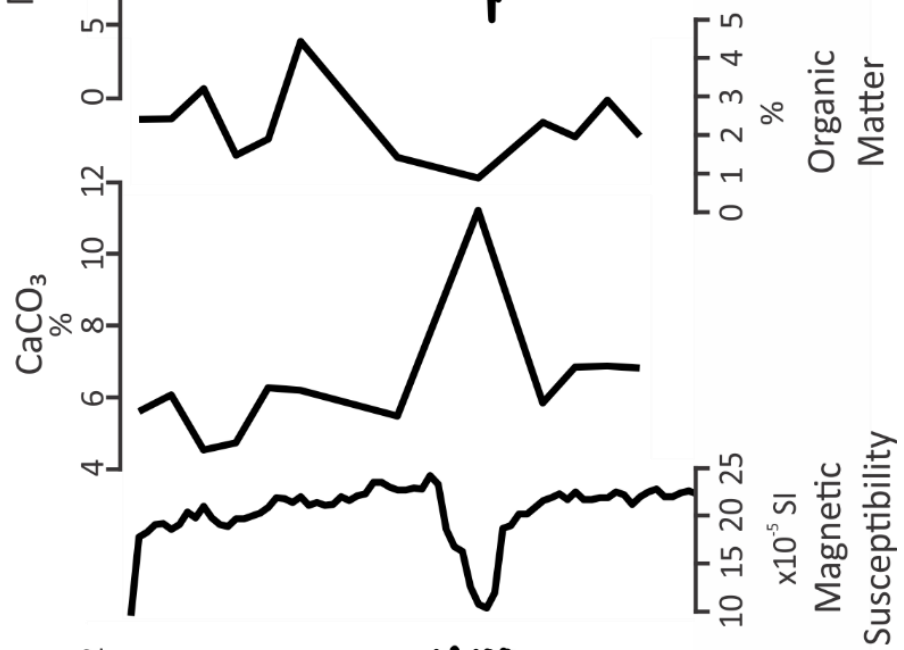

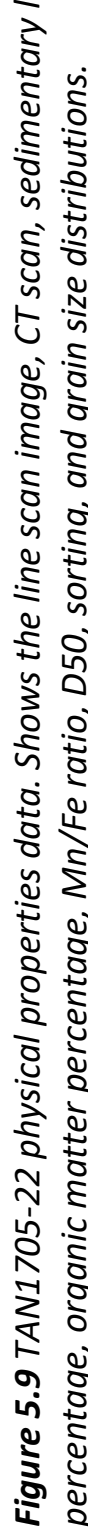
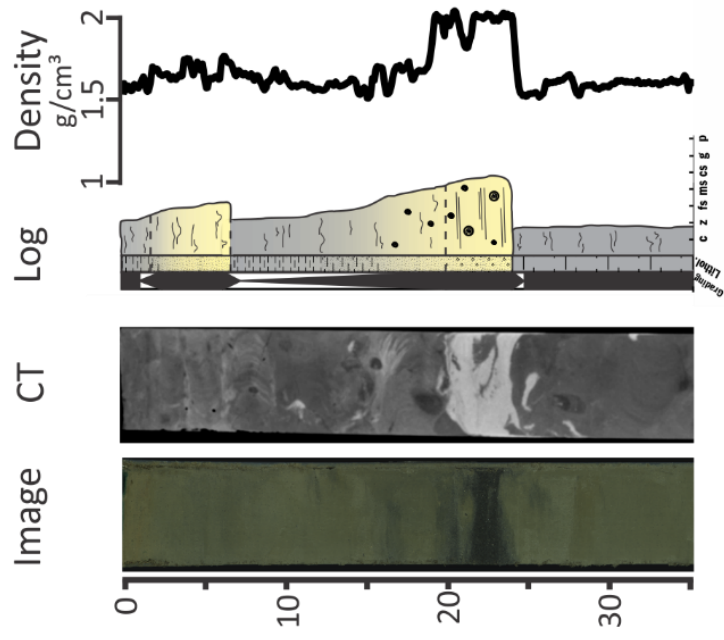

(uว) पวdə0 


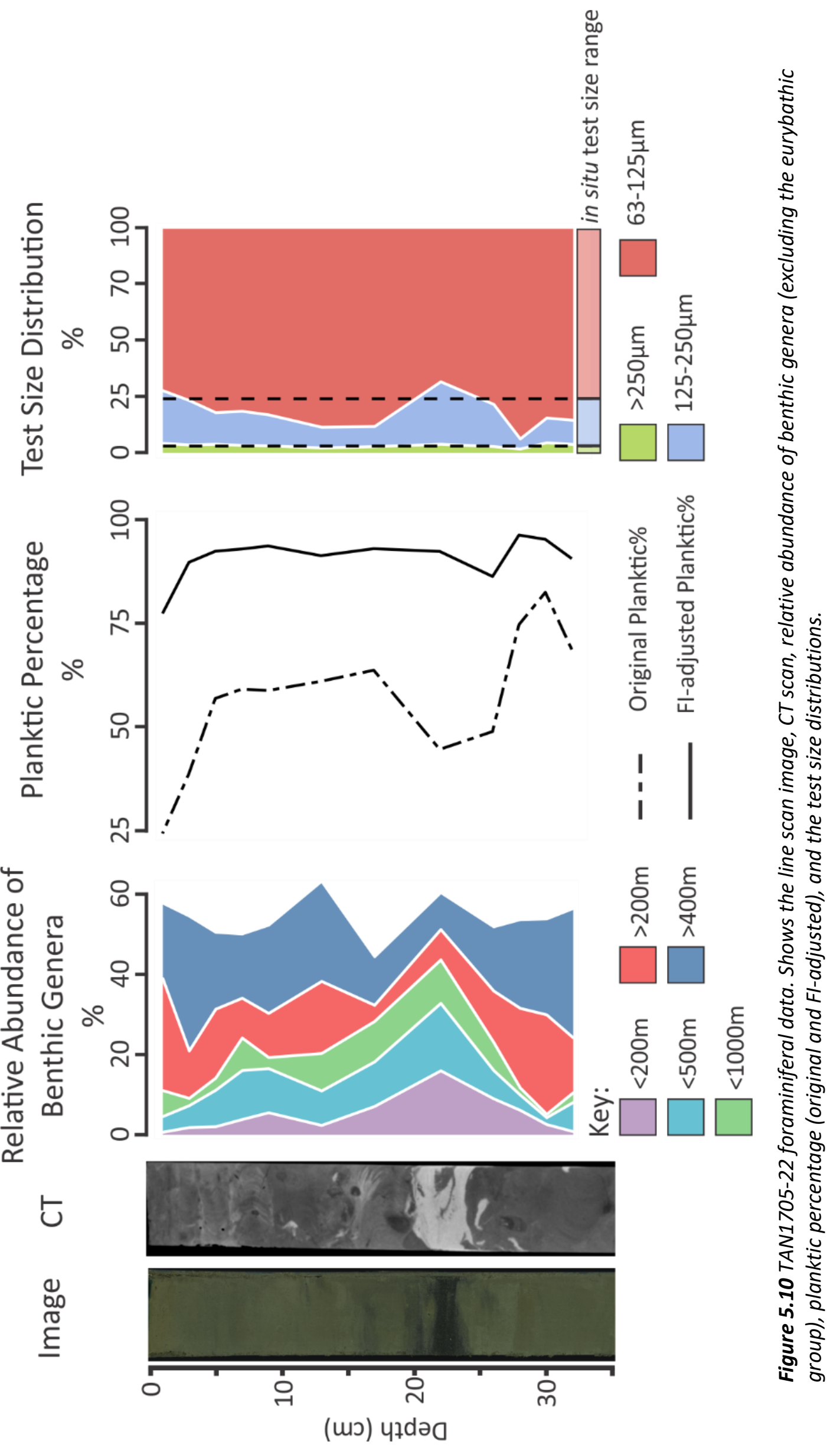




\subsubsection{Canyon-Distal: TAN1705-37}

TAN1705-37 is a $60 \mathrm{~cm}$ core that does not contain the Kaikōura turbidite, located at $1776 \mathrm{~m}$ water depth (Figure 5.11). The core is made up of olive grey (5Y 4/2), very fine sandy mud, with a faint oxic layer in the top $1 \mathrm{~cm}$, bioturbation (index 3 ) and darker colour mottling throughout the core. The density, magnetic susceptibility and grain size are all relatively constant with depth $\left(\sim 1.4 \mathrm{~g} / \mathrm{cm}^{3}, \sim 14 \times 10^{-5} \mathrm{SI}\right.$, and $\left.\sim 8.7 \mu \mathrm{m}\right)$. Sorting peaks at $\sim 6 \mathrm{~cm}$ depth at $25.3 \mu \mathrm{m}$, otherwise ranging between $\sim 12-20 \mu \mathrm{m}$. The percentage of carbonate and organic matter are similarly consistent, with carbonate ranging between $10.7-11.3 \%$, and organic matter ranging between $3.5-4.7 \%$. The $\mathrm{Mn} / \mathrm{Fe}$ ratio is relatively consistent down core.

\section{Foraminiferal Analysis}

The foraminiferal data shows the benthic foraminiferal assemblages dominated by the $>200 \mathrm{~m}$ and $>400 \mathrm{~m}$ groups (Figure 5.12). There are smaller numbers of tests from the $<500 \mathrm{~m}$ and $<1000 \mathrm{~m}$ groups in some of the samples. The fragmentation index is consistent down core, and the original planktic percentage is between $55-73 \%$, where in situ values for this depth are $~ 95 \%$. When adjusted for $\mathrm{Fl}$, the planktic\% rises to $87-$ $92 \%$. The test size distribution is close to in situ in the uppermost samples, while the lower samples show a greater relative abundance of small tests at the expense of medium-sized tests. 

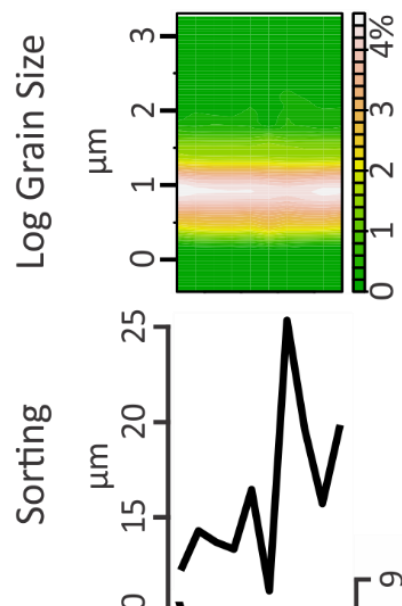

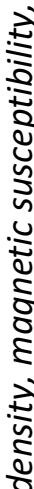

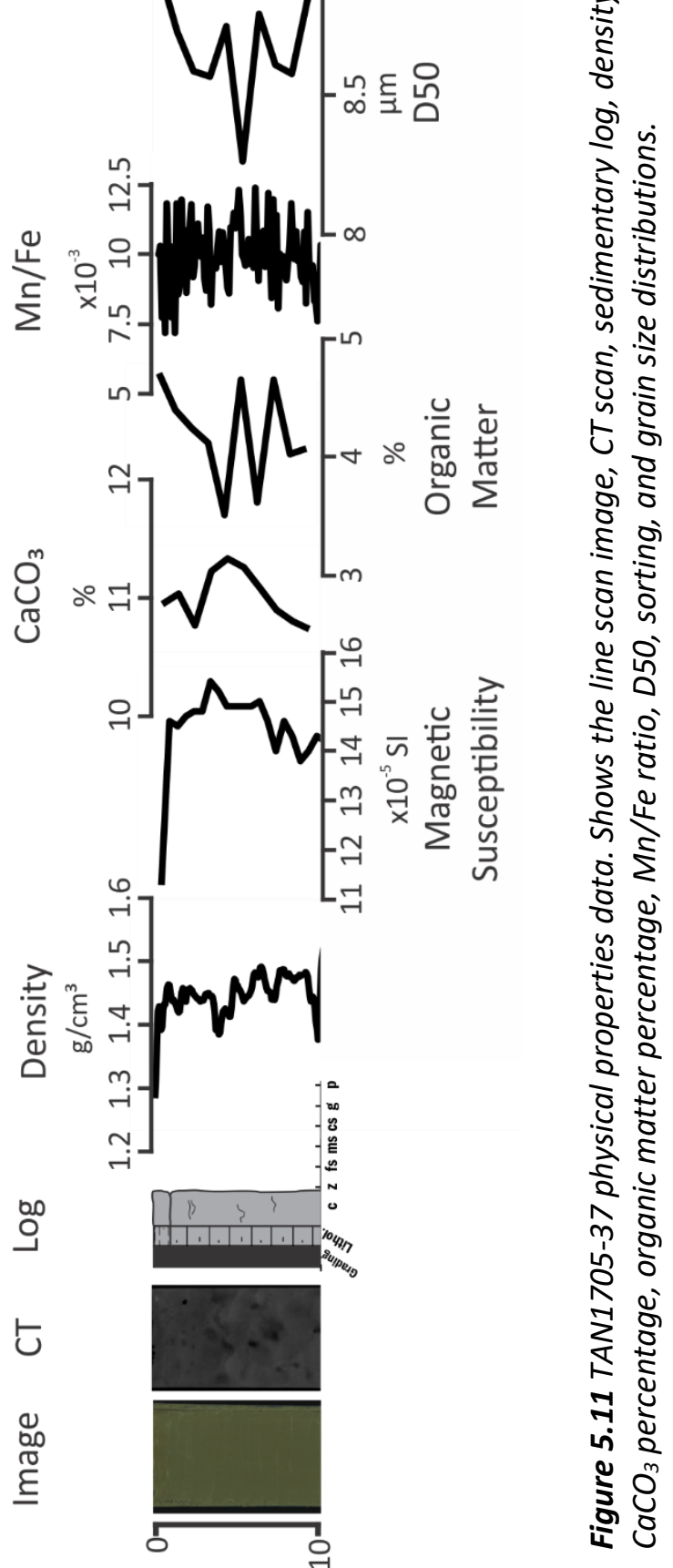

(uכ) प7də0 


\section{5: Results}

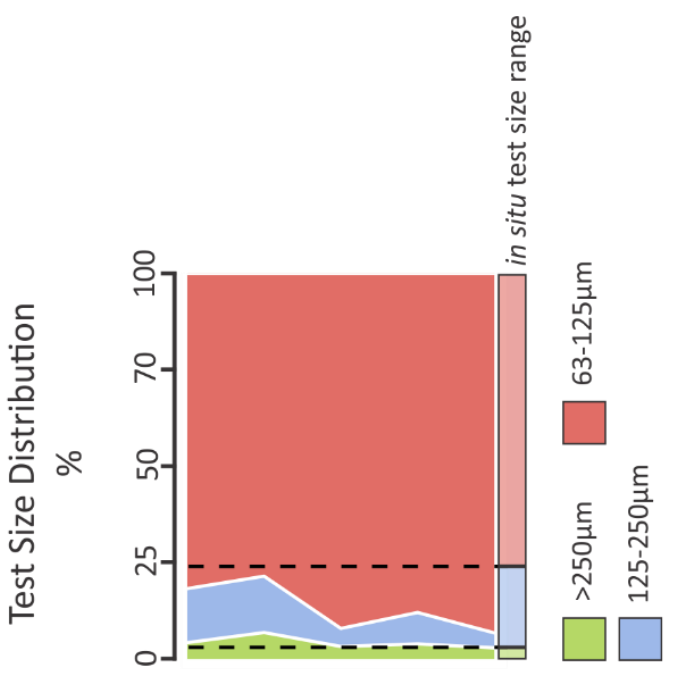

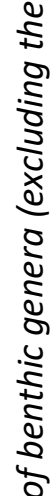

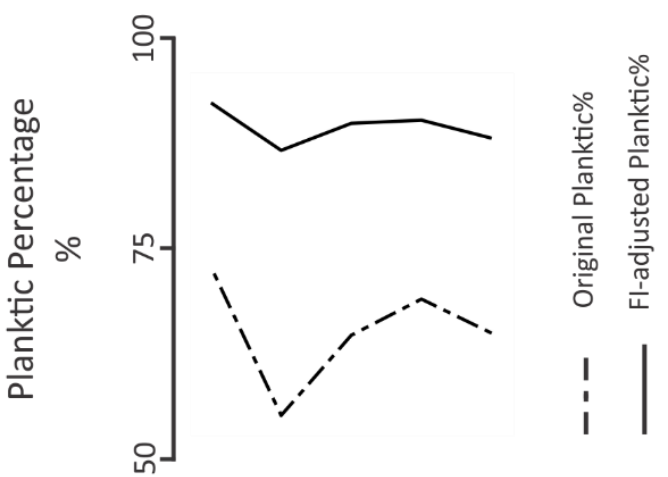

ษ

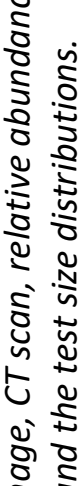

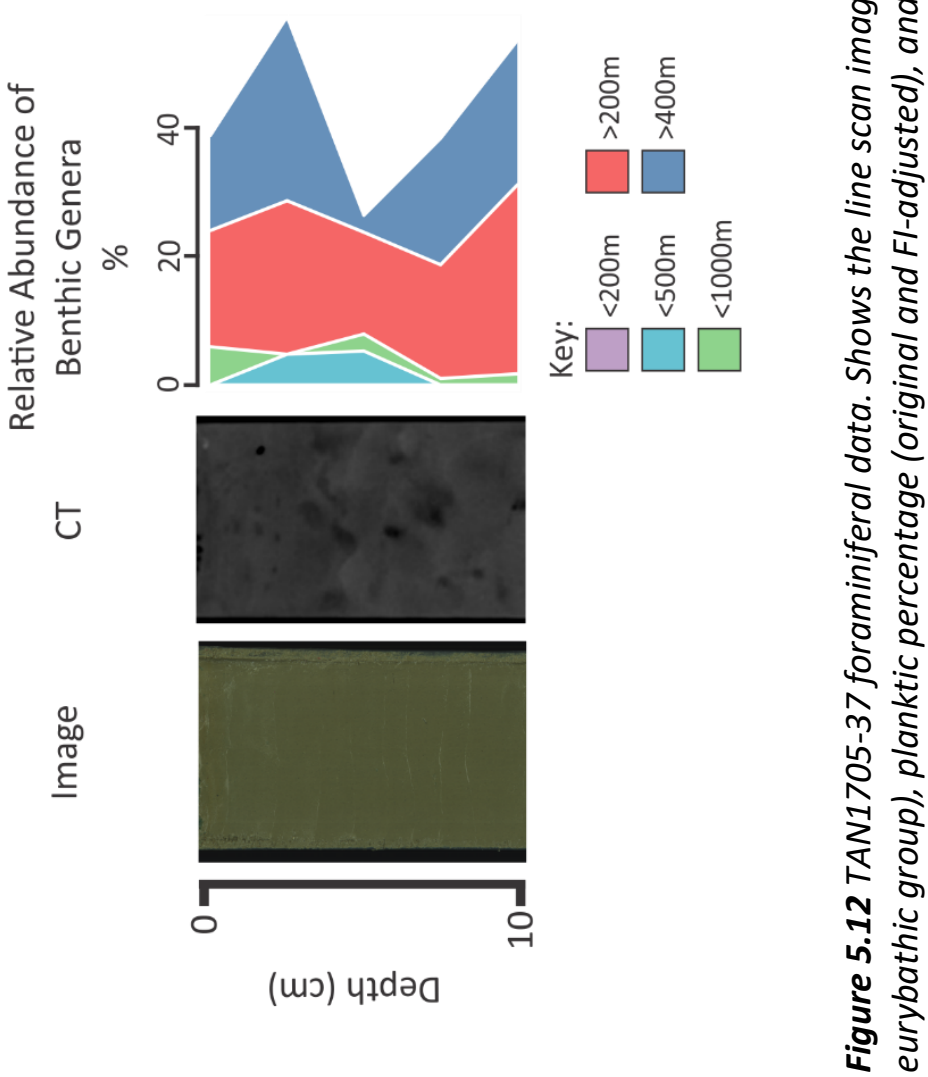




\subsubsection{Canyon-Distal: TAN1705-21}

TAN1705-21 is a $52.3 \mathrm{~cm}$ core with the Kaikōura turbidite in the top $9 \mathrm{~cm}$, located at $2733 \mathrm{~m}$ water depth (Figure 5.13). The base of this turbidite has a sharp planar contact, overlain by olive grey fine sand which grades upward into very fine sandy olive-grey (5Y 4/3) mud, with faint laminations of sand within the turbidite. The turbidite contains no bioturbation (index 1 ). Directly beneath the turbidite is a rustycoloured (5Y 4/2) layer with a gradiational basal contact into olive grey (5Y 4/3) very fine sandy mud, with faint colour mottling and bioturbation (index 3 ).

Within the turbidite, density and magnetic susceptibility are relatively constant ( 1.4 $\mathrm{g} / \mathrm{cm}^{3}$ and $\left.\sim 13 \times 10^{-5} \mathrm{SI}\right)$ with a slight peak $\left(\sim 1.5 \mathrm{~g} / \mathrm{cm}^{3}\right.$ and $\left.\sim 17 \times 10^{-5} \mathrm{SI}\right)$ in the top $2 \mathrm{~cm}$. Similarly, the grain size data shows a peak $(\sim 10 \mu \mathrm{m})$ in the D50 in the top $2 \mathrm{~cm}$, as well as a peak at the base of the turbidite, while sorting is highly variable ( $10-38 \mu \mathrm{m})$. The percentage of carbonate roughly increases with depth through the turbidite, ranging from $\sim 0-7 \%$, while the percentage of organic matter largely varies around $\sim 1-2 \%$, with a spike to $7 \%$ at $4.5 \mathrm{~cm}$ depth.

Beneath the turbidite, density and magnetic susceptibility both increase slightly with depth $\left(\sim 1.3-1.4 \mathrm{~g} / \mathrm{cm}^{3}\right.$ and $\left.\sim 10-14 \times 10^{-5} \mathrm{SI}\right)$. The percentage of carbonate also steadily increases with depth ( 8.5-11\%), while the grain size data shows some variability, with the D50 values ranging between $\sim 9-12 \mu \mathrm{m}$ and sorting decreasing from $\sim 34-12 \mu \mathrm{m}$. The percentage of organic matter is also variable, ranging between $\sim 0-4 \%$. The $\mathrm{Mn} / \mathrm{Fe}$ ratio shows a large spike directly beneath the Kaikōura turbidite.

\section{Foraminiferal Analysis}

The foraminiferal data, shows a distinct difference between turbidite and pre-turbidite sediments (Figure 5.14). Within the turbidite, there are very few specimens of benthic foraminifera, such that only the uppermost sample had only one specimen from the $<200 \mathrm{~m}$ group. Beneath the turbidite, the benthic assemblage is dominated by the $>200 \mathrm{~m}$ and $>400 \mathrm{~m}$ groups, with a small amount (0-2) of specimens from the $<500 \mathrm{~m}$ and $<1000 \mathrm{~m}$ groups. The fragmentation index is higher on average beneath the turbidite, while the original planktic percentage is lower $(70-84 \%)$ than within the turbidite (95-98\%), where in situ planktic\% is $\sim 97 \%$. When adjusted for $\mathrm{FI}$, the pre- 


\section{5: Results}

turbidite samples become 93-97\%, close to in situ. The turbidite values also increase to similar numbers, though this adjustment may be inappropriate due to potential mechanical fragmentation from the turbidity current. The test size distribution within the turbidite shows an increased amount of medium-sized tests while smaller sized tests are decreased, and the lowermost sample had too few tests for analysis. Beneath the turbidite, the majority of samples fall in line with in situ test size distributions, though two samples have an increased number of medium-sized tests at the expense of small tests.

\section{${ }^{210} \mathrm{~Pb}$ Analysis}

The ${ }^{210} \mathrm{~Pb}$ profile (Figure 5.15 ) has significantly lower values within the Kaikōura turbidite, increasing from $140 \mathrm{~Bq} / \mathrm{kg}$ to $630 \mathrm{~Bq} / \mathrm{kg}$ through the turbidite. Beneath the turbidite, ${ }^{210} \mathrm{~Pb}$ activity peaks at $963 \mathrm{~Bq} / \mathrm{kg}$ and decreases consistently down core from that point. Activity dips slightly to $27 \mathrm{~Bq} / \mathrm{kg}$ at $30 \mathrm{~cm}$ depth, corresponding with a shift in the CT imagery to denser sediments. Activity rises slightly to 46 and $51 \mathrm{~Bq} / \mathrm{kg}$ in the samples at 43-44 cm depth, beneath what appears to be a second turbidite. Supported ${ }^{210} \mathrm{~Pb}$ is estimated to be at maximum $\sim 45 \mathrm{~Bq} / \mathrm{kg}$ 

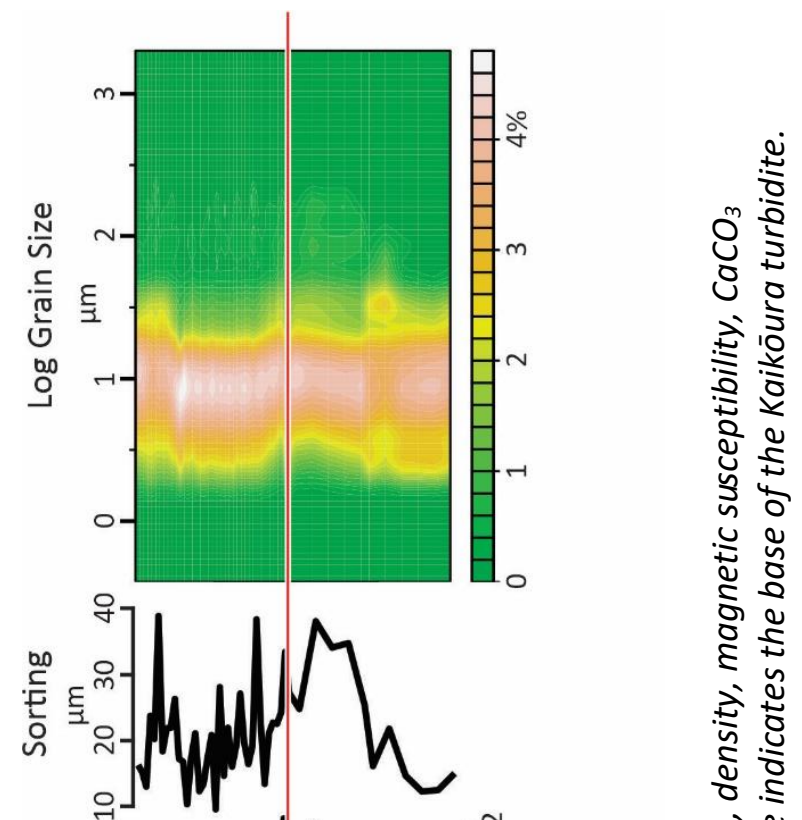

ㅎำ

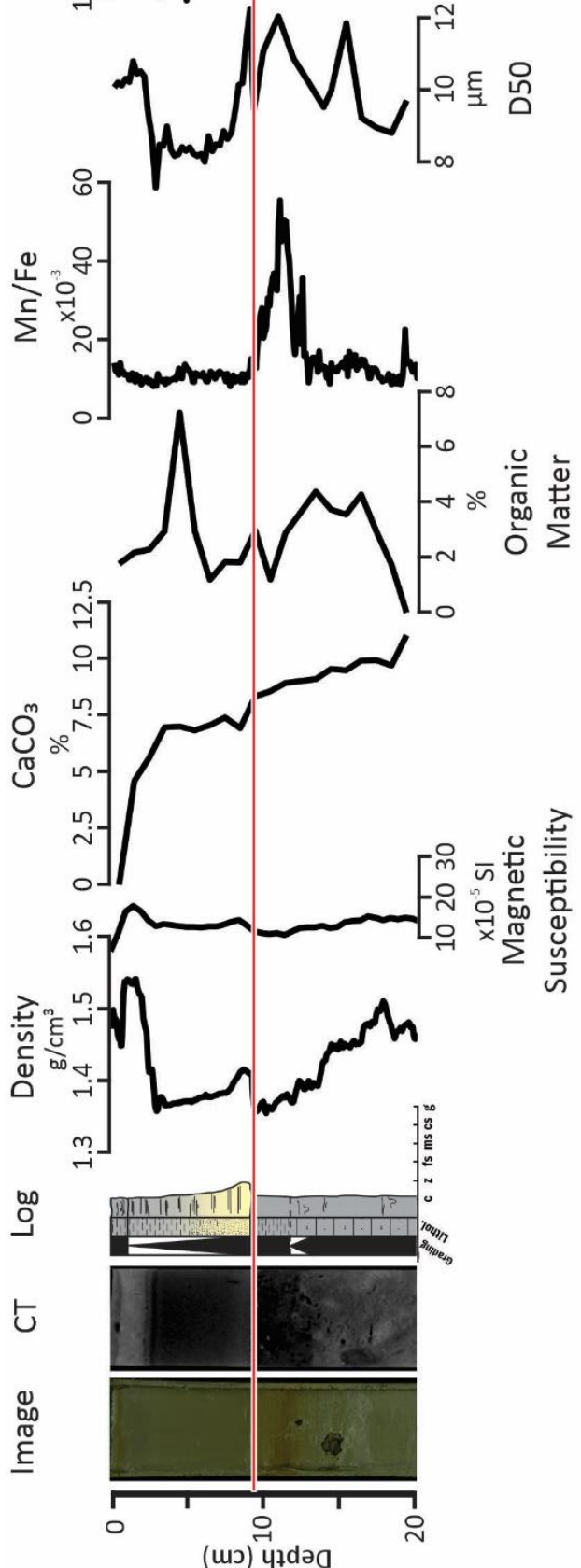

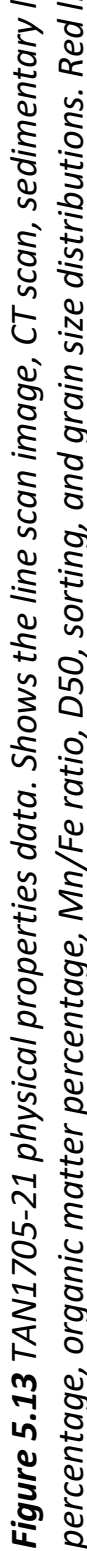

(யว) पฺdว 


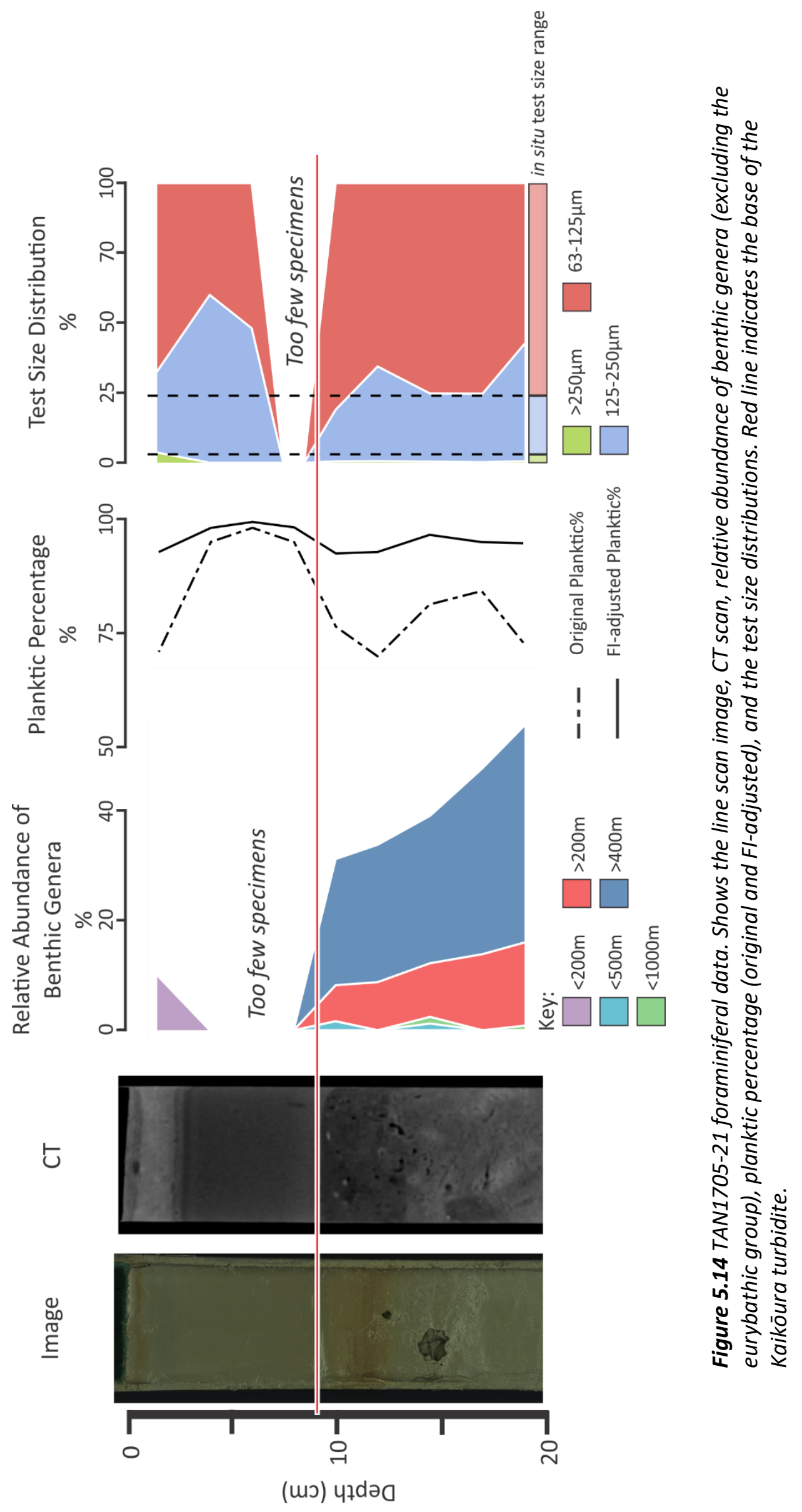




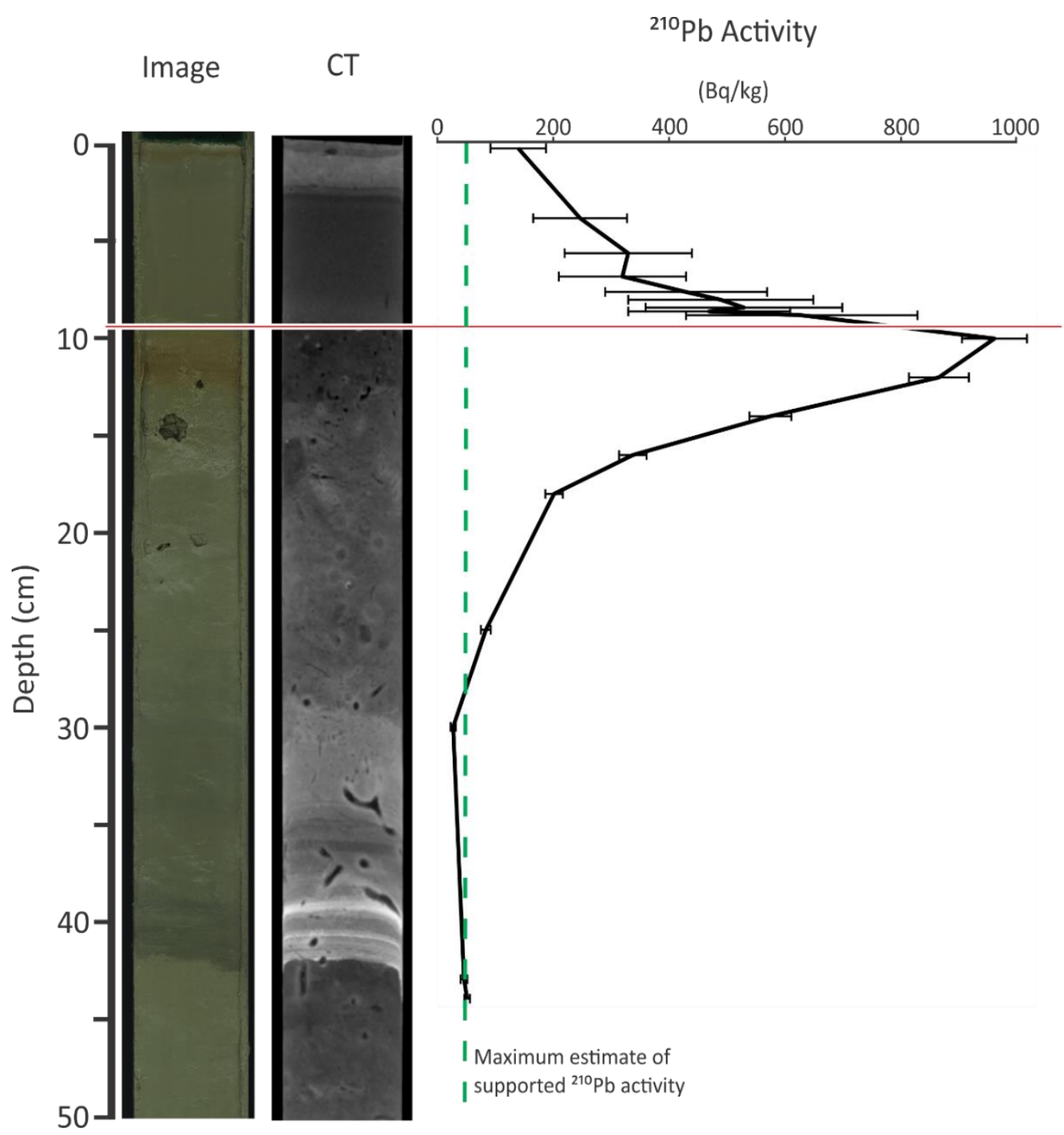

Figure 5.15 TAN1705-21 ${ }^{210} \mathrm{~Pb}$ activity data. Shows the line scan image, CT scan, and ${ }^{210} \mathrm{~Pb}$ activity profile. Green dashed line indicates the maximum estimate of supported ${ }^{210} \mathrm{~Pb}$ activity. Red line indicates the base of the Kaikōura turbidite. 


\section{5: Results}

\subsubsection{Canyon-Distal: TAN1705-18}

TAN1705-18 is a $53 \mathrm{~cm}$ core that does not contain the Kaikōura turbidite, located at $2409 \mathrm{~m}$ water depth (Figure 5.16). This core is characterized by a rusty-coloured (5Y 4/3) fine sandy mud in the top $2.7 \mathrm{~cm}$. Beneath, the rest of the core is an olive $(5 Y 5 / 2)$ very fine sandy mud, with bioturbation (index 3 ) and faint colour mottling close to the rusty layer. The density and magnetic susceptibility are relatively constant down core $\left(\sim 1.4 \mathrm{~g} / \mathrm{cm}^{3}\right.$ and $\left.\sim 12 \times 10^{-5} \mathrm{SI}\right)$, with a slight step up at $\sim 6 \mathrm{~cm}$ depth. D50 and percentage of organic matter both generally decrease with depth ( 8-7 $\mu \mathrm{m}$ and $\sim 3-1 \%)$. Percentage of carbonate, conversely, increases with depth down core ( 11-15\%). Sorting is variable down core $(\sim 13-31 \mu \mathrm{m})$, peaking at around $6 \mathrm{~cm}$. The $\mathrm{Mn} / \mathrm{Fe}$ ratio shows a large peak at the top of the core.

\section{Foraminiferal Analysis}

The foraminiferal data shows the benthic foraminiferal assemblage is dominated by the $>400 \mathrm{~m}$ group, with smaller numbers from the $>200 \mathrm{~m}$ and $<1000 \mathrm{~m}$ groups in each sample (Figure 5.17). The uppermost and lowermost samples both contain a small number of specimens from the $<200 \mathrm{~m}$ group. The fragmentation index is relatively high (11-17\%) for the depth of this core. The original planktic percentages are $32-88 \%$, where in situ accumulation is $~ 95 \%$. When adjusted for $\mathrm{Fl}$, the planktic\% becomes $67-$ $95 \%$. The test size distribution shows a greater percentage of small tests, and fewer medium-sized and large tests when compared to in situ distributions.

\section{${ }^{210} \mathrm{~Pb}$ Analysis}

The ${ }^{210} \mathrm{~Pb}$ activity profile (Figure 5.18 ) decreases from $916 \mathrm{~Bq} / \mathrm{kg}$ with depth through the core, plateauing at $\sim 50 \mathrm{~Bq} / \mathrm{kg}$ at $\sim 20 \mathrm{~cm}$ depth through the bottom three samples. Supported ${ }^{210} \mathrm{~Pb}$ is estimated to be at maximum $\sim 50 \mathrm{~Bq} / \mathrm{kg}$. 


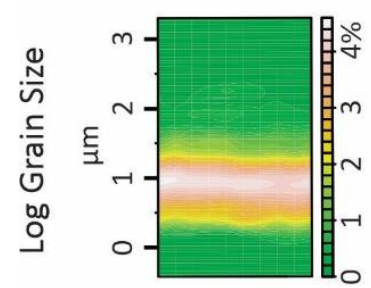

$\bigcup_{0}^{m}$
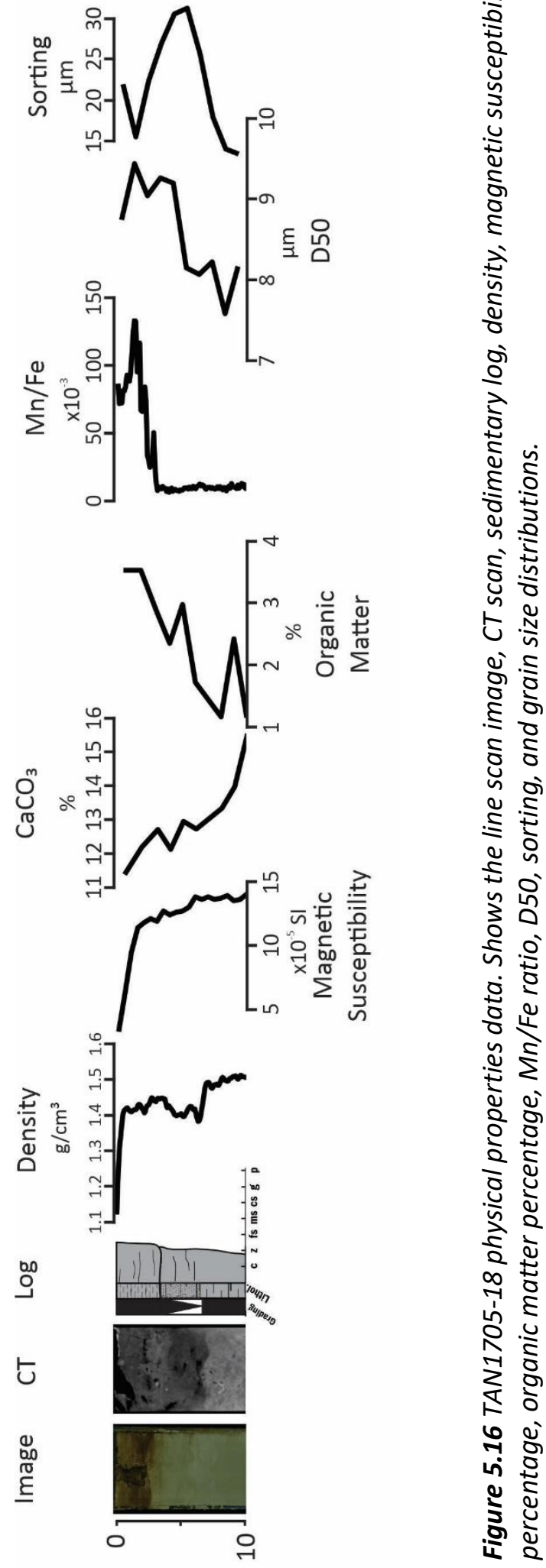

(uว) प7də0 


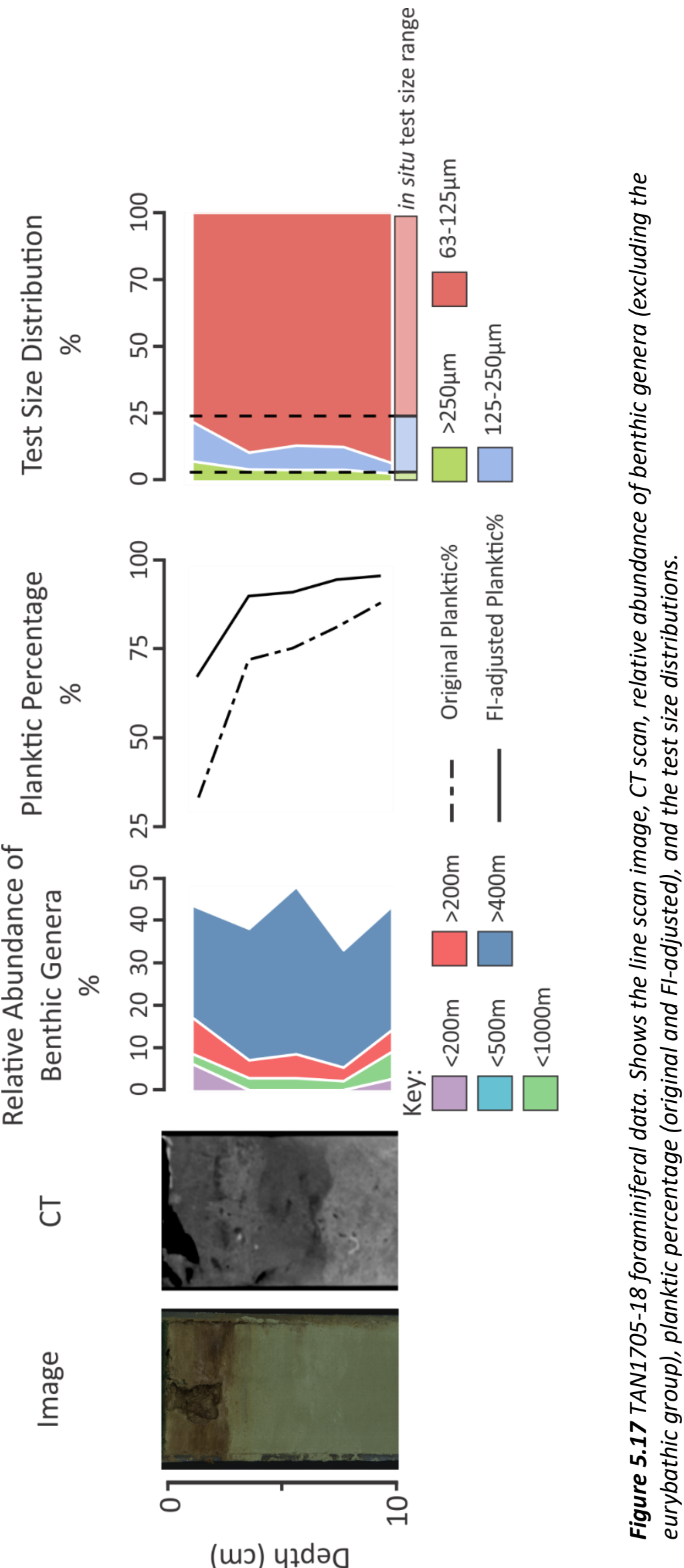




\section{${ }^{210} \mathrm{~Pb}$ Activity}
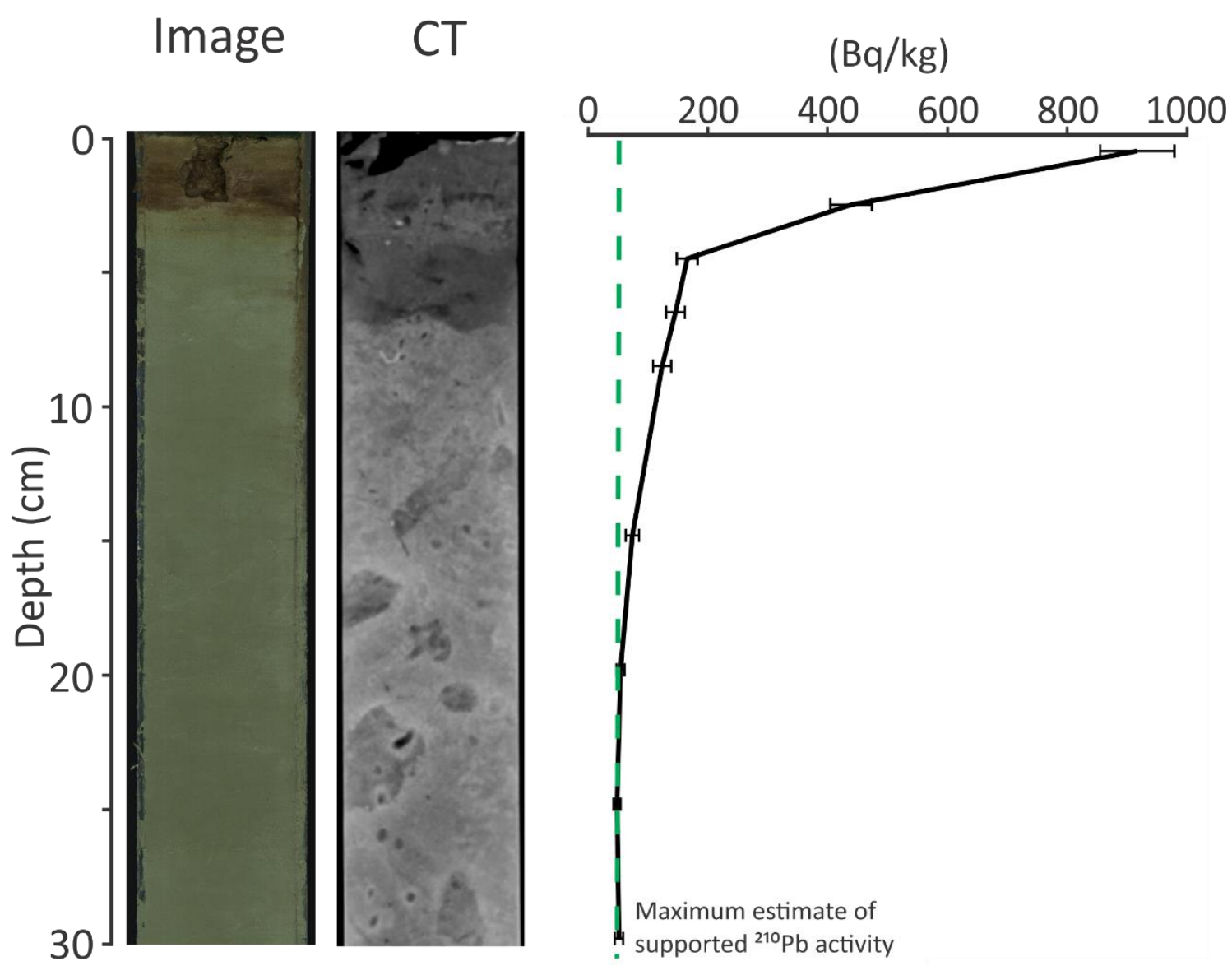

Figure 5.18 TAN1705-18 ${ }^{210} \mathrm{~Pb}$ activity data. Shows the line scan image, CT scan, and ${ }^{210} \mathrm{~Pb}$ activity profile. Green dashed line indicates the maximum estimate of supported ${ }^{210} \mathrm{~Pb}$ activity. 


\section{5: Results}

\subsubsection{Lithofacies}

The sedimentology described within these cores can be broken up into eight main lithofacies, labelled A-H (Table 5.1). Lithofacies A-C describe the Kaikōura turbidite sediments, from the coarser-grained basal laminations $(A)$, to laminated and normallygraded muds (B) and massive and normally-graded muds (C). The Kaikōura turbidite sediments are characterized by a lack of bioturbation (index 1), spikes in grain size, density, and magnetic susceptibility associated with planar laminae, slightly lower percentages of $\mathrm{CaCO}_{3}$, an abundance of shallow-restricted benthic foraminifera and foraminiferal test size distributions with overabundances of small or medium sized tests. The ${ }^{210} \mathrm{~Pb}$ activity profiles (where present) are highly variable through these lithofacies, indicating that these sediments are not the result of in situ accumulation.

Lithofacies $D$ is characterized by bioturbation ichnofabric index 3 , which equates to 10 $40 \%$ visible bioturbation, relatively constant density, magnetic susceptibility, and grain size values, and slightly higher percentages of $\mathrm{CaCO}_{3}$. There is a much greater proportion of benthic foraminifera from the $>200 \mathrm{~m}$ and $>400 \mathrm{~m}$ genus groups, consistent with core site depths, with very few shallow-restricted specimens. Test size distributions are variable, with a slight overabundance of small tests, though many samples plot within error of in situ analogues. The ${ }^{210} \mathrm{~Pb}$ activity profiles (where present) follow a consistent decay profile.

Lithofacies E-H are characterized by heavy bioturbation (index 4), but otherwise have similar characteristics to those of the Kaikōura turbidite, with an abundance of shallow-restricted benthic foraminifera, and spikes in grain size, density, and magnetic susceptibility associated with laminations within the sediment. These lithofacies range from dark grey, coarse sand (F) to $\mathrm{mm}$-scale laminated fine sands (G), planar laminated or massive normally-graded muds $(H)$ or massive mud $(E)$. 
Table 5.1 Summary of lithofacies present in the cores studied

\begin{tabular}{|c|c|c|c|}
\hline Lithofacies & Description & Interpretation & Examples \\
\hline$A$ & $\begin{array}{l}\text { Planar mm-scale laminations of dark } \\
\text { grey fine sand and very fine sandy silt. } \\
\text { Found at the base of the Kaikōura } \\
\text { turbidite. May show a spike in } \\
\% \mathrm{CaCO}_{3} \text {. Abundant shallow-restricted } \\
\text { benthic foraminifera, and an } \\
\text { overabundance of small tests relative } \\
\text { to other test sizes. }{ }^{210} \mathrm{~Pb} \text { profiles } \\
\text { (where present) do not follow a } \\
\text { consistent decay profile. }\end{array}$ & $\begin{array}{l}\text { Formed by the reworking } \\
\text { of very fine sand and } \\
\text { coarse grains in the } \\
\text { bedload of a low-density } \\
\text { turbidity current. } T_{D} \\
\text { facies* }\end{array}$ & $\begin{array}{l}\text { TAN1705-26 } \\
(\sim 18 \mathrm{~cm}) \\
\text { TAN1705-33 } \\
(\sim 4.5 \mathrm{~cm})\end{array}$ \\
\hline$B$ & $\begin{array}{l}\text { Planar laminated and normally graded } \\
\text { olive grey mud. Abundant shallow- } \\
\text { restricted benthic foraminifera, and } \\
\text { variable test size distributions, with } \\
\text { overabundances of medium and small } \\
\text { tests both observed. May contain } \\
\text { intervals with very few specimens. } \\
{ }^{210} \mathrm{~Pb} \text { profiles (where present) do not } \\
\text { follow a consistent decay profile. }\end{array}$ & $\begin{array}{l}\text { Formed by the settling of } \\
\text { fine-grained sediment } \\
\text { from a low-density } \\
\text { turbidity current. } T_{\mathrm{E}-1} \\
\text { facies* }\end{array}$ & $\begin{array}{l}\text { TAN1705-26 } \\
(\sim 1-6 \mathrm{~cm}) \\
\text { TAN1705-21 } \\
(\sim 1-9 \mathrm{~cm}) \\
\text { TAN1705-24 } \\
(\sim 0-6 \mathrm{~cm}) \\
\text { TAN1705-33 } \\
(\sim 0-4 \mathrm{~cm})\end{array}$ \\
\hline$C$ & $\begin{array}{l}\text { Massive and normally graded olive } \\
\text { grey mud. Abundant shallow- } \\
\text { restricted benthic foraminifera, and } \\
\text { variable test size distributions, with } \\
\text { overabundances of medium and small } \\
\text { tests both observed. May contain } \\
\text { intervals with very few specimens. } \\
{ }^{210} \mathrm{~Pb} \text { profiles (where present) do not } \\
\text { follow a consistent decay profile. }\end{array}$ & $\begin{array}{l}\text { Formed by the settling of } \\
\text { fine-grained sediment } \\
\text { from a low-density } \\
\text { turbidity current. } T_{E-2} \\
\text { facies* }\end{array}$ & $\begin{array}{l}\text { TAN1705-21 } \\
(0-1 \mathrm{~cm}) \\
\text { TAN1705-26 } \\
(0-1 \mathrm{~cm})\end{array}$ \\
\hline$D$ & $\begin{array}{l}\text { Massive olive grey fine/very fine } \\
\text { sandy mud. Faint colour mottling in } \\
\text { places, bioturbation (index } 3 \text { ), and } \\
\text { some cores have a rusty-coloured } \\
\text { layer at the top of the unit. Higher } \\
\% \mathrm{CaCO}_{3} \text { values on average than in } \\
\text { Kaikōura turbidite facies. Benthic } \\
\text { foraminifera are predominantly from } \\
\text { the }>200 \mathrm{~m},>400 \mathrm{~m} \text { and eurybathic } \\
\text { groups, with sparse numbers of } \\
\text { shallow-restricted tests. Variable test } \\
\text { size distributions, often with a slight } \\
\text { overabundance of small tests, though } \\
\text { many samples plot within error of in } \\
\text { situ analogues. }{ }^{210} \mathrm{~Pb} \text { profiles (where } \\
\text { present) follow a consistent decay } \\
\text { profile. }\end{array}$ & $\begin{array}{l}\text { Formed by the gradual } \\
\text { accumulation of sediment } \\
\text { from hemipelagic rain } \\
\text { and a small component of } \\
\text { terrigenous input, that } \\
\text { has been lightly } \\
\text { bioturbated with shallow- } \\
\text { derived material } \\
\text { introduced. }\end{array}$ & $\begin{array}{l}\text { TAN1705-18 } \\
(0-10.7 \mathrm{~cm}) \\
\text { TAN1705-37 } \\
(0-10 \mathrm{~cm}) \\
\text { TAN1705-21 } \\
(9-20 \mathrm{~cm}) \\
\text { TAN1705-26 } \\
(18-28 \mathrm{~cm}) \\
\text { TAN1705-24 } \\
(6-16 \mathrm{~cm})\end{array}$ \\
\hline
\end{tabular}




\begin{tabular}{|c|c|c|c|}
\hline$E$ & $\begin{array}{l}\text { Massive olive grey very fine sandy } \\
\text { mud, dark grey colour mottling, heavy } \\
\text { bioturbation (index 4) and organic- } \\
\text { rich mud blebs. Abundant shallow- } \\
\text { restricted benthic foraminifera, and } \\
\text { an overabundance of small tests } \\
\text { relative to other test sizes. }\end{array}$ & $\begin{array}{l}\text { Formed by the } \\
\text { bioturbation of turbidites } \\
\text { and surrounding } \\
\text { sediments to the point of } \\
\text { no recognition of internal } \\
\text { turbidite facies (e.g. } \\
\text { lithofacies A-C). }\end{array}$ & $\begin{array}{l}\text { TAN1705-33 } \\
(4.5-16.5 \mathrm{~cm})\end{array}$ \\
\hline$F$ & $\begin{array}{l}\text { Dark grey planar laminated coarse- } \\
\text { medium sand. Heavily bioturbated } \\
\text { (index } 4 \text { ). Marked by a peak in grain } \\
\text { size, } \% \mathrm{CaCO}_{3} \text {, and a trough in } \\
\text { magnetic susceptibility. Abundant } \\
\text { shallow-restricted benthic } \\
\text { foraminifera, and an overabundance } \\
\text { of medium tests relative to other test } \\
\text { sizes. }\end{array}$ & $\begin{array}{l}\text { Formed by the } \\
\text { bioturbation of coarse- } \\
\text { medium sand grains as } \\
\text { bedload beneath a } \\
\text { turbidity current, which } \\
\text { has subsequently been } \\
\text { reworked by biological } \\
\text { processes. } T_{\mathrm{B}-1} / \mathrm{T}_{\mathrm{C}} \text { facies* }\end{array}$ & $\begin{array}{l}\text { TAN1705-22 } \\
(\sim 22 \mathrm{~cm})\end{array}$ \\
\hline $\mathrm{G}$ & $\begin{array}{l}\text { Olive grey mm-scale laminations of } \\
\text { fine sand. Heavily bioturbated (index } \\
\text { 4). Abundant shallow-restricted } \\
\text { benthic foraminifera, and an } \\
\text { overabundance of small tests relative } \\
\text { to other test sizes }\end{array}$ & $\begin{array}{l}\text { Formed by the } \\
\text { bioturbation of very fine } \\
\text { sand and coarse grains as } \\
\text { bedload beneath a low- } \\
\text { density turbidity current, } \\
\text { which has subsequently } \\
\text { been reworked. } T_{D} \text { facies* }\end{array}$ & $\begin{array}{l}\text { TAN1705-22 } \\
(\sim 15-20 \mathrm{~cm})\end{array}$ \\
\hline $\mathrm{H}$ & $\begin{array}{l}\text { Planar laminated or massive and } \\
\text { normally graded olive grey mud. } \\
\text { Heavily bioturbated (index 4). } \\
\text { Abundant shallow-restricted benthic } \\
\text { foraminifera, and an overabundance } \\
\text { of small tests relative to other test } \\
\text { sizes. }\end{array}$ & $\begin{array}{l}\text { Formed by settling from a } \\
\text { low-density turbidity } \\
\text { current. } T_{E-1} / T_{E-2} \text { facies* }\end{array}$ & $\begin{array}{l}\text { TAN1705-22 } \\
(\sim 2-15 \mathrm{~cm})\end{array}$ \\
\hline
\end{tabular}

* Lithofacies classification as per Talling et al. 2012

Based on the interpretations of the data, there are three main lithofacies associations that can be identified within the cores studied: the Kaikōura turbidite (lithofacies A-C), background sedimentation (lithofacies $\mathrm{D}$ ), and other turbidites that predate the Kaikōura event (lithofacies E-H) (Table 5.1). The Kaikōura turbidite is easily identified as a surficial turbidite that has not been bioturbated, with disrupted profiles of ${ }^{210} \mathrm{~Pb}$ activity where that data is present. Similarly, pre-Kaikōura turbidites can have recognisable turbidite lithofacies (lithofacies $\mathrm{F}-\mathrm{H}$ ), but these have been altered by bioturbation since their deposition. Though there is no ${ }^{210} \mathrm{~Pb}$ data from cores containing these lithofacies, based on their condition compared to the lithofacies associated with the 2016 event and their stratigraphic position, it can be inferred that these turbidites predate the 2016 event. 
The ${ }^{210} \mathrm{~Pb}$ activity profiles show that supported ${ }^{210} \mathrm{~Pb}$ along the margin is likely to be $\sim 50 \mathrm{~Bq} / \mathrm{kg}$, which is reached in three of the four cores examined. Through Lithofacies $\mathrm{D},{ }^{210} \mathrm{~Pb}$ decreases monotonically until it reaches this value, indicating that these sediments have accumulated gradually in the background.

Typically, the sediment that accumulates in the background would be hemipelagite, which accumulates on continental margins slowly, made up of a mixture of indigenous biogenic material and silt/clay sized terrigenous detritus (Stow \& Piper, 1984). However, lithofacies $D$ has a number of anomalies that preclude it from being defined strictly as hemipelagite. The foraminiferal data show variable test size distributions, with many samples showing an overabundance of small tests relative to in situ accumulation, as well as a small, non-indigenous component of shallow-restricted benthic foraminifera. However, when compared to the turbidite lithofacies described in these cores, it is clear that lithofacies $D$ was not deposited by the same processes, as turbidite lithofacies contain a much greater abundance of shallow-restricted benthic foraminifera, and the ${ }^{210} \mathrm{~Pb}$ activity profiles within turbidites are disrupted. Thus, based on the ${ }^{210} \mathrm{~Pb}$ activity profile being consistent with gradual deposition and the clear differences between the foraminiferal assemblages of turbidite lithofacies and lithofacies D, the latter is defined as background sedimentation. The specific processes driving this background sedimentation will be explored in chapter 6.2.

\subsection{Quantification of turbidite and pre-turbidite sediments}

The destructive data, such as the grain size and percentage of carbonate and organic matter can show slight differences between turbidites (lithofacies A-C, E-H) and background sedimentation (lithofacies $\mathrm{D}$ ). XRF-derived geochemistry can provide geochemical proxies for this data, at higher resolution than can be feasibly sampled by hand. To validate the use of these proxies, they were compared to the physical properties data to establish that there is a correlation between proxy and direct measurement along the Hikurangi margin. This was done in two ways: visually assessing the down core profiles of the measured and proxy data, and using multidimensional scaling to visualise the similarities and confirm the significance of correlations between the two sets of data. 


\subsubsection{Visual Comparison}

\section{Carbonate Content}

The lab-measured percentage of carbonate was compared with the $\mathrm{Ca} / \mathrm{Sr}$ and $\mathrm{Ca} / \mathrm{Ti}$ ratios. Within turbidite lithofacies (lithofacies $A-C, E-H)$, carbonate content is generally lower than within background lithofacies (lithofacies D), which averages $\sim 9 \%$, while turbidite lithofacies (A-C, E, G, and H) average 6\%. For example, in TAN1705-21 (Figure 5.19), lower percentages of $\mathrm{CaCO}_{3}$ can be seen within the Kaikōura turbidite, with an increase in lithofacies $D$ below it. Lithofacies $F$ has a slightly higher value (11\%), however, this is based on a single measurement, as lithofacies $F$ is only observed in TAN1705-22 at $\sim 22 \mathrm{~cm}$.

The $\mathrm{Ca} / \mathrm{Sr}$ ratios average at $\sim 1.6$ within lithofacies $\mathrm{A}-\mathrm{C}$, and has slightly higher values in reworked turbidite lithofacies ( 1.9), while background lithofacies (D) are higher at 2.2. Similarly, the $\mathrm{Ca} / \mathrm{Ti}$ ratios are lower on average in the Kaikōura turbidite and reworked turbidite lithofacies at 3.6 and 4.5 respectively, while background lithofacies are higher at 5.4 on average. In TAN1705-21, the lower $\mathrm{Ca} / \mathrm{Sr}$ and $\mathrm{Ca} / \mathrm{Ti}$ values within the Kaikōura turbidite can be observed, and it can be seen that these ratios follow the same general trend as the percentage of $\mathrm{CaCO}_{3}$ (Figure 5.19). Plots for all other cores are available in Appendix $C$, and averaged values for each individual lithofacies over all cores are presented in Appendix D.

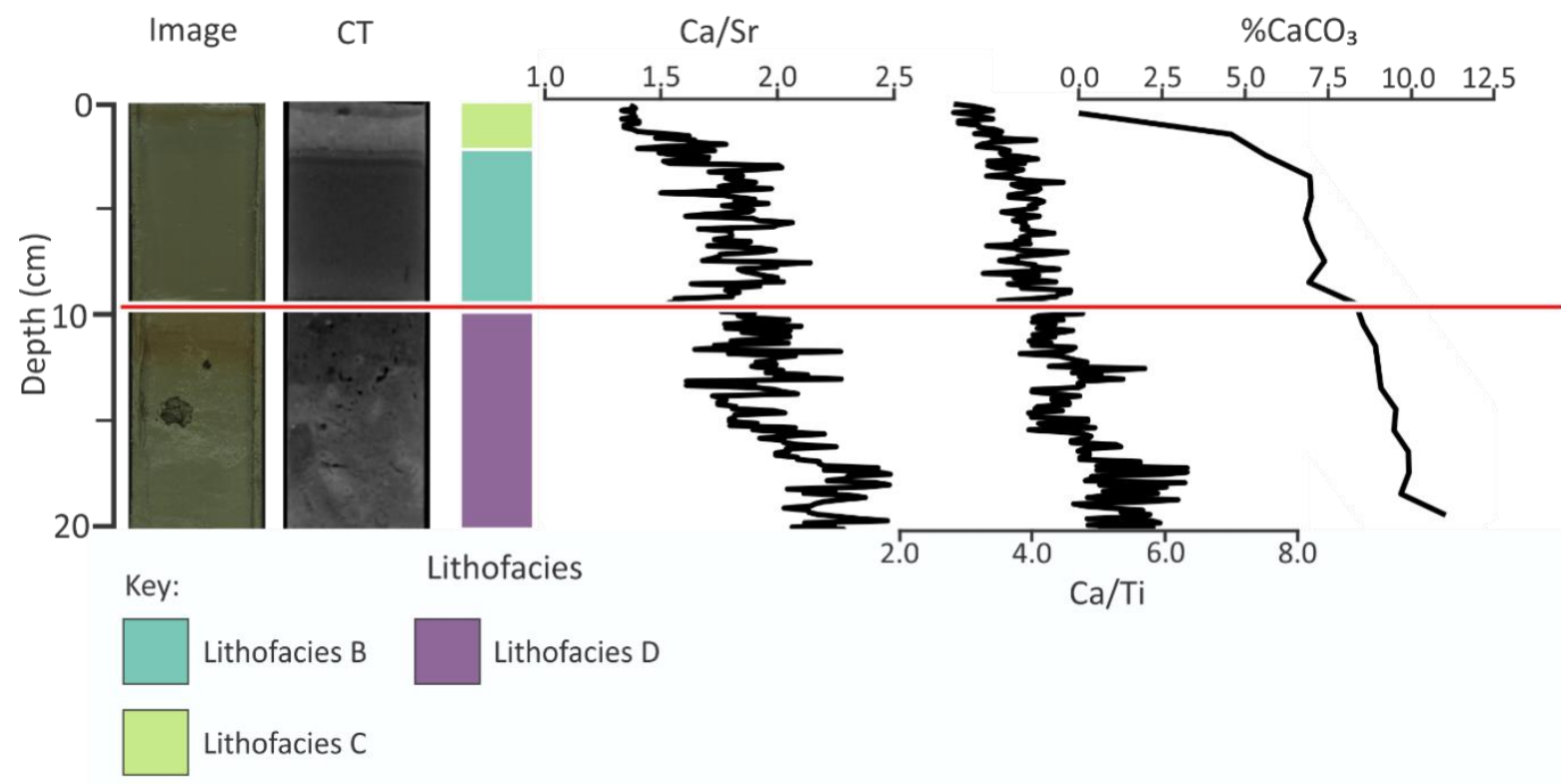

Figure 5.19 $\mathrm{TAN}_{1705-21} \% \mathrm{CaCO}_{3}$ and proxy data. Shows the line scan image, CT scan, lithofacies, $\mathrm{Ca} / \mathrm{Sr}$ ratio, $\mathrm{Ca} / \mathrm{Ti}$ ratio, and $\% \mathrm{CaCO}_{3}$. 


\section{Organic Matter}

The lab-measured percentage of organic matter was compared to inc/coh. The percentage of organic matter is higher on average within lithofacies $D$, at $\sim 3 \%$, while in turbidite lithofacies $(\mathrm{A}-\mathrm{C}, \mathrm{E}-\mathrm{H})$, it is lower, at $\sim 2 \%$. The inc/coh ratio shows more subtle variation, but does show the same trend, with higher values in lithofacies $D(\sim 3.8)$ and

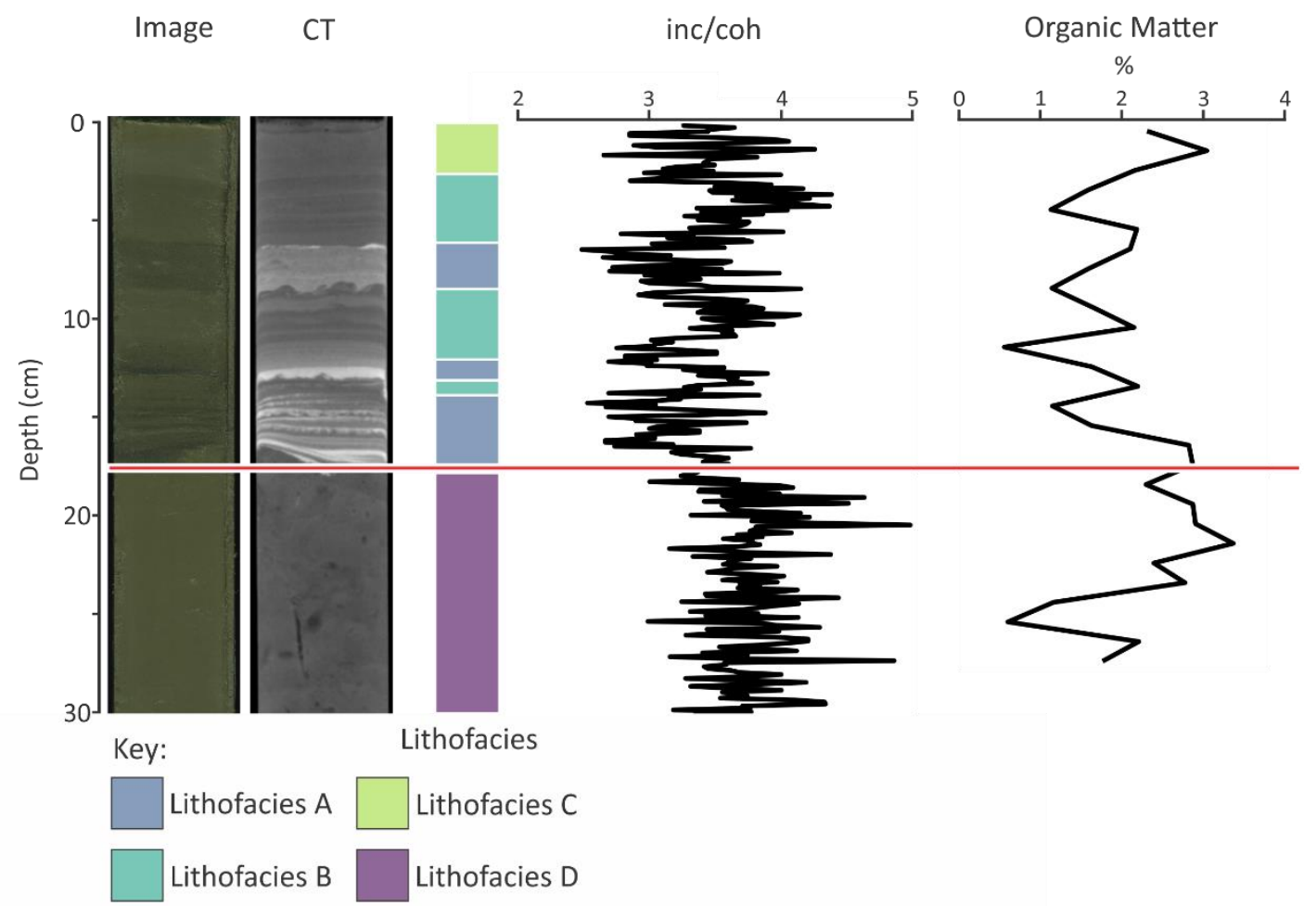

Figure 5.20 TAN1705-26\% Organic matter and proxy data. Shows the line scan image, CT scan, lithofacies, inc/coh ratio and \% Organic matter.

lower values in turbidite lithofacies ( 3.4). For example, in TAN1705-26 (Figure 5.20), inc/coh and percentage of organic matter follow similar trends, with increased values in lithofacies D when compared to lithofacies A-C (Figure 5.20).

\section{Grain Size}

The lab-measured grain size was plotted as both D50 and a heat map of the full grain size distribution, and compared to density, magnetic susceptibility, and Zr/Rb. D50 is on average higher within turbidite lithofacies than in lithofacies $D$, though the difference is subtle when compared to turbidite tail lithofacies (B/C). Density follows similar trends, with slightly higher values on average in turbidite tail lithofacies compared to lithofacies $D\left(1.46 \mathrm{~g} / \mathrm{cm}^{3}\right.$ vs. $\left.1.43 \mathrm{~g} / \mathrm{cm}^{3}\right)$, but greater differences in 


\section{5: Results}

lithofacies $A$ and all reworked turbidite lithofacies. Magnetic susceptibility also follows these trends, except for the anticorrelation with grain size seen in lithofacies F. Similarly, $\mathrm{Zr} / \mathrm{Rb}$ follows these trends, sitting at $\sim 0.93$ on average within lithofacies $\mathrm{D}$ and $\sim 1$ in lithofacies $B, C, E, G$, and $H$, and at $\sim 1.5$ in lithofacies $A$ and $F$. The grain size data (both D50 and heat map) show peaks corresponding to these trends, and likewise, density, magnetic susceptibility, and $\mathrm{Zr} / \mathrm{Rb}$ too show peaks in the same areas. These trends are seen in TAN1705-26, showing distinct peaks relating to the change into lithofacies A through the three "pulses" of the turbidite (Figure 5.21).

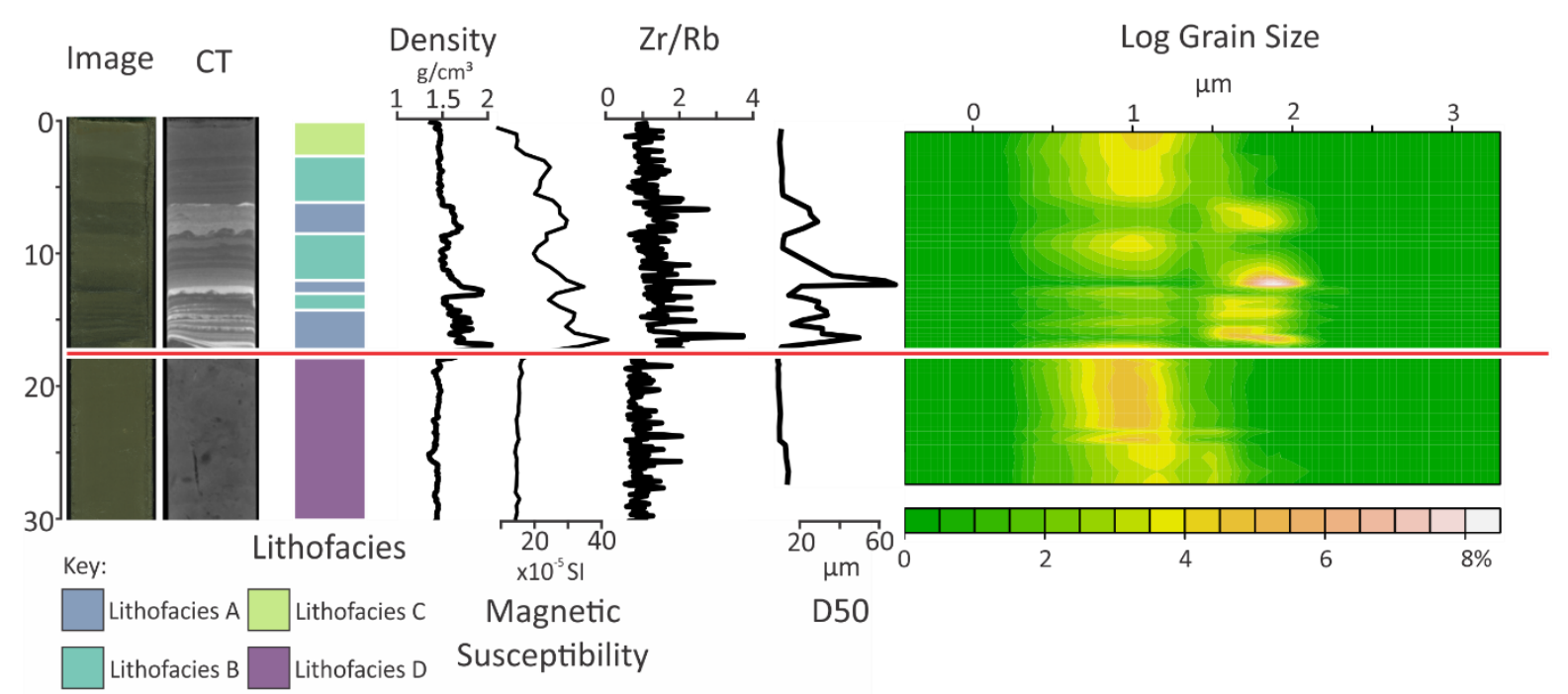

Figure 5.21 TAN1705-26 Grain size and proxy data. Shows the line scan image, CT scan, lithofacies, density, magnetic susceptibility, $\mathrm{Zr} / \mathrm{Rb}$ ratio, D50, and grain size distribution heat map.

\subsubsection{Multi-Dimensional Scaling (MDS)}

Visual assessment of the correlation between data is incredibly subjective. Thus, to quantitatively assess the relationship between the geochemical proxy data and the destructive data, nMDS was used (Figure 5.22). Every sample studied was plotted, and shows that the majority of samples plot close together, with the exception of samples from TAN1705-22, in particular the $21-23 \mathrm{~cm}$ sample interval, which plots in the bottom left of the figure. This sample corresponds to lithofacies F, which is unobserved in any other core. The statistical significance of the difference between lithofacies was tested using the "adonis" function, which gave a p-value of 0.001 , indicating that the differences between at least one of the lithofacies were statistically significant. 


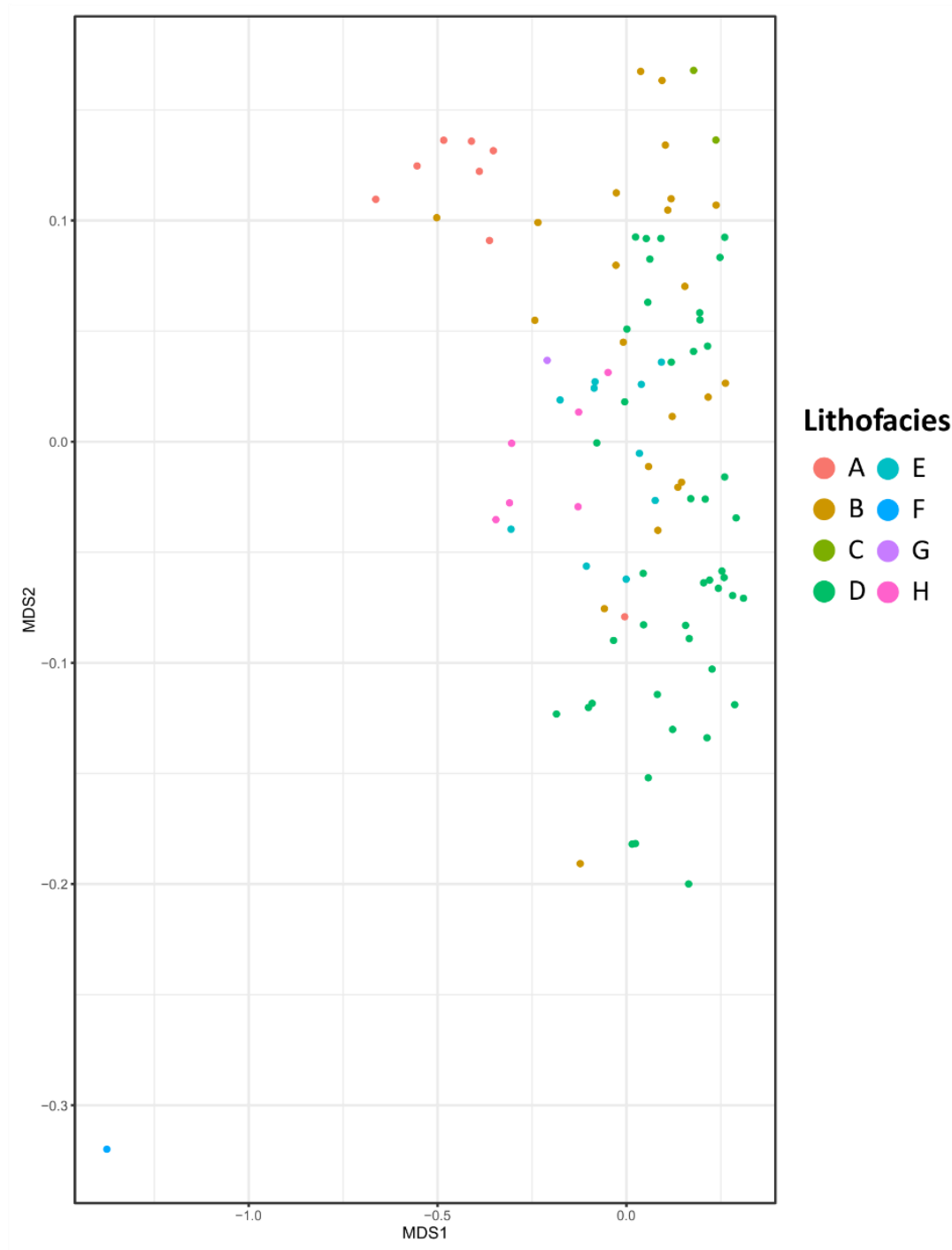

Figure 5.22 nMDS plot. Shows the correlation between each sample of each lithofacies calculated using density, magnetic susceptibility, $\mathrm{Ca} / \mathrm{Sr}, \mathrm{Ca} / \mathrm{Ti}, \mathrm{Zr} / \mathrm{Rb}$, inc/coh, \%CaCO3, \%Organic matter, $D 50$, mean grain size, and sorting. The Bray-Curtis dissimilarity metric was used to calculate the distance between each sample and plot this in a 2D space.

Figure 5.23 shows the visualisation of the correlation matrix, where variables that plot closer together are those that are more similar. It shows all the grain size data and proxies plotting to the left side of the diagram, while the carbonate data and its proxies also plot closely in the bottom right corner, and organic matter and inc/coh plot close together above them. This plot shows that there are similarities between the destructive and non-destructive data, and to test the statistical significance of this, Pearson's correlation test was used, comparing each destructive dataset with each of the relevant proxies, which gave $p$-values $<0.05$ for all non-destructive proxies (see Appendix D). This result indicates that there is a statistically significant correlation 


\section{5: Results}

between the destructive data and their non-destructive proxies, indicating that these proxies can be used in the absence of destructive data.

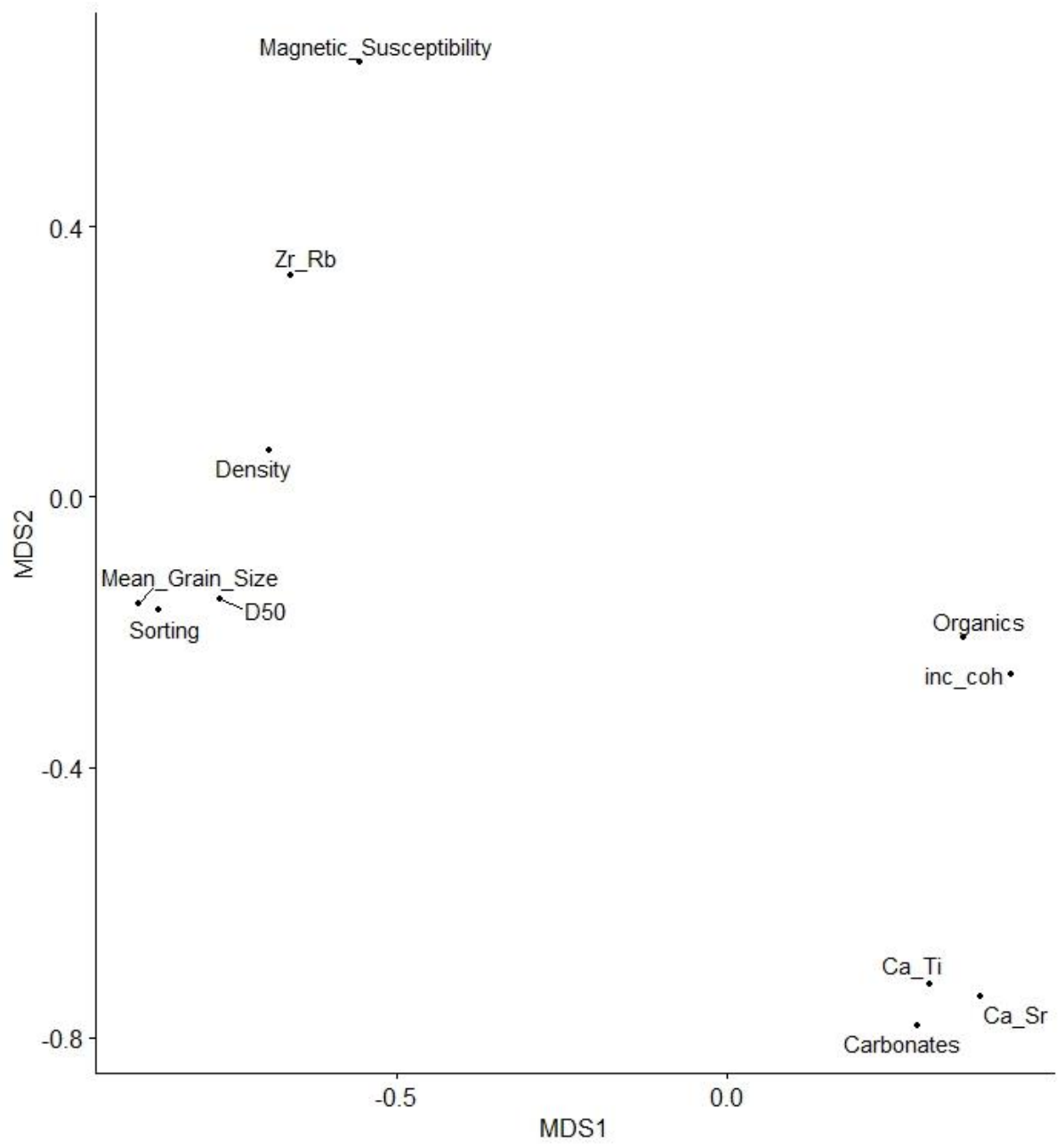

Figure 5.23 Visualisation of the correlation matrix, showing the correlation between variables input into the nMDS. Variables that plot closer together are more highly correlated.

\subsection{Use of non-destructive data to distinguish turbidite tails and background} sediments

From the MDS analysis, it can be shown that the destructive data can correlate with non-destructive proxies. Thus, non-destructive data could be used in the place of destructive data. Because obtaining destructive data is time consuming, produces lower-resolution datasets, and results in the destruction of core material, there are many benefits to analysing cores in a non-destructive manner - analysis is quicker, resolution is higher, and it is becoming a more routine practice for the analysis of sediment cores. Thus, the non-destructive data was examined, with the aim of 
determining if the non-destructive data could be used to distinguish between turbidite tails and background sediment.

To quantitatively assess the differences in the non-destructive datasets of turbidite tails (lithofacies B \& C) and background sedimentation (lithofacies D) linear discriminant analysis (LDA) was used. The data for all of the cores was examined as a whole, and then split into canyon-proximal and canyon-distal subsets. All samples that were not lithofacies $B, C$, or D were removed, while additional samples from within the Kaikōura turbidite tail in cores not sampled for destructive analyses (TAN1705-16, TAN1705-20, TAN1705-25, and TAN1705-36) were added, to provide additional instances of lithofacies B \& C.

Two different versions of the LDA model were created based on different combinations of the non-destructive data. The first (the "entire dataset") included the density, magnetic susceptibility, and selected micro-XRF derived geochemical proxies ( $\mathrm{Ca} / \mathrm{Sr}, \mathrm{Ca} / \mathrm{Ti}$, inc/coh, $\mathrm{Zr} / \mathrm{Rb}, \mathrm{Mn} / \mathrm{Fe}$ ). This dataset was restricted to $5 \mathrm{~mm}$ resolution due to the resolution of the magnetic susceptibility data. The second ("XRF-only dataset") contained only the micro-XRF derived geochemical proxies, and has $1 \mathrm{~mm}$ resolution.

\subsubsection{Model One: Entire Dataset}

\section{All Cores}

The entire dataset contained 185 (92 turbidite tail and 93 background sediment samples) data points to be input into the LDA. This was split into the training set (138 instances) and test set (47 instances). The decision rule scores (LD1) calculated on the training set for each class, show that while there is an amount of overlap between the two classes, they are visually distinct from one another (Figure 5.24A). 


\section{5: Results}
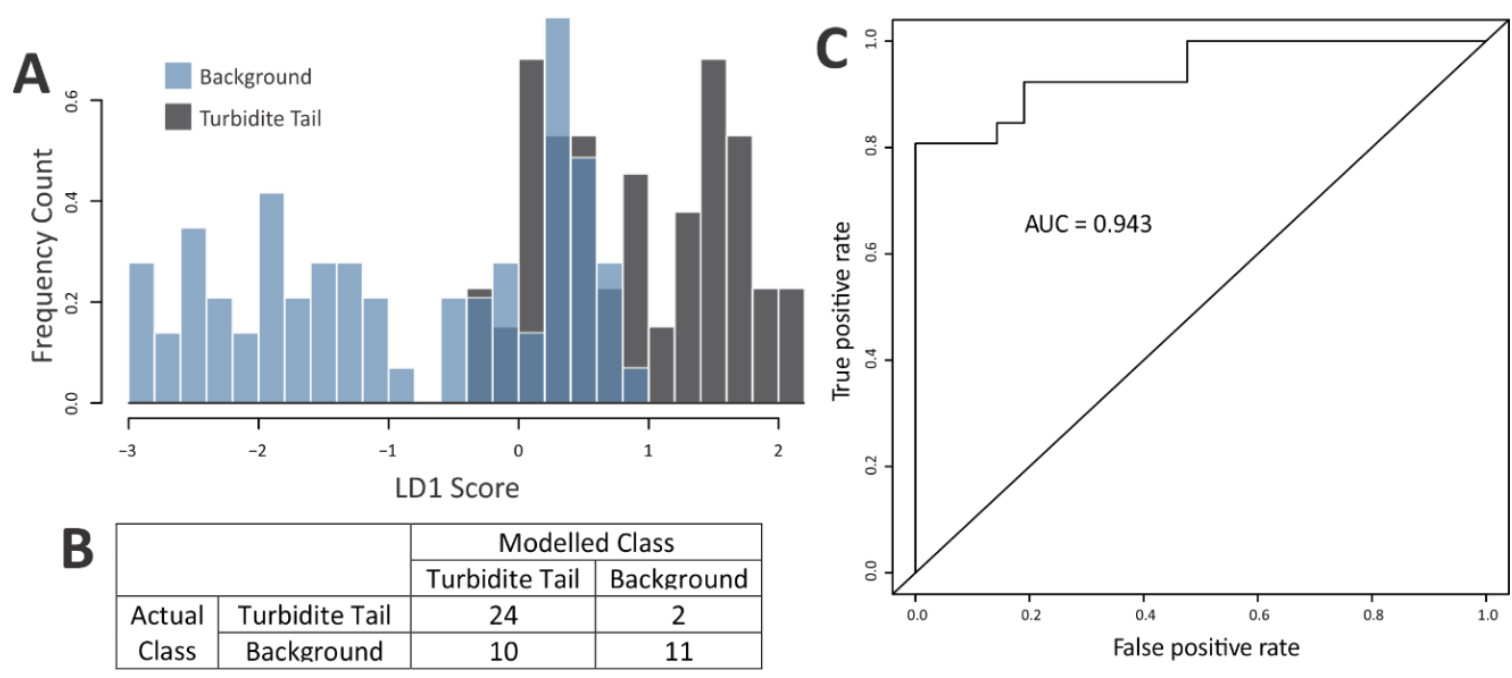

Figure 5.24 LDA results for model one, using all cores. A) Frequency histogram for LD1 scores calculated for the training set, showing the distribution and overlap of scores for background sediments (translucent blue) and turbidite tails (grey). B) Confusion matrix showing the results from the test set. C) ROC plot

The best performing model accurately classified $74 \%$ of the test set, using a decision threshold of 0.5 (will be used henceforth), as shown in the confusion matrix (Figure 5.24B) The model misclassified 2 turbidite tail samples as background sediment, and 10 background sediment samples as turbidite tails.

The ROC curve for this model has an AUC of 0.943 , meaning that the majority of instances of turbidite tail were given a higher score by the model than instances of background sediment, but not all, leading to a small amount of misclassification, as observed in the confusion matrix (Figure 5.24C).

\section{Canyon-Proximal Subset}

The canyon-proximal subset of the entire dataset contained 83 (48 turbidite tail and 35 background sediment samples) data points to be input into the LDA, which was split into the training (62 instances) and test ( 21 instances) sets. The decision rule scores calculated on the training set for each class, show that the two classes are distinct from one another, with nearly no overlap between the background and turbidite tail scores (Figure 5.25A). 

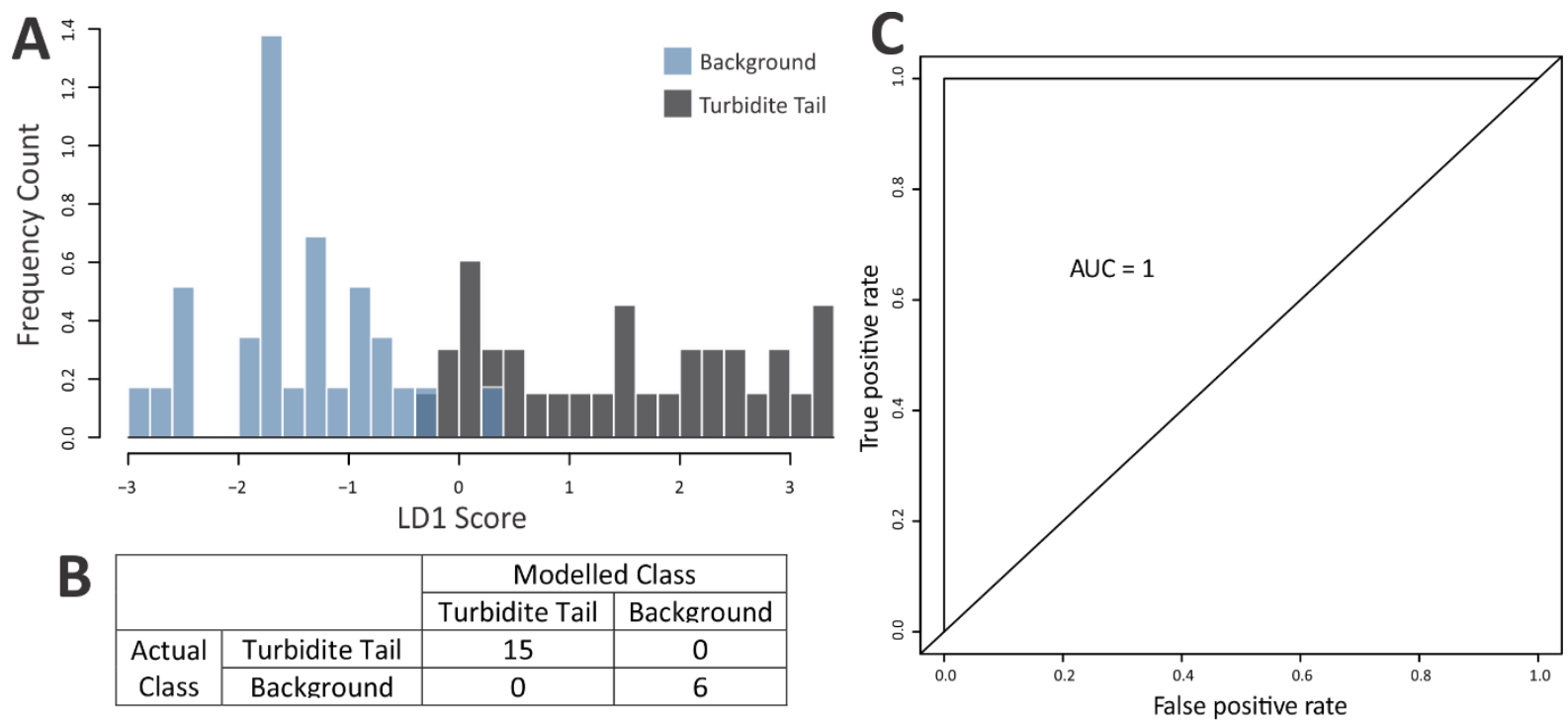

Figure 5.25 LDA results for model one, using canyon-proximal cores. A) Frequency histogram for LD1 scores calculated for the training set, showing the distribution and overlap of scores for background sediments (translucent blue) and turbidite tails (grey). B) Confusion matrix showing results from the test set. C) ROC plot

The best performing model accurately classified $100 \%$ of the test dataset, as shown in the confusion matrix (Figure 5.25B).

The ROC curve for the model has an AUC of 1 , meaning that all instances of turbidite tail were given a higher score by the model than all instances of background sediment (Figure 5.25C).

\section{Canyon-distal subset}

The canyon-distal subset of the entire dataset contained 102 (44 turbidite tail and 58 background sediment samples) data points to be input into the LDA, which was split into the training (76) and test (26) sets. The decision rule scores calculated on the training set for each class, show very clear separation between the two classes, with nearly no overlap between the turbidite tail and background sediment scores (Figure 5.26A). 

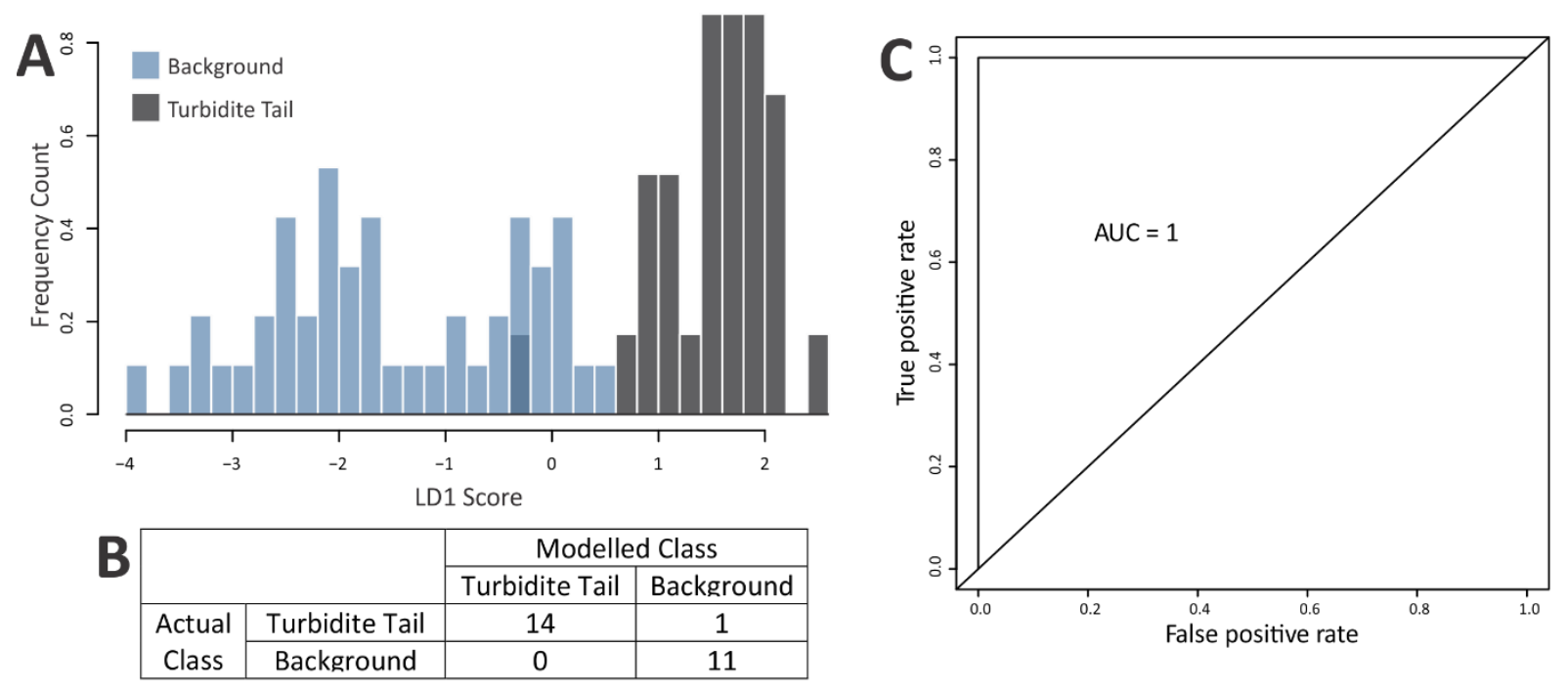

Figure 5.26 LDA results for model one, using canyon-distal cores. A) Frequency histogram for LD1 scores calculated for the training set, showing the distribution and overlap of scores for background sediments (translucent blue) and turbidite tails (grey). B) Confusion matrix showing results from the test set. C) ROC plot

The best performing model accurately classified $96 \%$ of the test dataset, as shown in the confusion matrix, misclassifying only one turbidite tail sample as background sediment (Figure 5.26B).

The ROC curve for this model has an AUC of 1 , meaning that all instances of turbidite tail were given a higher score by the model than all instances of background sediment (Figure 5.26C).

\subsubsection{Model Two: XRF-only Dataset}

\section{All Cores}

The XRF-only dataset contained 940 (460 turbidite tail and 480 background sediment samples) data points for the LDA, split into the training set (705 instances) and the test set (235 instances). The decision rule scores calculated on the training show that, similar to the decision rule plot from the entire dataset, the two classes have distinct distributions, though there is a significant amount of overlap (Figure 5.27A). 

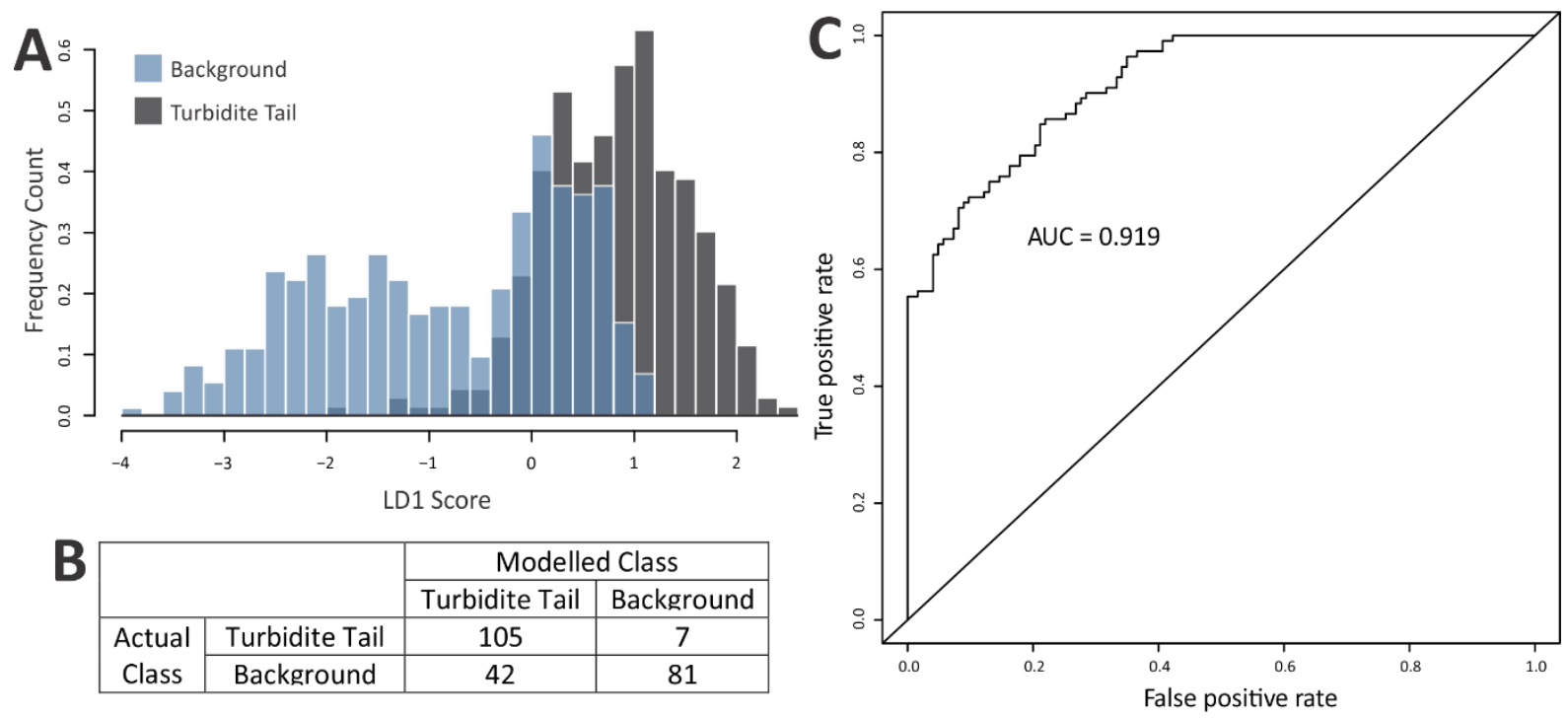

Figure 5.27 LDA results for model two, using all cores. A) Frequency histogram for LD1 scores calculated for the training set, showing the distribution and overlap of scores for background sediments (translucent blue) and turbidite tails (grey). B) Confusion matrix showing the results from the test set. C) ROC plot

The best performing model accurately classified $79 \%$ of the test set, as shown in the confusion matrix (Figure 5.27B). This misclassified 7 turbidite tail samples as background sediment, and 42 background sediment samples as turbidite tails.

The ROC curve for this model has an AUC of 0.919 , meaning that the majority of instances of turbidite tail were given a higher score by the model than instances of background sediment, but not all, leading to the misclassifications observed in the confusion matrix (Figure 5.27C).

\section{Canyon-proximal subset}

The canyon-proximal subset of the XRF-only dataset contained 412 (240 turbidite tail and 172 background sediment samples) data points to be input into the LDA, split into the training (309 instances) and test (103 instances) sets. The decision rule scores calculated on the training set show that while the two classes show clear differences, there is also a significant amount of overlap (Figure 5.28A). 

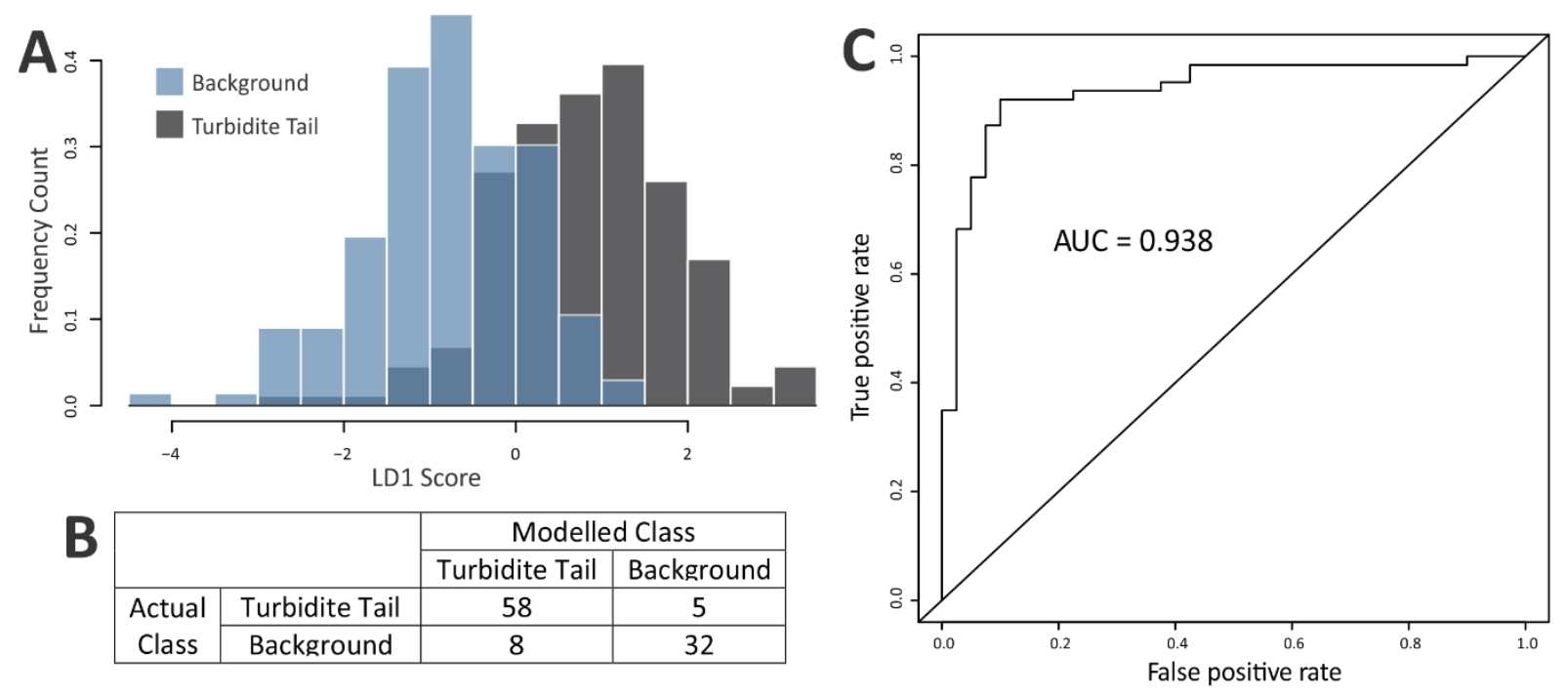

Figure 5.28 LDA results for model two, using canyon-proximal cores. A) Frequency histogram for LD1 scores calculated for the training set, showing the distribution and overlap of scores for background sediments (translucent blue) and turbidite tails (grey). B) Confusion matrix showing results from the test set. C) ROC plot

The best-performing model accurately classified $87 \%$ of the test set, as shown in the confusion matrix (Figure 5.28B).The model misclassified 5 turbidite tail samples as background sediment, and 8 background sediment samples as turbidite tail.

The ROC curve for this model has an AUC of 0.938 , meaning that the majority of instances of turbidite tail were given a higher score by the model than instances of background sediment, however, not all, leading to the cases of misclassification as observed in the confusion matrix (Figure 5.28C).

\section{Canyon-distal subset}

The canyon-distal subset of the XRF-only dataset contained 528 data points ( 220 turbidite tail and 308 background sediment samples) to be input into the LDA, which was split into the training (396) and test (132) sets. The decision rule scores calculated on the training set for each class, show very clear separation between the two classes, similar to what is observed in the canyon-distal subset of the entire dataset (Figure 5.29A). 


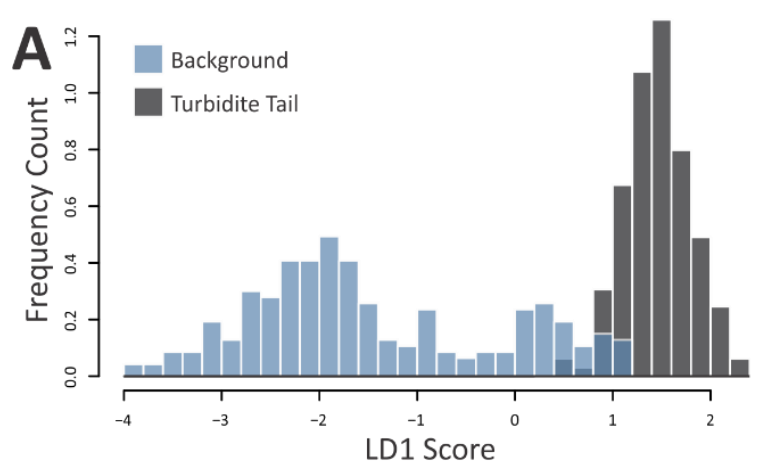

\begin{tabular}{|l|c|c|c|}
\hline \multicolumn{2}{|c|}{ B } & \multicolumn{2}{c|}{ Modelled Class } \\
\cline { 3 - 4 } & \multicolumn{2}{|c|}{ Turbidite Tail } & Background \\
\hline \multirow{2}{*}{$\begin{array}{c}\text { Actual } \\
\text { Class }\end{array}$} & Turbidite Tail & 57 & 0 \\
\cline { 3 - 4 } & Background & 16 & 59 \\
\hline
\end{tabular}

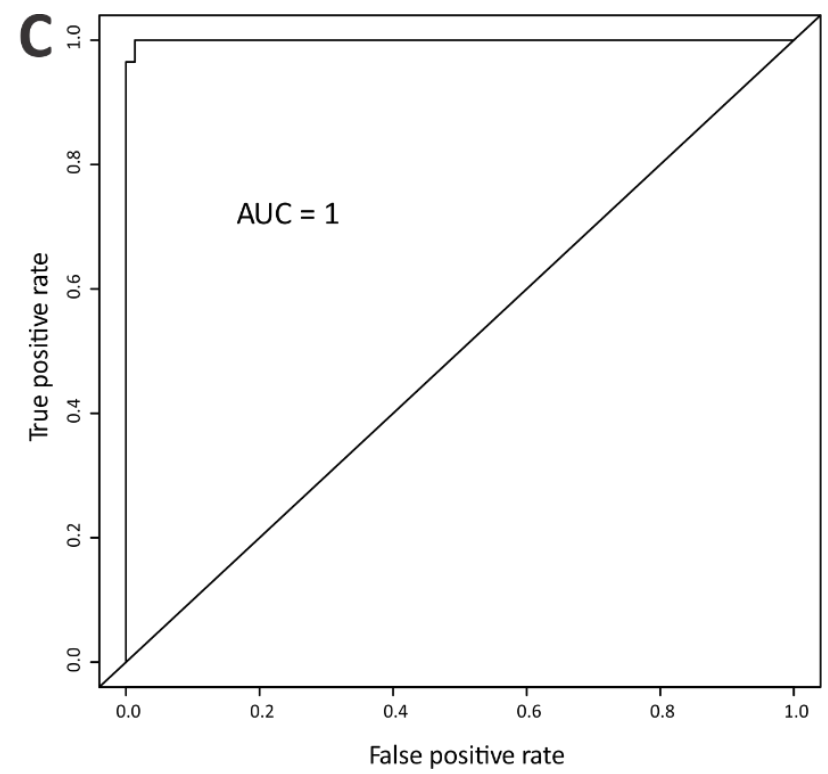

Figure 5.29 LDA results for model two, using canyon-distal cores. A) Frequency histogram for LD1 scores calculated for the training set, showing the distribution and overlap of scores for background sediments (translucent blue) and turbidite tails (grey). B) Confusion matrix showing results from the test set. C) ROC plot

The best-performing model accurately classified $88 \%$ of the test set, as shown in the confusion matrix (Figure 5.29B). The model misclassified 16 background sediment samples as turbidite tails, but does not class any turbidite tail samples as background sediments ( $0 \%$ false postivive rate).

The ROC curve for this model has an AUC of 0.9995, meaning that the vast majority of turbidite tail instances were given a higher score by the model than instances of background sediment (Figure 5.29C).

\subsection{Application of the approach for radiocarbon dating background sediment}

To obtain ages of turbidite deposits, the identification of background sediment is key for two main reasons: 1 ) to identify areas where planktic foraminifera have accumulated in situ, and thus can be radiocarbon dated; and 2) to use the thickness of the background sediment to inform age-depth models (Ramsey, 2008). To assess if the background sediment identified by the LDA models can produce reliable radiocarbon ages, samples targeted around the Taupō eruption isochron, dated at $\sim 1718 \mathrm{cal}$. yr. BP (Hopkins et al., 2020) were examined to test if these sediments could produce reliable radiocarbon ages. A core from a canyon-proximal core site, TAN1613-27, was examined for this purpose. 


\section{5: Results}

\subsubsection{Canyon-Proximal: TAN1613-27}

The LDA model trained on the data from within the Kaikōura turbidite and the underlying background sediment were applied to the data from TAN1613-27 section $4 / 5$, where primary Taupo tephra sits at $\sim 35 \mathrm{~cm}$ liner depth. The physical properties data for this core can be found in Appendix F. The posterior probabilities calculated from the canyon-proximal versions of each of the models were plotted, showing that the posterior probabilities from both models $1 \& 2$ indicate there is a good chance that the sample is background, though the upper sample is more borderline (Figure 5.30)

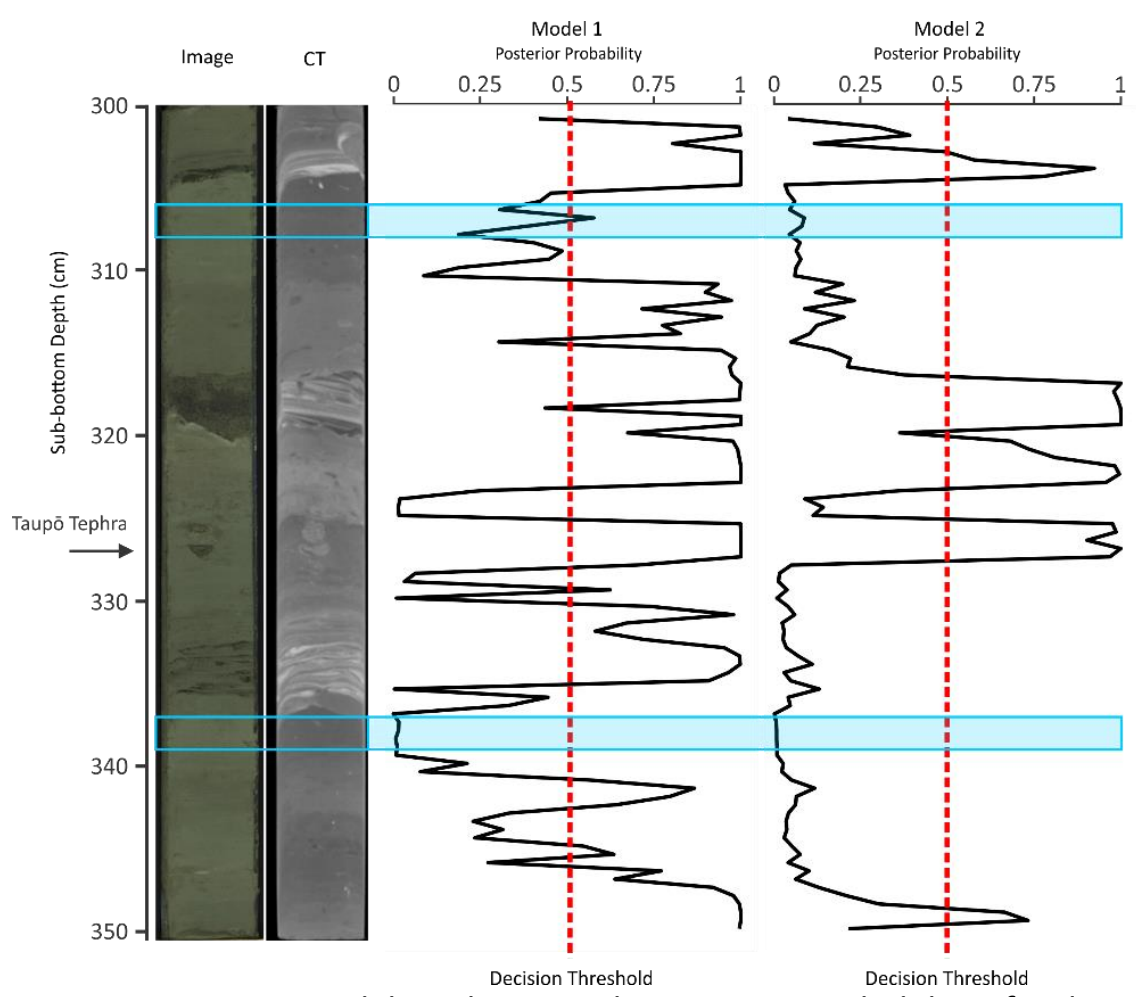

Figure 5.30 TAN1613-27 LDA model predictions. The posterior probability of sediment being classed as turbidite tail is plotted down core. To the right of the decision threshold of 0.5 (red dashed line) a sample is classed as turbidite tail, while to the left, it is classed as background sediment. Posterior probabilities are plotted for both model 1(entire dataset model) and model 2 (XRF-only dataset model), using the canyon-proximal training set. Blue boxes represent sampled intervals.

\section{Foraminiferal Analysis}

The foraminiferal data for these two samples shows the benthic foraminiferal assemblages are dominated by the $>200 \mathrm{~m}$ and $>400 \mathrm{~m}$ groups, with small numbers (1\%) of tests from the shallow-restricted groups (Figure 5.31). 
Relative Abundance of Benthic Genera

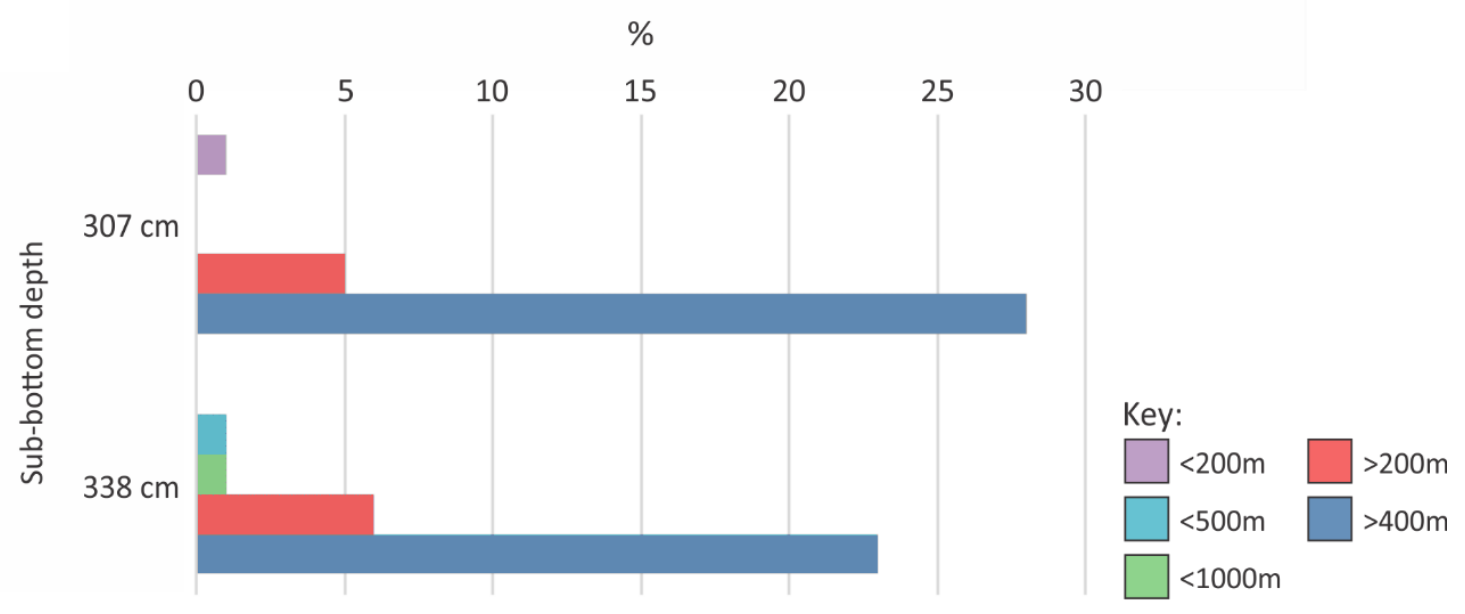

Figure 5.31 TAN1613-27 relative abundance of benthic genera plot.

The adjusted fragmentation index ( 83 for both samples) is roughly average for the depth of this core, and the adjusted planktic percentages (91 \& 94\%) are indicative of a depth $1000-2000 \mathrm{~m}$. The test size distributions of these samples both show an overabundance of small tests at the expense of medium-sized tests (Figure 5.32).

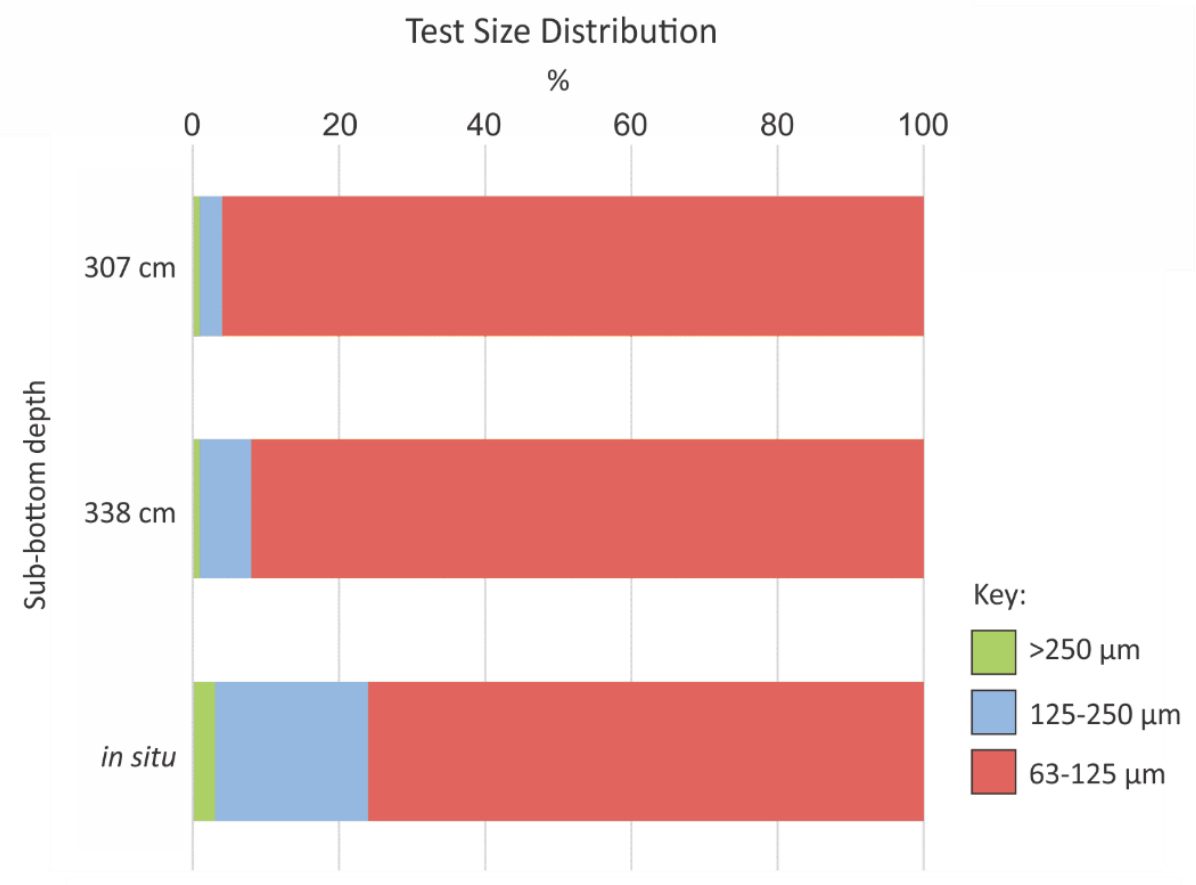

Figure 5.32 TAN1613-27 test size distribution plot.

Based on the independent foraminiferal data, both samples are classed as lithofacies D, as it is similar to what was observed in chapter 5.1. 


\section{5: Results}

\section{Radiocarbon Dating}

Both samples were submitted for radiocarbon dating. The upper sample $(7 \mathrm{~cm})$ was radiocarbon dated, while the lower sample $(38 \mathrm{~cm})$ was intended to also be dated, but the sample was lost due to an equipment error at Rafter Laboratory.

The radiocarbon age for the upper sample was calculated at 2768-3292 cal. yr. BP (Figure 5.33), older than the Taupō tephra below it, which is dated at 1718 cal. yr. BP (Hopkins et al., 2020).

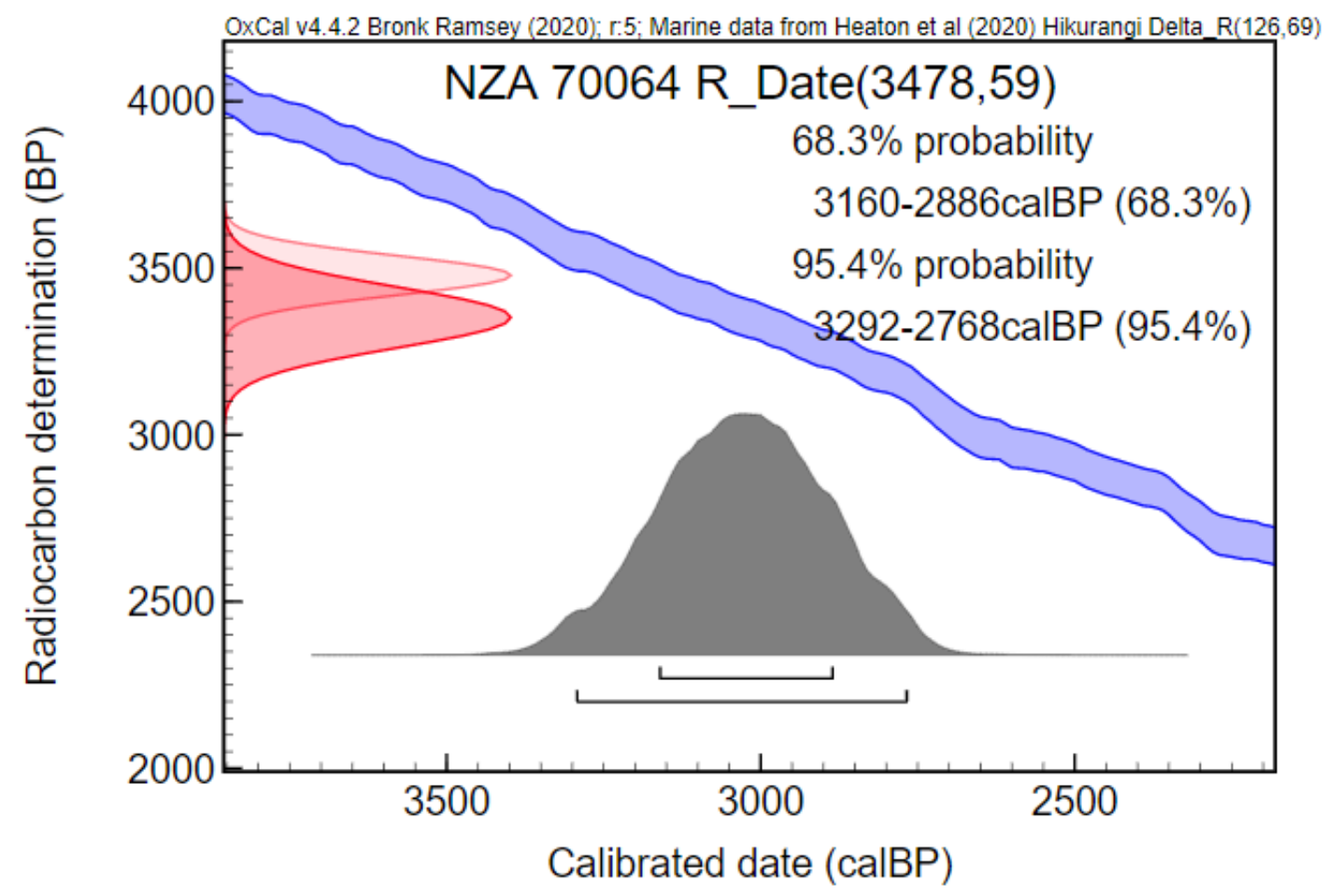

Figure 5.33 Calibrated radiocarbon age results for TAN1613-27 $307 \mathrm{~cm}, \sim 20 \mathrm{~cm}$ above primary Taupō tephra. 


\section{Discussion}

Turbidite paleoseismology is heavily reliant on the ability to temporally correlate turbidites deposited across a wide area, and thus, accurate dating of these deposits is crucial. As radiocarbon dating is the most widely used method for this purpose, it is vital for intervals of background sedimentation to be able to be accurately identified. Radiocarbon ages cannot be obtained from turbidites as they can contain older material that has been redeposited, and the development of age models requires an understanding of the thickness of sediments that have accumulated in situ. Thus, the identification of the sediments that have accumulated gradually in the background is key to the successful application of turbidite paleoseismology. To test the hypothesis that there is a quantifiable difference in the physical and geochemical properties of turbidite tails and background sediments along the southern Hikurangi margin that can be used to objectively identify these lithofacies, this project aimed to develop a quantitative method to distinguish between these lithofacies, such that dateable material can be identified simply and inexpensively. To do this, the following questions must be addressed:

1. Can the physical and geochemical properties of turbidite tails and background sediments be used to differentiate these sediments in a quantitative manner?

2. What are the processes by which these sediments are deposited?

3. What implications does this work have for turbidite paleoseismology studies along the Hikurangi margin and globally?

\subsection{Comparison of turbidite tail and background sediments}

In endeavouring to obtain the ages of turbidites, it is of the utmost importance to be able to differentiate between deposits that have accumulated gradually, in the background, and those that were deposited instantaneously by a turbidity current. Turbidite paleoseismology studies have distinguished turbidite tails from background sedimentation using a variety of techniques, including visual analysis (Goldfinger et al., 2012), differences in physical and geochemical properties (Gracia et al., 2010;

Pouderoux et al., 2014), and foraminiferal assemblages (Polonia et al., 2013). Studies in different locations have varying degrees of ease in distinguishing turbidite tails and 


\section{6: Discussion}

background sediment - for some it is as simple as the observation of colour changes in the sediment (Babonneau et al., 2017; Goldfinger, 2011), while in others it has proven more difficult (Bernhardt et al., 2015; Goldfinger et al., 2013). However, many previous studies rely on the assumption that background sediment can be identified based on qualitative interpretations of the visual, physical, and geochemical properties of the sediments. While this may be true, none of these properties give direct evidence that sediment has accumulated gradually and in situ. The assumption that these properties are indicative of background sedimentation is largely untested, as few natural experiments exist to determine if these properties can truly characterise background sedimentation.

Along the southern Hikurangi margin, turbidite tails and background sedimentation bear many resemblances to each other. The Kaikōura turbidite provides a unique opportunity to examine the tail of a turbidite without having to define the boundary between it and the overlying background sediment, as so little time passed between its emplacement and core retrieval ( 8 months) that any background sediment that had accumulated since the turbidite was deposited would be negligible. Given that sedimentation rates are averaged at $0.4 \mathrm{~mm} / \mathrm{yr}$ along the Hikurangi margin (Henrys, Ellis, \& Uruski, 2003), only $\sim 0.2 \mathrm{~mm}$ of sediment would have accumulated in the 8 months following the earthquake. Therefore, the Kaikōura turbidite provides a natural experiment. The tail of the Kaikōura turbidite was used as an end-member to define the physical and geochemical properties of turbidite tails. The sediment underlying the turbidite was independently identified as background sedimentation using ${ }^{210} \mathrm{~Pb}$ activity profiles to recognise sediment that had accumulated gradually. Additionally, foraminiferal assemblage data was also used to determine if sediment had been transported from shallower depths, thus providing an end-member for background sediments.

The Kaikōura turbidite tails are made up of sediments from both lithofacies B and C, which equated to $\mathrm{T}_{\mathrm{E}-1}$ and $\mathrm{T}_{\mathrm{E}-2}$ lithofacies as per Talling et al. (2012); laminated or massive normally-graded muds with an abundance of shallow-restricted benthic foraminifera and highly variable ${ }^{210} \mathrm{~Pb}$ activity. Background sedimentation comprises lithofacies $D$, bioturbated mud, with benthic foraminifera predominantly derived from the $>200 \mathrm{~m},>400 \mathrm{~m}$, and eurybathic groups. These sediments have ${ }^{210} \mathrm{~Pb}$ activity 
profiles that follow a consistent decay profile. These analyses give a robust definition of both turbidite tails and background sediments, however, the ${ }^{210} \mathrm{~Pb}$ and foraminiferal data are both costly and time consuming to obtain, and in the case of ${ }^{210} \mathrm{~Pb}$, cannot be used to define sediments older than 150 years (Dezileau et al., 2016).

Thus, the physical and geochemical properties of these sediments were analysed to characterise both turbidite tails and background sediments, using the definitions of these groups as derived from the stratigraphic position of the Kaikōura turbidite, as well as the ${ }^{210} \mathrm{~Pb}$ activity profiles and foraminiferal assemblage data. Non-destructive datasets in particular were targeted, as these datasets are routinely generated on cores at high resolutions (Rothwell \& Rack, 2006).

There are subtle differences between the physical and geochemical properties of turbidite tails and background sedimentation (see chapter 5.2). Grain size (D50, sorting) is generally higher within turbidite tail lithofacies than in background sediment lithofacies, and similarly, the non-destructive proxies for grain size, density, magnetic susceptibility, and $\mathrm{Zr} / \mathrm{Rb}$ are all slightly higher in turbidite tail lithofacies. The percentage of carbonate, meanwhile, is slightly higher on average within background sediment lithofacies, along with its non-destructive proxies $\mathrm{Ca} / \mathrm{Sr}$ and $\mathrm{Ca} / \mathrm{Ti}$. The percentage of organic matter is also higher within background sediment lithofacies, and so too is its non-destructive proxy, inc/coh. However, all of these differences between lithofacies are very subtle, making any qualitative examination of these differences potentially problematic. Difficulties in qualitatively identifying background sediment using the subtle variations in physical and geochemical properties is not exclusive to the Hikurangi margin. For example, Goldfinger et al. (2013) used density and magnetic susceptibility to identify mud turbidites, identifying that these values both decreased through the fining-upward sequence of the turbidite, reaching an inflection point at the transition from turbidite tail to background sediments. However, the inflection point was sometimes observed to be blurred by bioturbation, making this method not entirely effective. Thus, instead of relying on qualitative analysis of the physical and geochemical properties data, machine learning was applied to determine if the differences between turbidite tail and background sediment lithofacies could be quantitatively determined. 


\section{6: Discussion}

\subsubsection{Distinguishing turbidite tails and background sediments using machine learning}

The subtle differences in the non-destructive data can be separated out using the LDA models, which are free from the inherent biases of visual assessment. The scores assigned to each instance in the training set show how well the model can separate out each of the classes using the data provided. The distribution of these scores on each of the location-specific models was plotted to observe the differences between the canyon-proximal and canyon-distal models (Figure 6.1). The location-specific models are examined as these perform better than the models created from all of the cores studied (Figures 5.24 and 5.27). The all-core models show a great deal more overlap in the LD1 scores than the location-specific models, which suggests that background sedimentation may vary depending on the depositional setting. For this reason, the location-specific models are favoured to account for the location-related variation. The canyon-proximal cores are located at, within, or at the outlets of active canyons, while the canyon-distal cores are located away from active canyons, in slope basins on the lower slope, in the Hikurangi Trough, or located in relict canyon systems.
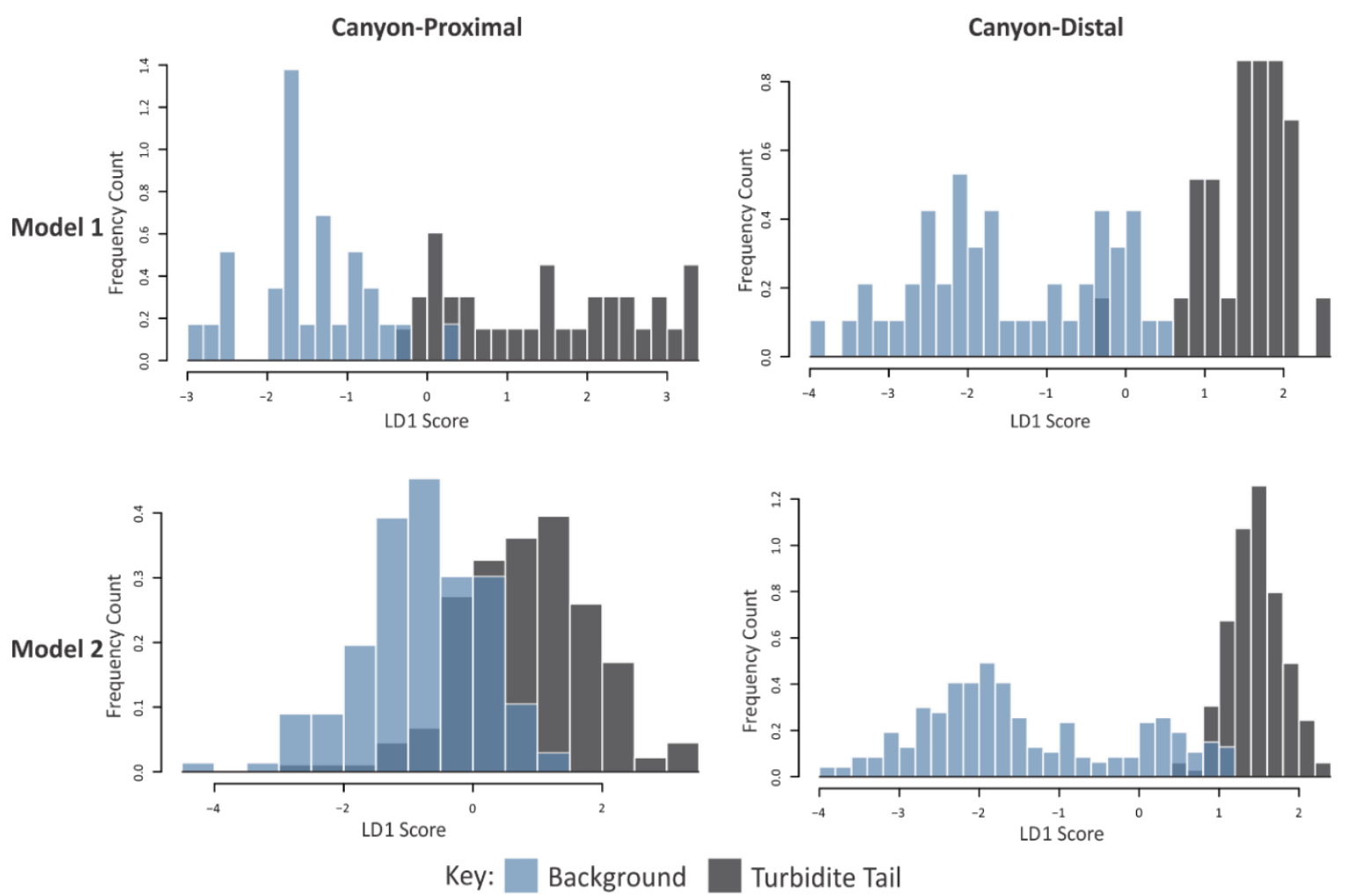

Figure 6.1 Distribution of decision rule scores for each of the location-specific models (detailed in section 5.3). Model 1 is made up of the entire dataset (density, magnetic susceptibility, XRF proxies), while model 2 is made up of only the XRF proxies. 
The frequency distributions of the LD1 scores generated on the training sets for each model show the differences in the scores generated by each model between turbidite tails and background sediment. Thus, these frequency distributions give an indication of both the variability within turbidite tails or background sediment, and the overlap of these distributions show the degree of similarity between these groups.

The canyon-distal models both show a low, broad distribution of LD1 scores for background sediments, while turbidite tail LD1 scores show a much taller, constrained peak, and there is very little overlap between the two groups. These distributions indicate that the physical and geochemical properties of the background sediments are more variable than those of the turbidite tails in canyon-distal cores, while the minimal overlap between turbidite tail and background sediment LD1 scores shows that the two groups are distinct. Because the scores of these groups are so distinct from one another, the predictive power of these models is likely higher.

Contrastingly, the canyon-proximal models show taller, more constrained frequency distributions of LD1 scores for background sediments and broader distributions of turbidite tail scores than those seen in the canyon-distal models. The differences between turbidite tail frequency distributions between the canyon-proximal and canyon-distal core sites may be because the canyon-proximal sites sample canyonspecific flows, whereas the canyon-distal sites capture the amalgamation of these flows that traversed the Hikurangi channel during the Kaikōura earthquake triggered turbidity current. Thus, this difference produces wider frequency distributions in the LD1 scores in canyon-proximal sites.

Model 1 shows good separation between background sediments and turbidite tails across both the canyon-proximal and canyon-distal models. In model 2, however, there is a significant amount of overlap between turbidite tail and background sediment scores in the canyon-proximal model, indicating that these groups are less distinct from each other than in the canyon-distal cores. Model 2, therefore has less predictive power than model 1, particularly at canyon-proximal sites, due to the omission of density and magnetic susceptibility from the model. 


\section{6: Discussion}

Overall, Model 1 shows the highest degree of separation between turbidite tails and background sediment, in both the canyon-proximal and canyon-distal models. Therefore, using the full suite of physical and geochemical data available produces models with the greater predictive power. Additionally, both canyon-distal models show background sediments are more distinct from turbidite tails at distal sites, indicating that these sites may provide more accurate classifications of turbidite tails and background sediments than canyon-proximal sites.

\subsubsection{Can background and turbidite tail sediments be predicted using machine learning?}

The LDA models produced in this study distinguish between turbidite tails and background sediments with a high degree of accuracy using the physical and geochemical properties. However, it should be noted that these models are trained on only one turbidite - the Kaikōura turbidite. As the goal of this model is to use it to distinguish turbidite tails and background sediments in much older sediments, the ability of the model to detect turbidites that are not the Kaikōura turbidite must be tested. To do this, the reworked turbidite lithofacies from TAN1705-33 and TAN170522 were examined, to determine if the model would identify these samples as such. These sediments were independently determined to be reworked turbidites based on the foraminiferal data, and as data from these sediments was not used to train the models, it provides an independent test to check that the models are performing as intended. 


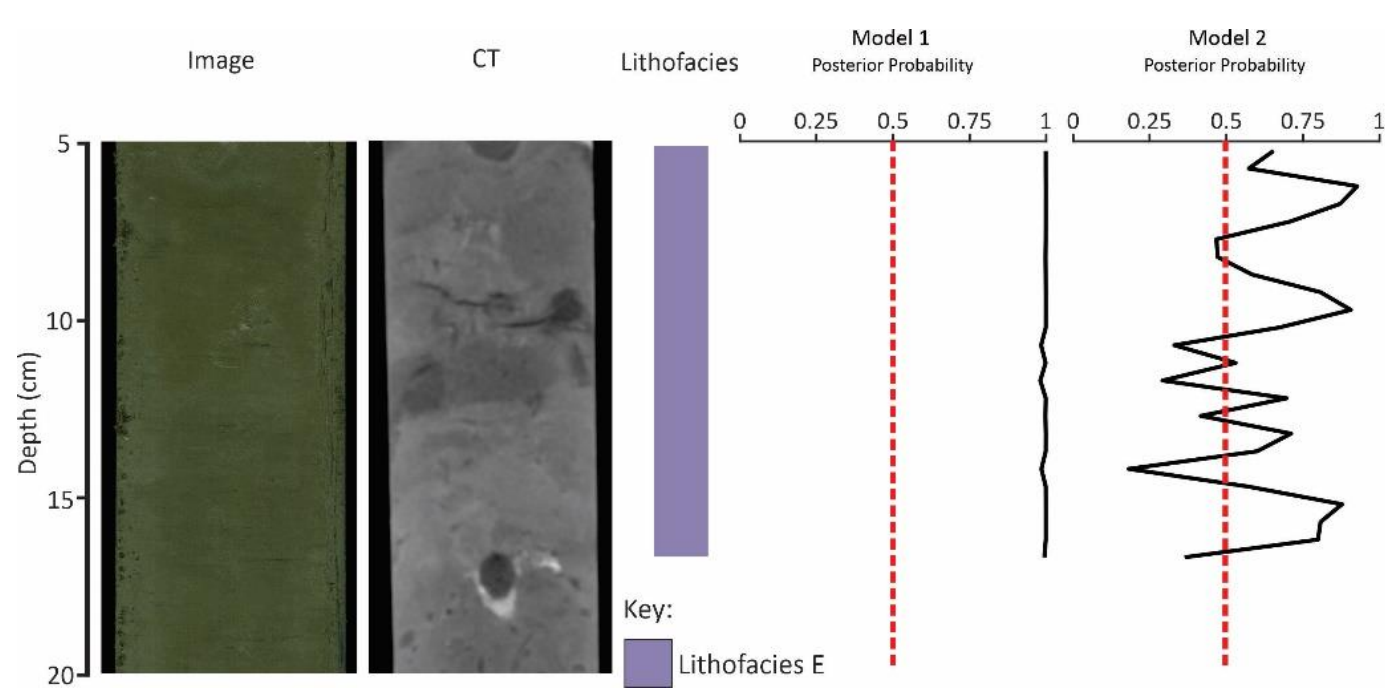

Figure 6.2 Posterior probabilities of a sample being a turbidite tail calculated using the canyonproximal models, plotted for TAN1705-33. Red dashed line indicates the decision threshold (0.5), samples to the left of this line are classed as background sediments (closer to a posterior probability of 0 ), while samples to the right are classed as turbidite tail (closer to a posterior probability of 1).

Model 1 has posterior probabilities of $\sim 1$ through the lithofacies E section of TAN170533 (Figure 6.2). Model 2 shows more variability down core, but the majority of samples lie above the decision threshold and are thus classed as turbidite tails. The additional variability in model 2 could be the result of lithofacies $E$ being a bioturbated lithofacies, and thus contains a mixture of turbidite and background sediments. Because the nondestructive data is of higher resolution than was sampled for foraminiferal analyses, it is possible that model 2 is picking up the inclusions of background sediment within lithofacies $E$ that are not observed at the resolution of the foraminiferal data. However, model 2 also shows the greatest amount of overlap in the LD1 scores of the two canyon-proximal models, indicating that this model may not be as good at distinguishing between turbidite tails and background sediments (Figure 6.1). Given the overlap in the LD1 scores in model 2, it is more likely that the posterior probabilities reflect the uncertainty in the model rather than the inclusion of background sediments via bioturbation. The posterior probabilities generated by model 1 are therefore deemed to produce the most accurate classification of these sediments, thus defining these sediments as turbidite tails, which aligns with the foraminiferal data obtained from this core (Figure 5.2). 


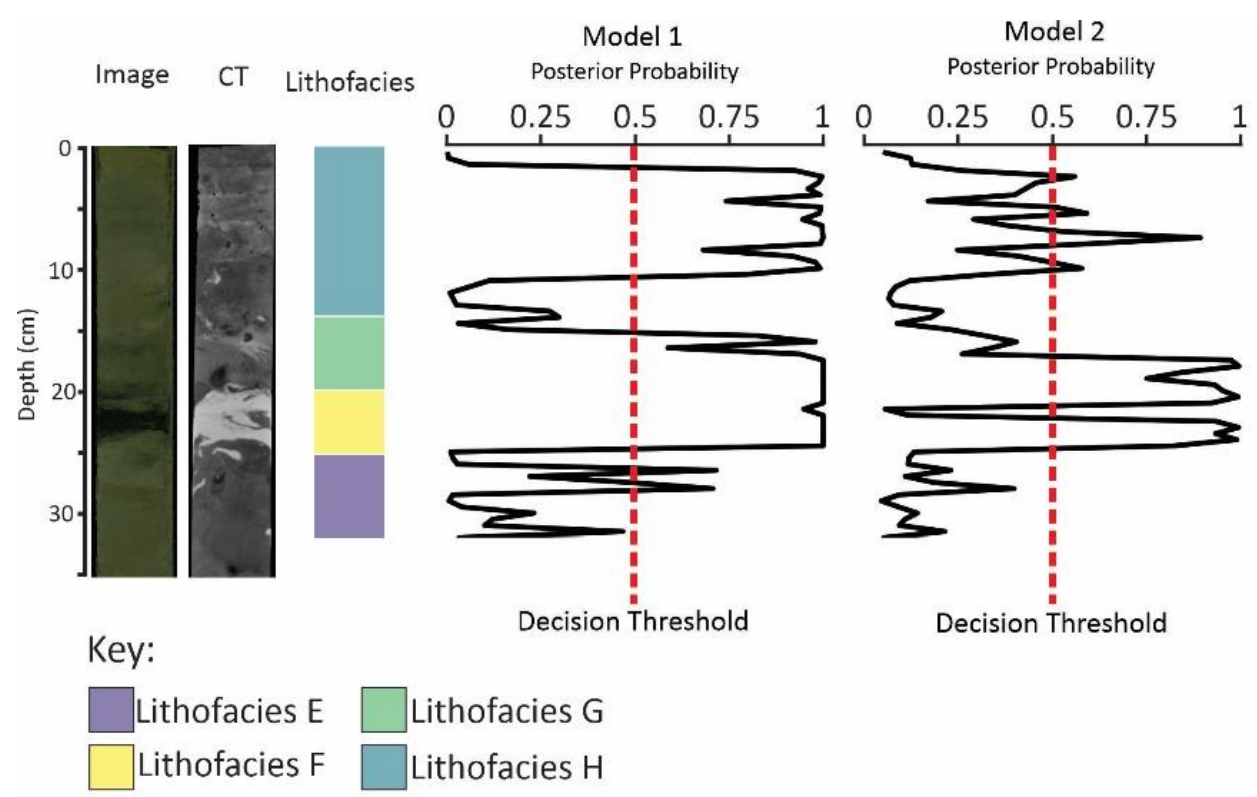

Figure 6.3 Posterior probabilities of a sample being a turbidite tail calculated using the canyonproximal models, plotted for TAN1705-22. Red dashed line indicates the decision threshold (0.5), samples to the left of this line are classed as background sediments (closer to a posterior probability of 0 ), while samples to the right are classed as turbidite tail (closer to a posterior probability of 1).

Both models show more variability through TAN1705-22 than in TAN1705-33 (Figure 6.3). Both models identify intervals of background sediment at $12 \mathrm{~cm}$ depth, within lithofacies $\mathrm{H}$, and below $25 \mathrm{~cm}$ depth, within lithofacies $\mathrm{E}$, where more samples are classed as background. At $12 \mathrm{~cm}$ depth, the foraminiferal data shows no indication that this sediment is different than the sediments surrounding it, implying that perhaps the probabilities produced by the models are incorrect. However, the sampling resolution of this data is higher than that of the model $(2 \mathrm{~cm}$ vs. $0.5 \mathrm{~cm})$, so this change may simply be undetected in the foraminiferal data. Below $25 \mathrm{~cm}$ depth, the relative abundance of benthic genera (Figure 5.10) shows lower percentages of shallow-restricted benthic groups, which is more consistent with lithofacies $D$ (background sediment). As the sediment in this core is highly bioturbated, the sections of this core that the model classifies as background could be indicative of background sediments being present amongst the turbidites of this core, but the bioturbation has removed any true background sediment lithofacies (lithofacies $D$ ), such that all of the sediments in this core contain at least some component of turbidite sediments.

The tests on reworked turbidite lithofacies show that the models are not limited by the fact that they are trained solely on the Kaikōura turbidite, and other turbidite tail 
lithofacies can be identified using this technique. However, TAN1705-22 shows that the signal of turbidite lithofacies can be distorted by bioturbation. Additionally, the two cores discussed above are located at canyon-proximal sites, which show less distinct separation between turbidite tails and background sediments (Figure 6.1). However, there are no reworked turbidite lithofacies in the studied canyon-distal cores that have been analysed for ${ }^{210} \mathrm{~Pb}$ activity profiles and foraminiferal assemblages to independently test the models on.

These above tests of the models only examine the performance of the model on shallow sediments, similar to the sediments from which the models were derived. To use these models to identify background sediment between turbidite deposits for the purposes of radiocarbon dating, they would need to be applied to older, deeper sediments. Thus, it is important to examine the behaviour of these models in older sediments. While this examination does not provide a robust test for the models, as there is no independent data to compare the model's predictions to, visual identification of clear turbidite lithofacies (e.g. $T_{D}, T_{C}$ ) is possible, and can provide some perspective on the effectiveness of the models down-core. To examine the performance of the model on older sediments, located at greater core depths, two cores were examined, a canyon-proximal core, TAN1613-27, and a canyon-distal core TAN1613-25.

In TAN1613-27 it is clear from the CT imagery that there are a number of turbidites within this core, and definitive $T_{D}$ and $T_{C}$ lithofacies can be observed (Figure 6.4). However, turbidite tails and background sediments are less obvious from the linescan and CT imagery alone. Therefore, the LDA models may be able to distinguish these sediments. Model 1 identifies more of the core as turbidite tail than model 2 , and the latter clearly misses the turbidite visible in the CT imagery at $\sim 335 \mathrm{~cm}$ depth. This oversight of the model may be due to the fact that it has not been trained on all turbidite lithofacies. Being located at a canyon-proximal core site, the models also may be less accurate due to the greater amount of overlap between turbidite tails and background sediments in those models. Model 1 appears to perform the best on this core, as it clearly identifies turbidite lithofacies as turbidite tails, whereas model 2 identifies intervals of obvious turbidite lithofacies as background sediments. 


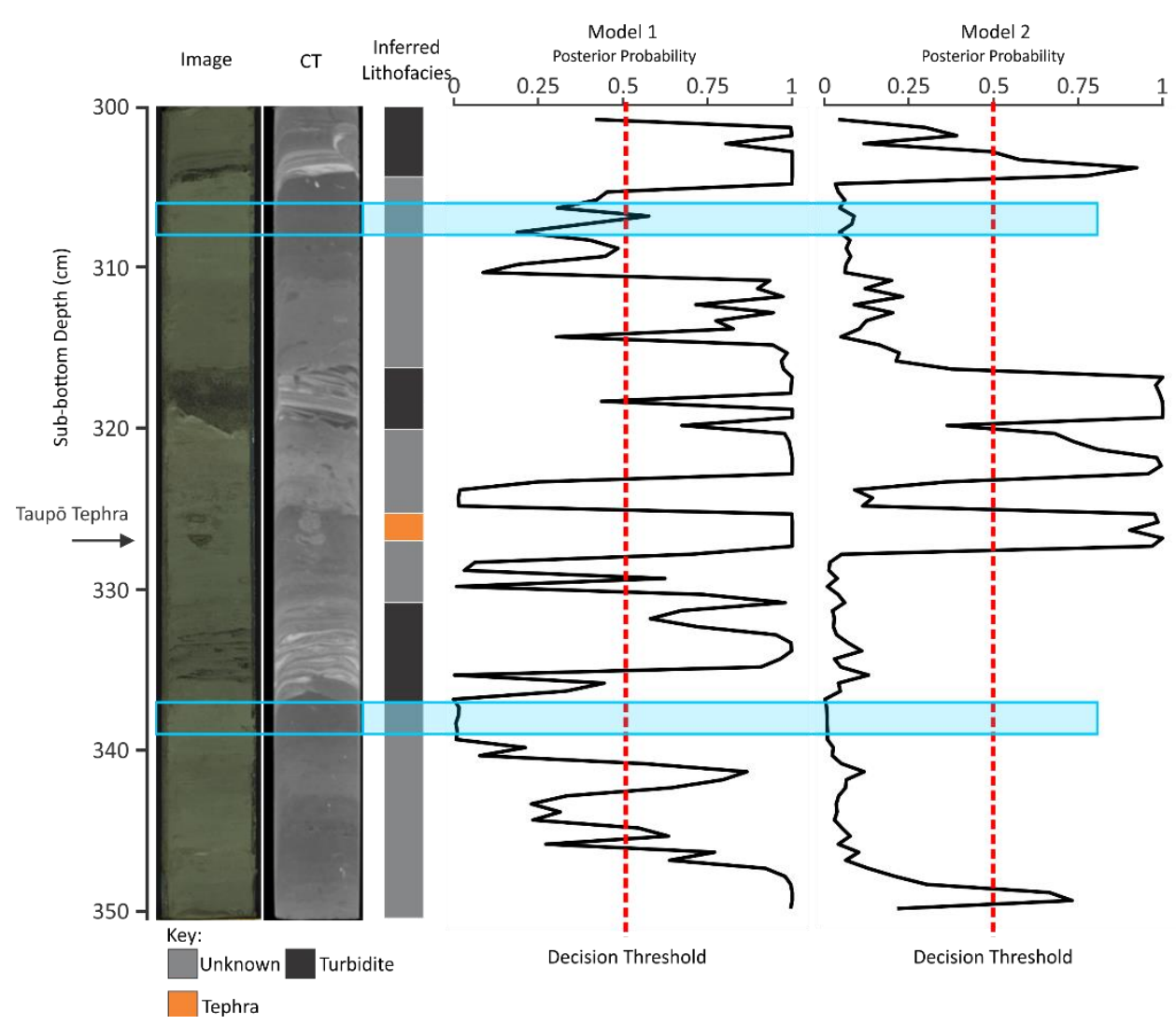

Figure 6.4 Posterior probabilities of a sample being a turbidite tail calculated using the canyonproximal models, plotted for TAN1613-27. Grey intervals are "unknown" lithofacies, and could be either turbidite tails or background sediments, while black intervals are undeniably turbidite lithofacies, based on the linescan and CT imagery. The red dashed line indicates the decision threshold (0.5), samples to the left of this line are classed as background sediments (closer to a posterior probability of 0 ), while samples to the right are classed as turbidite tail (closer to a posterior probability of 1). Blue indicates sampled intervals for radiocarbon dating.

In TAN1613-25, there are also some turbidite deposits that are clear in the CT imagery (Figure 6.5). Model 1 classifies three intervals as turbidite tails, at $\sim 105 \mathrm{~cm}, \sim 145 \mathrm{~cm}$, and $\sim 190 \mathrm{~cm}$. Model 2 only identifies two intervals as turbidite tails ( $\sim 105 \mathrm{~cm}$ and $\sim 145$ $\mathrm{cm}$ ) while identifying the lowermost section identified by model 1 as background sediment. Additionally, in the turbidite at $\sim 145 \mathrm{~cm}$, model 2 misclassifies the base of this turbidite as background. Again, this misclassification may be due to the fact that both models are trained solely on $\mathrm{T}_{\mathrm{E}-1}$ and $\mathrm{T}_{\mathrm{E}-2}$ facies, but model 1 does not seem to be impacted by this at all. Additionally, the lower turbidite only identified by model 1 may be identified largely on the basis of the magnetic susceptibility data, which shows a small increase just below $190 \mathrm{~cm}$ and decreases upwards, which could indicate the presence of a silty turbidite at this depth not picked up by the other physical and geochemical properties (Appendix Figure F.2). 


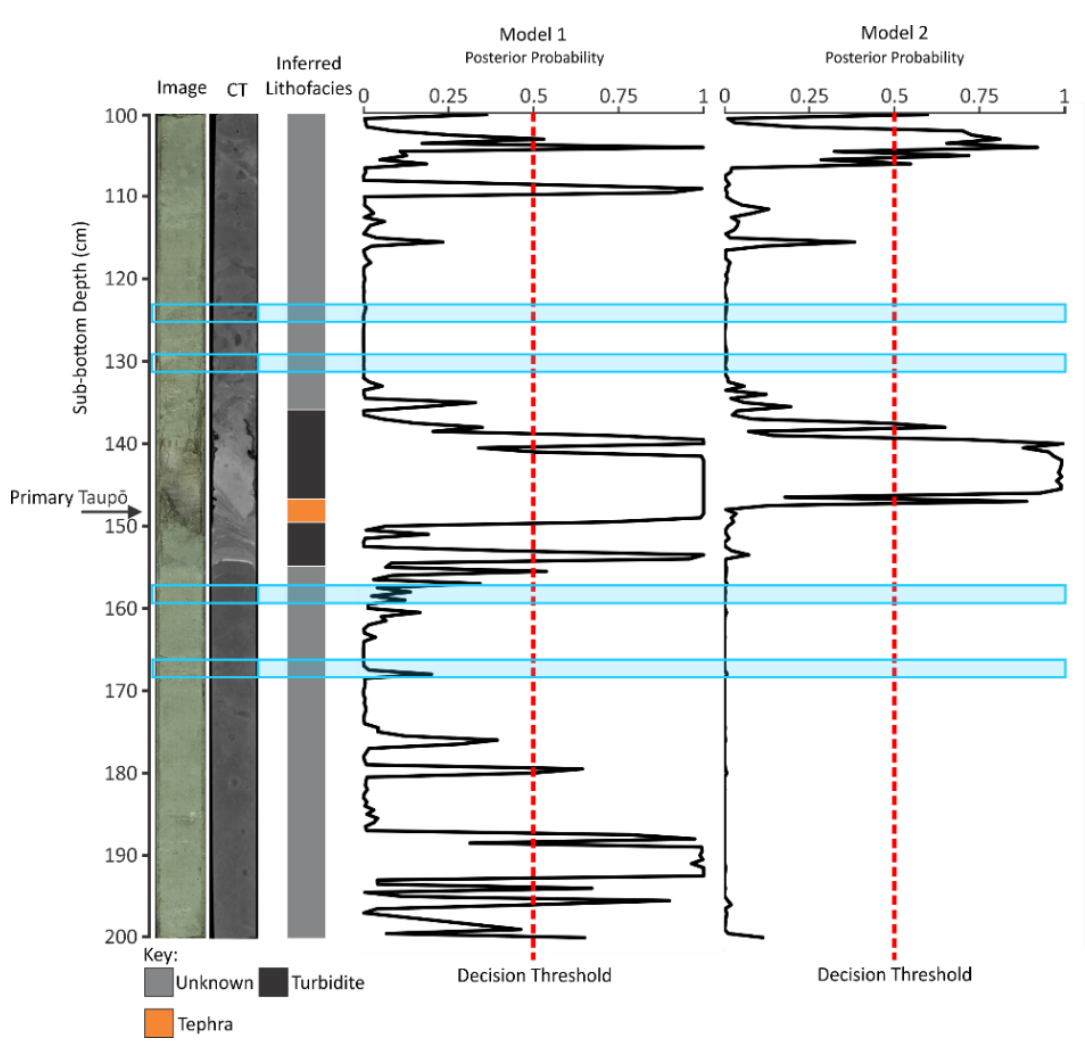

Figure 6.5 Posterior probabilities of a sample being a turbidite tail calculated using the canyondistal models, plotted for TAN1613-25. Grey intervals are "unknown" lithofacies, and could be either turbidite tails or background sediments, while black intervals are undeniably turbidite lithofacies, based on the linescan and CT imagery. The red dashed line indicates the decision threshold (0.5), samples to the left of this line are classed as background sediments (closer to a posterior probability of 0 ), while samples to the right are classed as turbidite tail (closer to a posterior probability of 1). Blue indicates sampled intervals.

\subsubsection{Differences between models and limitations}

The above examples show the differences between the two models. These models tend to perform comparatively, particularly in TAN1613-27 (Figure 6.4) and TAN161325 (Figure 6.5), following similar patterns, but model 2 tends to miss some obvious turbidite lithofacies.

Model 1 is trained on the density, magnetic susceptibility, and micro-XRF derived geochemical proxies. Because this model includes magnetic susceptibility, it has the smallest training set, as all data had to be averaged to $5 \mathrm{~mm}$ intervals to match the resolution of the magnetic susceptibility data. Magnetic susceptibility's key role in turbidite tail identification is its use as a proxy for grain size. However, magnetic susceptibility can also be affected by post-depositional diagenetic mineralization, meaning that additional magnetic minerals, such as pyrite, could appear in older background sediments, thus confusing the model and producing false readings ( $\mathrm{Li}$, 


\section{6: Discussion}

Zhang, Bai, \& Fang, 2010). This may be present at 170-180 cm depth in TAN1613-25, as there are small increases in magnetic susceptibility where there does not appear to be any other indication of a turbidite in the other physical properties data (Appendix Figure F.2). However, this overlies the inferred silty turbidite at $\sim 190 \mathrm{~cm}$ depth, so it cannot be entirely ruled out that these magnetic susceptibility increases are unrelated to that turbidite, given the prevalence of bioturbation.

Model 2 is trained solely on the micro-XRF derived geochemical proxies, thus allowing application at a higher resolution than model 1 , as the data is available in $1 \mathrm{~mm}$ resolution. The XRF data is normalised by using ratios rather than taking the raw counts per second (cps) of each element, to negate any closed-sum effects (Croudace \& Rothwell, 2015). Thus, by using the ratios of elements, this data is unaffected by systematic down-core variation in physical properties associated with compaction, which may be useful in the application of the model to long records of turbidites from a single core, that may be impacted by compaction.

When tested, model 1 performs better than model 2, more accurately identifying turbidite tails and other turbidite lithofacies. It identifies the reworked turbidite lithofacies in TAN1705-33 and TAN1705-22 with more certainty, and still performs reasonably well in deeper sections, where qualitative inferences can be made about turbidite lithofacies from visual analysis of the cores. Model 2 does perform comparatively, however, it misclassifies obvious turbidite lithofacies in both TAN161327 and TAN1613-25. The misclassification may be because all models are limited by the fact that they are trained on only turbidite tail lithofacies rather than all turbidite lithofacies, which can result in misidentification of sediments that are clearly turbidites. The goal of the model's use is to find background sediment based on subtle differences, and therefore the misclassification issue could be avoided by simply avoiding areas in which it is clear that samples are turbidites (e.g. lithofacies A). However, model 1 appears to be more robust to misclassification of clear turbidite lithofacies, which is unsurprising given that it includes more parameters. Further tests on the down-core application of model 1 would be desirable to ensure that it is robust in a wide variety of settings, which could be achieved by further investigating the foraminiferal assemblages of intervals inferred to be background sediments by the model. Additionally, there are the differences between the canyon-proximal and 
canyon-distal versions of the models. The canyon-proximal models show a greater amount of overlap between turbidite tails and background sediment than canyondistal models, and thus, both models have more predictive power when applied to sediments from canyon-distal core sites. This difference is likely due to changes in the depositional processes acting on core sites in proximity to active canyons and further away from active canyons. The potential driving forces for these differences will be discussed in detail below.

\subsection{Defining the sediments and depositional processes present along the southern Hikurangi margin}

The southern Hikurangi margin contains a range of sediments, largely made up of turbidites and gradually-accumulating background sediment.

\subsubsection{Turbidites}

Turbidites are the deposits that result from the settling of a turbidity current (Kuenen, 1964). These deposits are identified by their characteristic graded deposits, with a sharp, coarser-grained base grading up into mud (Stow \& Smillie, 2020). A variety of facies models have been proposed to describe the internal structures of turbidites (Bouma, 1962; Pickering \& Hiscott, 2015; Stow \& Piper, 1984; Talling et al., 2012). Along the southern Hikurangi margin, turbidites make up the majority of described lithofacies (A-C, E-H), split into two main groups; lithofacies pertaining to the Kaikōura turbidite, and lithofacies pertaining to older turbidites. Lithofacies A-C can be equated to the classification terminology of Talling et al. (2012). Lithofacies A represents the planar-laminated fine sand of $T_{D}$, deposited by dilute flow, while lithofacies $B$ and $C$ represent the finely laminated and graded muds of $\mathrm{T}_{\mathrm{E}-1}$ and $\mathrm{T}_{\mathrm{E}-2}$ respectively, deposited by floc settling of fine grains in suspension. While bioturbation overprints the internal structures of turbidite lithofacies, based on the grain size, lithofacies $F$ likely represents $\mathrm{T}_{\mathrm{B}-1}$ or $\mathrm{T}_{\mathrm{C}}$ facies, deposited by dilute flow or low amplitude bed waves in dilute flow, however, due to bioturbation, it is impossible to discern between the two lithofacies. Similarly, lithofacies $\mathrm{G}$ also represents bioturbated $\mathrm{T}_{\mathrm{D}}$ lithofacies, deposited by dilute flow resulting in planar-laminated deposits. Lithofacies $H$ represents $T_{E-1}$ and $T_{E-2}$ lithofacies that have been bioturbated, while lithofacies E represents turbidite tail 


\section{6: Discussion}

lithofacies that have been bioturbated to the point that no internal turbidite structures can be observed, and may include a component of background sediment mixed in.

Turbidity currents are fast-moving, gravity-driven flows where particles are largely suspended by fluid turbulence (Meiburg \& Kneller, 2010). These flows largely result from the destabilization of sediments on the continental slope, entraining significant amounts of sediment and transporting it up to several hundred kilometres to the deep ocean through submarine canyons and channels (Piper \& Normark, 2009; Talling, Paull, \& Piper, 2013). Turbidity currents can be triggered by a range of processes at a variety of scales, from localised events affecting a single canyon with an indiscernible trigger, or regional events triggered by large earthquakes where multiple canyons are impacted, resulting in a large turbidity current where these canyons merge (Adams, 1990; Paull et al., 2018).

The relationships between flow processes and deposits are often inferred, rather than derived from direct observations due to the limited monitoring data on turbidity currents available to link process and deposits. However, in recent times, turbidity currents have been able to be studied directly. Paull et al. (2018) monitored turbidity currents in Monterey canyon, offshore California over a period of 18 months. This study examined the structure of turbidity currents in Monterey canyon, inferring that they are made up of fast-moving and dense near-bed layers, formed through liquefaction or mechanical erosion of loose-packed sand. The dense layer is overlain by dilute, turbulent sediment clouds formed by shear between the dense layer and the overlying water, and this turbulent layer eventually outruns the dense layer when the velocity of the latter decreases. These observations link to the facies and processes described by Talling et al. (2012), where $T_{A}$ and $T_{B}$ facies may have resulted from processes similar to the dense fast-moving layers observed in Monterey canyon, while $T_{C}$ and $T_{D}$ facies correspond with the dilute, turbulent layer that eventually outruns the dense layer.

The data from the Monterey Canyon study detected 15 turbidity currents over the 18 month monitoring period, and showed that turbidity currents did not necessarily require a large external trigger, as powerful turbidity currents were observed that did not coincide with any earthquake, large storm, or flooding, indicating that small 
perturbations, such as normal wave heights, could cause slope failure and thus trigger a turbidity current in the upper and middle reaches of the canyon (Paull et al., 2018). Conversely, Mountjoy et al. (2018) studied the 2016 Kaikōura earthquake, which triggered a turbidity current that flushed the Kaikōura canyon, and showed that these large events are the drivers of canyon incision. This study compared the modelled peak ground accelerations (PGA) with the distribution of canyon-rim landsliding along the Kaikōura canyon to determine the threshold PGA for the triggering of canyon-flushing events. The recurrence interval of these events was determined to be $\sim 140$ years, derived from the PGA vs. recurrence interval curve for Kaikōura Canyon from the National Seismic Hazard Model (NSHM). From this recurrence interval it was calculated that the canyon is incised at an average rate of $40 \mathrm{~mm} / \mathrm{yr}$, and thus concluded that on active continental margins, earthquake-triggered canyon flushing is the dominant process driving sediment transfer to the deep oceans and geomorphic change in submarine canyons over long timescales.

Two cores analysed in this study, TAN1613-27 and TAN1613-25 are located down from Madden canyon, where the former is located proximal to the canyon, and the latter is located distal from the canyon. These cores both contain primary Taupō tephra but in the canyon-proximal core this tephra horizon is located at $\sim 325 \mathrm{~cm}$ depth, while in the canyon-distal core it is located at $\sim 150 \mathrm{~cm}$ depth. The canyon proximal core has many more turbidites above the Taupō tephra than the canyon-distal core, which could be due to shorter run-out turbidity currents occurring more frequently, similar to what is observed in Monterey canyon, while the canyon-distal core may only capture less frequent canyon-flushing events that run-out farther. The canyon-proximal cores are more likely to experience a higher rate of turbidite deposition from flows of a range of magnitudes. Thus, it follows that in canyon-proximal settings, background sediment is more likely to be perturbed by the greater frequency of low-magnitude turbidity currents that deposit silt turbidites, which are more difficult to distinguish from background sediments due to bioturbation. Conversely, as canyon-distal sites observe turbidity currents less frequently, background sediment is not impacted as often, potentially creating a greater distinction between turbidite tails and background sediments. 


\section{6: Discussion}

\subsubsection{Background Sediments}

Along the southern Hikurangi margin, background sediment is shown to be accumulating gradually via ${ }^{210} \mathrm{~Pb}$ activity profiles, however the foraminiferal assemblages show small amounts of shallow-restricted benthic genera throughout the background sediment, planktic percentages that do not align with in situ, and most test size distributions show an overabundance of small tests relative to in situ data. This data suggests that the background sedimentation processes are not solely derived from the rain of biogenic and clastic material through the water column, and there is some component of transported sediment introducing shallow-restricted benthic foraminifera and altering the test size distributions. However, these sediments are distinct from the turbidite lithofacies observed in the same suite of cores, as shown by the LDA models, so it is clear that undetected turbidites are not the explanation for these apparent discrepancies.

Background sediment is defined as the material that accumulates gradually on the sea floor by vertical settling processes in the open ocean, typically taking the form of pelagite or hemipelagite (Stow \& Smillie, 2020). These sediments are largely made up of skeletal plankton remains, with a component of terrigenous sediment. There are four main hemipelagite/pelagite facies, with classifications based on the biogenic and terrigenous components of the sediments. Pelagic ooze is made up of $>75 \%$ biogenics; muddy pelagic ooze has $25-75 \%$ biogenics and a terrigenous component that is predominantly clay; pelagic clay has $<25 \%$ biogenics, and a terrigenous component that is $>60 \%$ clay; and hemipelagite, that has $>5 \%$ biogenics and a terrigenous component that is $>40 \%$ silt (Stow \& Piper, 1984; Stow \& Tabrez, 1998). Hemipelagite is an ungraded mud, a characteristic that has been used to distinguish it from turbidite muds (Brunner \& Ledbetter, 1987). Based on the grain size, percentage of organic matter, and percentage of carbonate data obtained from lithofacies $D$ in the cores studied, this lithofacies would be defined as hemipelagite.

Hemipelagic sedimentation comprises a complex mixture of processes (Figure 6.6). The biogenic component of hemipelagites originates from slow vertical settling under the influence of gravity, as is the case for pelagites. The terrigenous component of hemipelagites comes from a combination of aeolian, fluvial, glacial, volcanic, or 
coastal-shelf mechanisms. These processes all introduce suspended plumes to the sea surface. Additionally, fine-grained sediment can be re-suspended by a variety of other processes, including the interaction between internal tides and waves and the sea floor, large eddies detaching from bottom currents and introducing the sediment they contain to suspension, and the detaching of the fine-grained component of a turbidity current at density discontinuities in the water column. The sediment in suspension can be transported via surface current transport, or if it has sufficient excess density the suspension will sink and more downslope as a very dilute and slow-moving density flow. In a process called suspension cascading, the density flow detaches from the bed at a density discontinuity, flowing out into the water column as an interflow. The interflow then decelerates, with the sediment settling vertically, regrouping at a deeper density interface, then flowing again, repeating the process. Very dilute suspensions form mid and bottom water nepheloid layers, that can move along and down slope via slow lateral advection (Stow \& Tabrez, 1998).

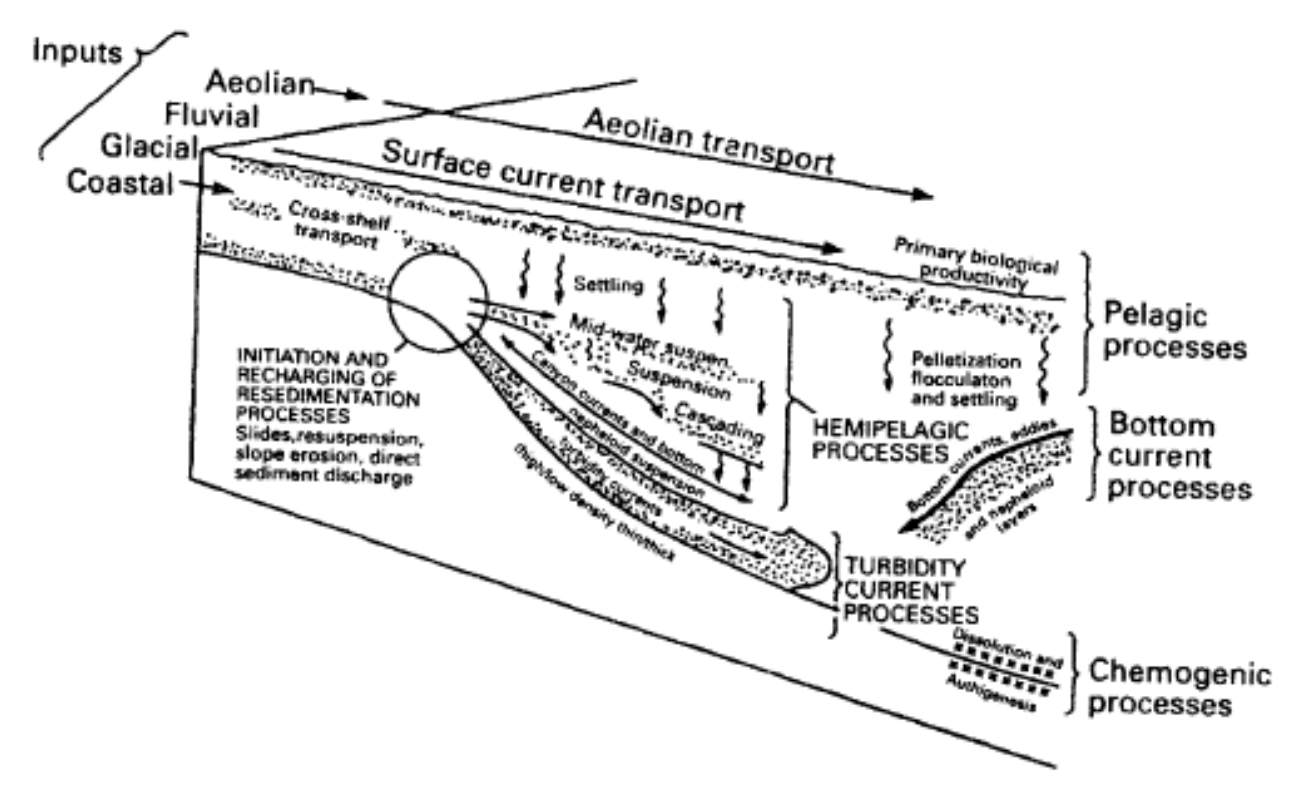

Figure 6.6 Model for the deposition of fine-grained sediments in deep water environments, from Stow \& Tabrez (1998).

The process of hemipelagic deposition can be complex, and in addition to this complexity, there is a degree of overlap between hemipelagites, turbidites, and contourites, and the processes that deposit these do not exist independent of one another. There can be close interaction between turbidity currents, bottom currents, and hemipelagic deposition, as both turbidity currents and bottom currents can 


\section{6: Discussion}

directly impact the slow settling of hemipelagic material. As such, hybrid deposits can form through the interaction between these processes (Stow \& Smillie, 2020). Bottom currents are driven by thermohaline, wind, or tidal forces and can transport sediment as a suspended load or via bed-load traction (Shanmugam, 2008). Strong bottom currents are also capable of winnowing and reworking sediment, and preventing the deposition of hemipelagic or pelagic sediments. Bottom currents can interact with other sedimentation types, entraining material from hemipelagic rain and the suspended loads of distal turbidity currents, or the upper parts of flows that have overspilled channel levees, resulting in hybridized facies. Bottom-current reworked hemipelagites form as a result of the interaction between weak bottom currents and the settling of material accumulating in the background, gently winnowing and reworking the hemipelagic rain and underlying deposits. These reworked deposits may be characterized by local winnowing and concentration of foraminiferal sands, regional variations in thickness, or widespread hiatuses (Stow \& Smillie, 2020).

Along the southern Hikurangi margin, the observed transported component of the background sediments could be the result of interaction between hemipelagic processes, sediment cascading, and weak, non-erosive bottom currents that move parallel to the shelf or flow up and down canyons. Sediment cascading and weak bottom currents may introduce material winnowed from shallower depths, introducing a greater abundance of smaller tests, skewing the foraminiferal test size distributions, and introducing shallow-restricted benthic foraminifera. Potentially, the canyon-proximal cores may be more significantly impacted by these processes. The LDA models show that there is greater distinction between turbidite tails and background sediment in canyon-distal cores, while canyon-proximal cores show more overlap (Figure 6.1). However, the foraminiferal evidence (see section 5.1) does not show clear evidence that one setting is more affected than the other.

Despite the likely impact of weak bottom currents and sediment cascading, these sediments can still be classed as gradually accumulating background sediment, as evidenced by the ${ }^{210} \mathrm{~Pb}$ activity profiles. Hemipelagite is said to be a slowlyaccumulating mixture of indigenous biogenic material and terrigenous detritus, deposited primarily by slow settling of material through the water column, unaffected by any substantial turbidity current or bottom current activity (Stow \& Piper, 1984). By 
this definition, the sediments present along the southern Hikurangi margin appear to sit at the very edge of the definition of hemipelagite.

\subsection{Implications for turbidite paleoseismology}

Turbidite paleoseismology is heavily reliant on the identification of material that can provide robust age control, to obtain evidence that turbidites across a wide area are temporally linked (Patton et al., 2015). To obtain this age control requires accurate distinction between turbidite tails and background sedimentation for two main reasons: 1) To identify background sediment that contains planktic foraminifera that have accumulated in situ for radiocarbon dating, as turbidite tails contain reworked foraminifera that may be older than the depositional age of the sediment in which they are found; and 2) to produce accurate age models of the sediment. Age models assume background sediment accumulates at approximately constant rates, and turbidites are removed as they are deposited instantaneously. As such, the thickness of the background sediment and turbidites must be constrained as well as possible to produce the most accurate age model (Ramsey, 2008). The method devised in this study shows that background sediment can be identified and distinguished from turbidite tails objectively, which has a number of implications for turbidite paleoseismology.

\subsubsection{Implications for the Hikurangi margin}

Along the southern Hikurangi margin, this study has been able to quantitatively distinguish turbidite tails from background sediments using machine learning, and the models produced using the Kaikōura turbidite dataset can easily be applied to cores with older sediments along the margin, as was done for TAN1613-27 and TAN1613-25 in this study. The models allow for a more robust definition of the upper boundary of a turbidite, which, as discussed above, allows for greater control when creating age models. Additionally, it allows for the observation of very fine-grained turbidites predominantly made up of $\mathrm{T}_{\mathrm{E}-1}$ and $\mathrm{T}_{\mathrm{E}-2}$ lithofacies that do not have a distinct base, such as can be seen at the top and near the bottom of TAN1613-25 (Figure 6.5), and may be able to identify those not visually discernible even using CT imagery. 


\section{6: Discussion}

Along the southern Hikurangi margin, background sediments have been identified that can be defined as hemipelagite, however, these sediments have an additional component of shallow-derived material, introduced by bottom currents and sediment cascading. As these deposits show evidence of gradual accumulation, it may be possible to obtain reliable radiocarbon ages from this sediment despite the introduction of shallower material. Cores containing the Taupō tephra, dated at 1718 cal. yr. B.P. (Hopkins et al., 2020) were targeted to determine if viable radiocarbon ages could be obtained from these background sediments. Only one age from TAN1613-27 was able to be obtained, which was $~ 1574-1050$ years older (2768-3292 cal. yr. B.P.) than the Taupō tephra, despite being above the tephra stratigraphically. The older than expected age could indicate that a substantial component of foraminifera within the hemipelagite on the southern Hikurangi margin is introduced via bottom currents and suspension cascading. If this is the case, radiocarbon dating of foraminifera from within these sediments cannot be used to obtain the ages of turbidites, limiting the potential use of turbidite paleoseismology along this margin. Alternatively, this sample is from a canyon-proximal core, the LDA models for which show less distinction between turbidite tails and background sediments. Canyonproximal sites are more likely to be subjected to a more diverse suite of processes than canyon-distal sites, and may be more greatly impacted by weak bottom currents and suspension cascading. Additionally, the posterior probabilities from model 1 (the preferred model) for this sample are only marginally below the decision threshold, and thus it is less certain that this sample is strictly background. The radiocarbon age obtained from TAN1613-27 could indicate that radiocarbon ages are unobtainable proximal to canyons, but ages may be able to be obtained from canyon-distal cores, where the distinction between turbidite tails and background sediments is clearer. Ultimately, conclusions cannot be drawn from a single radiocarbon age, and thus, future work will seek to obtain a wider suite of radiocarbon ages surrounding the Taupō tephra in multiple core locations across the slope and trough to fully explore the potential for radiocarbon dating the background sediments found along the southern Hikurangi margin. 


\subsubsection{Global implications}

Ideally, settings that have been targeted for turbidite paleoseismology have easily distinguishable background sediment deposits between turbidites, to allow for radiocarbon dating of the intervening sediments to be conducted. However, these kinds of settings appear to be the exception rather than the rule. Many turbidite paleoseismology studies have recognised the difficulty in distinguishing between turbidite tails and background sediments (Babonneau et al., 2017; Bernhardt et al., 2015; Ratzov et al., 2015). Even in Cascadia, which is deemed to be an ideal setting for the application of turbidite paleoseismology, mud turbidites were found in sediments initially thought to be background sediments, highlighting the need for clear differentiation between background and turbidite tails (Goldfinger et al., 2013). Due to the similarities between fine-grained mud turbidites and background sediments in many settings, it has become increasingly clear globally that a multi-proxy approach is necessary to fully grasp the differences between turbidite tails and background sedimentation, such that they can be distinguished from one another. As such, many recent turbidite paleoseismology studies have employed multi-proxy approaches to identify dateable material (e.g. Gracia et al., 2010; Polonia et al., 2013; Ratzov et al., 2015). However, these studies have relied on subjective interpretation of the data.

The results of this study have shown that the differences between turbidite tails and background sediment can be subtle and difficult to discern qualitatively. But, using machine learning, these subtle differences can be used to distinguish background sediments from turbidite tails in a quantitative manner. This quantitative approach allows for much less ambiguity, and areas where qualitative analysis leaves distinction uncertain can be targeted with greater confidence. However, this method is reliant on a natural experiment such as was provided by the Kaikōura earthquake, in that it requires both turbidite tails and background sediment to be identified independently to produce a dataset with which to train the LDA. This requirement means that the applicability of this method globally is restricted to locations in which turbidites have deposited very recently. However, it does highlight that a quantitative definition of turbidite tails and background sediments is highly effective at distinguishing these sediments. If similar datasets could be curated elsewhere, the approach outlined in 


\section{6: Discussion}

this study would allow for quick and simple analysis of the sediments to determine the likelihood that a particular interval is a turbidite tail or background sediment. This will be highly useful for studies attempting to produce ages for many turbidites across a margin to obtain evidence of simultaneous triggering, as it streamlines the process for the identification of background sedimentation, in a way that is not subjected to human biases. Additionally, as the non-destructive datasets used are those that are routinely collected on sediment cores, it is cheaper and quicker than multi-proxy destructive analysis, while preserving material for other analyses, such as radiocarbon dating.

The method is not infallible, but could be used as a tool in conjunction with more robust techniques such as the analysis of foraminiferal assemblages. Given the difficulties in distinguishing between background sediments and turbidite tails recognised globally, more straightforward, quantitative approaches should become the standard for turbidite paleoseismology studies, as it reduces the ambiguity that comes with qualitatively analysing subtle differences in physical and geochemical properties, and will allow for more accurate determination of the thickness of background sediments, which is crucial in developing age-depth models. 


\section{Conclusions}

The southern Hikurangi margin poses a major source of seismic and tsunami hazard for New Zealand (Clark et al., 2015; Clark et al., 2019; Wallace et al., 2014), and thus, expanding the paleoseismic record is crucial in assessing the hazard posed by the subduction zone. Turbidite paleoseismology provides an avenue with which to extend this record. However, due to its dependency on robust age correlations to establish synchronicity of triggering, it requires a considered approach to the dating of turbidites, and thus, requires a robust understanding of the difference between the fine-grained tails of turbidites and the sediment that has accumulated gradually in the background.

\subsection{Summary}

This study utilized the turbidite deposited by the Kaikōura earthquake to determine if the physical and geochemical properties of turbidite tails and background sediments could be differentiated in a quantitative manner. It was hypothesized that there would be a subtle, but quantifiable difference in these properties between lithofacies, and that this could be exploited to objectively identify these lithofacies in sediment cores. Background sedimentation was independently identified using ${ }^{210} \mathrm{~Pb}$ activity profiles and foraminiferal assemblages, however, it contains a small component of shallowderived benthic foraminifera and anomalous foraminiferal test-size distributions. This evidence indicates that there is some transport process interacting with background sedimentation processes, however, the foraminiferal data is distinct from the data obtained from turbidites, indicating that these anomalous results were not the result of turbidity current transport. It is inferred that the transported component of these sediments has been introduced via weak bottom currents and suspension cascading that are dropping fine, shallow-derived material at the core sites, resulting in the increased abundance of small foraminiferal test sizes and shallow-derived benthic foraminifera.

Despite this interaction between background sedimentation processes, suspension cascading and weak bottom currents, the results show that there is a tangible, quantitative difference between background sediments and turbidite tails along the 


\section{7: Conclusions}

southern Hikurangi margin. Background sediments are higher in carbonates and organics, and generally have lower grain size, density, and magnetic susceptibility, while turbidite tails are lower in carbonate and organics, and have higher grain size, density, and magnetic susceptibility. Additionally, it was determined that these differences could extracted from the non-destructive datasets that correlate with the destructive data, and thus, these differences between turbidite tails and background sediments can be seen in non-destructive datasets that are routinely obtained from marine sediment cores (Rothwell \& Rack, 2006).

As turbidite tails and background sediments are quantifiably different, the LDA models were used to determine if these differences could be used to predict if a sample was turbidite tail or background sediment based solely on the physical properties and geochemical data. Two models were developed for this purpose, the entire dataset model (model 1) and the XRF-only model (model 2). Each of these models was divided into location-specific subsets of canyon-proximal and canyon-distal to encapsulate the differences between these two settings. The canyon-distal models showed the best separation between turbidite tails and background sediments, however, the canyonproximal models still show clear differences between the groups, though this was more evident in model 1 than in model 2. This difference between the canyonproximal and canyon-distal cores could be due to the impacts of bottom currents and suspension cascading, as canyon-proximal cores may be more greatly affected by this process than canyon-distal cores.

Additionally, the LDA models were successfully applied to older sediments, showing that these models are not limited by the fact that they are trained solely on the Kaikōura turbidite. The models were applied to inform sampling strategies for radiocarbon dating. However, it is yet to be determined if the background sediments identified using this technique are able to produce accurate radiocarbon ages. The one radiocarbon age produced in this study was significantly older than the isochron underlying it. However, this sample was sourced from a canyon-proximal core, which could have been more greatly impacted by bottom currents and suspension cascading. The findings of this study confirm the initial hypothesis, and show that background sediments and turbidite tails can be effectively distinguished in a quantitative manner, 
despite the fact that the differences between the two groups are often subtle. This quantitative approach removes the inherent biases of qualitative analysis, and as it uses routinely obtained non-destructive datasets, it is quicker and cheaper than undertaking a multi-proxy destructive analysis. The LDA model can be used to both identify intervals of background sedimentation to inform sampling for radiocarbon dating, and to more robustly identify the thickness of these intervals through a core to inform age-depth models. Thus, the model allows for more accurate dating of turbidites, which is crucial in the application of turbidite paleoseismology. Given the difficulties experienced in distinguishing turbidite tails from background sediments globally, a quantitative approach is clearly the next step forward.

\subsection{Future Directions}

To determine if accurate radiocarbon ages can be obtained from the background sediment identified along the southern Hikurangi margin in this study, more radiocarbon ages need to be obtained from cores containing the Taupō tephra that provides an isochron. This work is already being undertaken for TAN1613-25, but should also be applied to other cores along the margin, both canyon-proximal and canyon-distal, to determine where dateable background sediment exists along the Hikurangi margin.

Additionally, the LDA models produced here use a two-class classification system, however, LDA models can be created for more than two classes (Izenman, 2008). As such, a model could be created that allows for the identification of all lithofacies recognised within these cores, not solely turbidite tails and background sediments. $A$ multiple-class LDA model could be used to great effect in identifying the full suite of turbidite facies, allowing for objective assessment of how turbidity current processes vary along a margin, both spatially and temporally. 
Conclusions 


\section{References}

Adams, J. (1990). Paleoseismicity of the Cascadia subduction zone: Evidence from turbidites off the Oregon-Washington margin. Tectonics, 9(4), 569-583.

Appleby, P. (1998). Dating recent sediments by $210 \mathrm{~Pb}$ : Problems and solutions. Retrieved from

Atwater, B. F., Carson, B., Griggs, G. B., Johnson, H. P., \& Salmi, M. S. (2014). Rethinking turbidite paleoseismology along the Cascadia subduction zone. Geology, 42(9), 827-830.

Austin, W. E. N., \& Hibbert, F. D. (2012). Tracing time in the ocean: a brief review of chronological constraints (60-8 kyr) on North Atlantic marine event-based stratigraphies.(Chronology). Quaternary Science Reviews, 36, 28.

Babonneau, N., Cattaneo, A., Ratzov, G., Déverchère, J., Yelles-Chaouche, A., Lateb, T., \& Bachir, R. S. (2017). Turbidite chronostratigraphy off Algiers, central Algerian margin: A key for reconstructing Holocene paleo-earthquake cycles. Marine Geology, 384, 63-80. doi:https://doi.org/10.1016/j.margeo.2016.10.017

Barnes, P. M., Bostock, H. C., Neil, H. L., Strachan, L. J., \& Gosling, M. (2013). A 2300Year Paleoearthquake Record of the Southern Alpine Fault and Fiordland Subduction Zone, New Zealand, Based on Stacked Turbidites. Bulletin of the Seismological Society of America, 103(4), 2424-2446.

Barnes, P. M., Lamarche, G., Bialas, J., Henrys, S., Pecher, I., Netzeband, G. L., . . . Crutchley, G. (2010). Tectonic and geological framework for gas hydrates and cold seeps on the Hikurangi subduction margin, New Zealand. Marine Geology, 272(1-4), 26-48.

Bernhardt, A., Melnick, D., Hebbeln, D., Lückge, A., \& Strecker, M. R. (2015). Turbidite paleoseismology along the active continental margin of Chile-Feasible or not? Quaternary Science Reviews, 120, 71-92.

Berryman, K., Clark, K., Cochran, U., Beu, A., \& Irwin, S. (2018). A geomorphic and tectonic model for the formation of the flight of Holocene marine terraces at Mahia Peninsula, New Zealand. Geomorphology, 307, 77-92.

Berryman, K., Ota, Y., Miyauchi, T., Hull, A., Clark, K., Ishibashi, K., . . Litchfield, N. (2011). Holocene paleoseismic history of upper-plate faults in the southern Hikurangi subduction margin, New Zealand, deduced from marine terrace records. Bulletin of the Seismological Society of America, 101(5), 2064-2087.

Beuselinck, L., Govers, G., Poesen, J., Degraer, G., \& Froyen, L. (1998). Grain-size analysis by laser diffractometry: comparison with the sieve-pipette method. CATENA, 32(3), 193-208. doi:https://doi.org/10.1016/S0341-8162(98)00051-4

Blaauw, M., \& Christen, J. A. (2011). Flexible paleoclimate age-depth models using an autoregressive gamma process. Bayesian analysis, 6(3), 457-474.

Blott, S. J., \& Pye, K. (2001). GRADISTAT: a grain size distribution and statistics package for the analysis of unconsolidated sediments. Earth surface processes and Landforms, 26(11), 1237-1248.

Boespflug, X., Long, B., \& Occhietti, S. (1995). CAT-scan in marine stratigraphy: a quantitative approach. Marine Geology, 122(4), 281-301. 
Bouma, A. H. (1962). Sedimentology of some Flysch deposits; a graphic approach to facies interpretation. Amsterdam: Elsevier Pub. Co.

Breitzke, M. (2000). Acoustic and elastic characterization of marine sediments by analysis, modeling, and inversion of ultrasonic $P$ wave transmission seismograms. Journal of Geophysical Research: Solid Earth, 105(B9), 2141121430.

Briggs, R. W., Engelhart, S. E., Nelson, A. R., Dura, T., Kemp, A. C., Haeussler, P. J., . . Bradley, L. A. (2014). Uplift and subsidence reveal a nonpersistent megathrust rupture boundary (Sitkinak Island, Alaska). Geophysical Research Letters, 41(7), 2289-2296.

Broecker, W. S. (2014). 5.9 - Radiocarbon: Elsevier Ltd.

Brunner, C. A., \& Ledbetter, M. T. (1987). Sedimentological and micropaleontological detection of turbidite muds in hemipelagic sequences: An example from the late Pleistocene levee of Monterey Fan, central California continental margin. Marine Micropaleontology, 12, 223-239. doi:https://doi.org/10.1016/03778398(87)90022-3

Carter, L., Manighetti, B., Elliot, M., Trustrum, N., \& Gomez, B. (2002). Source, sea level and circulation effects on the sediment flux to the deep ocean over the past 15 ka off eastern New Zealand. Global and Planetary Change, 33(3-4), 339-355.

Cattaneo, A., Babonneau, N., Ratzov, G., Dan-Unterseh, G., Yelles, K., Bracène, R., . . . Déverchère, J. (2012). Searching for the seafloor signature of the 21 May 2003 Boumerdes earthquake offshore central Algeria. Natural Hazards and Earth System Sciences, 12(7), 2159. doi:10.5194/nhess-12-2159-2012

Chiswell, S. M. (2002). Wairarapa coastal current influence on sea surface temperature in Hawke Bay, New Zealand. New Zealand journal of marine and freshwater research, 36(2), 267-279.

Chiswell, S. M. (2005). Mean and variability in the Wairarapa and Hikurangi eddies, New Zealand. New Zealand journal of marine and freshwater research, 39(1), 121-134.

Cisternas, M., Atwater, B. F., Torrejón, F., Sawai, Y., Machuca, G., Lagos, M., . . . Kamataki, T. (2005). Predecessors of the giant 1960 Chile earthquake. Nature, 437(7057), 404.

Clark, K., Hayward, B. W., Cochran, U. A., Wallace, L. M., Power, W. L., \& Sabaa, A. T. (2015). Evidence for past subduction earthquakes at a plate boundary with widespread upper plate faulting: Southern Hikurangi margin, New Zealand. Bulletin of the Seismological Society of America, 105(3), 1661-1690.

Clark, K., Howarth, J., Litchfield, N., Cochran, U., Turnbull, J., Dowling, L., . . . Wolfe, F. (2019). Geological evidence for past large earthquakes and tsunamis along the Hikurangi subduction margin, New Zealand. Marine Geology, 412, 139-172. doi:https://doi.org/10.1016/j.margeo.2019.03.004

Clark, K., Johnson, P., Turnbull, I., \& Litchfield, N. (2011). The 2009 Mw 7.8 earthquake on the Puysegur subduction zone produced minimal geological effects around Dusky Sound, New Zealand. New Zealand Journal of Geology and Geophysics, 54(2), 237-247.

Clark, K., Litchfield, N. J., Cochran, U. A., Berryman, K. R., Power, W. L., \& Steele, R. (2016). Constraints on Paleotsunami Runup Derived from Sand Deposits Mantling Three Holocene Marine Terraces at Puatai Beach, Northern Hikurangi Subduction Margin, New Zealand. AGUFM, 2016, NH43A-1801. 
Cox, M. A., \& Cox, T. F. (2008). Multidimensional scaling Handbook of data visualization (pp. 315-347): Springer.

Croudace, I. W., Rindby, A., \& Rothwell, R. G. (2006). ITRAX: description and evaluation of a new multi-function X-ray core scanner. Geological Society, London, Special Publications, 267(1), 51-63.

Croudace, I. W., \& Rothwell, R. G. (2015). Micro-XRF Studies of Sediment Cores: Applications of a non-destructive tool for the environmental sciences (Vol. 17): Springer.

Dezileau, L., Lehu, R., Lallemand, S., Hsu, S. K., Babonneau, N., Ratzov, G., . . . Dominguez, S. (2016). Historical reconstruction of submarine earthquakes using $210 \mathrm{~PB}, 137 \mathrm{CS}$, and $241 \mathrm{AM}$ turbidite chronologyand radiocarbon reservoir age estimation off East Taiwan. Radiocarbon, 58(1), 1-12. doi:10.1017/RDC.2015.3

Drab, L., Ferrari, A., Schmidt, S., \& Martinez, P. (2012). The earthquake sedimentary record in the western part of the Sea of Marmara, Turkey. Natural Hazards and Earth System Sciences, 12(4), 1235. doi:10.5194/nhess-12-1235-2012

Ebaid, Y., \& Khater, A. (2006). Determination of $210 \mathrm{~Pb}$ in environmental samples. Journal of Radioanalytical and Nuclear Chemistry, 270. doi:10.1007/s10967006-0470-5

Evans, H. B. (1965). GRAPE*-A Device for Continuous Determination of Material Density and Porosity. Paper presented at the SPWLA 6th Annual Logging Symposium (Volume II).

Fernandez, D., Bowen, M., \& Sutton, P. (2018). Variability, coherence and forcing mechanisms in the New Zealand ocean boundary currents. Progress in Oceanography, 165, 168-188.

Flach, P. A. (2010). ROC Analysis. In C. Sammut \& G. I. Webb (Eds.), Encyclopedia of Machine Learning (pp. 869-875). Boston, MA: Springer US.

Fujii, Y., Satake, K., Sakai, S. i., Shinohara, M., \& Kanazawa, T. (2011). Tsunami source of the 2011 off the Pacific coast of Tohoku Earthquake. Earth, planets and space, 63(7), 55.

Fukuma, K. (1998). 23. Origin and applications of whole-core magnetic susceptibility of sediments and volcanic rocks from Leg152. Paper presented at the Proceedings of the Ocean Drilling Program.

Garrett, E., Fujiwara, O., Garrett, P., Heyvaert, V. M., Shishikura, M., Yokoyama, Y., . . . De Batist, M. (2016). A systematic review of geological evidence for Holocene earthquakes and tsunamis along the Nankai-Suruga Trough, Japan. EarthScience Reviews, 159, 337-357.

Goldfinger, C. (2011). Submarine Paleoseismology Based on Turbidite Records. Annual Review of Marine Science, 3(1), 35-66. doi:10.1146/annurev-marine-120709142852

Goldfinger, C., Morey, A., Black, B., Beeson, J., Nelson, C., \& Patton, J. (2013). Spatially limited mud turbidites on the Cascadia margin: segmented earthquake ruptures? Natural Hazards and Earth System Sciences, 13(8), 2109. doi:10.5194/nhess-13-2109-2013

Goldfinger, C., Nelson, C. H., \& Johnson, J. E. (2003). Deep-water turbidites as Holocene earthquake proxies: the Cascadia subduction zone and northern San Andreas fault systems. Annals of Geophysics, 46(5). 
Goldfinger, C., Nelson, C. H., Morey, A. E., Johnson, J. E., Patton, J. R., Karabanov, E. B., ... Dunhill, G. (2012). Turbidite event history--Methods and implications for Holocene paleoseismicity of the Cascadia subduction zone (2330-7102). Retrieved from

Goldfinger, C., Patton, J. R., Van Daele, M., Moernaut, J., Nelson, C. H., De Batist, M., \& Morey, A. E. (2014). Can turbidites be used to reconstruct a paleoearthquake record for the central Sumatran margin. Comment: Geology, 42, e344.

Gracia, E., Vizcaino, A., Escutia, C., Asioli, A., Rodes, A., Pallas, R., . . Goldfinger, C. (2010). Holocene earthquake record offshore Portugal (SW Iberia): testing turbidite paleoseismology in a slow-convergence margin. Quaternary Science Reviews, 29(9-10), 1156-1172.

Hamling, I. J., Hreinsdóttir, S., Clark, K., Elliott, J., Liang, C., Fielding, E., . . . Wright, T. J. (2017). Complex multifault rupture during the $2016 \mathrm{Mw} 7.8$ Kaikōura earthquake, New Zealand. Science, 356(6334).

Hayward, B. W., Sabaa, A. T., \& Triggs, C. M. (2019). Using foraminiferal test-size distribution and other methods to recognise Quaternary bathyal turbidites and taphonomically-modified faunas. Marine Micropaleontology.

Hayward, B. W., \& Triggs, C. M. (2016). USING MULTI-FORAMINIFERAL-PROXIES TO RESOLVE THE PALEOGEOGRAPHIC HISTORY OF A LOWER MIOCENE, SUBDUCTION-RELATED, SEDIMENTARY BASIN (WAITEMATA BASIN, NEW ZEALAND). Journal of Foraminiferal Research, 46(3), 285-313. doi:10.2113/gsjfr.46.3.285

Heaton, T. J., Köhler, P., Butzin, M., Bard, E., Reimer, R. W., Austin, W. E., . . Kromer, B. (2020). Marine20-the marine radiocarbon age calibration curve $(0-55,000$ cal BP). Radiocarbon, 1-42.

Heezen, B. C., \& Ewing, W. M. (1952). Turbidity currents and submarine slumps, and the 1929 Grand Banks [Newfoundland] earthquake. American journal of Science, 250(12), 849-873.

Heiri, O., Lotter, A. F., \& Lemcke, G. (2001). Loss on ignition as a method for estimating organic and carbonate content in sediments: reproducibility and comparability of results. Journal of Paleolimnology, 25(1), 101-110. doi:10.1023/a:1008119611481

Henrys, S. A., Ellis, S., \& Uruski, C. (2003). Conductive heat flow variations from bottom-simulating reflectors on the Hikurangi margin, New Zealand. Geophysical Research Letters, 30(2).

Hicks, D. M., Gomez, B., \& Trustrum, N. A. (2004). Event suspended sediment characteristics and the generation of hyperpycnal plumes at river mouths: East Coast Continental Margin, North Island, New Zealand. The Journal of Geology, 112(4), 471-485.

Holden, C., Kaneko, Y., D'Anastasio, E., Benites, R., Fry, B., \& Hamling, I. (2017). The 2016 Kaikōura earthquake revealed by kinematic source inversion and seismic wavefield simulations: Slow rupture propagation on a geometrically complex crustal fault network. Geophysical Research Letters, 44(22), 11,320-311,328.

Hopkins, J. L., Wysoczanski, R. J., Orpin, A. R., Howarth, J. D., Strachan, L. J., Lunenburg, R., ... Camp, S. (2020). Deposition and preservation of tephra in marine sediments at the active Hikurangi subduction margin. Quaternary Science Reviews, 247, 106500. 
Howarth, J. D., Cochran, U. A., Langridge, R. M., Clark, K., Fitzsimons, S. J., Berryman, K., ... Strong, D. T. (2018). Past large earthquakes on the Alpine Fault: Paleoseismological progress and future directions. New Zealand Journal of Geology and Geophysics, 61(3), 309-328.

Howarth, J. D., Orpin, A., Kaneko, Y., Strachan, L. J., Nodder, S. D., Mountjoy, J., . . Holden, $C$. (in review). Calibrating the marine turbidite paleoseismometer.

Ikehara, K., Kanamatsu, T., Nagahashi, Y., Strasser, M., Fink, H., Usami, K., . . . Wefer, G. (2016). Documenting large earthquakes similar to the 2011 Tohoku-oki earthquake from sediments deposited in the Japan Trench over the past 1500 years. Earth and Planetary Science Letters, 445, 48-56.

Izenman, A. J. (2008). Linear Discriminant Analysis Modern Multivariate Statistical Techniques: Regression, Classification, and Manifold Learning (pp. 237-280). New York, NY: Springer New York.

Jansen, J., Van der Gaast, S., Koster, B., \& Vaars, A. (1998). CORTEX, a shipboard XRFscanner for element analyses in split sediment cores. Marine Geology, 151(1-4), 143-153.

Jones, G. A., \& Kaiteris, P. (1983). A vacuum-gasometric technique for rapid and precise analysis of calcium carbonate in sediments and soils: Research-method paper. Journal of Sedimentary Research, 53(2).

Joseph, L. H., Rea, D. K., \& van der Pluijm, B. A. (1998). Use of grain size and magnetic fabric analyses to distinguish among depositional environments. Paleoceanography, 13(5), 491-501. doi:10.1029/98PA01939

Kanamatsu, T., Usami, K., McHugh, C. M., \& Ikehara, K. (2017). High-resolution chronology of sediment below CCD based on Holocene paleomagnetic secular variations in the T ohoku-oki earthquake rupture zone. Geochemistry, Geophysics, Geosystems, 18(8), 2990-3002.

Kanamori, H. (1972). Mechanism of tsunami earthquakes. Physics of the Earth and Planetary Interiors, 6(5), 346-359.

Kassambara, A. (2018). Machine Learning Essentials: Practical Guide in R: sthda.

Koshimura, S., \& Shuto, N. (2015). Response to the 2011 Great East Japan earthquake and tsunami disaster. Philosophical Transactions of the Royal Society A: Mathematical, Physical and Engineering Sciences, 373(2053), 20140373.

Kuenen, P. H. (1964). Deep-sea sands and ancient turbidites Developments in sedimentology (Vol. 3, pp. 3-33): Elsevier.

Lay, T., Ammon, C. J., Kanamori, H., Xue, L., \& Kim, M. J. (2011). Possible large neartrench slip during the $2011 \mathrm{M}$ w 9.0 off the Pacific coast of Tohoku Earthquake. Earth, planets and space, 63(7), 32.

Le, J., \& Shackleton, N. J. (1992). Carbonate dissolution fluctuations in the western equatorial Pacific during the late Quaternary. Paleoceanography, 7(1), 21-42.

Lehu, R., Lallemand, S., Hsu, S.-K., Babonneau, N., Ratzov, G., Lin, A. T., \& Dezileau, L. (2015). Deep-sea sedimentation offshore eastern Taiwan: Facies and processes characterization. Marine Geology, 369, 1-18. doi:https://doi.org/10.1016/i.margeo.2015.05.013

Lehu, R., Lallemand, S., Ratzov, G., Babonneau, N., Hsu, S.-K., Lin, A., \& Dezileau, L. (2016). An attempt to reconstruct 2700 years of seismicity using deep-sea turbidites offshore eastern Taiwan. Tectonophysics, 692, 309. 
Lewis, K. B. (1980). Quaternary sedimentation on the Hikurangi oblique-subduction and transform margin, New Zealand Sedimentation in oblique-slip mobile zones (Vol. 4, pp. 171-189).

Lewis, K. B. (1994). The 1500-km-long Hikurangi Channel: trench-axis channel that escapes its trench, crosses a plateau, and feeds a fan drift. Geo-Marine Letters, 14(1), 19-28.

Lewis, K. B., \& Barnes, P. L. (1999). Kaikoura Canyon, New Zealand: active conduit from near-shore sediment zones to trench-axis channel. Marine Geology, 162(1), 3969. doi:10.1016/s0025-3227(99)00075-4

Lewis, K. B., Collot, J. Y., \& Lallem, S. E. (1998). The dammed Hikurangi Trough: a channel-fed trench blocked by subducting seamounts and their wake avalanches (New Zealand-France GeodyNZ Project). Basin Research, 10(4), 441468.

Li, H., Zhang, S., Bai, L., \& Fang, N. (2010). Diagenetic control of magnetic susceptibility variation in Core MD98-2172 from the Eastern Timor Sea. Chinese Journal of Oceanology and Limnology, 28(6), 1350-1361.

Mcllroy, D. (2004). Some ichnological concepts, methodologies, applications and frontiers. Geological Society, London, Special Publications, 228(1), 3-27.

McKeown, M. (2018). Understanding the Physical sedimentology of the Madden Canyon distributary system, New Zealand. ResearchSpace@ Auckland.

McLaren, P. (1981). An interpretation of trends in grain size measures. Journal of Sedimentary Research, 51(2), 611-624. doi:10.1306/212f7cf2-2b24-11d7$8648000102 \mathrm{c} 1865 \mathrm{~d}$

McSaveney, M. J., Graham, I. J., Begg, J. G., Beu, A. G., Hull, A. G., Kim, K., \& Zondervan, A. (2006). Late Holocene uplift of beach ridges at Turakirae Head, south Wellington coast, New Zealand. New Zealand Journal of Geology and Geophysics, 49(3), 337-358.

Meiburg, E., \& Kneller, B. (2010). Turbidity Currents and Their Deposits. Annual Review of Fluid Mechanics, 42, 135-156. doi:10.1146/annurev-fluid-121108-145618

Micallef, A., \& Mountjoy, J. J. (2011). A topographic signature of a hydrodynamic origin for submarine gullies. Geology, 39(2), 115-118.

Moernaut, J., Van Daele, M., Fontijn, K., Heirman, K., Kempf, P., Pino, M., . . . De Batist, M. (2018). Larger earthquakes recur more periodically: New insights in the megathrust earthquake cycle from lacustrine turbidite records in south-central Chile. Earth and Planetary Science Letters, 481, 9-19.

Mountjoy, J. J., Barnes, P. M., \& Pettinga, J. R. (2009). Morphostructure and evolution of submarine canyons across an active margin: Cook Strait sector of the Hikurangi Margin, New Zealand. Marine Geology, 260(1-4), 45-68.

Mountjoy, J. J., Howarth, J. D., Orpin, A. R., Barnes, P. M., Bowden, D. A., Rowden, A. A., ... Kane, T. (2018). Earthquakes drive large-scale submarine canyon development and sediment supply to deep-ocean basins. Science Advances, 4(3). doi:10.1126/sciadv.aar3748

Mueller, C. S., Briggs, R. W., Wesson, R. L., \& Petersen, M. D. (2015). Updating the USGS seismic hazard maps for Alaska. Quaternary Science Reviews, 113, 39-47.

Nicol, A., \& Beavan, J. (2003). Shortening of an overriding plate and its implications for slip on a subduction thrust, central Hikurangi Margin, New Zealand. Tectonics, 22(6). 
Nicol, A., Mazengarb, C., Chanier, F., Rait, G., Uruski, C., \& Wallace, L. (2007). Tectonic evolution of the active Hikurangi subduction margin, New Zealand, since the Oligocene. Tectonics, 26(4).

Noda, A., Tuzino, T., Kanai, Y., Furukawa, R., \& Uchida, J.-I. (2008). Paleoseismicity along the southern Kuril Trench deduced from submarine-fan turbidites. Marine Geology, 254(1), 73-90. doi:10.1016/j.margeo.2008.05.015

Nour, S., Burnett, W. C., \& Horwitz, E. P. (2002). 234Th analysis of marine sediments via extraction chromatography and liquid scintillation counting. Applied Radiation and Isotopes, 57(2), 235-241. doi:10.1016/S0969-8043(02)00088-X

Oksanen, J., Blanchet, F. G., Kindt, R., Legendre, P., Minchin, P. R., O'hara, R., . . . Wagner, H. (2013). Package 'vegan'. Community ecology package, version, 2(9), 1-295.

Orsi, T. H., Edwards, C. M., \& Anderson, A. L. (1994). X-ray computed tomography: a nondestructive method for quantitative analysis of sediment cores. Journal of Sedimentary Research, 64(3).

Ota, Y., Pillans, B., Berryman, K., Beu, A., Fujimori, T., Miyauchi, T., . . Climo, F. (1996). Pleistocene coastal terraces of Kaikoura peninsula and the Marlborough coast, South Island, New Zealand. New Zealand Journal of Geology and Geophysics, 39(1), 51-73.

Patton, J., Goldfinger, C., Morey, A. E., Ikehara, K., Romsos, C., Stoner, J., . . Vizcaino, A. (2015). A 6600 year earthquake history in the region of the 2004 SumatraAndaman subduction zone earthquake. Geosphere, 11(6), 2067-2129.

Patton, J., Romsos, C., Black, B., Morey, A., Djadjadihardja, Y., \& Goldfinger, C. (2013). Seismoturbidite record as preserved at core sites at the Cascadia and SumatraAndaman subduction zones.

Paull, C. K., Talling, P. J., Maier, K. L., Parsons, D., Xu, J., Caress, D. W., . . Cartigny, M. J. (2018). Powerful turbidity currents driven by dense basal layers. Nature Communications, 9(1), 4114. doi:10.1038/s41467-018-06254-6

Philp, R. P., \& Jardé, E. (2007). APPLICATION OF STABLE ISOTOPES AND RADIOISOTOPES IN ENVIRONMENTAL FORENSICS. Introduction to environmental forensics, 455-512. doi:10.1016/B978-012369522-2/50011-7

Pickering, K. T., \& Hiscott, R. N. (2015). Deep marine systems: processes, deposits, environments, tectonics and sedimentation: John Wiley \& Sons.

Pickering, K. T., Stow, D., Watson, M., \& Hiscott, R. (1986). Deep-water facies, processes and models: a review and classification scheme for modern and ancient sediments. Earth-Science Reviews, 23(2), 75-174.

Piper, D. J., \& Normark, W. R. (2009). Processes that initiate turbidity currents and their influence on turbidites: a marine geology perspective. Journal of Sedimentary Research, 79(6), 347-362.

Polonia, A., Panieri, G., Gasperini, L., Gasparotto, G., Bellucci, L., \& Torelli, L. (2013). Turbidite paleoseismology in the Calabrian Arc subduction complex (Ionian Sea). Geochemistry, Geophysics, Geosystems, 14(1), 112-140.

Pouderoux, H., Lamarche, G., \& Proust, J.-N. (2012). Building an 18 000-year-long paleo-earthquake record from detailed deep-sea turbidite characterisation in Poverty Bay, New Zealand. 
Pouderoux, H., Proust, J.-N., \& Lamarche, G. (2014). Submarine paleoseismology of the northern Hikurangi subduction margin of New Zealand as deduced from Turbidite record since $16 \mathrm{ka}$. Quaternary Science Reviews, 84, 116.

Pouderoux, H., Proust, J.-N., Lamarche, G., Orpin, A., \& Neil, H. (2012). Postglacial (after $18 \mathrm{ka}$ ) deep-sea sedimentation along the Hikurangi subduction margin (New Zealand): Characterisation, timing and origin of turbidites. Marine Geology, 295, 51-76.

Ramsey, C. B. (2008). Deposition models for chronological records. Quaternary Science Reviews, 27(1-2), 42-60.

Ratzov, G., Cattaneo, A., Babonneau, N., Déverchère, J., Yelles, K., Bracene, R., \& Courboulex, F. (2015). Holocene turbidites record earthquake supercycles at a slow-rate plate boundary. Geology, 43(4), 331-334.

Reilly, B., Stoner, J., \& Wiest, J. (2017). Sed CT: MATLAB ${ }^{\mathrm{TM}}$ tools for standardized and quantitative processing of sediment core computed tomography (CT) data collected using a medical CT scanner. Geochemistry, Geophysics, Geosystems, 18(8), 3231-3240.

Rothwell, R. G., \& Rack, F. R. (2006). New techniques in sediment core analysis: an introduction. Geological Society, London, Special Publications, 267(1), 1-29.

Sawai, Y., Namegaya, Y., Okamura, Y., Satake, K., \& Shishikura, M. (2012). Challenges of anticipating the 2011 Tohoku earthquake and tsunami using coastal geology. Geophysical Research Letters, 39(21).

Shane, P. (2000). Tephrochronology: a New Zealand case study. Earth-Science Reviews, 49(1), 223-259. doi:https://doi.org/10.1016/S0012-8252(99)00058-6

Shanmugam, G. (2008). Deep-water bottom currents and their deposits. Developments in sedimentology, 60, 59-81.

Sieh, K., Natawidjaja, D. H., Meltzner, A. J., Shen, C.-C., Cheng, H., Li, K.-S., . . Edwards, R. L. (2008). Earthquake supercycles inferred from sea-level changes recorded in the corals of west Sumatra. Science, 322(5908), 1674-1678.

Stow, D., \& Piper, D. (1984). Deep-water fine-grained sediments: facies models. Geological Society, London, Special Publications, 15(1), 611-646.

Stow, D., \& Smillie, Z. (2020). Distinguishing between Deep-Water Sediment Facies: Turbidites, Contourites and Hemipelagites. Geosciences, 10(2), 68.

Stow, D., \& Tabrez, A. R. (1998). Hemipelagites: processes, facies and model. Geological Society, London, Special Publications, 129(1), 317-337.

Sumner, E., Siti, M., McNeill, L. C., Talling, P., Henstock, T., Wynn, R., ... Permana, H. (2013). Can turbidites be used to reconstruct a paleoearthquake record for the central Sumatran margin? Geology, 41(7), 763-766. doi:10.1130/G34298.1

Talling, P. J. (2014). On the triggers, resulting flow types and frequencies of subaqueous sediment density flows in different settings. Marine Geology, 352, 155-182. doi:https://doi.org/10.1016/j.margeo.2014.02.006

Talling, P. J., Masson, D. G., Sumner, E. J., \& Malgesini, G. (2012). Subaqueous sediment density flows: Depositional processes and deposit types. Sedimentology, 59(7), 1937-2003.

Talling, P. J., Paull, C. K., \& Piper, D. J. (2013). How are subaqueous sediment density flows triggered, what is their internal structure and how does it evolve? Direct observations from monitoring of active flows. Earth-Science Reviews, 125, 244287. 
Thomson, J., \& Weaver, P. (1994). An AMS radiocarbon method to determine the emplacement time of recent deep-sea turbidites. Sedimentary Geology, 89(12), 1-7.

Ting, K. M. (2017). Confusion Matrix. In C. Sammut \& G. I. Webb (Eds.), Encyclopedia of Machine Learning and Data Mining (pp. 260-260). Boston, MA: Springer US.

Usami, K., Ikehara, K., Jenkins, R. G., \& Ashi, J. (2017). Benthic foraminiferal evidence of deep-sea sediment transport by the 2011 Tohoku-oki earthquake and tsunami. Marine Geology, 384, 214-224.

Usami, K., Ikehara, K., Kanamatsu, T., \& McHugh, C. M. (2018). Supercycle in great earthquake recurrence along the Japan Trench over the last 4000 years. Geoscience Letters, 5(1), 1-12.

Wallace, L. M., Barnes, P., Beavan, J., Van Dissen, R., Litchfield, N., Mountjoy, J., . . . Pondard, N. (2012). The kinematics of a transition from subduction to strikeslip: An example from the central New Zealand plate boundary. Journal of Geophysical Research: Solid Earth, 117(B2).

Wallace, L. M., Cochran, U. A., Power, W. L., \& Clark, K. J. (2014). Earthquake and tsunami potential of the Hikurangi subduction thrust, New Zealand: Insights from paleoseismology, GPS, and tsunami modeling. Oceanography, 27(2), 104117.

Wallace, L. M., Reyners, M., Cochran, U., Bannister, S., Barnes, P. M., Berryman, K., . . Ellis, S. (2009). Characterizing the seismogenic zone of a major plate boundary subduction thrust: Hikurangi Margin, New Zealand. Geochemistry, Geophysics, Geosystems, 10(10).

Zolitschka, B., Mingram, J., Van Der Gaast, S., Jansen, J. F., \& Naumann, R. (2002). Sediment logging techniques Tracking environmental change using lake sediments (pp. 137-153): Springer. 
References 


\section{Appendices}

\section{A. Core Site Maps}

Appendix A contains maps of the bathymetry surrounding each core site.

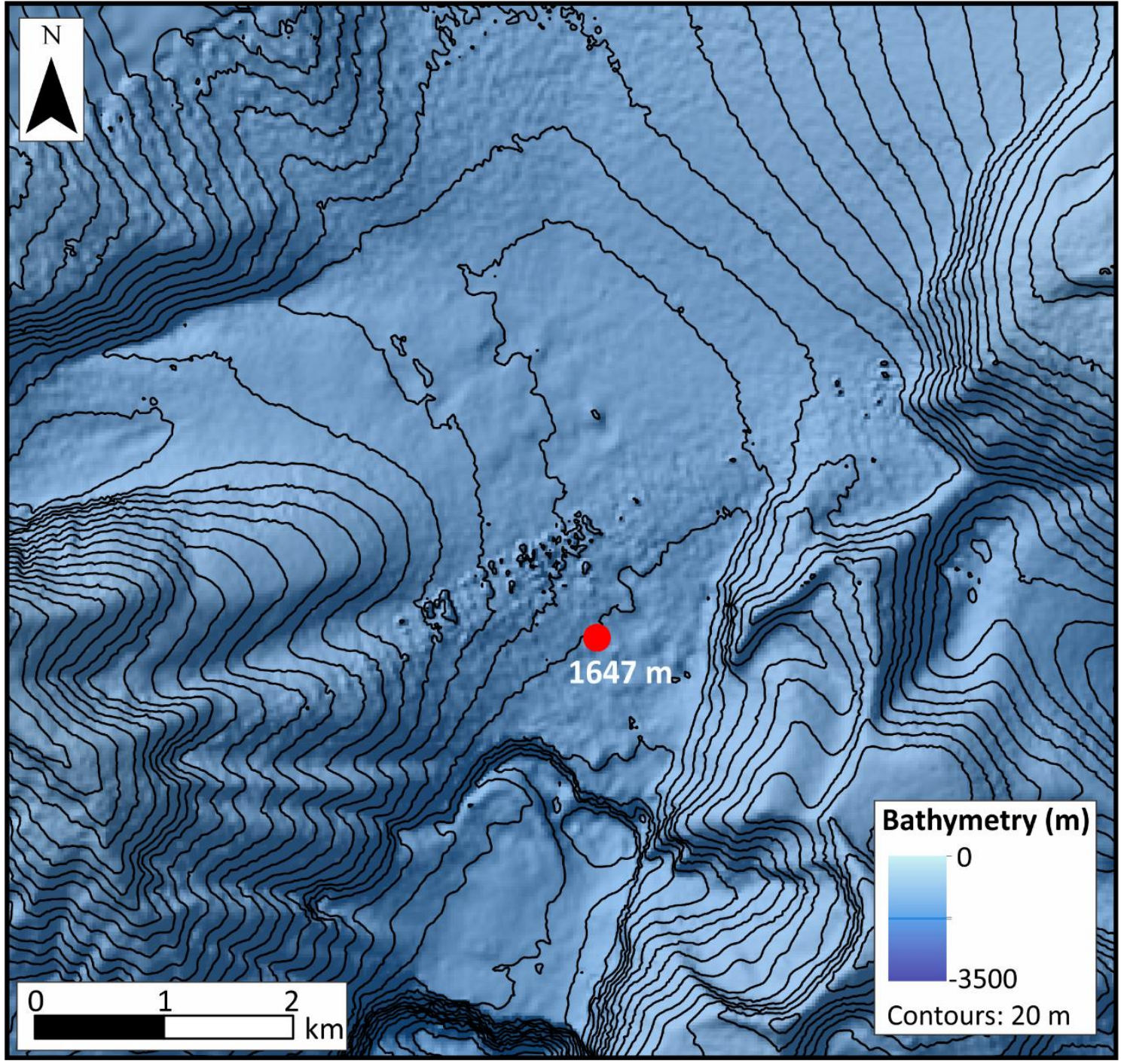

Figure A.1 TAN1705-36 core site bathymetry 


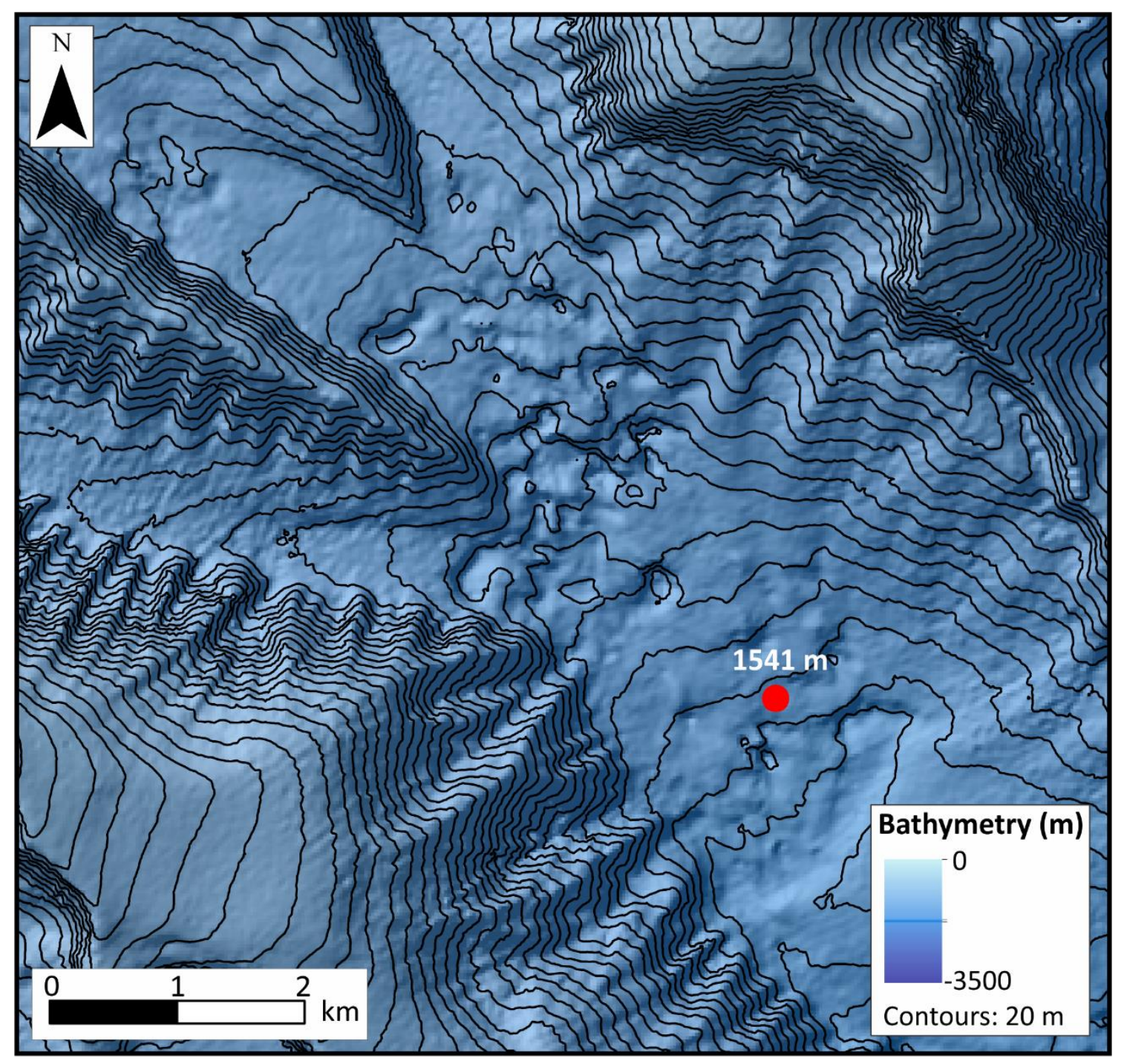

Figure A.2 TAN1705-33 core site bathymetry 


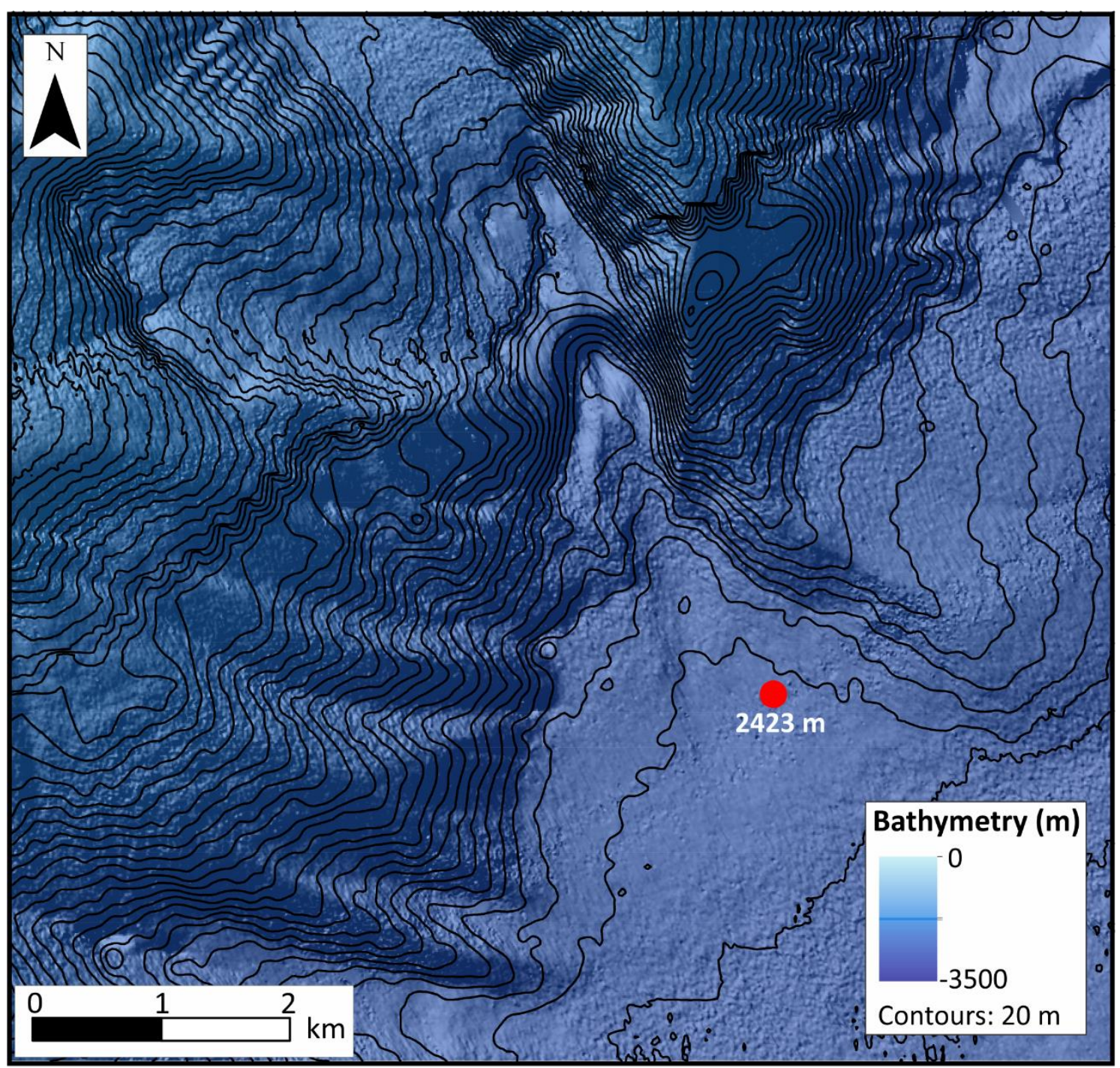

Figure A.3 TAN1705-26 core site bathymetry. 


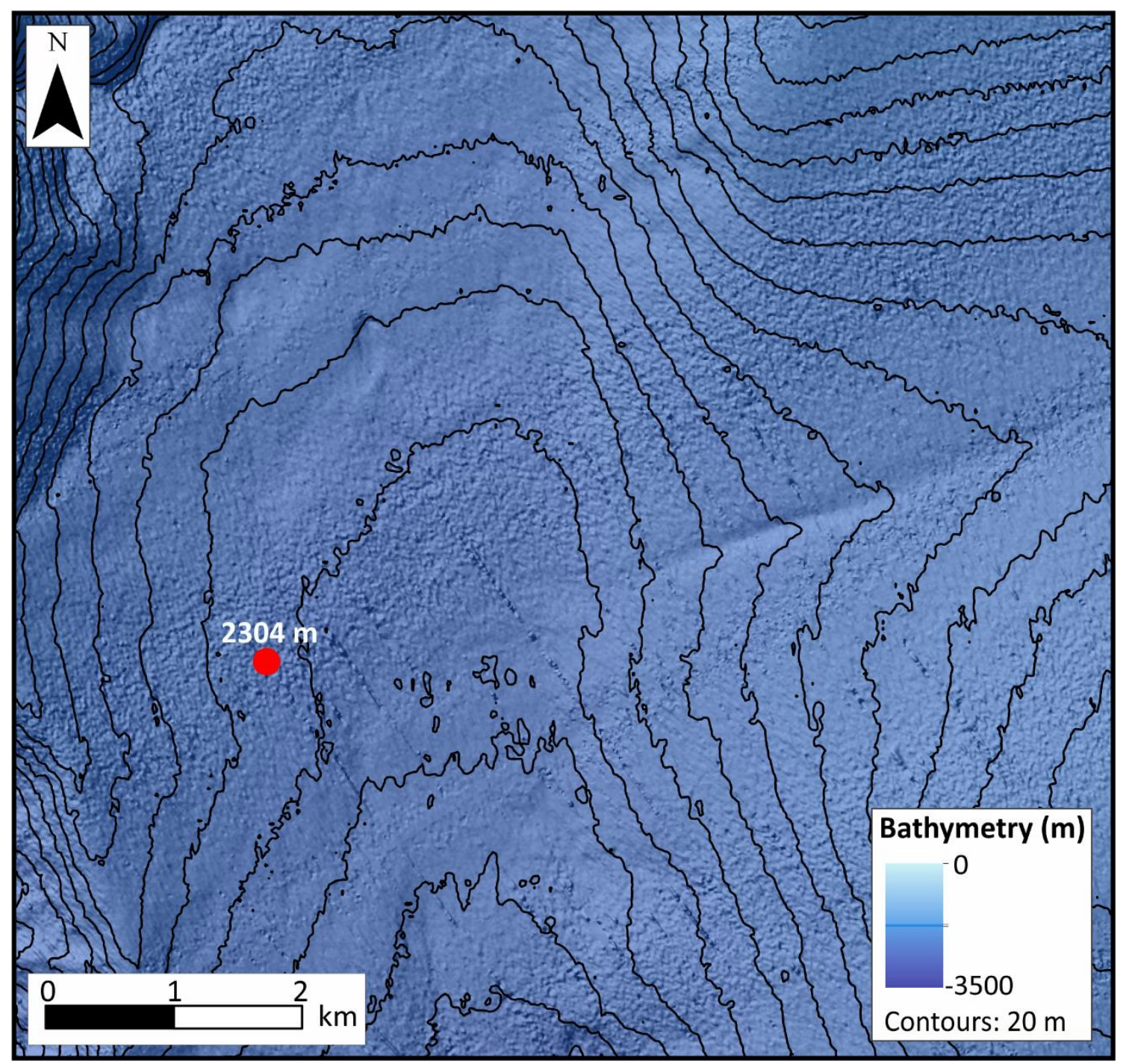

Figure A.4 TAN1705-25 core site bathymetry. 


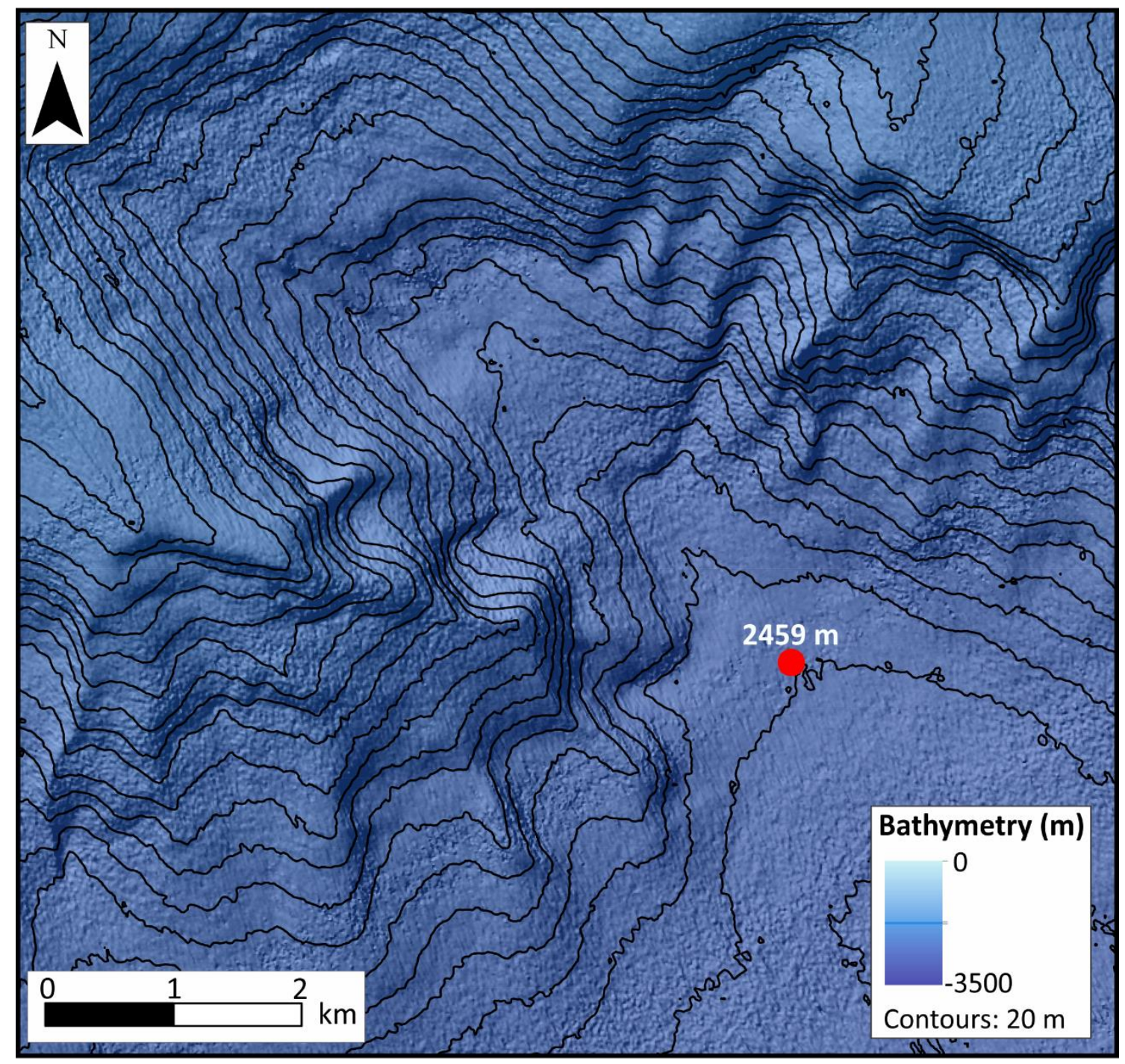

Figure A.5 TAN1705-24 core site bathymetry. 


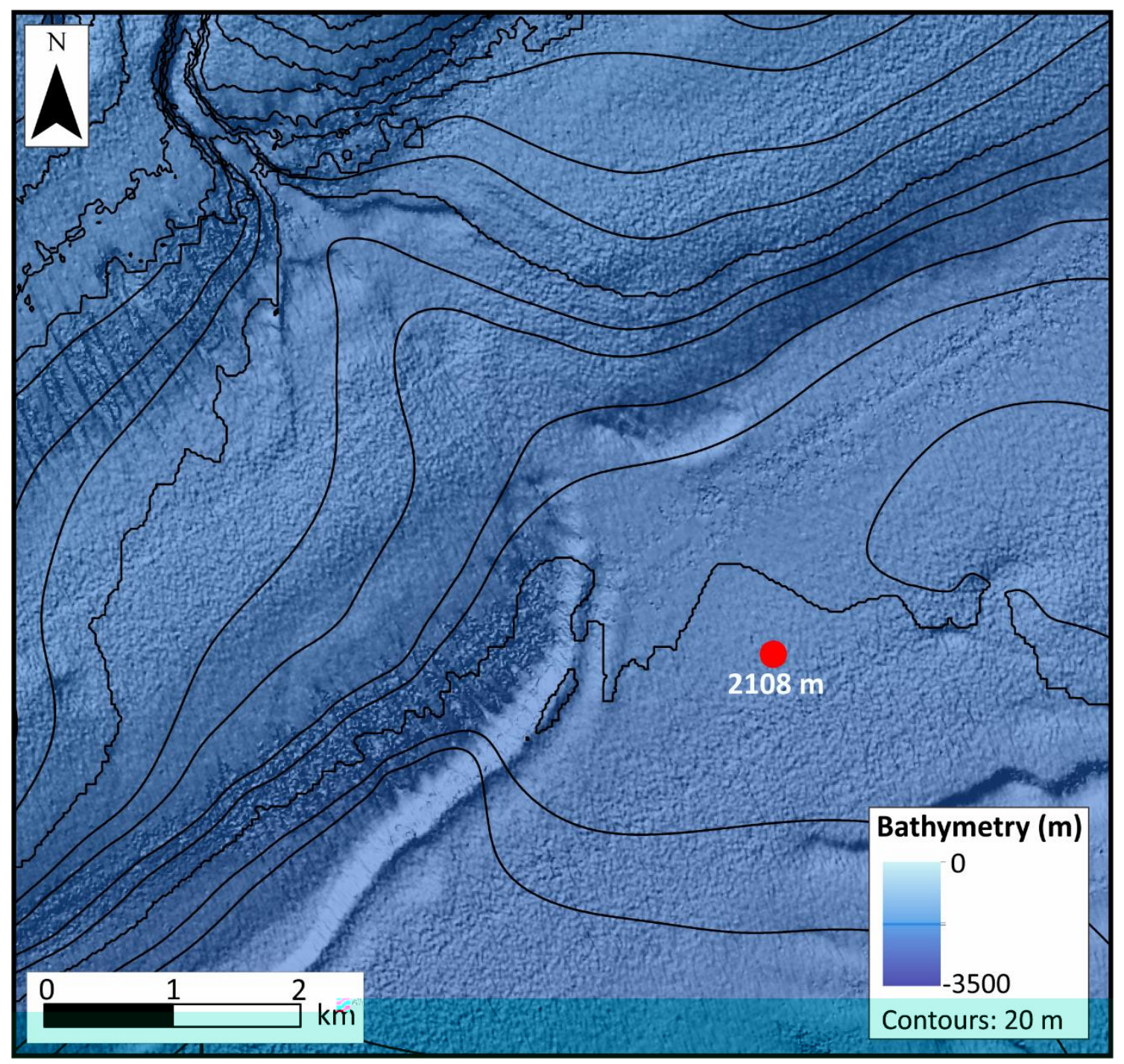

Figure A.6 TAN1705-22 core site bathymetry. 


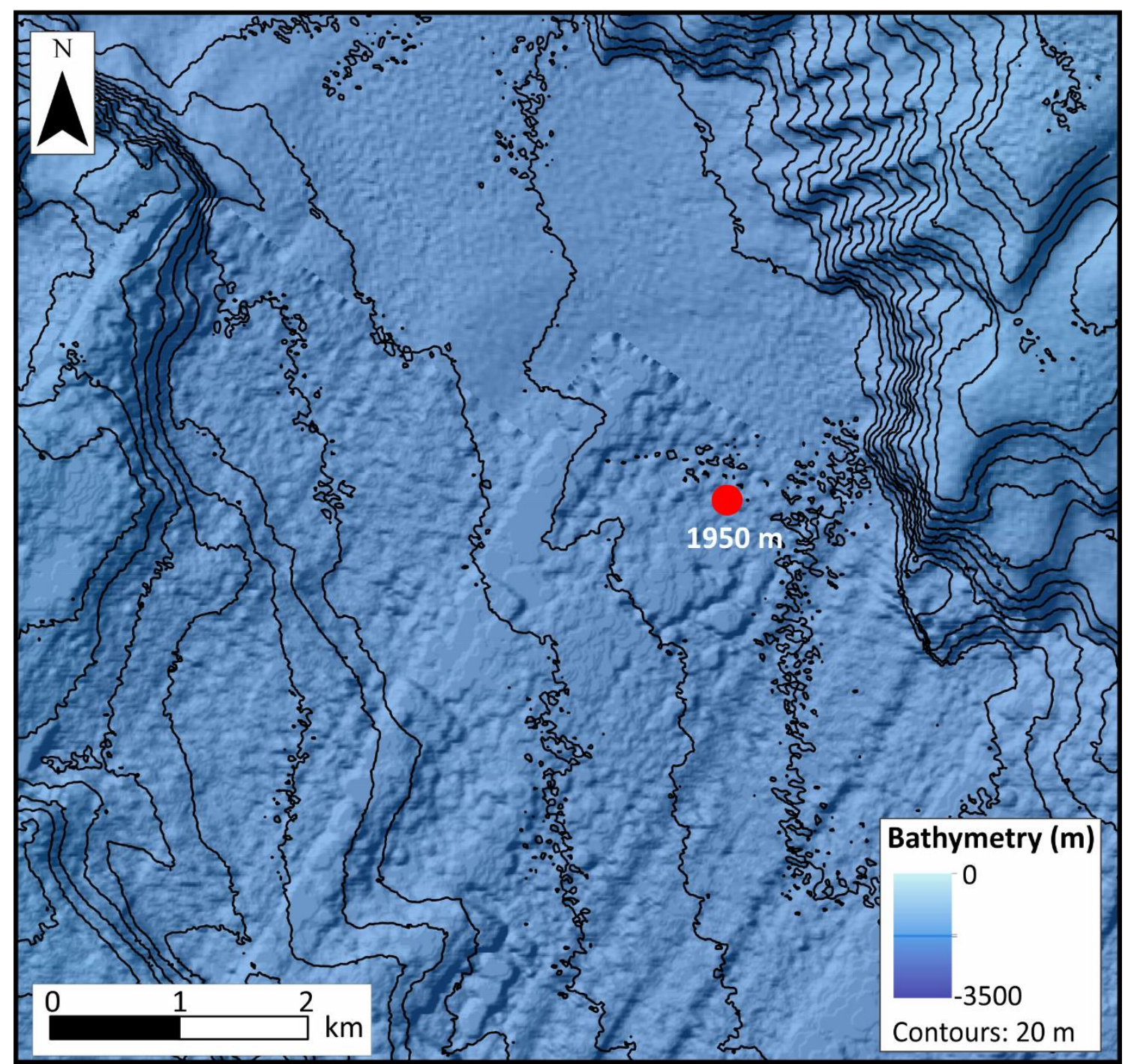

Figure A.7 TAN1613-27 core site bathymetry. 


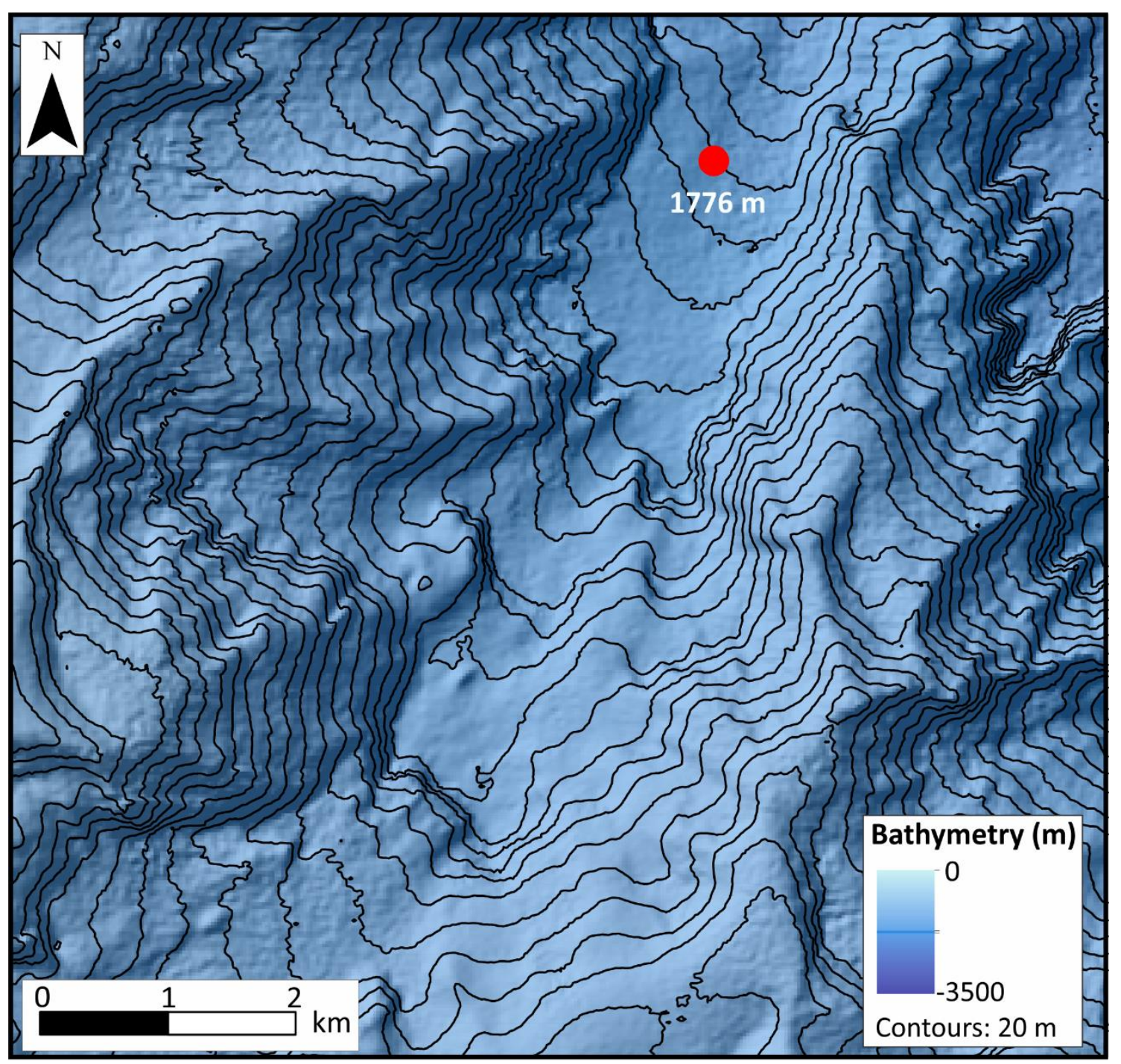

Figure A.8 TAN1705-37 core site bathymetry. 


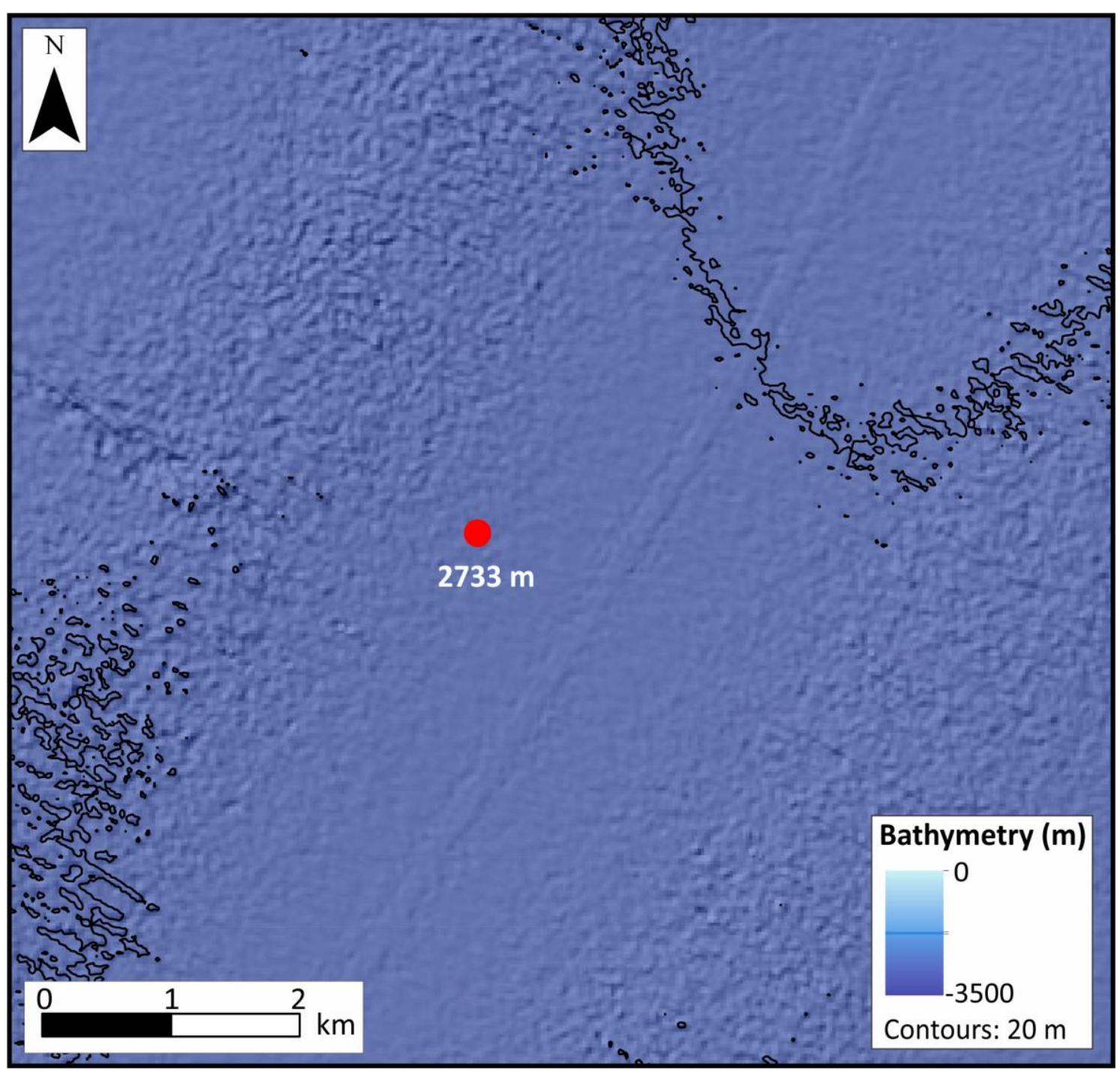

Figure A.9 TAN1705-21 core site bathymetry. 


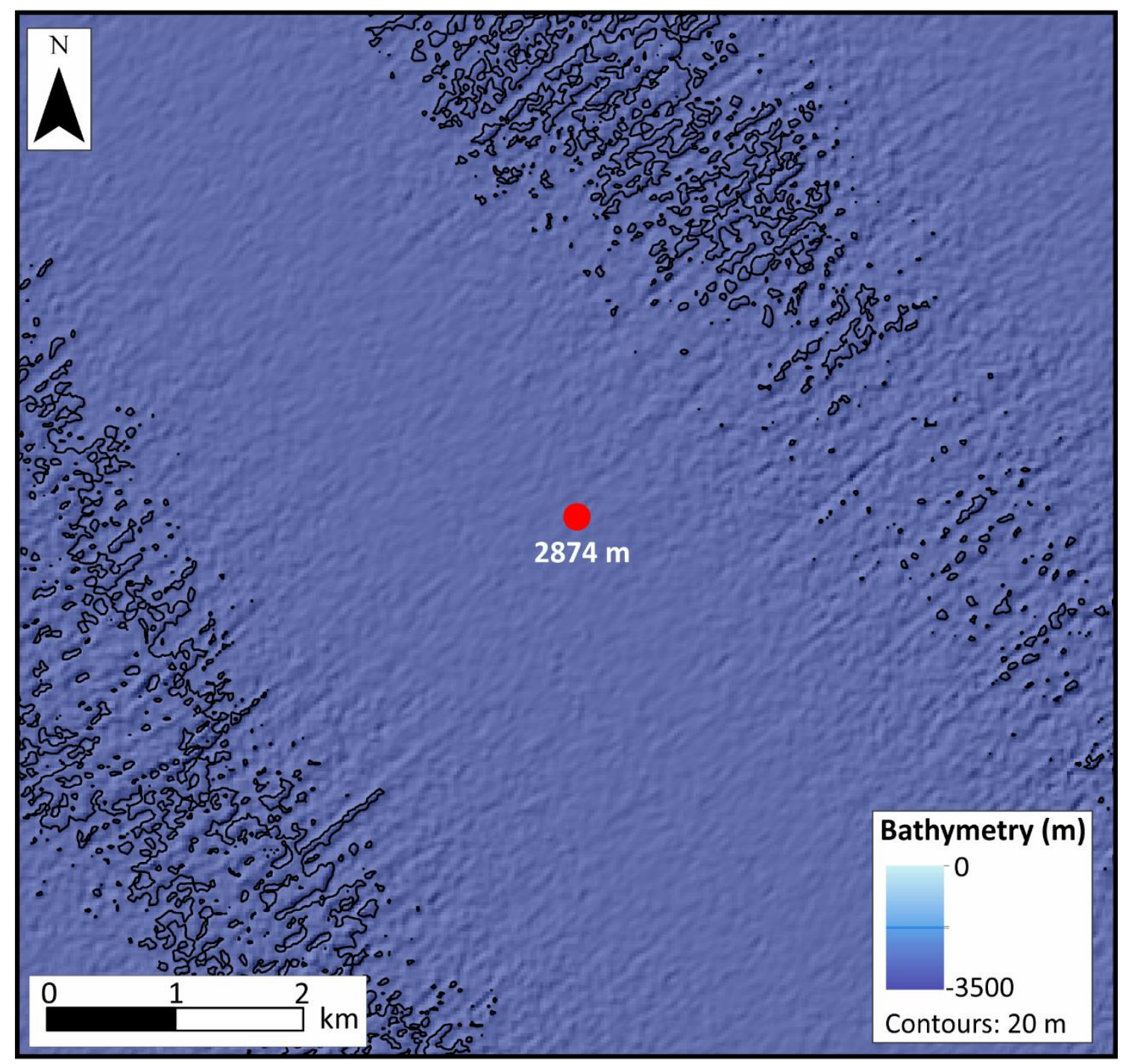

Figure A.10 TAN1705-20 core site bathymetry. 


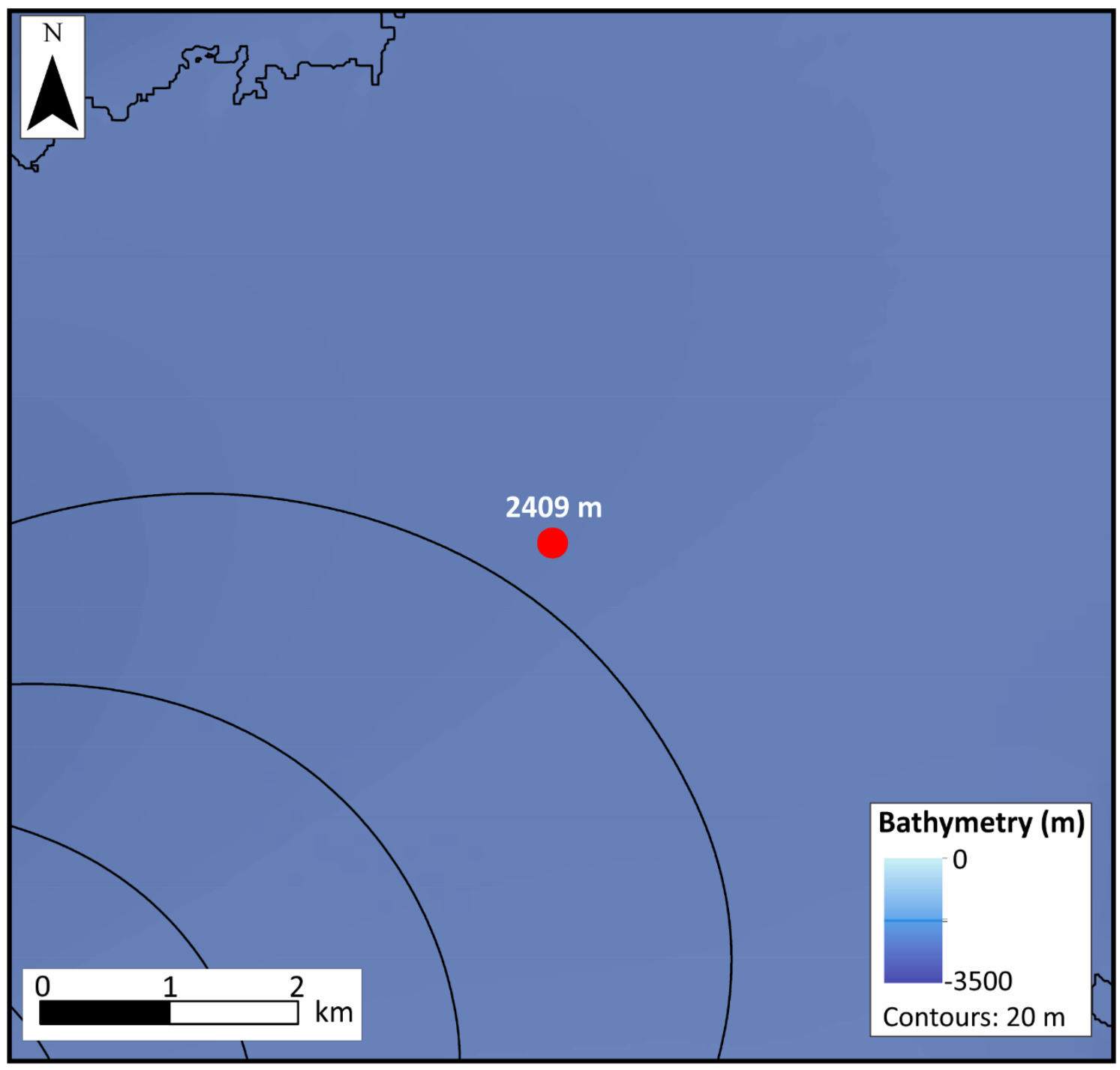

Figure A.11 TAN1705-18 and TAN1613-25 core site bathymetry. 


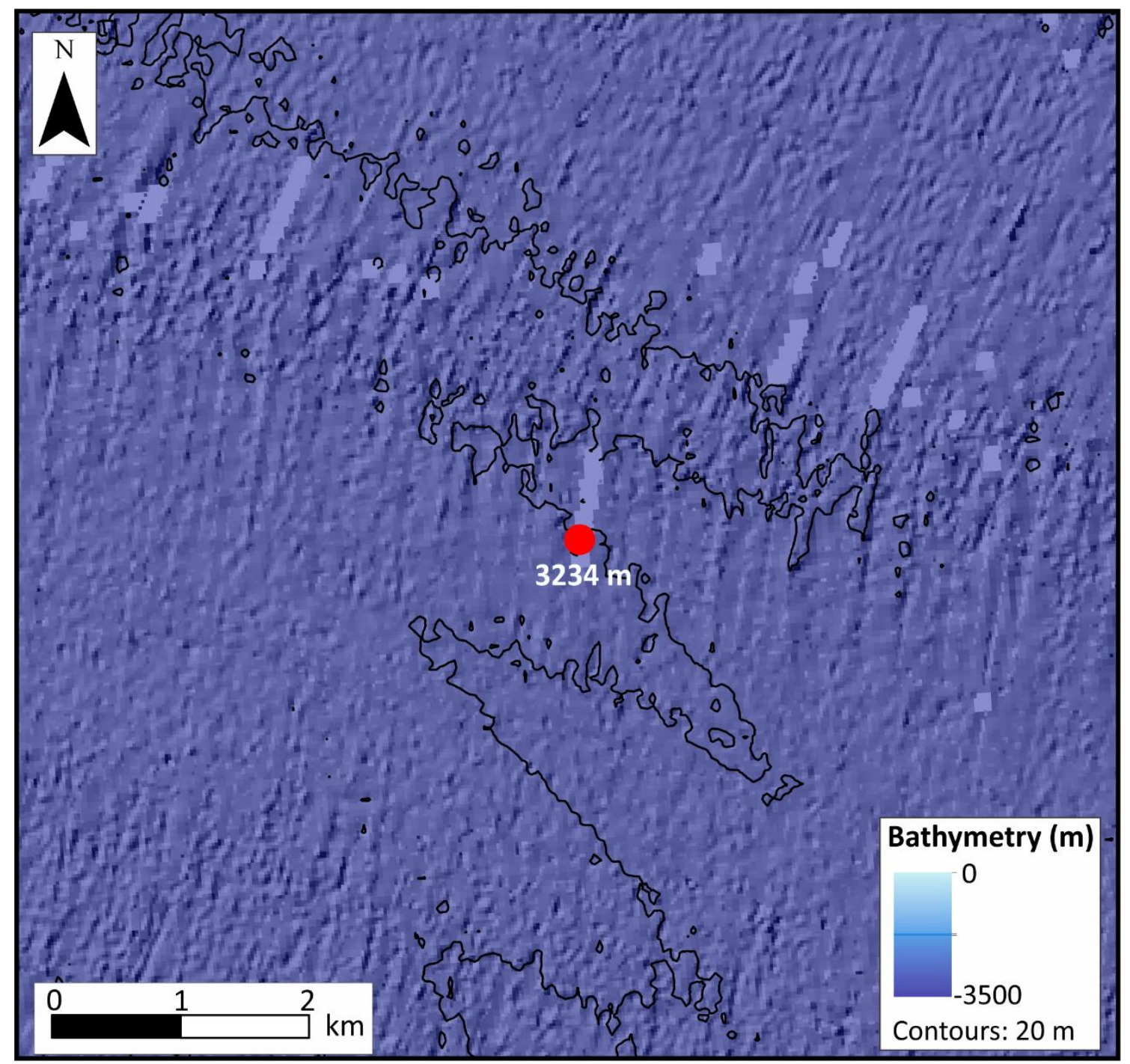

Figure A.12 TAN1705-16 core site bathymetry. 


\section{B. Foraminiferal Data Tables}

Appendix B contains tables of the foraminiferal dataset, calculated by Bruce Hayward and Ashwaq Sabaa of Geomarine Research.

Table B.1 TAN1705-33 foraminiferal data table

\begin{tabular}{|c|c|c|c|c|c|c|c|c|}
\hline Sample & Tests/g & $\begin{array}{c}\text { Fragmentation } \\
\text { index }\end{array}$ & Planktic\% & $\begin{array}{c}\text { Revised } \\
\text { Fragmentation } \\
\text { index }\end{array}$ & $\begin{array}{l}\text { Fl-adjusted } \\
\text { Planktic\% }\end{array}$ & $\begin{array}{c}\%>250 \\
\mu \mathrm{m}\end{array}$ & $\begin{array}{l}\% 125- \\
250 \mu \mathrm{m}\end{array}$ & $\begin{array}{c}\% \text { 63-125 } \\
\mu \mathrm{m}\end{array}$ \\
\hline $3-5 \mathrm{~cm}$ & 222.81 & 17.97 & 62.34 & 77.80 & 88.17 & 1.02 & 2.97 & 96.01 \\
\hline $5-7.5 \mathrm{~cm}$ & 721.87 & 18.42 & 82.89 & 78.32 & 95.72 & 3.92 & 9.49 & 86.59 \\
\hline $7.5-9.5 \mathrm{~cm}$ & 1742.25 & 15.92 & 82.35 & 75.18 & 94.95 & 2.39 & 5.16 & 92.45 \\
\hline $9.5-11.5 \mathrm{~cm}$ & 1043.31 & 20.66 & 90.74 & 80.65 & 98.06 & 4.93 & 4.99 & 90.08 \\
\hline $11.5-13.5 \mathrm{~cm}$ & 1728.07 & 17.75 & 79.50 & 77.54 & 94.52 & 1.73 & 6.18 & 92.09 \\
\hline $13.5-15.5 \mathrm{~cm}$ & 1153.74 & 14.29 & 90.63 & 72.73 & 97.26 & 2.96 & 5.21 & 91.82 \\
\hline $15.5-17.5 \mathrm{~cm}$ & 1011.18 & 21.29 & 83.33 & 81.23 & 96.38 & 2.05 & 6.30 & 91.65 \\
\hline $17.5-19.5 \mathrm{~cm}$ & 816.77 & 19.94 & 89.68 & 79.94 & 97.74 & 3.83 & 8.18 & 87.99 \\
\hline
\end{tabular}


Table B.2 TAN1705-26 foraminiferal data table

\begin{tabular}{|c|c|c|c|c|c|c|c|c|}
\hline Sample & Tests/g & $\begin{array}{c}\text { Fragmentation } \\
\text { index }\end{array}$ & Planktic\% & $\begin{array}{c}\text { Revised } \\
\text { Fragmentation } \\
\text { index }\end{array}$ & $\begin{array}{c}\text { Fl-adjusted } \\
\text { Planktic\% }\end{array}$ & $\begin{array}{c}\text { \% >250 } \\
\boldsymbol{\mu m}\end{array}$ & $\begin{array}{c}\text { \% 125- } \\
\mathbf{2 5 0} \boldsymbol{\mu m}\end{array}$ & $\begin{array}{c}\text { \% 63- } \\
\mathbf{1 2 5} \boldsymbol{\mu \mathbf { m }}\end{array}$ \\
\hline $0-2 \mathrm{~cm}$ & 7.01 & 19.50 & 54.00 & 79.50 & 85.10 & 0.00 & 20.00 & 80.00 \\
\hline $2-4 \mathrm{~cm}$ & 87.91 & 23.50 & 34.00 & 83.10 & 75.40 & 0.00 & 10.48 & 89.52 \\
\hline $4-6 \mathrm{~cm}$ & 752.90 & 37.40 & 37.00 & 90.50 & 85.90 & 0.28 & 12.45 & 87.27 \\
\hline $6-8 \mathrm{~cm}$ & 2958.96 & 41.20 & 34.00 & 91.80 & 86.50 & 0.19 & 8.96 & 90.85 \\
\hline $8-10 \mathrm{~cm}$ & 1296.72 & 41.10 & 33.00 & 91.80 & 85.80 & 0.07 & 2.26 & 97.67 \\
\hline $10-11 \mathrm{~cm}$ & 2700.33 & 27.80 & 33.00 & 86.00 & 77.50 & 0.05 & 1.65 & 98.30 \\
\hline $11-12 \mathrm{~cm}$ & 9697.64 & 40.30 & 32.00 & 91.50 & 84.50 & 0.31 & 7.55 & 92.14 \\
\hline $12-13 \mathrm{~cm}$ & 6278.97 & 43.40 & 37.00 & 92.50 & 88.80 & 0.10 & 3.69 & 96.21 \\
\hline $13-14 \mathrm{~cm}$ & 9212.96 & 38.10 & 42.00 & 90.80 & 88.80 & 0.03 & 1.56 & 98.41 \\
\hline $14-15 \mathrm{~cm}$ & 4588.39 & 44.40 & 38.00 & 92.80 & 89.40 & 0.06 & 3.66 & 96.29 \\
\hline $15-16 \mathrm{~cm}$ & 9606.07 & 35.90 & 33.00 & 90.00 & 83.30 & 0.22 & 3.89 & 95.89 \\
\hline $16-17 \mathrm{~cm}$ & 2057.01 & 32.70 & 37.00 & 88.60 & 83.50 & 1.27 & 10.77 & 87.96 \\
\hline $17-18 \mathrm{~cm}$ & 974.65 & 45.20 & 42.00 & 92.90 & 91.30 & 0.58 & 10.79 & 88.63 \\
\hline $18-20 \mathrm{~cm}$ & 327.97 & 38.50 & 36.00 & 90.90 & 86.30 & 0.36 & 21.46 & 78.18 \\
\hline $20-22 \mathrm{~cm}$ & 205.61 & 38.10 & 35.00 & 90.80 & 85.10 & 0.45 & 25.00 & 74.55 \\
\hline $22-24 \mathrm{~cm}$ & 1514.62 & 28.80 & 42.00 & 86.60 & 84.50 & 0.03 & 4.90 & 95.07 \\
\hline $24-26 \mathrm{~cm}$ & 219.96 & 20.70 & 39.00 & 80.60 & 76.90 & 0.87 & 22.34 & 76.79 \\
\hline $26-28 \mathrm{~cm}$ & 419.85 & 23.10 & 38.00 & 82.80 & 77.80 & 0.50 & 10.65 & 88.85 \\
\hline & & & & & & \\
\hline
\end{tabular}


Table B.3 TAN1705-24 foraminiferal data table

\begin{tabular}{|c|c|c|c|c|c|c|c|c|}
\hline Sample & Tests/g & $\begin{array}{c}\text { Fragmentation } \\
\text { index }\end{array}$ & Planktic\% & $\begin{array}{c}\text { Revised } \\
\text { Fragmentation } \\
\text { index }\end{array}$ & $\begin{array}{c}\text { Fl-adjusted } \\
\text { Planktic\% }\end{array}$ & $\begin{array}{c}\mathbf{\%} \mathbf{2 5 0} \\
\boldsymbol{\mu m}\end{array}$ & $\begin{array}{c}\mathbf{\%} \mathbf{1 2 5}- \\
\mathbf{2 5 0} \boldsymbol{\mu m}\end{array}$ & $\begin{array}{c}\mathbf{\%} \mathbf{6 3 -} \\
\mathbf{1 2 5} \boldsymbol{\mu m}\end{array}$ \\
\hline $0-2 \mathrm{~cm}$ & 85.75 & 23.64 & 82.81 & 83.20 & 96.63 & 2.52 & 44.08 & 53.40 \\
\hline $2-4 \mathrm{~cm}$ & 72.43 & 17.04 & 70.42 & 76.67 & 91.08 & 0.83 & 15.83 & 83.33 \\
\hline $4-6 \mathrm{~cm}$ & 157.38 & 20.31 & 75.00 & 80.30 & 93.84 & 0.30 & 2.08 & 97.62 \\
\hline $6-8 \mathrm{~cm}$ & 135.23 & 20.48 & 38.89 & 80.48 & 76.52 & 3.26 & 10.54 & 86.21 \\
\hline $8-10 \mathrm{~cm}$ & 296.67 & 22.92 & 46.95 & 82.63 & 83.60 & 3.37 & 12.73 & 83.90 \\
\hline $10-12 \mathrm{~cm}$ & 250.45 & 20.60 & 49.34 & 80.59 & 83.38 & 5.82 & 8.24 & 85.94 \\
\hline $12-14 \mathrm{~cm}$ & 296.89 & 19.91 & 45.75 & 79.91 & 80.76 & 2.71 & 14.91 & 82.39 \\
\hline $14-16 \mathrm{~cm}$ & 327.65 & 23.81 & 42.14 & 83.33 & 81.38 & 3.23 & 10.13 & 86.64 \\
\hline
\end{tabular}


Table B.4 TAN1705-22 foraminiferal data table

\begin{tabular}{|c|c|c|c|c|c|c|c|c|}
\hline Sample & Tests/g & $\begin{array}{c}\text { Fragmentation } \\
\text { index }\end{array}$ & Planktic\% & $\begin{array}{c}\text { Revised } \\
\text { Fragmentation } \\
\text { index }\end{array}$ & $\begin{array}{c}\text { Fl-adjusted } \\
\text { Planktic\% }\end{array}$ & $\begin{array}{c}\text { \% >250 } \\
\boldsymbol{\mu m}\end{array}$ & $\begin{array}{c}\text { \% 125- } \\
\mathbf{2 5 0} \boldsymbol{\mu m}\end{array}$ & $\begin{array}{c}\mathbf{\%} \mathbf{6 3 -} \\
\mathbf{1 2 5} \boldsymbol{\mu m}\end{array}$ \\
\hline $0-2 \mathrm{~cm}$ & 411.05 & 37.31 & 24.51 & 90.50 & 77.36 & 4.19 & 23.41 & 72.41 \\
\hline $2-4 \mathrm{~cm}$ & 561.80 & 44.12 & 38.89 & 92.66 & 89.66 & 3.53 & 19.67 & 76.80 \\
\hline $4-6 \mathrm{~cm}$ & 956.55 & 33.58 & 56.96 & 89.00 & 92.33 & 3.80 & 14.01 & 82.19 \\
\hline $6-8 \mathrm{~cm}$ & 823.72 & 33.26 & 59.19 & 88.86 & 92.86 & 3.32 & 15.11 & 81.57 \\
\hline $8-10 \mathrm{~cm}$ & 956.73 & 36.51 & 58.87 & 90.20 & 93.59 & 3.09 & 13.75 & 83.16 \\
\hline $12-14 \mathrm{~cm}$ & 1440.23 & 26.11 & 61.08 & 84.97 & 91.26 & 2.19 & 9.16 & 88.65 \\
\hline $16-18 \mathrm{~cm}$ & 2315.64 & 28.85 & 63.74 & 86.64 & 92.94 & 2.75 & 8.91 & 88.34 \\
\hline $21-23 \mathrm{~cm}$ & 411.17 & 46.29 & 44.72 & 93.24 & 92.29 & 3.82 & 27.67 & 68.51 \\
\hline $25-27 \mathrm{~cm}$ & 1152.14 & 25.70 & 49.01 & 84.69 & 86.26 & 2.77 & 18.72 & 78.51 \\
\hline $27-29 \mathrm{~cm}$ & 2532.56 & 32.22 & 74.69 & 88.38 & 96.21 & 1.67 & 4.48 & 93.85 \\
\hline $29-31 \mathrm{~cm}$ & 1527.31 & 16.67 & 82.46 & 76.19 & 95.18 & 4.47 & 10.95 & 84.57 \\
\hline $31-33 \mathrm{~cm}$ & 1040.92 & 17.37 & 68.72 & 77.08 & 90.55 & 3.74 & 10.70 & 85.57 \\
\hline
\end{tabular}


Table B.5 TAN1705-37 foraminiferal data table

\begin{tabular}{|c|c|c|c|c|c|c|c|c|}
\hline Sample & Tests/g & $\begin{array}{c}\text { Fragmentation } \\
\text { index }\end{array}$ & Planktic\% & $\begin{array}{c}\text { Revised } \\
\text { Fragmentation } \\
\text { index }\end{array}$ & $\begin{array}{c}\text { Fl-adjusted } \\
\text { Planktic\% }\end{array}$ & $\begin{array}{c}\mathbf{\%}>\mathbf{2 5 0} \\
\boldsymbol{\mu m}\end{array}$ & $\begin{array}{c}\mathbf{\%} \mathbf{1 2 5}- \\
\mathbf{2 5 0} \boldsymbol{\mu m}\end{array}$ & $\begin{array}{c}\mathbf{\%} \mathbf{6 3 -} \\
\mathbf{1 2 5} \boldsymbol{\mu m}\end{array}$ \\
\hline $0-2 \mathrm{~cm}$ & 288.94 & 17.84 & 72.89 & 77.65 & 92.33 & 4.23 & 14.01 & 81.76 \\
\hline $2-4 \mathrm{~cm}$ & 50.93 & 21.04 & 55.32 & 81.00 & 86.70 & 6.85 & 14.61 & 78.54 \\
\hline $4-6 \mathrm{~cm}$ & 309.07 & 19.32 & 64.81 & 79.30 & 89.90 & 3.24 & 4.67 & 92.10 \\
\hline $6-8 \mathrm{~cm}$ & 267.24 & 16.45 & 69.09 & 75.91 & 90.27 & 3.89 & 8.15 & 87.96 \\
\hline $8-10 \mathrm{~cm}$ & 565.97 & 15.75 & 65.06 & 74.94 & 88.14 & 2.88 & 3.87 & 93.25 \\
\hline
\end{tabular}

Table B.6 TAN1705-21 foraminiferal data table

\begin{tabular}{|c|c|c|c|c|c|c|c|c|}
\hline Sample & Tests/g & $\begin{array}{c}\text { Fragmentation } \\
\text { index }\end{array}$ & Planktic\% & $\begin{array}{c}\text { Revised } \\
\text { Fragmentation } \\
\text { index }\end{array}$ & $\begin{array}{l}\text { Fl-adjusted } \\
\text { Planktic\% }\end{array}$ & $\begin{array}{c}\%>250 \\
\mu \mathrm{m}\end{array}$ & $\begin{array}{l}\% 125- \\
250 \mu \mathrm{m}\end{array}$ & $\begin{array}{c}\% 63- \\
125 \mu \mathrm{m}\end{array}$ \\
\hline $3-5 \mathrm{~cm}$ & 3.80 & 9.43 & 95.00 & 62.50 & 98.06 & 0.00 & 60.00 & 40.00 \\
\hline $5-7 \mathrm{~cm}$ & 9.96 & 11.59 & 98.08 & 67.71 & 99.37 & 0.00 & 48.08 & 51.92 \\
\hline $11-13 \mathrm{~cm}$ & 156.41 & 22.05 & 69.94 & 81.90 & 92.78 & 0.60 & 33.83 & 65.57 \\
\hline $13-16 \mathrm{~cm}$ & 279.41 & 25.33 & 81.29 & 84.44 & 96.54 & 0.39 & 24.34 & 75.27 \\
\hline $16-18 \mathrm{~cm}$ & 250.41 & 13.60 & 84.23 & 71.58 & 94.95 & 0.20 & 24.50 & 75.31 \\
\hline $18-20 \mathrm{~cm}$ & 379.35 & 26.11 & 72.92 & 84.97 & 94.71 & 0.55 & 41.96 & 57.49 \\
\hline
\end{tabular}


Table B.7 TAN1705-18 foraminiferal data table

\begin{tabular}{|c|c|c|c|c|c|c|c|c|}
\hline Sample & Tests/g & $\begin{array}{c}\text { Fragmentation } \\
\text { index }\end{array}$ & Planktic\% & $\begin{array}{c}\text { Revised } \\
\text { Fragmentation } \\
\text { index }\end{array}$ & $\begin{array}{c}\text { Fl-adjusted } \\
\text { Planktic\% }\end{array}$ & $\begin{array}{c}\text { \% >250 } \\
\boldsymbol{\mu m}\end{array}$ & $\begin{array}{c}\mathbf{\%} \mathbf{1 2 5}- \\
\mathbf{2 5 0} \boldsymbol{\mu m}\end{array}$ & $\begin{array}{c}\text { \% 63- } \\
\mathbf{1 2 5} \boldsymbol{\mu m}\end{array}$ \\
\hline $0-2.7 \mathrm{~cm}$ & 113.27 & 17.28 & 31.97 & 76.97 & 67.11 & 6.96 & 14.60 & 78.44 \\
\hline $2.7-4.7 \mathrm{~cm}$ & 596.71 & 13.21 & 71.94 & 70.89 & 89.80 & 4.01 & 6.29 & 89.69 \\
\hline $4.7-6.7 \mathrm{~cm}$ & 461.07 & 12.57 & 75.17 & 69.69 & 90.90 & 3.81 & 9.11 & 87.09 \\
\hline $6.7-8.7 \mathrm{~cm}$ & 975.80 & 15.58 & 81.09 & 74.70 & 94.43 & 3.84 & 8.56 & 87.60 \\
\hline $8.7-10.7 \mathrm{~cm}$ & 1762.05 & 10.62 & 87.93 & 65.53 & 95.48 & 2.49 & 4.01 & 93.50 \\
\hline
\end{tabular}

Table B.8 TAN1613-27 foraminiferal data table

\begin{tabular}{|c|c|c|c|c|c|c|c|}
\hline Sample & $\begin{array}{c}\text { Fragmentation } \\
\text { index }\end{array}$ & Planktic\% & $\begin{array}{c}\text { Revised } \\
\text { Fragmentation } \\
\text { index }\end{array}$ & $\begin{array}{c}\text { Fl-adjusted } \\
\text { Planktic\% }\end{array}$ & $\begin{array}{c}\mathbf{\%}>\mathbf{2 5 0} \\
\boldsymbol{\mu m}\end{array}$ & $\begin{array}{c}\mathbf{\%} \mathbf{1 2 5}- \\
\mathbf{2 5 0} \boldsymbol{\mu m}\end{array}$ & $\begin{array}{c}\mathbf{\%} \mathbf{6 3}- \\
\mathbf{1 2 5} \boldsymbol{\mu m}\end{array}$ \\
\hline $6-8 \mathrm{~cm}$ & 23.00 & 64.00 & 83.00 & 91.00 & 1.00 & 3.00 & 96.00 \\
\hline $5-7.5 \mathrm{~cm}$ & 24.00 & 71.00 & 83.00 & 94.00 & 1.00 & 7.00 & 97.00 \\
\hline
\end{tabular}




\section{Core Datasets}

Appendix $\mathrm{C}$ contains the plots of each core studied with all physical and geochemical non-destructive data plotted alongside the destructive datasets (excl. foraminifera).

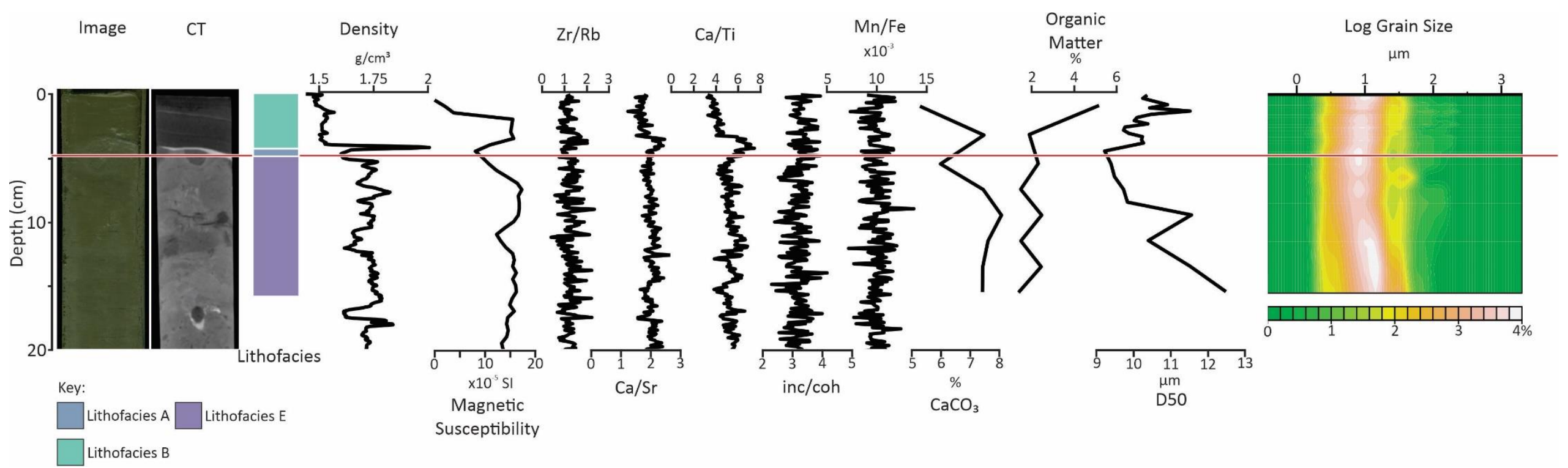

Figure C.1 TAN1705-33 destructive and non-destructive datasets. Shows the linescan image, CT scan, lithofacies classification, density, magnetic susceptibility, $\mathrm{Zr} / \mathrm{Rb}, \mathrm{Ca} / \mathrm{Sr}, \mathrm{Ca} / \mathrm{Ti}$, inc/coh, $\mathrm{Mn} / \mathrm{Fe}$, percentage of carbonate, percentage of organic matter, D50, and grain size distribution heat map. Red line indicates the base of the Kaikōura turbidite. 


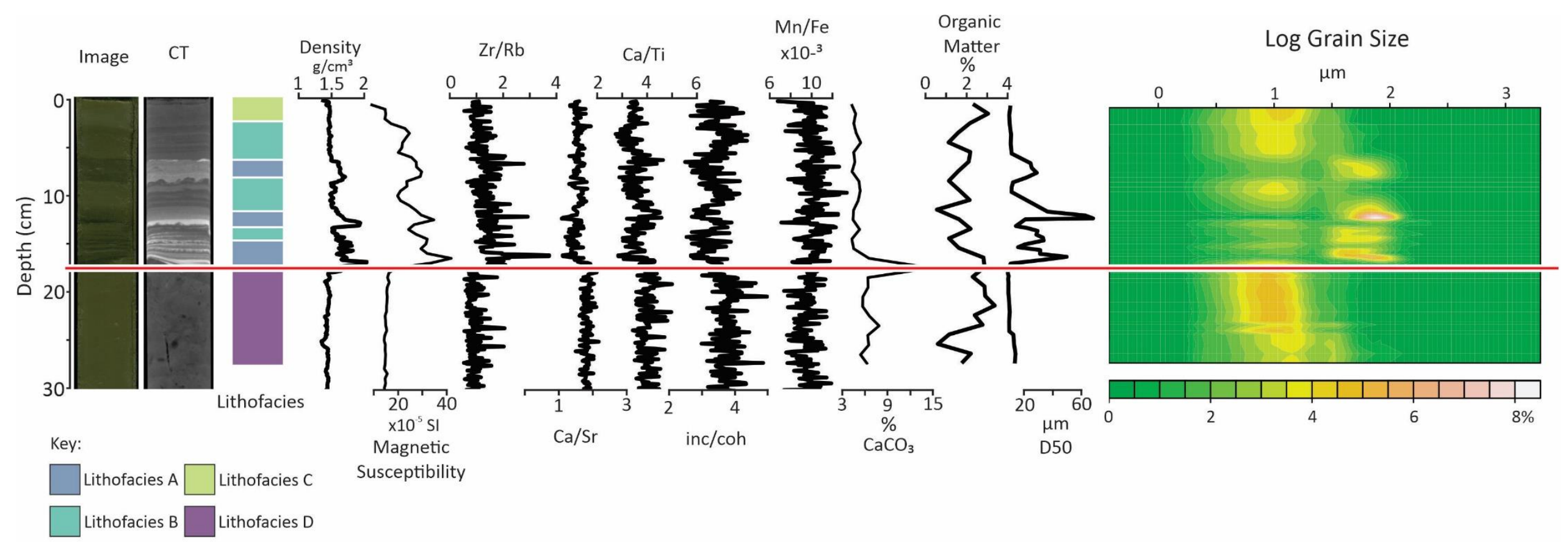

Figure C.2 TAN1705-26 destructive and non-destructive datasets. Shows the linescan image, CT scan, lithofacies classification, density, magnetic susceptibility, $\mathrm{Zr} / \mathrm{Rb}, \mathrm{Ca} / \mathrm{Sr}, \mathrm{Ca} / \mathrm{Ti}$, inc/coh, $\mathrm{Mn} / \mathrm{Fe}$, percentage of carbonate, percentage of organic matter, D50, and grain size distribution heat map. Red line indicates the base of the Kaikōura turbidite. 


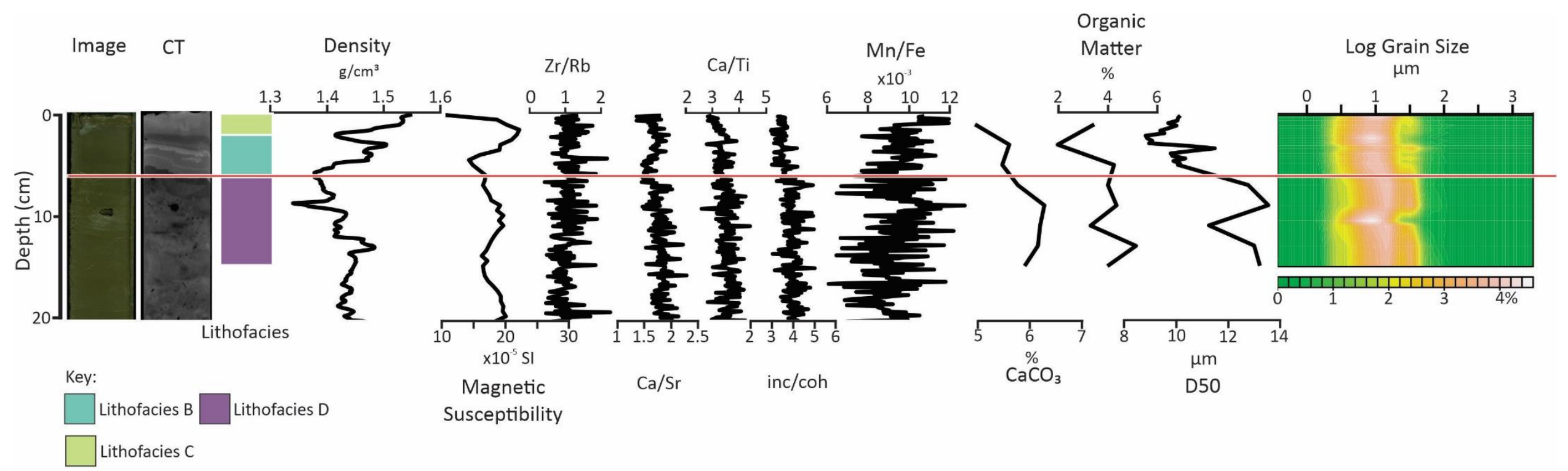

Figure C.3 TAN1705-24 destructive and non-destructive datasets. Shows the linescan image, CT scan, lithofacies classification, density, magnetic susceptibility, $\mathrm{Zr} / \mathrm{Rb}, \mathrm{Ca} / \mathrm{Sr}, \mathrm{Ca} / \mathrm{Ti}$, inc/coh, $\mathrm{Mn} / \mathrm{Fe}$, percentage of carbonate, percentage of organic matter, D50, and grain size distribution heat map. Red line indicates the base of the Kaikōura turbidite. 


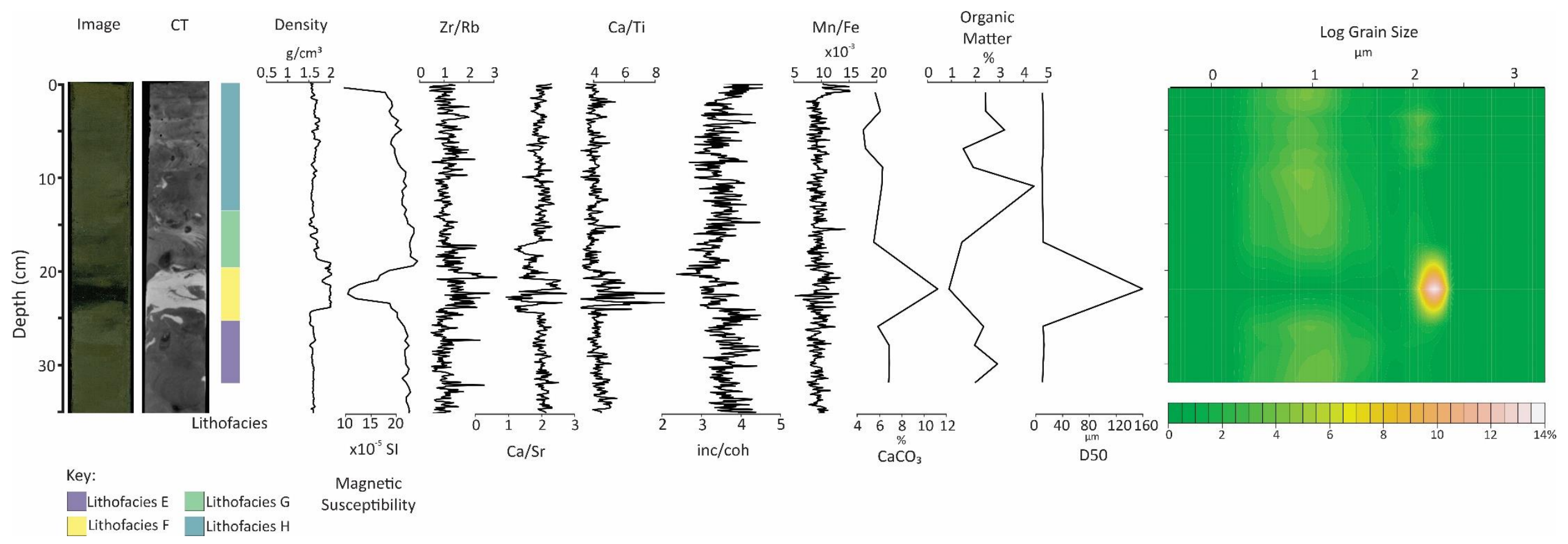

Figure C.4 TAN1705-22 destructive and non-destructive datasets. Shows the linescan image, CT scan, lithofacies classification, density, magnetic susceptibility, $\mathrm{Zr} / \mathrm{Rb}, \mathrm{Ca} / \mathrm{Sr}, \mathrm{Ca} / \mathrm{Ti}$, inc/coh, $\mathrm{Mn} / \mathrm{Fe}$, percentage of carbonate, percentage of organic matter, D50, and grain size distribution heat map. 


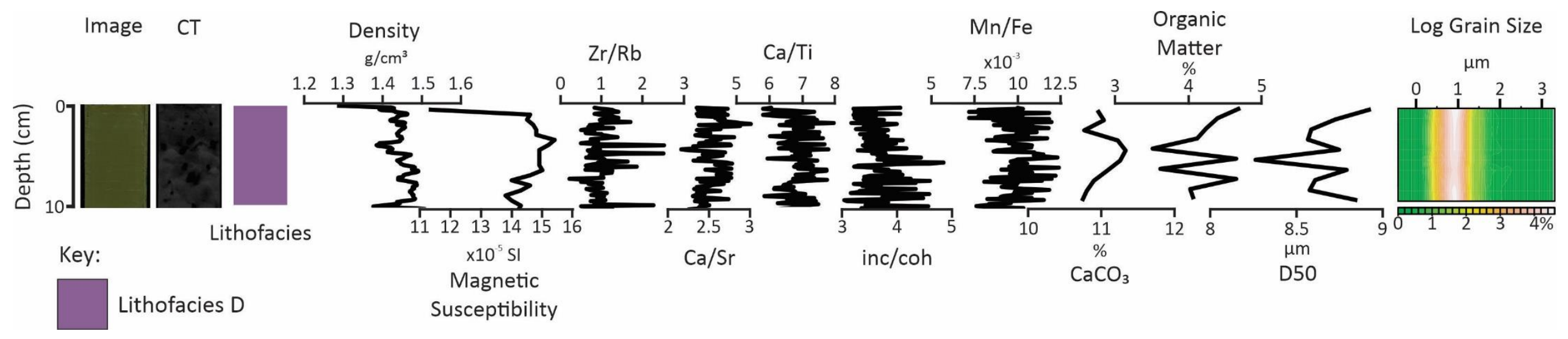

Figure C.5 TAN1705-37 destructive and non-destructive datasets. Shows the linescan image, CT scan, lithofacies classification, density, magnetic susceptibility, $\mathrm{Zr} / \mathrm{Rb}, \mathrm{Ca} / \mathrm{Sr}, \mathrm{Ca} / \mathrm{Ti}$, inc/coh, $\mathrm{Mn} / \mathrm{Fe}$, percentage of carbonate, percentage of organic matter, D50, and grain size distribution heat map. 


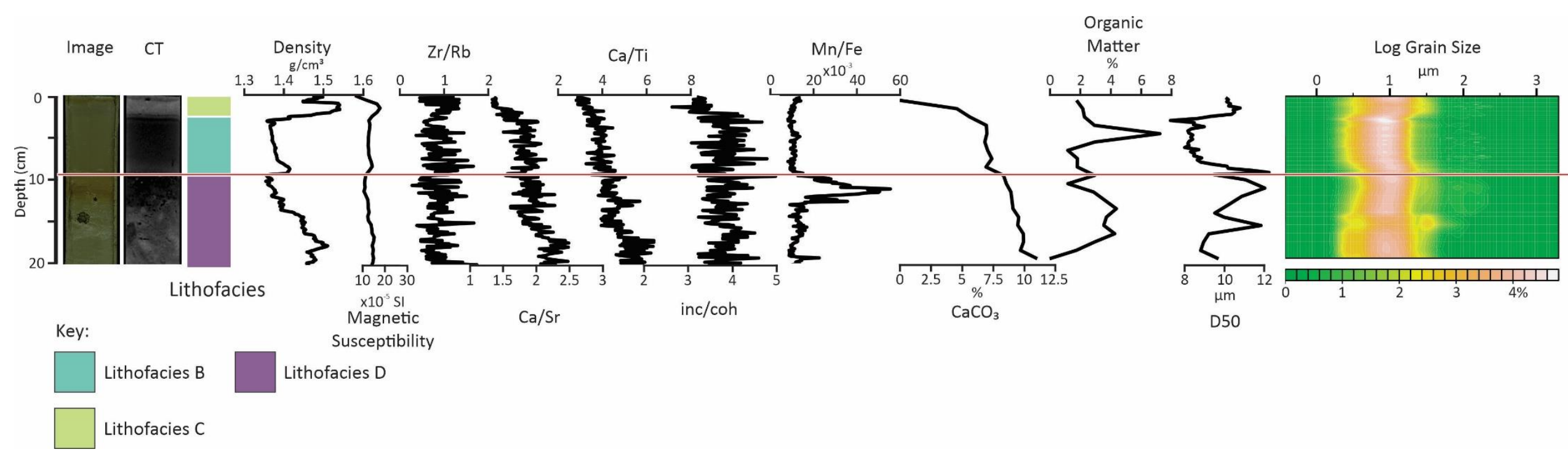

Figure C.6 TAN1705-21 destructive and non-destructive datasets. Shows the linescan image, CT scan, lithofacies classification, density, magnetic susceptibility, $\mathrm{Zr} / \mathrm{Rb}, \mathrm{Ca} / \mathrm{Sr}, \mathrm{Ca} / \mathrm{Ti}$, inc/coh, $\mathrm{Mn} / \mathrm{Fe}$, percentage of carbonate, percentage of organic matter, D50, and grain size distribution heat map. Red line indicates the base of the Kaikōura turbidite. 


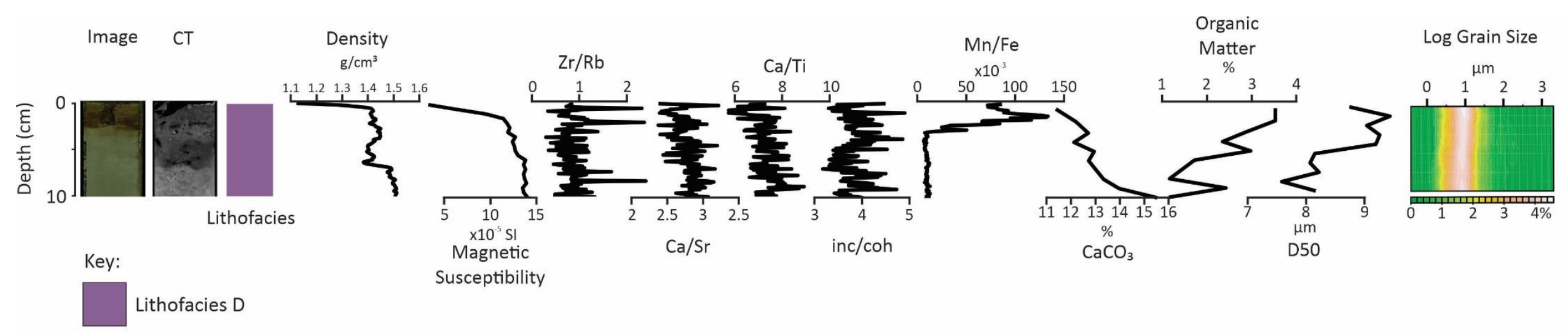

Figure C.7 TAN1705-18 destructive and non-destructive datasets. Shows the linescan image, CT scan, lithofacies classification, density, magnetic susceptibility, $\mathrm{Zr} / \mathrm{Rb}, \mathrm{Ca} / \mathrm{Sr}, \mathrm{Ca} / \mathrm{Ti}$, inc/coh, $\mathrm{Mn} / \mathrm{Fe}$, percentage of carbonate, percentage of organic matter, D50, and grain size distribution heat map. 


\section{Additional Statistics}

Table D.1 Lithofacies Averages. Values for physical and geochemical properties, averaged by lithofacies and rounded to $3 \mathrm{dp}$.

\begin{tabular}{|c|c|c|c|c|c|c|c|c|c|c|c|}
\hline Lithofacies & Density & $\begin{array}{c}\text { Magnetic } \\
\text { Susceptibility }\end{array}$ & $\mathrm{Ca} / \mathrm{Sr}$ & $\mathrm{Ca} / \mathrm{Ti}$ & $\mathrm{Zr} / \mathrm{Rb}$ & inc/coh & D50 & Sorting & $\begin{array}{c}\text { Mean } \\
\text { Grain Size }\end{array}$ & \%Organics & \%Carbonates \\
\hline A & 1.677 & 28.9 & 1.539 & 3.669 & 1.569 & 3.225 & 28.482 & 34.91 & 38.637 & 2.001 & 6.096 \\
\hline$B$ & 1.467 & 17.215 & 1.683 & 3.691 & 1.081 & 3.56 & 11.388 & 22.006 & 18.545 & 2.49 & 5.7 \\
\hline$C$ & 1.446 & 12.65 & 1.45 & 3.305 & 0.975 & 3.322 & 10.445 & 14.28 & 14.682 & 2.038 & 2.105 \\
\hline D & 1.433 & 14.164 & 2.208 & 5.414 & 0.93 & 3.808 & 9.998 & 19.379 & 16.237 & 3.1 & 9.295 \\
\hline$E$ & 1.67 & 17.696 & 2.006 & 4.891 & 1.17 & 3.285 & 11.032 & 27.99 & 21.108 & 2.081 & 7.039 \\
\hline$* \mathrm{~F}$ & 1.964 & 12.42 & 2.01 & 5.109 & 1.589 & 3.362 & 159.498 & 47.236 & 157.863 & 0.893 & 11.218 \\
\hline$* G$ & 1.649 & 22.825 & 1.69 & 3.846 & 1.188 & 3.279 & 11.397 & 36.301 & 25.85 & 1.429 & 5.489 \\
\hline $\mathrm{H}$ & 1.636 & 19.621 & 1.951 & 4.047 & 1.144 & 3.507 & 10.661 & 38.61 & 28.472 & 2.646 & 5.578 \\
\hline
\end{tabular}

* Note: lithofacies F and G both only have one sampled example (TAN1705-22 $21-23 \mathrm{~cm}$ and $16-18 \mathrm{~cm}$, respectively). 
Table D.2 Lithofacies standard deviations. Standard deviations for all physical and geochemical properties, by lithofacies.

\begin{tabular}{|c|c|c|c|c|c|c|c|c|c|c|c|}
\hline Lithofacies & Density & $\begin{array}{c}\text { Magnetic } \\
\text { Susceptibility }\end{array}$ & $\mathrm{Ca} / \mathrm{Sr}$ & $\mathrm{Ca} / \mathrm{Ti}$ & $\mathrm{Zr} / \mathrm{Rb}$ & $\mathrm{inc} / \mathrm{coh}$ & D50 & Sorting & $\begin{array}{l}\text { Mean Grain } \\
\text { Size } \\
\end{array}$ & \%Organics & \%Carbonates \\
\hline A & 0.077 & 5.669 & 0.173 & 0.188 & 0.271 & 0.129 & 12.128 & 4.698 & 10.777 & 0.616 & 3.593 \\
\hline B & 0.069 & 5.391 & 0.139 & 0.456 & 0.192 & 0.248 & 4.96 & 7.721 & 7.073 & 1.494 & 1.036 \\
\hline C & 0.003 & 1.344 & 0.1 & 0.286 & 0.146 & 0.144 & 0.385 & 3.915 & 0.599 & 0.387 & 2.977 \\
\hline D & 0.036 & 2.177 & 0.404 & 1.501 & 0.112 & 0.15 & 1.796 & 7.048 & 3.509 & 1.202 & 2.563 \\
\hline$E$ & 0.073 & 3.859 & 0.075 & 0.587 & 0.18 & 0.448 & 1.124 & 9.04 & 4.431 & 0.505 & 0.704 \\
\hline$* \mathrm{~F}$ & - & - & - & - & - & - & - & - & - & - & - \\
\hline$*_{G}$ & - & - & - & - & - & - & - & - & - & - & - \\
\hline $\mathrm{H}$ & 0.039 & 1.892 & 0.076 & 0.108 & 0.151 & 0.195 & 0.917 & 8.889 & 7.574 & 1.05 & 0.761 \\
\hline
\end{tabular}

* Note: lithofacies F and G only have one sampled example each, (TAN1705-22 $21-23 \mathrm{~cm}$ and $16-18 \mathrm{~cm}$, respectively) and thus do not have a calculated standard deviation.

Table D.3 P-values calculated for the correlation of destructive data and the relevant non-destructive proxies using Pearson's correlation test.

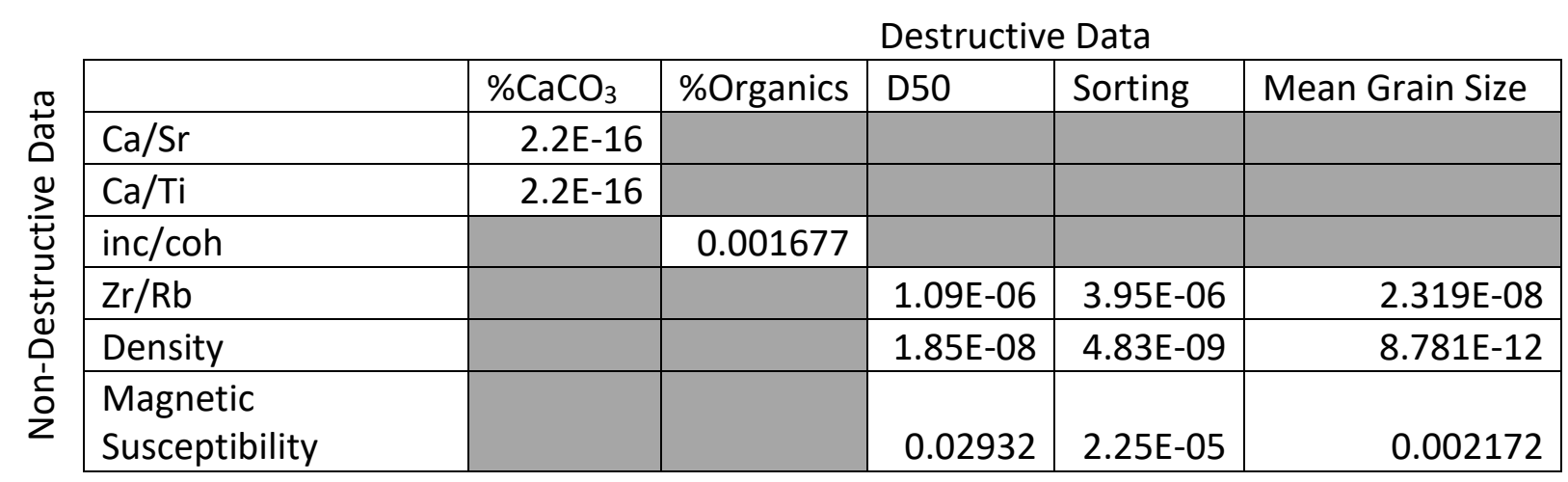




\section{E. Non-Destructive Datasets for Additional Cores}

Appendix $E$ contains plots of the non-destructive datasets for cores that were not destructively sampled, but were added to the LDA datasets to obtain additional instances of turbidites tails.

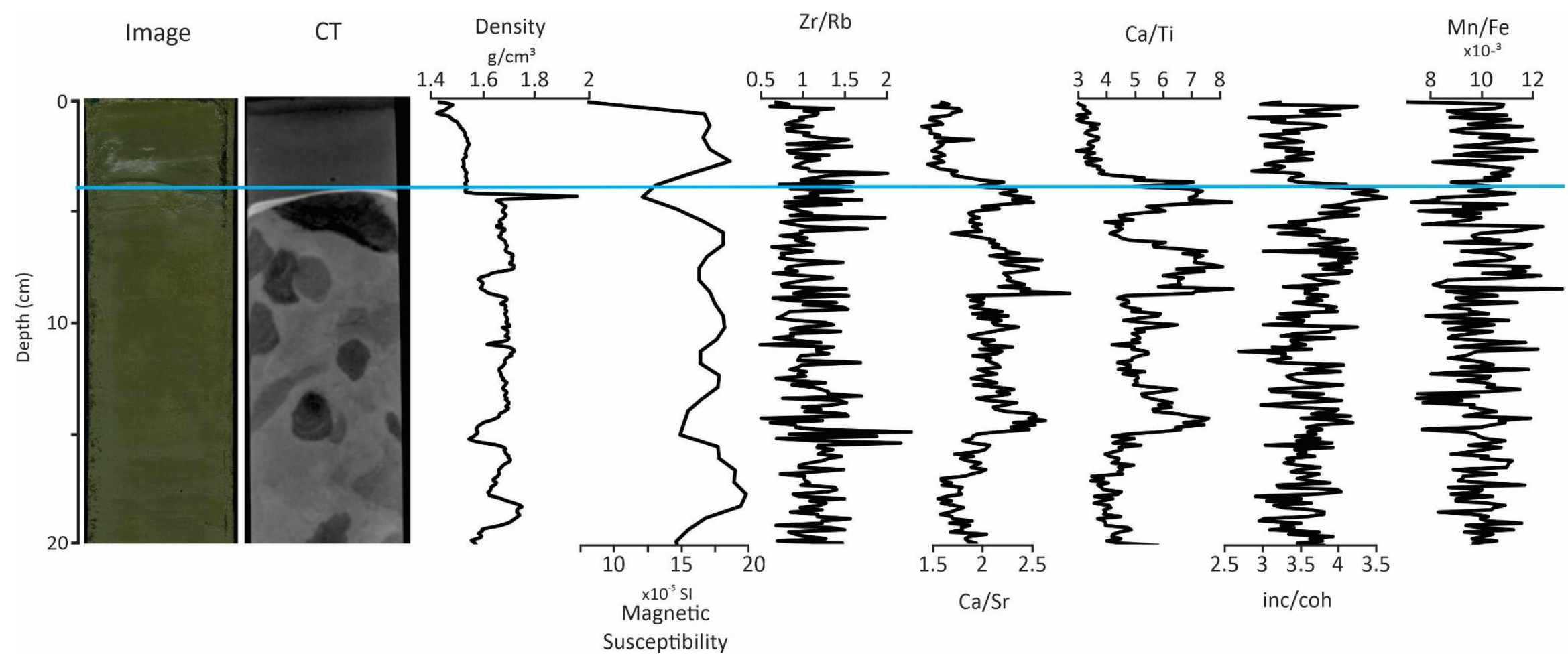

Figure E.1 TAN1705-36 non-destructive dataset. Shows the linescan image, CT scan, density, magnetic susceptibility, $\mathrm{Zr} / \mathrm{Rb}, \mathrm{Ca} / \mathrm{Sr}, \mathrm{Ca} / \mathrm{Ti}$, inc/coh, and Mn/Fe. Data above the blue line was added to the training model as instances of turbidite tail. 


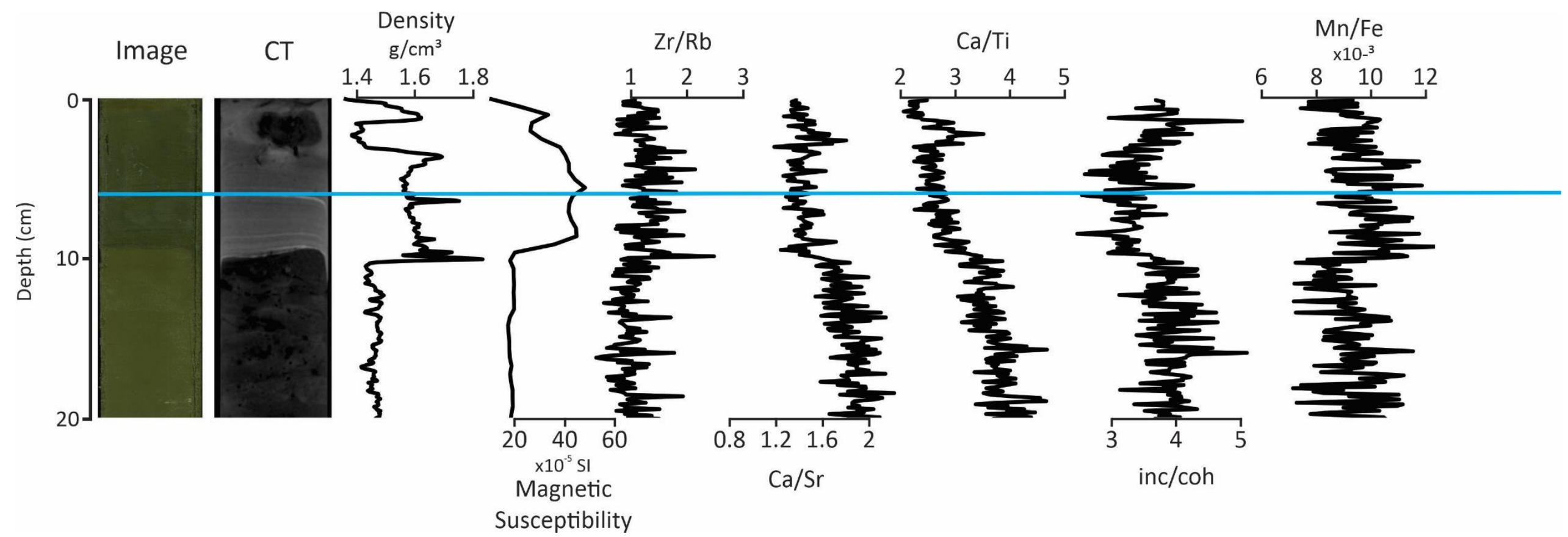

Figure E.2 TAN1705-25 non-destructive dataset. Shows the linescan image, CT scan, density, magnetic susceptibility, Zr/Rb, Ca/Sr, Ca/Ti, inc/coh, and Mn/Fe. Data above the blue line was added to the training model as instances of turbidite tail. 


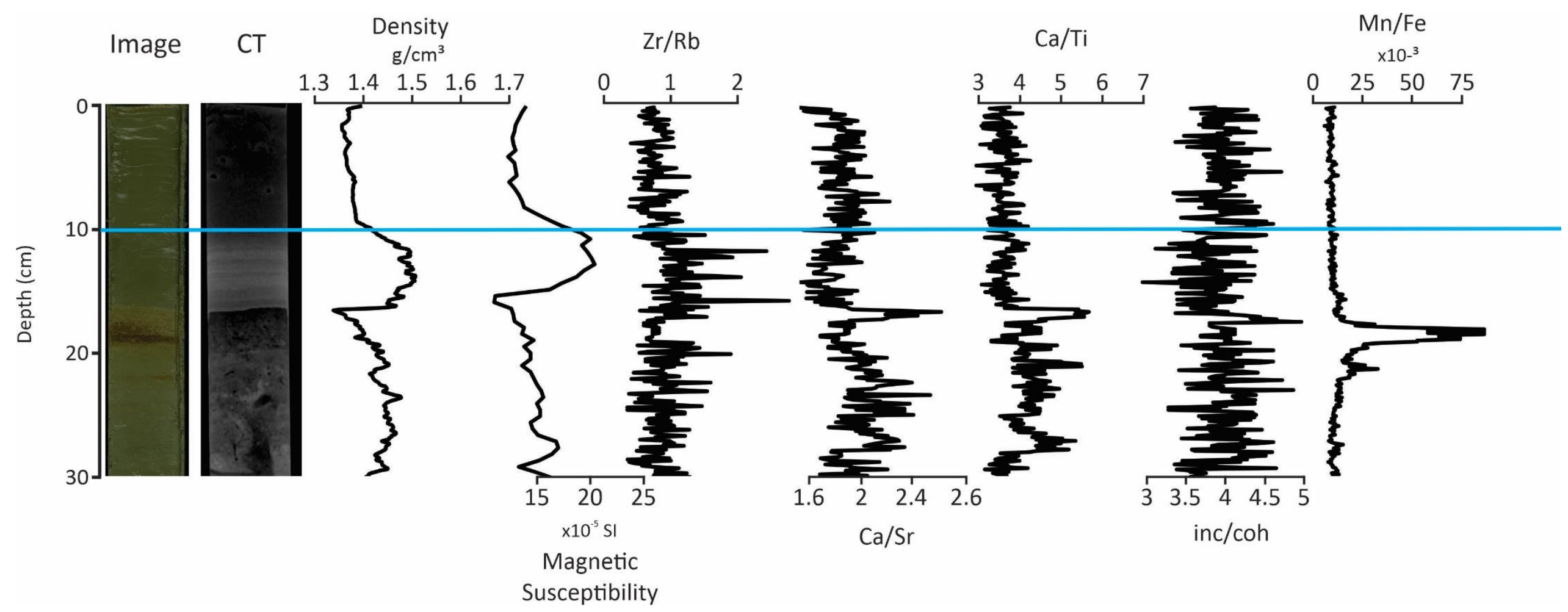

Figure E.3 TAN1705-20 non-destructive dataset. Shows the linescan image, CT scan, density, magnetic susceptibility, $\mathrm{Zr} / \mathrm{Rb}, \mathrm{Ca} / \mathrm{Sr}, \mathrm{Ca} / \mathrm{Ti}$, inc/coh, and Mn/Fe. Data above the blue line was added to the training model as instances of turbidite tail. 


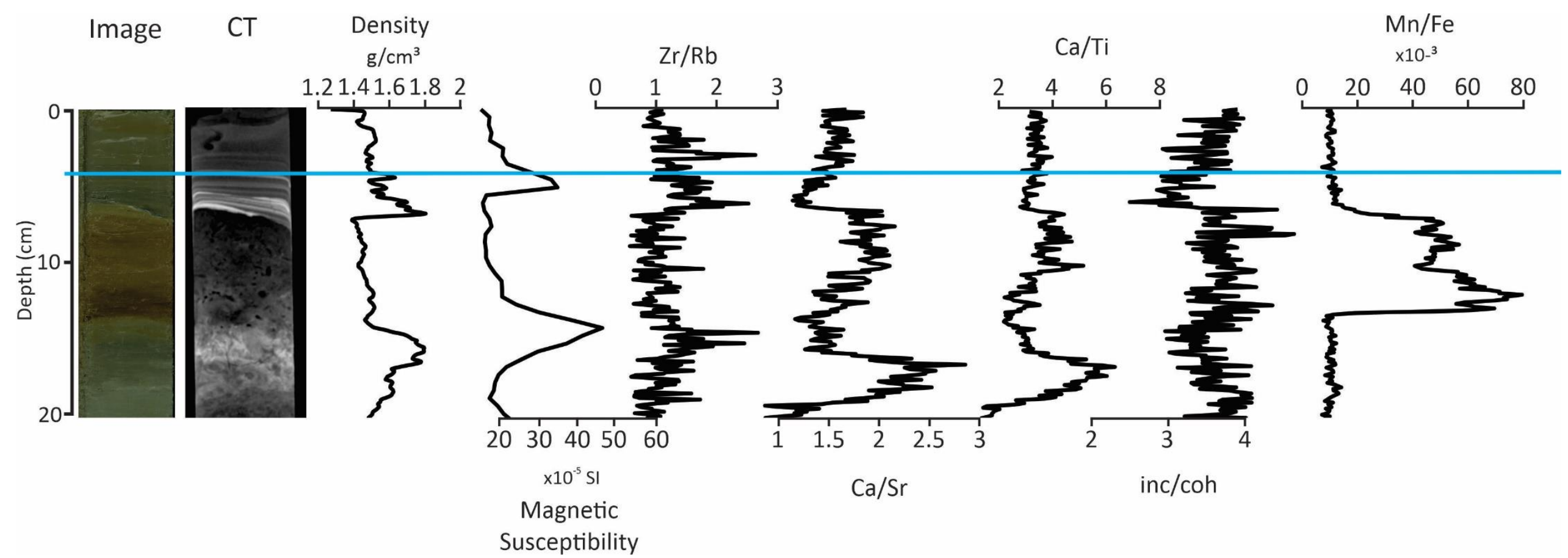

Figure E.4 TAN1705-16 non-destructive dataset. Shows the linescan image, CT scan, density, magnetic susceptibility, Zr/Rb, Ca/Sr, Ca/Ti, inc/coh, and Mn/Fe. Data above the blue line was added to the training model as instances of turbidite tail. 


\section{F. Datasets for TAN1613 Cores}

Appendix F contains plots of the destructive and non-destructive datasets for the two TAN1613 cores (TAN1613-27 and TAN1613-25) that contain the Taupō tephra, and were used to assess the performance of the LDA models on older sediments. 


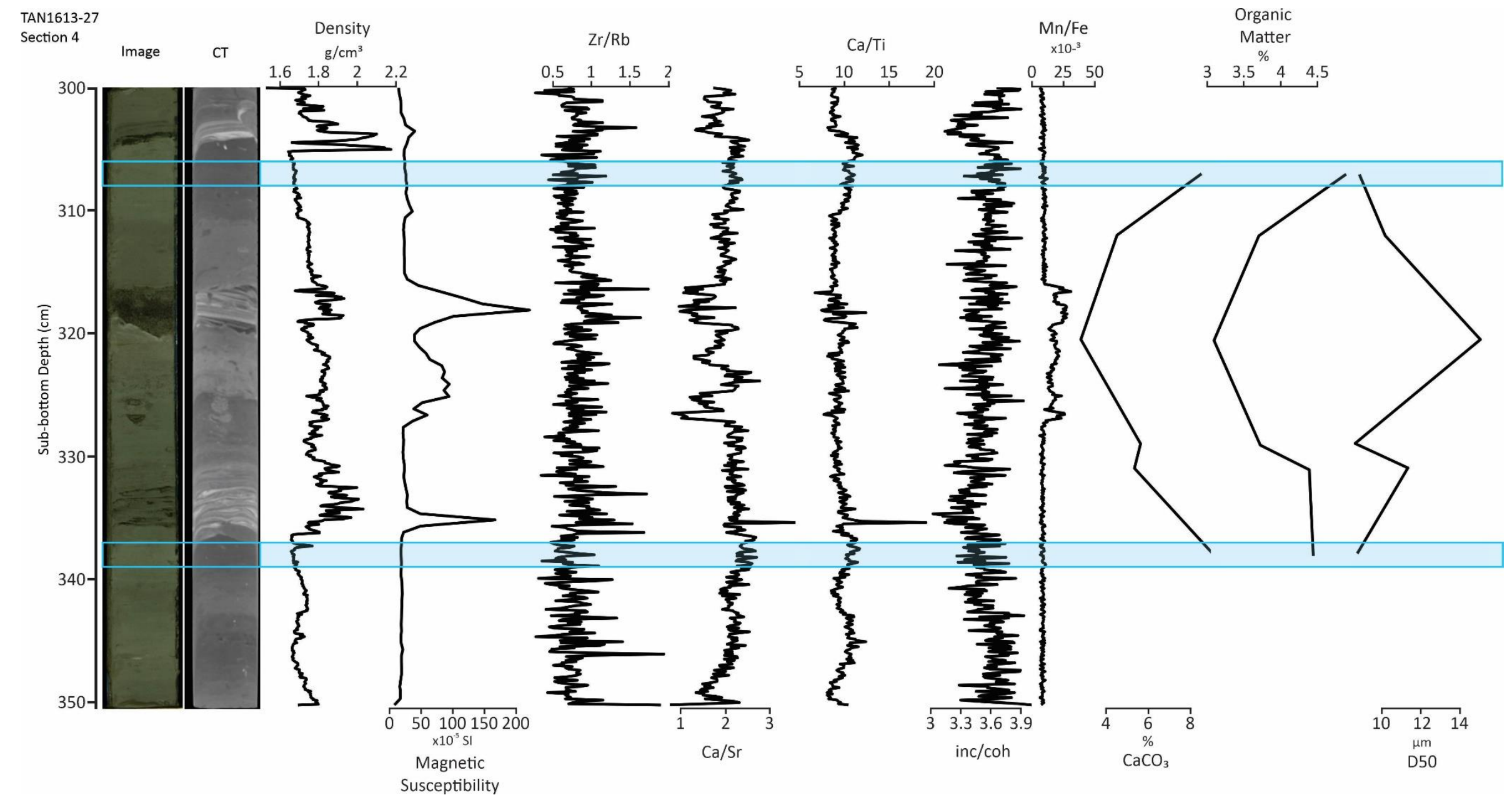

Figure F.1 TAN1613-27 destructive and non-destructive datasets. Shows the linescan image, CT scan, density, magnetic susceptibility, Zr/Rb, Ca/Sr, Ca/Ti, inc/coh $\mathrm{Mn} / \mathrm{Fe}$, percentage of carbonate, percentage of organic matter, and D50. Blue boxes show where samples were taken for radiocarbon dating. 


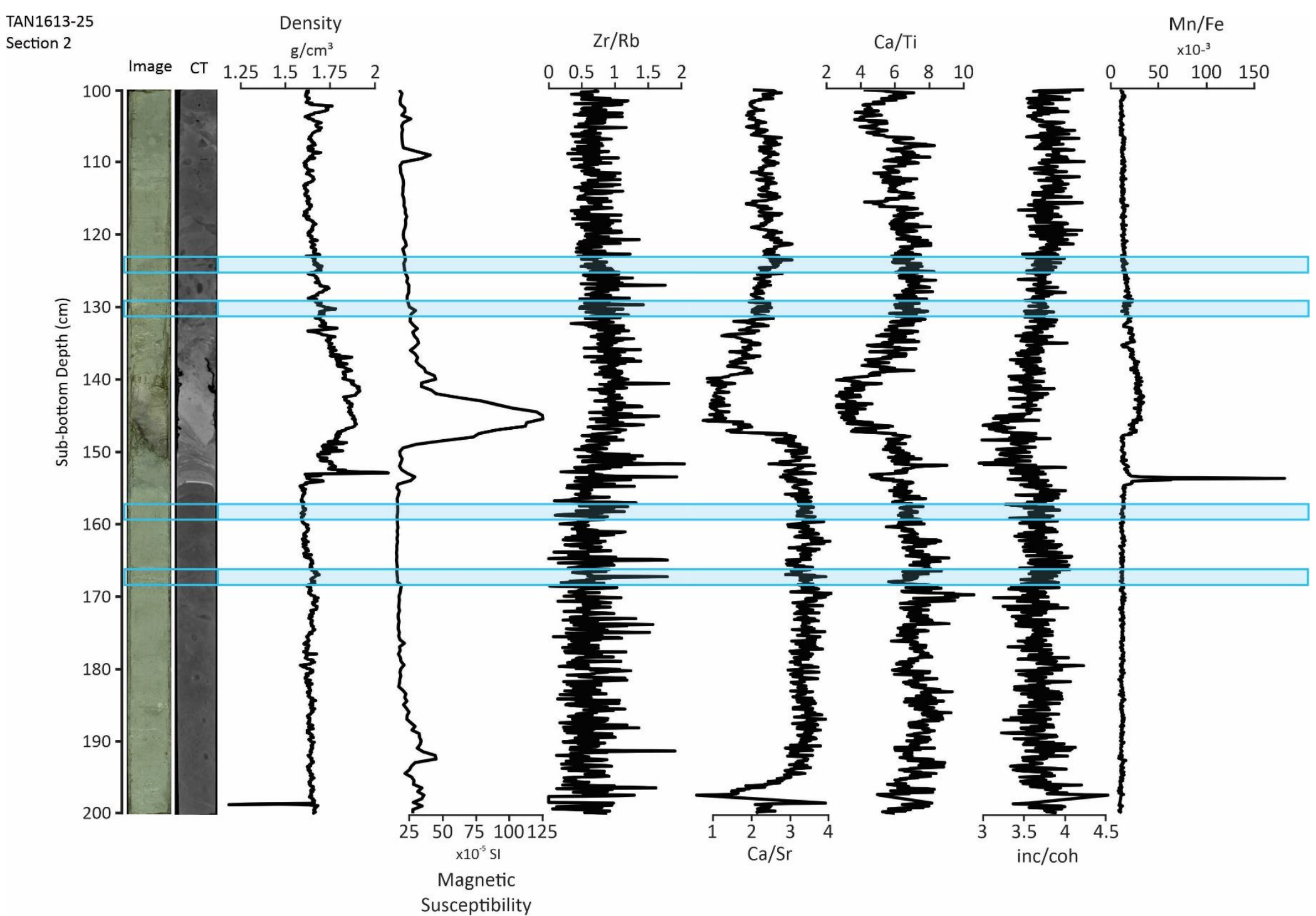

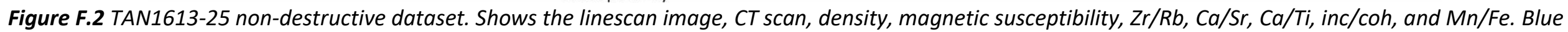
boxes show where samples were taken for radiocarbon dating. 